\title{
'DOING TIME ON THE OUTSIDE': TRANSCARCERATION AND THE SOCIAL CONTROL OF CRIMINALIZED WOMEN IN THE COMMUNITY
}

\author{
by
}

MaDonna R. Maidment, B.A., M.A.

\author{
A thesis submitted to \\ the Faculty of Graduate Studies and Research \\ in partial fulfilment of \\ the requirements for the degree of \\ Doctor of Philosophy \\ Department of Sociology \& Anthropology \\ Carleton University \\ Ottawa, Ontario \\ January 2005 \\ (C) Copyright \\ 2005, MaDonna R. Maidment
}




$\begin{array}{ll}\begin{array}{l}\text { Library and } \\ \text { Archives Canada }\end{array} & \begin{array}{l}\text { Bibliothèque et } \\ \text { Archives Canada }\end{array} \\ \begin{array}{l}\text { Published Heritage } \\ \text { Branch }\end{array} & \begin{array}{l}\text { Direction du } \\ \text { Patrimoine de l'édition }\end{array} \\ \begin{array}{l}\text { 395 Wellington Street } \\ \text { Ottawa ON K1A ON4 }\end{array} & \begin{array}{l}\text { 395, rue Wellington } \\ \text { Ottawa ON K1A ON4 } \\ \text { Canada }\end{array}\end{array}$

Your file Votre référence

ISBN: 0-494-00805-9

Ourfile Notre référence

ISBN: 0-494-00805-9

NOTICE:

The author has granted a nonexclusive license allowing Library and Archives Canada to reproduce, publish, archive, preserve, conserve, communicate to the public by telecommunication or on the Internet, loan, distribute and sell theses worldwide, for commercial or noncommercial purposes, in microform, paper, electronic and/or any other formats.

The author retains copyright ownership and moral rights in this thesis. Neither the thesis nor substantial extracts from it may be printed or otherwise reproduced without the author's permission.
AVIS:

L'auteur a accordé une licence non exclusive permettant à la Bibliothèque et Archives Canada de reproduire, publier, archiver, sauvegarder, conserver, transmettre au public par télécommunication ou par l'Internet, prêter, distribuer et vendre des thèses partout dans le monde, à des fins commerciales ou autres, sur support microforme, papier, électronique et/ou autres formats.

L'auteur conserve la propriété du droit d'auteur et des droits moraux qui protège cette thèse. $\mathrm{Ni}$ la thèse ni des extraits substantiels de celle-ci ne doivent être imprimés ou autrement reproduits sans son autorisation.
In compliance with the Canadian

Privacy Act some supporting forms may have been removed from this thesis.

While these forms may be included in the document page count, their removal does not represent any loss of content from the thesis.
Conformément à la loi canadienne sur la protection de la vie privée, quelques formulaires secondaires ont été enlevés de cette thèse.

Bien que ces formulaires aient inclus dans la pagination, il n'y aura aucun contenu manquant.

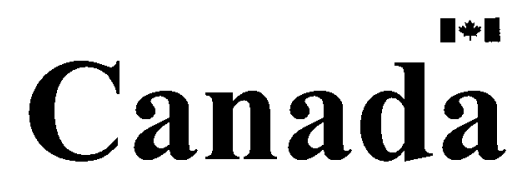




\begin{abstract}
This study identifies four major factors contributing to women's 'successful reintegration'. The foremost finding reveals that for those women experiencing relatively fewer 'layers of social control' prior to her prison term, the greater chance she has of staying out of prison. The convergence of state-imposed regulatory agencies in the lives of criminalized women has been duly noted (c.f., Carlen, 1988). The accumulated disempowerment brought about by a lifetime of formal social control agents leaves many women vulnerable and highly dependent on continued intervention by their oppressors. Prison life simply represents an extension of this dependency and a further contributor to women's institutionalization. Chances of staying out are increased considerably if a woman has managed to escape a formalized history of state control (namely child custody interventions, welfare caseworkers, and mental health agents) prior to her entering prison.

Second, strict categorical definitions of 'success' do not coincide with official definitions. Recidivism rates, not surprisingly, are inaccurate measures of quantifying women's successes or failures post-release. For many women who have spent their lives controlled by state agencies, managing a relatively short period of independence in the community marks a major milestone. Also, we know that a reconviction does not necessarily translate into the commission of a new offence but rather may result from a technical violation of one's often untenable parole conditions. Therefore, beginning from the measurement of success based on recidivism rates is a faulty starter and contributes to a misrepresentation of women's own perceived and real successes.

Third, for those women who have managed to stay out of the criminal justice system, a majority remain tightly entangled in other state-sponsored control regimes. Patterns of dependency, medicalization, and infantilization still persist in the treatment of women in the community. Transcarceration, defined as the blurring of state control systems, primarily under the guise of criminal justice and mental health agencies, continues to pervade the lives of women who have spent the majority of their lives under formalized controls. Furthermore, state controls often become disguised in the form of underfunded and under-resourced community-based agencies who continue to operate at the behest of state agendas.

Fourth, familial and social support networks are paramount to women's successful reintegration, far more so than professional supports provided by state and community agencies. Those women who managed to maintain a supportive kinship network during their time of institutionalization stood a much stronger chance of staying out of prison than those who did not have the support of family members. Therefore, resource allocations in the form of professional support networks (e.g., parole and probation officers) would be better directed towards the inclusion of family and peer support programs for criminalized women on community release.

Overall, the convergence of these four major findings have significant policy implications for how we conceive of, and design, both prison and community-based programs for women. Therefore, on one level, it demonstrably calls into question well-entrenched criminal justice policies which fail to account for the economic, social, medical, and cultural realities of women's lives. On a broader, and arguably much more meaningful and significant level, it calls for the targeting and dismantling of neo-conservative and neo-liberal socio-economic policies to address the widening inequalities which lend themselves to women's criminalization in the first place.




\section{ACKNOWLEDGEMENTS}

This research is marked by the passing of my beloved father, Eldon (Coute) Maidment, whom I love and miss terribly. The title of this work, 'Doing Time on the Outside' is borrowed from his repertoire of insightful observations on social (in)justice. His resonant wisdom would fill volumes. I continue to prosper from the wisdom, unwavering guidance and grounded intellect of my mother, Dianne Flynn, who is my salient mentor and humanitarian role model. I am abundantly privileged to have the support of my sisters, Cathy, Lisa and Carole, brother, Gerry, and step-father, Brian. The fruits of our lengthy and challenging discussions on issues of social (in)justice over many years are reflected in this work

Academic supports along the road to completing this project have been numerous. I express sincere gratitude to Dr. Walter DeKeseredy, Dr. Colette Parent, Dr. Dennis Forcese, and Dr. Colleen Dell for allowing me to make errors in judgement, to veer off the track, and to be there to sustain me along the path to completion. Each of my committee members bring their own unique talents to the task at hand and have complemented one another in the most rewarding ways. I am also appreciative of the continued support provided to me, most notably at that crucial early stage of my doctoral work, by Dr. Wallace Clement, Carleton University.

I am very fortunate to have shared a friendship with a number of women involved in the struggle for social justice. The genesis of my involvement took hold through the establishment of a local E-Fry Society in Newfoundland \& Labrador. These wonderful women share a vision and commitment to women's equality and continue to blaze trails in advancing women's justice. Dorothy Proctor, Kim Pate, Joyce Hancock, Rebecca Woodrow, Kelly HannahMoffat, and Kathy Kendall have collectively influenced my work in distinguishable ways over the years. It is in their footsteps that I strive to actively work towards a critical appraisal of women at the margins. I am most indebted, as always, to the many wonderful women who agreed to take part in this research, to share their stories and their lives, and open their homes and hearts to me. You are the true scholars.

This research has been supported financially through a number of sources including a departmental scholarship at Carleton University, a doctoral dissertation award (Faculty of Graduate Studies \& Research) and the Ontario Ministry of Education (Ontario Graduate Scholarship). Warmest thanks are extended to Diane Berezowski for helping me out of a number of jams and for always being there to lend support above and beyond her professional calling.

Finally, but in no small way, the faculty and staff at Memorial University of Newfoundland (MUN) have always been a major source of support and inspiration for my work over many years. In particular, I acknowledge the collegiality of Dr. Larry Felt for sharing his data set on criminalized women. Many thanks to all in the Department of Sociology for allowing me a space to work, the encouragement and camaraderie needed to keep going, and the kindest of colleagues and mentors one could ever hope to encounter. 


\section{TABLE OF CONTENTS}

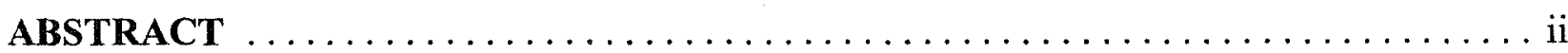

ACKNOWLEDGEMENTS $\ldots \ldots \ldots \ldots \ldots \ldots \ldots \ldots \ldots \ldots \ldots \ldots \ldots \ldots \ldots \ldots \ldots \ldots$ ii

LIST OF TABLES $\ldots \ldots \ldots \ldots \ldots \ldots \ldots \ldots \ldots \ldots \ldots \ldots \ldots$ vii

LIST OF APPENDICES $\ldots \ldots \ldots \ldots \ldots \ldots \ldots \ldots \ldots \ldots \ldots \ldots$ viii

CHAPTER 1: INTRODUCTION $\ldots \ldots \ldots \ldots \ldots \ldots \ldots \ldots \ldots \ldots \ldots \ldots \ldots \ldots \ldots \ldots \ldots \ldots$

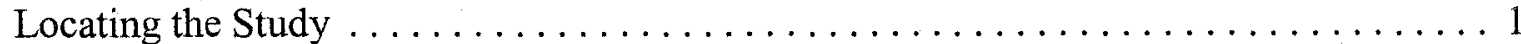

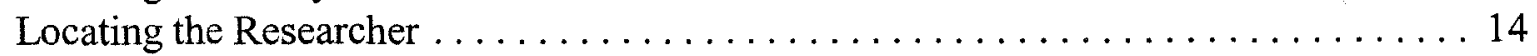

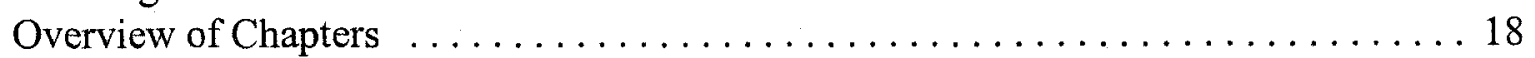

CHAPTER 2: PENAL CONTROLS OF CRIMINALIZED WOMEN $\ldots \ldots \ldots \ldots \ldots 23$

Language Used to Individualize Women's Crime $\ldots \ldots \ldots \ldots \ldots \ldots \ldots \ldots \ldots$

'Penal Industrial Complex' .................................. 27

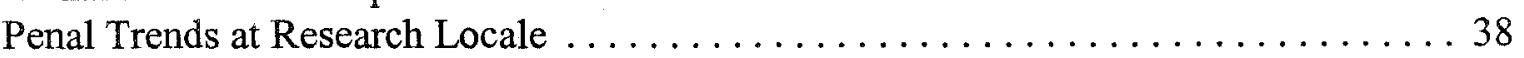

CHAPTER 3: SOCIO-POLITICAL CONTEXT OF CRIMINALIZING WOMEN . . . . 44

Neo-Liberal and Neo-Conservative Strategies of Criminalization $\ldots \ldots \ldots \ldots \ldots 44$

'Equality Versus Difference' Paradigm $\ldots \ldots \ldots \ldots \ldots \ldots \ldots \ldots \ldots \ldots \ldots, \ldots \ldots$

Penal Responses to Criminalized Women $\ldots \ldots \ldots \ldots \ldots \ldots \ldots \ldots \ldots \ldots \ldots \ldots$

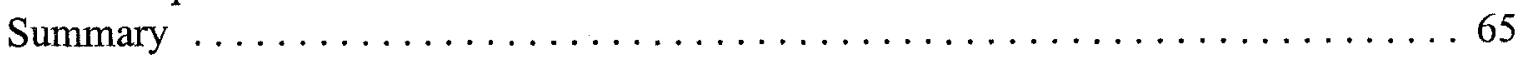

CHAPTER 4: THEORETICAL INFLUENCES $\ldots \ldots \ldots \ldots \ldots \ldots \ldots \ldots \ldots \ldots \ldots$

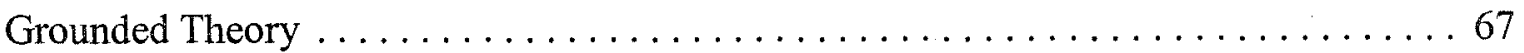

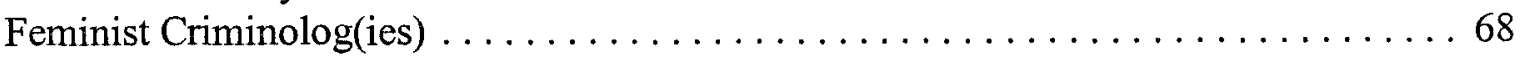

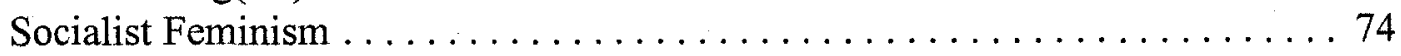

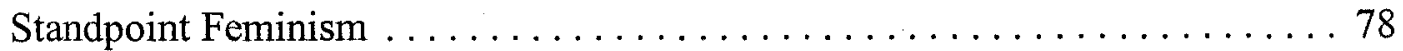

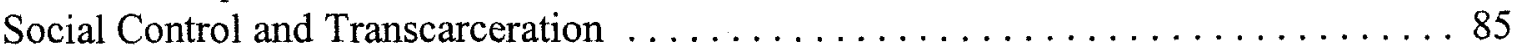

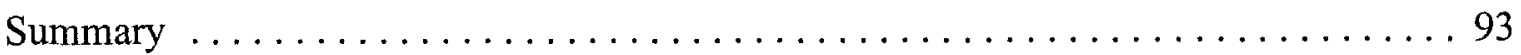

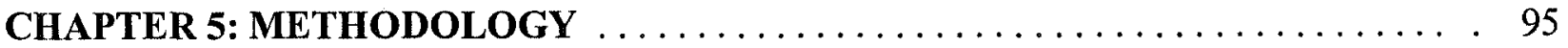

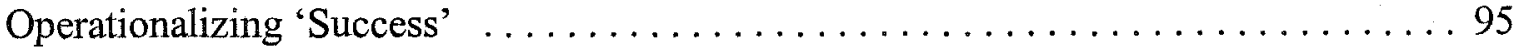

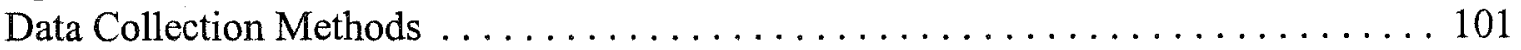

Grounded Theory Methodology ............................ 110

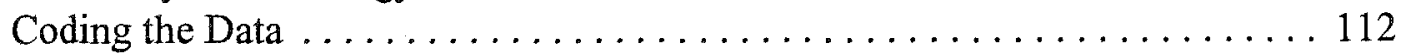

Identification of Core Categories . . . . . . . . . . . . . . . . . . 115

Identification of Core Variables ......................... 116

Generation of Theoretical Memos $\ldots \ldots \ldots \ldots \ldots \ldots \ldots \ldots \ldots \ldots \ldots \ldots$

Generation of Substantive Theory ..................... 117

Applied Feminist Methodologies . . . . . . . . . . . . . . . . . . . . . 118

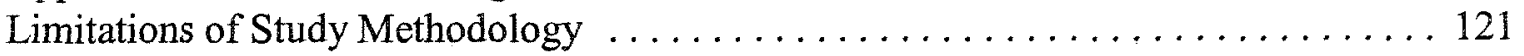

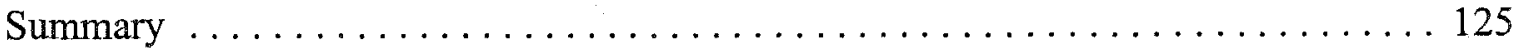


CHAPTER 6: GETTING IN: PATHWAYS TO PRISON $\ldots \ldots \ldots \ldots \ldots \ldots \ldots \ldots$

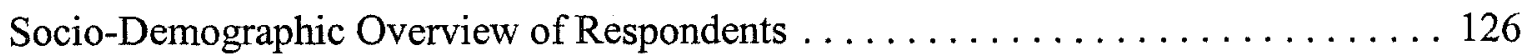

Pathways to Crime . . . . . . . . . . . . . . . . . . . . . . . 133

Poverty Trap . . . . . . . . . . . . . . . . . . . . . . 133

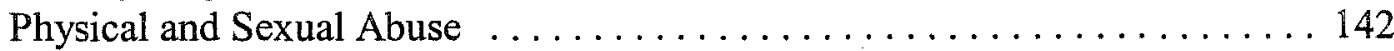

Layering of State Controls . . . . . . . . . . . . . . . . . . . . . 149

Defiance of Gender Norms . . . . . . . . . . . . . . . . . 154

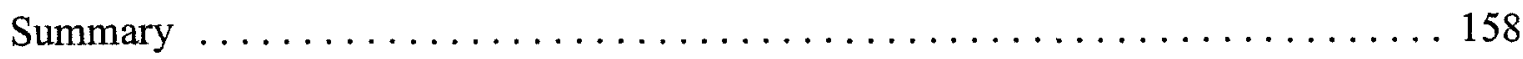

CHAPTER 7: DOING TIME ON THE 'INSIDE' $\ldots \ldots \ldots \ldots \ldots \ldots \ldots \ldots \ldots$

Two-Tiered 'Corrections' . . . . . . . . . . . . . . . . . . . . . . . . . . . . . . 159

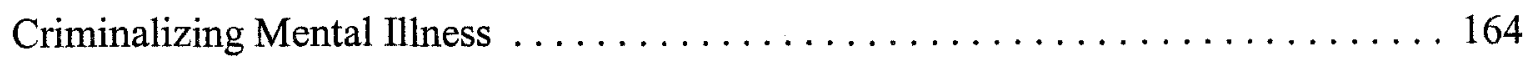

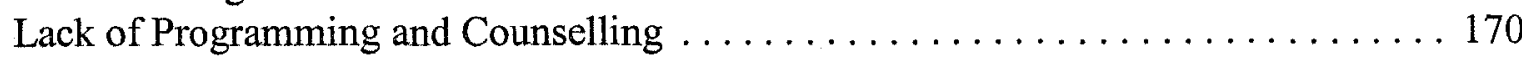

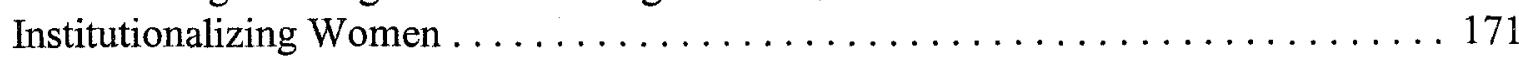

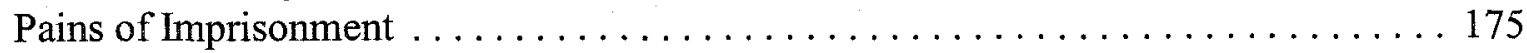

CHAPTER 8: GETTING OUT: COMMUNITY TRANSITIONS $\ldots \ldots \ldots \ldots \ldots \ldots$

Safe and Affordable Housing . . . . . . . . . . . . . . . . . . 179

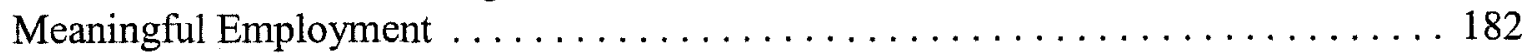

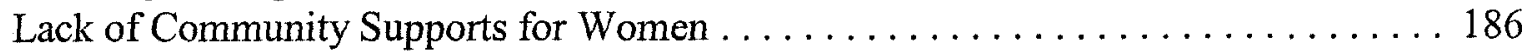

Police Surveillance . . . . . . . . . . . . . . . . . . . . . . . 188

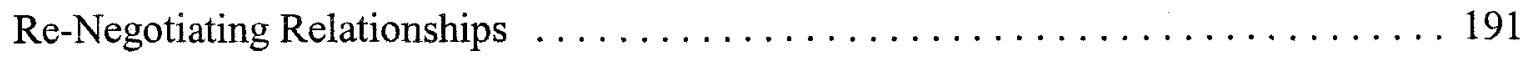

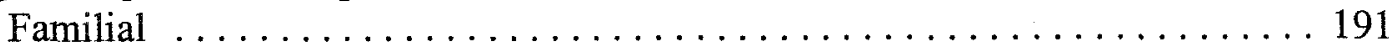

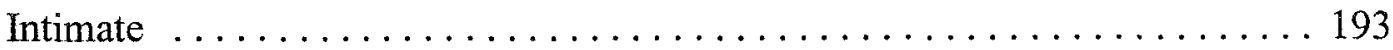

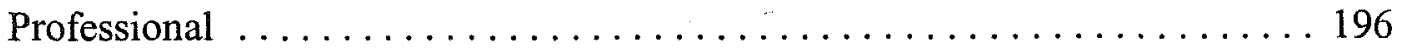

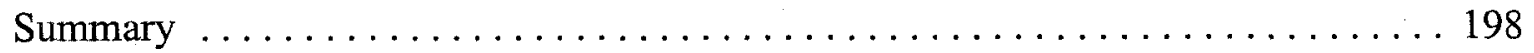

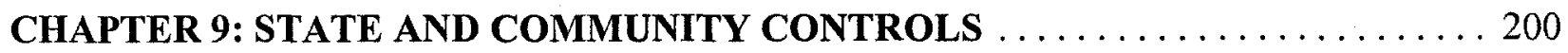

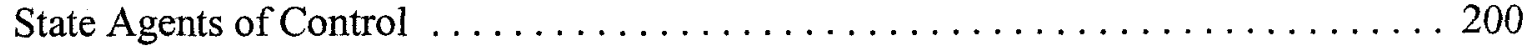

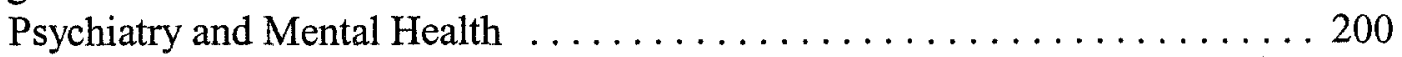

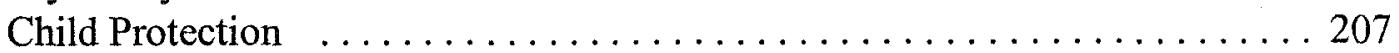

Social Services . . . . . . . . . . . . . . . . . . . . . . . . . 209

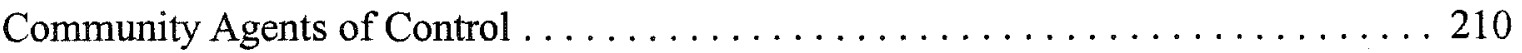

'Home Care' . . . . . . . . . . . . . . . . . . . . . . . . . . . . 213

Residential Centres ............................ 216

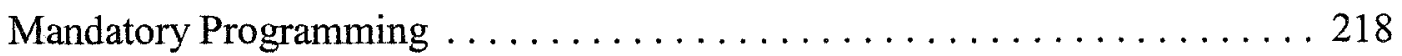

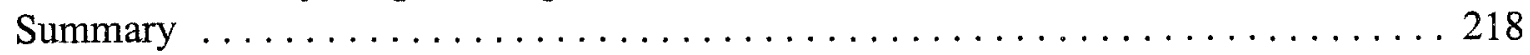

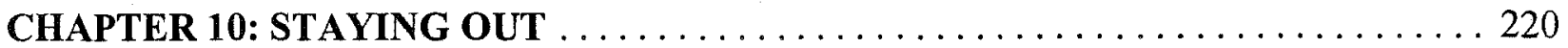

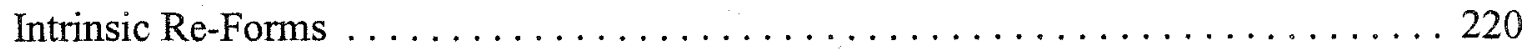

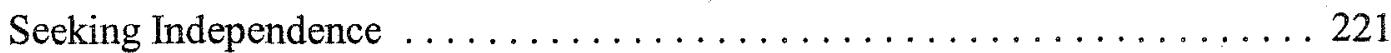

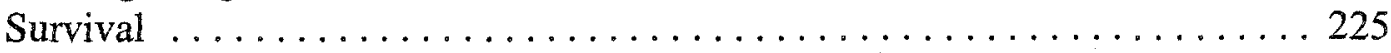

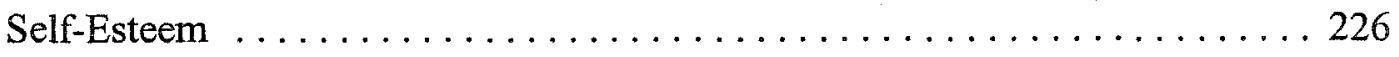




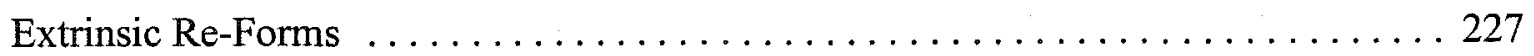

Child Care Responsibilities .......................... 227

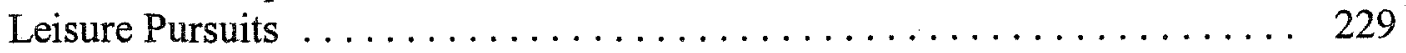

'Paying Back' . . . . . . . . . . . . . . . . . . . . . . . . . . . 230

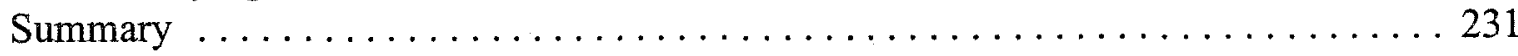

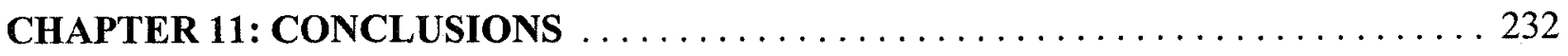

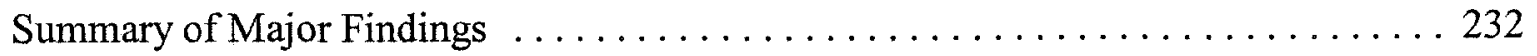

Research Directions ..................................... 235

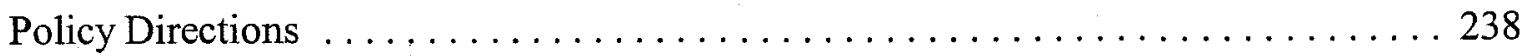

Classification Systems ............................ 238

Provision of Community Mental Health Services ................ 239

Conditional Release Strategy for Women . . . . . . . . . . . . . . . 240

Funding for Provincial Elizabeth Fry Society $\ldots \ldots \ldots \ldots \ldots \ldots \ldots \ldots .241$

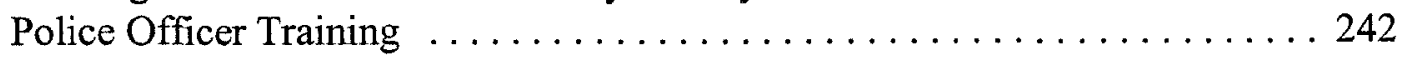

Broader Vision .................................. 243

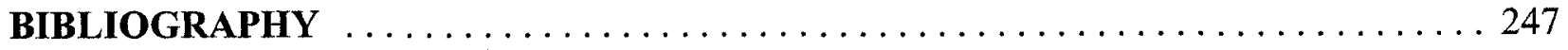




\section{LIST OF TABLES}

Table 3.1: Canadian Low-Income Cutoffs, Based on Population Size, 2003 . . . . 53

Table 3.2: $\quad$ Social Assistance Rates and Population of Unattached Individuals and Lone-Parent Families in Newfoundland and Labrador, 1999-2003 . . . . 54

Table 3.3: Unemployment Rate (\%), Canada \& Provinces, 1997-2003 Annual,

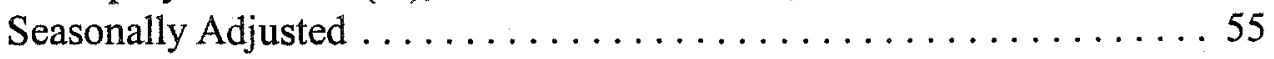

Table 5.1: Proportion of Lone Parents with Earnings, Canada, Provinces and

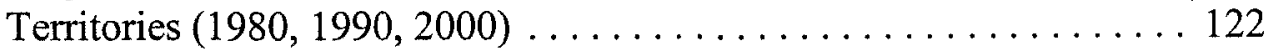

Table 6.1: $\quad$ Socio-Demographic Profile of Total Sample . . . . . . . . . . . 128

Table 6.2: $\quad$ Comparative Socio-Demographic Profile . . . . . . . . . . . . . 129

Table 6.3: Comparative Nature of Criminal Convictions $\ldots \ldots \ldots \ldots \ldots \ldots 131$

Table 6.4: Comparative Child Care Responsibilities $\ldots \ldots \ldots \ldots \ldots \ldots \ldots$ 


\section{LIST OF APPENDICES}

Appendix A:

Appendix B:

Appendix C:

Appendix D:

Appendix E:

Appendix F:
Letter of Information 268

Informed Consent Form 271

$$
\text { Research Instrument . }
$$

$$
\text { Carleton University Ethics Application }
$$

Letter of Support

Map of Newfoundland \& Labrador 287

viii 


\section{CHAPTER 1: INTRODUCTION}

The experience of imprisonment is not one to equip a woman to cope more effectively with life. (Eaton, 1993: 174)

\section{Locating the Study}

Since the early 1990s, there has been considerable social and political pressure on the Canadian government to revamp its approach to dealing with criminalized women. This pressure has been invoked by feminist activists and scholars who called for sweeping changes to women's penal regimes. Recent inquiries and government reports (e.g., Arbour Commission Report, 1996; Canadian Human Rights Commission, 2003) have highlighted the deficiencies of female corrections $^{1}$ (e.g., male-based assessment tools, stereotypical gender-blind programming) and call for a 'woman-wise' approach (c.f., Carlen, 1989) to guide future programming for criminalized women. However, this guiding 'women-centered philosophy'2, with its purported emphasis on empowering women ${ }^{3}$, has focussed primarily on the situation of incarcerated ${ }^{4}$ women and has

${ }^{1}$ The 'corrective' nature of the competing goals of incarceration (e.g., punishment versus rehabilitation) is challenged throughout this research. As Horii (2000:107) clearly argues, "[c]orrections is plainly a misnomer since reformatories, lockups, jails, prisons and penitentiaries correct nothing, rather they err."

${ }^{2}$ The presumption and advancement of a 'woman-centered' philosophy adopted by Correctional Services Canada (CSC) in recent years is taken up and critiqued throughout this research. It is argued that this philosophy has amounted to little more than a misappropriation of feminist goodwill and guiding principles which serve a further injustice to criminalized women.

${ }^{3}$ Empowering women in the most disempowering of environments such as the prison, has been debated by feminist scholars (c.f., Hannah-Moffat, 2000; Pollack, 2000).

${ }^{4}$ This term customarily refers to physical incapacitation in a prison. It is understood, however, that incarceration takes many forms and women can be as readily incapacitated in their homes and communities. In the case of correctional controls, for example, electronic monitoring and house arrest programs are also regarded as forms of incarceration (c.f., Maidment, 2002). 
neglected the realm of community-based corrections. To date, there have not been any assessments of how such an approach would apply to women serving sentences under various forms of conditional and community releases in Canada. Likewise, in the Unites States, 'selective inattention' has been paid to researching the lives of women after they have completed their prison terms and how they cope with, and often overcome, the challenges of 'staying out' (Covington, 2003; Petersilia, 2003; O’Brien, 2001). My research seeks to fill this gap.

In Canada, a large body of literature shows that the criminal justice system does not adequately reflect or meet the needs of criminalized women (e.g., Boritch, 1997; DeKeseredy, 2000; Faith, 1993). On the contrary, the correctional enterprise is primarily a tool used to control criminalized men and neglects the complex differences of their female counterparts. The most noteworthy of these differences include an overwhelming percentage of women as sole support providers for their children (Faith, 1993), high numbers of women with histories of physical and sexual abuse (Shaw and Rodgers, 1990), patterns of self-injury (Filmore et al., 2001), and mental health needs (Rivera, 1996).

It has been well documented that recent attempts to adopt a 'woman-centered' approach to corrections in Canada (Auditor General of Canada, 2003; Public Accounts Committee, 2003; Canadian Human Rights Committee, 2003; Correctional Investigator, 2003; Task Force on Federally Sentenced Women, 1990) have failed and continue to perpetuate stereotypical gender roles that inadequately prepare women for release back into the community (Hannah-Moffat, 1995; Canadian Association of Elizabeth Fry Societies, 1998; Martel, 1999; Shaw and HannahMoffat, 2004).

By moving beyond an examination of well-known, albeit crucial factors, which propel 
women back into prison (i.e., inadequate housing, lack of meaningful employment/training, lack of family supports, etc.), this research focuses on the life trajectories of criminalized women; the structural and systemic factors which contribute to the criminalizing process by conflating the needs of disenfranchised women as risk markers; the all-important transition from prison back into the community; and the internal resources and strategies relied upon by women to stay out of prison. Whether the connections between attaining these rather ambitious goals noted above (that is, the well-defined risk/need markers enshrined in correctional policy and subsequent links to staying out of prison) is an empirical question that will be addressed in this study.

It is argued throughout this research that women who manage to successfully complete their community terms are not suddenly becoming gainfully employed, securing adequate housing, reuniting with children and families, developing strong peer supports, and developing 'pro-social attitudes', all of which are well-established in the correctional lexicon of risk management. However, my research demonstrates that something more, or something quite different, is happening in women's lives post-incarceration. That is, wherein the criminal justice system releases its control of women, other state-run and community ${ }^{5}$ agencies are stepping in to replace control, both formally and informally, in women's lives.

In Atlantic Canada, for example, there is a disproportionately high prevalence of women in the criminal justice system with mental disabilities (Canadian Association of Elizabeth Fry

${ }^{5}$ A critical investigation of what constitutes the 'community' for this group of sentenced women in Newfoundland and Labrador is a major focus of my Research Instrument (See Appendix C). However, in keeping with a grounded theoretical approach to data analysis, it is critical that the women themselves were given the opportunity to define what the 'community' means for them. 
Societies, 2003a). In particular, in Newfoundland and Labrador, a substantial number of women parolees cycle in and out of mental health institutions both before prison and throughout their parole tenures (Seymour and Greene, 2000). Therefore, while women probationers and parolees may be avoiding a return to prison, they are not entirely, and in many cases not at all, breaking free of the social, economic, legal, medical, and 'psy' entific (Kendall, 2000) establishments that operate within the community and continue to control women's lives long after their prison sentences have expired. Patterns of transcarceration and dependency continue for women long after the completion of their community sentences.

The conceptual notion of 'transcarceration' builds upon the work of Michel Foucault (1977) and his argument that "discipline and surveillance create a more extensive form of power...in which the power to punish is inserted more deeply and more certainly into the social fabric. The advent of community corrections and other non-segregative techniques of control has resulted in more control, not less, as the control net is widened and its mesh thinned" (Lowman et al., 1987: 9).

While 'transcarceration' and 'transinstitutionalization' are often used interchangeably, as Lowman et al., (1987: 9) point out, "[i]t is not simply in institutional terms that the impact of changing control strategies must be conceptualized... [t]ransinstitutionalization...[c]an only offer a partial understanding of the modern education-health-welfare-criminal-justice complex. It confines the understanding of control strategies to their institutional expression." Transcarceration, then, is a "perspective which captures the holistic and diffused character of state power over dependents and deviants, and its permeation through the regulatory systems of civil society" (Lowman et al., 1987: 2). Expanded discussions of transcarceration take place in a later 
chapter dealing with theoretical influences (Chapter 4). Suffice it to say at this point that women's entanglement with/in the criminal justice system and with other state agencies and community organizations continues to be a major component of their lives post-release.

An exploratory study of women serving sentences in the community, then, is important for several reasons. As noted, little is known about women and their experiences with community corrections or about gender bias in service delivery (Davies and Cook, 1999; O’Brien, 2001; Covington, 2003; Petersilia, 2003). Second, the majority of research about women's community experiences is based mainly on research conducted in the United Kingdom (e.g., Carlen, 1990; Eaton, 1993; Worrall, 1997), while the topic is under-researched in Canada. Third, overwhelmingly, the English Canadian literature on criminalized women is directed toward federally sentenced women while very little is known or understood about their provincial counterparts (c.f., Comack, 1996; Women's Issues Task Force, 1995; Nova Scotia Correctional Services, 1992). Furthermore, the available English Canadian literature is based mainly on secondary analyses of government reports and task forces while an absence of primary research on women's pathways to, and experiences of, imprisonment and community sentencing has been made available. Fourth, in recent years, the numbers of criminalized women has increased dramatically. Admissions to federal Canadian prisons were $33.1 \%$ higher for women in 2001-02 than in 1994-95, with an increase in actual numbers from 151 to 201 over the eight year period. This increase is in stark contrast to women's offending rates which have been steadily decreasing over the past decade (Solicitor General Canada, 2002).

Likewise, community release sanctions such as probation and parole are increasing for women despite a continual decline in their offending rates. Between the period from 1996-97 to 
$2001-02$, the number of federally criminalized women in the community has increased by $22 \%$, from 325 to 409 (Solicitor General Canada, 2002). Furthermore, it is important to explore these trends specifically within the context of Newfoundland and Labrador as research indicates that in the Atlantic region, between 1994-95 and 2000-01, there was a slight increase in prison populations and a significant increase in probation as a sanction (Solicitor General Canada, 2002).

Recent Canadian developments regarding criminalized women make this study a timely and important one. Canada has become increasingly reliant on community-based release programs. Currently, the vast majority of criminalized men and women in Canada are under some form of community supervision. In 2001-02, there were 101,915 persons serving a sentence of probation, with an additional 8,578 under some form of conditional release (federal and provincial parole). In contrast, there were 31,926 persons incarcerated (Bonta et al., 2003). At some point in their sentences, over 90 percent of incarcerated persons will be released into the community.

The move toward community release programs is largely due to financial considerations which put pressure on governments to find less expensive ways of dealing with criminalized populations while maintaining public safety. In July 2003, for example, of the 822 women serving federal sentences in Canada, 374 were incarcerated in an institution (45\%) while the remaining 448 were supervised in a large number of communities across Canada (55\%). By contrast, $61 \%$ $(12,221$ out of 20,029$)$ of federally sentenced men were incarcerated in institutions while a significantly fewer number were supervised in the community (39\%) (Canadian Human Rights Commission, 2003). Therefore, the need to shift the research focus onto women's experiences of 
community sentences is increasingly more relevant and urgent given their disproportionate representation in community-based programs.

In Canada, the success ${ }^{6}$ rates of women who complete their term of supervision in the community is also quite high. Of the 172 full paroles granted to federally sentenced women in Canada during the period between April 2000 to March 2001, for example, 79\% successfully completed their terms. Similarly, for the 237 women granted day parole in the same period, $82 \%$ were successful in completing their terms (Solicitor General Canada, 2002). Given the high numbers of women who complete their terms of conditional release, it is important both sociologically and practically to focus attention to those women who stay out of prison rather than narrowing our analysis to only those women who go back into custody. There is a huge potential to learn more about 'what works' in corrections by examining the life histories and experiences of the majority of women who do not return to custody.

The findings from this study have important policy implications for criminalized women. Foremost, it calls into question the well-entrenched and highly controversial risk and need factors which are currently used to assess criminalized women. At present, classification and assessment tools are criticized based on their reliance on a male model which fails to account for the experiences of gender and culture (Hannah-Moffat and Shaw, 2001). Stemming from this

${ }^{6}$ A singular, quantifiable definition of 'success' is not proffered in my research. However, according to Correctional Services Canada definitions, recidivism rates are the official barometer of success and defined as "any new conviction for an offence committed within two years of release from prison" (Bonta, Rugge, and Dauvergne, 2003; Bonta, Pang, WallaceCarpretta, 1995). This definition is problematic for a number of reasons which will be explored throughout the research. In keeping with the basic tenets of feminist methodologies, it was recognized at the conceptual and research design stages that the Research Instrument be flexible enough to allow respondents to define their own perceived 'successes' or 'failures' according to their own lived experiences. 
critique, my research contributes to the debates surrounding actuarial assessments of criminalized women. It is evidenced throughout this study that 'success' is not wholly determined based on the dynamic (e.g., substance abuse, unemployment) and static (e.g., age at first offence, prior criminal history) factors typically used by state correctional agencies, but rather is attributable to less known characteristics and circumstances in women's lives. Other previously unexplored factors are at play (i.e. learning to cope, learning to adapt to the criminal justice system, becoming entrenched in other state-run social systems) that account for women's 'success' in communitybased corrections programs.

In particular, this study reveals four major factors which account for women's successes in avoiding a return to prison. The foremost finding reveals that for those women experiencing relatively fewer 'layers of social control' prior to her prison term, the greater chance she has of staying out of prison. The convergence of state-imposed regulatory agencies in the lives of criminalized women has been duly noted (c.f., Carlen, 1988). The accumulated disempowerment brought about by a lifetime of formal social control agents leaves many women vulnerable and highly dependent on continued intervention by their oppressors. Prison life simply represents an extension of this dependency and a further contributor to women's institutionalization. Chances of staying out are increased considerably if a woman has managed to escape a formalized history of state control (namely child custody interventions, welfare caseworkers, and mental health agents) prior to her entering prison.

Second, as earlier eluded, strict categorical definitions of 'success' do not coincide with official definitions. Recidivism rates, not surprisingly, are inaccurate measures of quantifying women's successes or failures post-release. For many women who have spent their lives 
controlled by state agencies, managing a relatively short period of independence in the community marks a major milestone. Also, for many women, a reconviction did not translate into the commission of a new offence but rather resulted from a technical violation of their often untenable parole conditions. Therefore, beginning from the measurement of success based on recidivism rates is a faulty starter and contributes to a misrepresentation of women's own perceived and real successes.

Third, for those women who have managed to stay out of the criminal justice system, a majority remain tightly entangled in other state-sponsored control regimes. Patterns of dependency, medicalization, and infantilization still persist in the treatment of women in the community. Transcarceration, primarily characterized under the guise of criminal justice and mental health agencies, continues to pervade the lives of women who have spent the majority of their lives under formalized controls. Furthermore, state controls were often disguised in the form of underfunded and under-resourced community-based agencies who continue to operate at the behest of state agendas.

Fourth, familial and social support networks are paramount to women's successful reintegration, far more so than professional supports provided by state and community agencies. That is, those women who managed to maintain a supportive kinship network during their time of institutionalization stood a much stronger chance of staying out of prison than those who did not have the support of family members. Varying levels of professional interventions (i.e., probation and/or parole officers; psychiatrists and psychological counsellors; residential supervisors, etc.) did not play a significant role in determining women's successful re-integration. In many cases, professional contacts contributed to a further sense of dependency and persistent control in the 
lives of women post-release. Each of these major findings is discussed in-depth in the data analysis chapters (Chapters 6 through 10).

On another distinct level, this research marks a significant contribution to the Canadian literature on criminalized women by its inclusion of women in both provincial and federal prison systems. Currently and historically, the available primary research on provincially sentenced ${ }^{7}$ women has been scant. What we have come to know about criminalized women in Canada is based on socio-demographic information and critical evaluations of federally sentenced women in this country. Given the divergence of the two populations (i.e., length of incarceration and associated pains of imprisonment) we can expect some important differences to emerge. Attempts then to address policy issues for provincially sentenced women based on statistical profiles and first-hand accounts of federally sentenced women is a non-starter and further disadvantages women at the provincial level. In order to broaden our understanding of the unique situation facing provincially sentenced women such as remote locations of prisons, limited access to health care services, and lack of availability of rehabilitative, cultural and counselling services (Monster, 2000) there is a need to conduct empirical research specific to this population.

The major focus of my research seeks to understand the processes and challenges women face upon their release from prison. The overarching question driving this research then is:

How is it that some criminalized women, following further marginalization and institutionalization brought about by their prison experiences, manage to avoid going back

${ }^{7}$ My research examines both provincially and federally sentenced women. However, given the absence of a federal prison for women in Newfoundland, all of the respondents in my sample have spent some period of time in the Newfoundland and Labrador Correctional Centre for Women (NLCCW) either under the Federal/Provincial Exchange of Services Agreement, while awaiting transfer to the federal prison in Truro, Nova Scotia, or due to their original sentence length which resulted in a provincial term. 
into custody, while others do not?

Based on the above research question, this study combines both quantitative and qualitative methodologies to provide a more accurate understanding of the plight of criminalized women in an Eastern Canadian province. A SPSS database containing the socio-demographic profile of all sentenced women in the province of Newfoundland and Labrador $(n=359)$ over an 11-year period (1990-2000) serves as the starting point for analyzing women's correctional trends. From here, semi-structured interviews with twenty-two (22) federally and provincially sentenced women who have, upon their release from institutional custody, served a portion of their remaining sentence in the province of Newfoundland and Labrador, were carried out.

From a methodological stance, it is important to note the serious lack of provincial data which exists on women in the criminal justice system in all Canadian provinces. While my research sample draws almost equally from both federally and provincially sentenced women, the bulk of reference material cited throughout this study is taken from the federal female prison population. While the lack of comparable provincial data is recognized as a limitation of this study given the divergence of the two populations, it is an unavoidable consequence of the dearth of provincial data-keeping on criminalized women more generally. Knowledge of provinciallybased statistics would undoubtedly shed light on specific trends taking place for women in various regions of Canada. Specifically, comparable provincial statistics highlighting regional variations would certainly lend itself to a broader and more in-depth analysis of some important findings from this study. For instance, it is generally understood that the criminalization of women with mental health diagnoses is more acute in the Atlantic region. However, solid empirical support for this claim is lacking. Certainly, more rigour and uniformity in provincial 
data tracking is seriously needed to better identify areas of importance to both researchers and policymakers.

Notwithstanding this lack of available provincial data, my study seeks to shed some light on the differences which may exist for both populations in terms of their efforts to stay out of prison. Interviews, then, were constructed to compare the experiences of a group of repeatedly criminalized women ${ }^{8}$ who have been returned to prison within a two-year period of their release (recidivists), with a matched group of women who have managed to avoid a return to prison for a minimum two-year period (non-recidivists) ${ }^{9}$. This research study chronicles the systemic barriers which exist in society (e.g., feminization of poverty, women's child care responsibilities, lack of familial and peer supports, medicalization of criminalized women) and the structural barriers within correctional institutions (e.g., gender blind standardized risk assessments, mandatory treatment attendance, lack of gender appropriate programming, lack of treatment services for mental health detainees) and examines the strategies used by women to overcome these barriers in order to stay out of prison. Comparatively, this study investigates the life histories of another group of women, faced with seemingly similar circumstances and life opportunities or lack thereof, who consistently cycle in and out of the criminal justice system throughout most of their

\footnotetext{
${ }^{8}$ For the purposes of this study, 'repeatedly criminalized' women were defined as those having at least four separate prison admissions as an adult. The sampling, selection, and recruitment of this group is discussed in greater detail in the Methodology Section.

${ }^{9}$ While this research does not make initial claims as to the definition of 'success' or 'failure', it was determined at the sampling stage to impose the two-year non-custodial cut-off as a measure in keeping with the official definitions of recidivism for sampling purposes only. However, imposing this two-year time period raised important concerns and questions regarding the reliability and validity of this measurement tool. For example, staying out of prison past two years did not necessarily translate into being offence-free during this same time. Again, the problems inherent in defining recidivism are discussed in the Methodology Section.
} 
adult lives.

In order to empirically assess the above research question, the following subsidiary questions are explored. Given the large numbers of women who do manage to stay out of prison following their period of community release, several important questions arise which include:

- How is 'success' defined? (i.e., recidivism or re-arrest rates) By whom? (i.e., state officials versus criminalized women)

- What factors contribute to women's criminalization in the first place?

- What factors contribute to women's 'successes' and 'failures' post-release? (i.e., intrinsic versus extrinsic factors)

- Are women's 'successes' in part artificial? (i.e., overwhelming front-end support from service delivery agencies followed by a lack of supports post-probation and parole)?

- What are the challenges faced by women in their attempts to overcome the obstacles to community re-integration and how are they surmounted?

- How does the 'prisoning ${ }^{10}$ ' of women contribute to 'success' or 'failure' postrelease?

- What are the internal and/or social resources women draw upon to avoid further criminalization?

- Are strategies of decarceration in both criminal justice and mental health sectors being replaced by transcarceration for women?

These questions are both implicitly and explicitly taken up in the research to provide a better understanding of the realities of women's lives post-incarceration and form the nexus of my research analyses. However, it should be noted that these guiding departures of inquiry (as set out in the Research Instrument, Appendix C) undergo a major transformation and re-focussing

${ }^{10}$ The term 'prisoning' is adopted from Comack (1996: 124) and refers to "the process of incarceration/imprisonment and...plac[ing] the focus on women's experiences of that process." 
throughout the data analysis sections as it becomes increasingly more evident that women's attempts to negotiate their lives post-incarceration have little to do with officially sanctioned characteristics (dynamic and static indicators) and much more to do with state-sponsored strategies of social control.

\section{Locating the Researcher}

Feminist epistemologies have contributed to the now common and useful practice of researchers locating themselves in direct position to their research to demonstrate the often subjective and biassed nature of social scientific research. This is important not only to enable the reader to examine the interconnectedness between the research topic and the researcher's social location but, more importantly, it is a worthwhile exercise for the researcher to grapple with at all stages of the research process, any preconceived notions they might have about the study and its subsequent results. This epistemological practice, known as positionality, refers to researchers locating themselves within the context of their research and sharing their particular standpoint with their readers. In understanding the relationship between researcher and researched, whereby the biographies of the researched are often times revealed, it is important to also shed light on the biography of the researcher as it relates to their study. It is argued that since researchers are active participants in the data collection process, it is imperative that the researcher's position is known and understood (e.g., gender, race/ethnicity, and class) before interpreting the data. Hertz (1997: viii) emphasizes the following framework of positionality:

Through personal accounting, researchers must become more aware of how their own positions and interests are imposed at all stages of the research process-from the questions they ask to those they ignore, from who they study to who they ignore, from problem formulation to analysis, representation, and writing - in order to produce less distorted accounts of the social world. 
Feminist researchers attempting to gain a fuller understanding of women's experiences are also enabled through the closely connected process of reflexivity. Reflexivity, as defined by Mauthner and Doucet (1998:121) means:

[R]eflecting upon and understanding our own personal, political, and intellectual autobiographies as researchers and making explicit where we are located in relation to our research respondents. Reflexivity also means acknowledging the critical role we play in creating, interpreting and theorizing research data. Reflexivity during the data collection process requires constant and intensive scrutiny of what we know and how we come to know as researchers. This involves a process of actively constructing interpretations of field experiences and then interpreting how those experiences came about.

Both feminist epistemological practices are introduced below in terms of tracing my own connections to the research which is heavily influenced and shaped by a number of experiences converging throughout my personal, political and intellectual autobiography. While these epistemological processes are referred to at various stages throughout the research process (i.e., data analysis), they are introduced at this early point to bring the reader along through my own positioning in the social world and hence from where I begin to frame and interpret the research concept, design, and subsequent findings.

To begin from my personal journey, interest in undertaking this study developed as a result of my experiences as a working class, white, urban woman in a relatively small Canadian Metropolitan Area (CMA). I have long recognized the fine line I traversed between the official status of 'offender' and 'non-offender'"1. The question driving this current research could easily

${ }^{11}$ It is extremely difficult to try and locate the factors which contribute to conformity (in the legal sense) and subsequent non-criminalization. Indeed this is a massive undertaking which would undoubtedly produce inconclusive results as attempts to isolate dependent from independent variables would vary widely. For example, the weighting of different variables (i.e., work ethic, family support, role modelling, (in)formal education, et cetera.) would prove extremely problematic to quantify, disentangle, and prioritize. 
be expanded to reflect my longstanding attempts to understand, "How it is that some girls/women from lower working class, disenfranchised backgrounds avoid the criminalizing process in the first place (or avoid getting caught and subsequently labelled ${ }^{12}$ ) while others do not?" This began as the overarching question imposing on my research as I took inventory of fellow classmates and neighbours who have ended up on the 'other side of the law' while I managed to escape that dooming fate. However, this is another project for another time but one that is constantly in the fore of my mind as I meet and conduct research with 'women in trouble', many of whom once sat as young friends in an elementary classroom alongside me.

My political journey to this research was much more uneven. While I realized relatively early on in life that in order to effect social change I needed to position myself to influence macro social policy development and implementation, the execution of this seemingly grandiose task was conflated. The conversion of 'private troubles' into 'public issues', as formulated by C. Wright Mills (1959), was the driving force behind my thinking at that time. While I did not articulate this position back then, I discovered early in my undergraduate career that I needed to challenge the decision-making which unevenly discriminated against members of our society based primarily on divisions of class, race, gender, and sexuality.

My intellectual journey began as an undergraduate student nearing the completion of my arts degree. Around that time, I conducted a study of women on house arrest and was alarmed at the incongruency of women's dual status as prisoners and full-time caregivers in their own

${ }^{12}$ It is recognized and acknowledged that many of us, for a variety of reasons, escape the formal criminalization process (i.e., arrest and sentencing), particularly as young persons, despite the commission of criminal activities. This would certainly constitute an important area of investigation in and of itself. 
homes. It became evident at this point that the criminal justice system did not take into account the gendered realities of women's lives by failing to acknowledge women's roles as primary caregivers and their concomitant responsibilities for domestic tasks both within and outside the home (Maidment, 1999). On the one hand, the criminal justice system confined women within the domestic sphere while making absolutely no allowance for societal expectations of their roles as mothers thereby setting women up for failure of one or both systems (Schur, 1984). Subsequent research at the graduate level further endorsed the claim of corrections as an androcentric enterprise wherein the experiences of men are taken as the starting and finishing point by which women are judged and processed. It was also abundantly clear throughout this earlier research that the community is often regarded by policy officials and the public as the lesser of two evils and the ultimate end for individuals leaving prison. All too often, the community becomes the 'catch-all' and escapes the critical interrogation which has been lauded on the prison, especially as it applies to women. The extant literature on corrections focuses primarily on the prison and neglects almost entirely the realities facing women and men upon their return to the very places where their troubles began. The whole notion of 're-integration' became a major area of inquiry for me as I watched women return (integrate) to the very same socially and economically disadvantaged locations in their communities which brought them into 'conflict with the law' in the first place. The concept of re-integration appeared at least ambiguous and very much based on white, male, middle-class values, norms, and expectations.

Around this same time, I became an active member of the Canadian Association of Elizabeth Fry Societies (CAEFS) and co-founded the local branch of Elizabeth Fry in Newfoundland and Labrador. Increasingly, I became aware of the neglect of criminalized women 
internationally, nationally, and locally. All the while, I was ever cognizant of the reality facing women upon return to their home communities and the growing number of social, cultural and economic forces competing to bring women down and keep them down (poverty, inadequate child care services, lack of education and employment opportunities, histories of sexual and physical abuse, criminalization of mental health). Again, the concept of 're-integration' against

the backdrop of these much broader systemic issues facing women in their 'communities' seemed (oxy)moronic.

My doctoral research comes full circle back to the question of why some women become entangled in the criminal justice system in the first place. More precisely, the focus of empirical inquiry deals with attempts to better understand the convergence of factors which not only contribute to women's criminalization in the first place but which continue to play out in women's almost daily struggle to stay 'out of trouble'. Personal reflections and issues of social positioning will be revisited throughout the research process as it relates to the presentation and interpretation of key findings. Suffice it to say that I come at this research with quite a number of perplexing questions and concerns which have not been satisfactorily addressed in the literature on women's corrections more generally. Like many social scientists, areas of overarching personal standpoint seek to inform and drive the direction of our research agendas. This is very much the impetus for my study.

\section{Overview of Chapters}

Chapter One has located the research in terms of the scope and relevance of the study. It has also gone through the important exercise of locating the researcher within the context of the 
study and exploring my own connections and preconceptions about women's criminalization and the inadequate attention paid by scholars and administrators in examining community-based realities for women. This section also provided an overview of key research questions and outlined the more precise focus of my study.

Chapter Two launches into an examination of the extant research literature in the area of penal controls. It is important to provide an overview of recent trends in women's corrections and explore the connections between ideological philosophies and material practices which get played out in the prison setting and, in many interconnected ways, in the community. It is also imperative at this early stage to interrogate the discourse surrounding women's criminalization in terms of the language used to set women in opposition to the social, economic, political, and cultural constructs of society which contribute to their violation of gender and legal norms.

Chapter Three examines the socio-political context of women's criminalization in an attempt to shed light on the research findings which examine, in part, women's pathways into crime. Here, the range of structural and systemic factors (social, economic, political, and cultural) which bring women into the criminal justice system and reveal the human costs of criminalizing women are explored. Recent national and international developments in women's corrections are discussed and linked to future directions which give rise to a renewed focus on the community. Ideological debates surrounding the discourse of women's corrections are also touched upon to provide the rationale for more neo-liberal penal controls in Canada and elsewhere.

Chapter Four discusses a number of converging theoretical frameworks which influence the design and analysis of the research. Given the exploratory nature of this research and the dearth of empirical literature on women's community re-integration, a grounded theoretical 
approach is adopted. From here, the application of feminist criminolog(ies), most notably socialist and standpoint feminism are discussed. Theories of social control and transcarceration are analyzed and applied within the context of this study. While this section is laid out in a separate chapter, theoretical analyses and reformulation are identifiable throughout the research, most notably in the data analyses and policy reform sections.

Chapter Five details the research design and methodology. It provides a rationale for a mixed methodology combining quantitative data analysis with a qualitative design involving indepth, semi-structured interviews. It deals with the impetus for adopting a grounded theory approach to data analysis and goes through the important exercise of explicating the steps involved in carrying out such an approach. This section also deals with issues of sample selection, locating respondents, gaining access to respondents, and operationalizing key concepts (i.e., success, recidivism). Finally, methodological limitations of this study are addressed.

Chapter Six begins to make sense of the data by looking at key socio-demographic conditions of respondents. It looks specifically at women's pathways into prison (poverty, histories of physical and/or sexual abuse, histories of state controls, and defiance of gender norms) and draws important connections to the myriad of factors which converge to bring women into 'conflict with the law' in the first place. Many of the themes raised in this chapter are revisited in subsequent sections dealing with women's attempts to re-integrate back into their communities.

Chapter Seven explores the 'prisoning' of women by looking at time spent on the inside, an integral component of women's chances of 'making it' on the outside. The major categories emerging from this examination include: two-tiered corrections (federal versus provincial, 
equality versus difference); criminalization of mental illness; lack of gender appropriate programming and psychiatric services; institutionalization; and the associated pains of imprisonment. Again, these discussions are advanced in an attempt to connect women's experiences at all stages of the criminal justice system, most notably in identifying the important transitional links from prison back to the community.

Chapter Eight looks specifically at women's transitioning from prison back into the community. Key themes presented here include the role of relationships (familial, intimate, professional, peer groups); securing safe and adequate housing, meaningful employment, police surveillance, and lack of community supports for women. All of these themes emerge as common denominators amongst both groups of women and are framed in a general way as critical factors facing all women upon immediate release back to their home communities.

Chapters Nine and Ten focus explicitly on women's experiences of getting out and staying out of prison. Key discussions related to transcarceration and social control are advanced. Here, I look specifically at the differences reported amongst both groups of women in terms of staying out or, alternatively, going back into custody. The findings reported in these chapters deal almost exclusively with the sample of repeatedly criminalized women who have, up until this point, managed to stay out of prison following a two-year period in the community. It deals with women's agency, resiliency, and the internal resources which drive their desire to avoid a return to prison. It also looks to structural forces which either facilitate or block women's bid to stay out of prison. Moreover, the shifting onto community-run control systems and the 'layering of social controls' for criminalized women is advanced.

Finally, Chapter Eleven reviews the key findings and conclusions of the study. More 
importantly, based on these findings, progressive policy recommendations are put forth on two distinct levels. First, on the level of criminal justice reforms, it demonstrably calls into question well-entrenched androcentric policies which fail to account for the economic, social, medical, and cultural realities of women's lives. On a broader, and arguably much more meaningful and significant level, it calls for the targeting of neo-conservative and neo-liberal socio-economic policies to address the widening inequalities which lend themselves to women's criminalization in the first place. Lastly, future areas of research and limitations of this study are addressed. 


\section{CHAPTER 2: \\ PENAL CONTROLS OF CRIMINALIZED WOMEN}

The punishing community, far from encouraging reintegration and conformity, may instead be creating a parallel universe, reinforcing for some an embeddedness which takes for granted that the only way to behave is criminally. (Worrall, 1997: 59)

Canada is now being hailed internationally as a leader among industrialized countries in their approach to dealing with criminalized women. Developments over the past decade have documented a purported shift in correctional philosophy which now drives policy and practice for criminalized women in this country. This chapter sets the contextual backdrop for later discussions surrounding recent increases in women's incarceration despite declining arrest rates; fiscally-imposed government agendas aimed at finding less costly ways of delivering corrections; philosophical debates which locate community sanctions as alternative punishments; and the overall move toward widespread use of community-based release programs. To begin, this chapter interrogates the discourse surrounding women's involvement in crime by deconstructing the guiding paradigms and language which have dominated correctional ideologies and material practices in women's prisons. From here, discussions of institutional responses to criminalized women are debated. Next, analysis is brought back to the community level where debates and criticisms of 'alternatives to incarceration' are taken up. Finally, the provincial site of the research study is introduced and contextualized. It is to the important debate surrounding language which launch these discussions.

\section{Language Used to Individualize Women's Crime}

As a starting point to assessing the neo-liberal climate which is ever-increasingly more punitive and individualizing of women's criminality, it is imperative that the language 
used to describe women's involvement with the criminal (in)justice system ${ }^{13}$ be critically examined. The deconstruction of language is much more than a matter of semantics. It is the very use of language which contributes to the defining of behaviours and actions by women as a violation of their prescribed social order. It sets the most disenfranchised women in opposition to the very systems (e.g. criminal justice, social welfare, mental health) that are oppressing them economically, socially, culturally, politically, and ever-increasing, medically. These important discussions are posed at the early stages of my research as I continually struggle with making sense of, and locating, the myriad of terminologies (e.g. 'women in conflict with the law', female offender) and 'control talk' (e.g. corrections, re-integration, cognitive behavioural therapies) used to describe women's encounters with their oppressors (Cohen, 1985).

Several feminist authors have begun the process of deconstructing language used to describe women's entanglement with the criminal justice system (c.f., Comack and Balfour, 2004; Horii, 2000; Comack, 1996; Faith, 1993). Labels such as "female offender," "women in trouble", and "women in conflict with the law" have all been used to locate women's criminality. However, as Faith (1993) succinctly points out, a term such as 'women in conflict with the law': [D]enies the fundamental inequality of the relationship... [O]ne cannot simply be in conflict with power to which one is subordinate" (Faith:1993: 58)

Faith (1993) further argues that use of the term "female offender" fails to account for the fact that only a small portion of those who offend get caught or whose offending behaviour has

${ }^{13}$ It has been argued that any criminal justice system does not serve justice for all or in all circumstances. For example, it has been consistently well-documented that the poor are discriminated against at every stage of the criminal justice system (e.g., Merton, 1938; Cohen, 1955; Cloward and Ohlin, 1960; Quinney, 1970; Carlen, 1988; Young, 1999; Reiman, 2004). Others show that the same holds true for women, (e.g. Faith 1993), First Nations people (e.g. Nielsen \& Silverman 1996) and minorities (e.g. Mann, 1993). 
been criminalized. Comack (1996) expands on this argument and postulates "women in trouble" as a phrase that sensitizes the reader to the personal and legal troubles women encounter. She refers to "troubles" as "those that emanate from women's particular locations within a society that is capitalist, racist and patriarchal." Furthermore, as Horii (2000: 107) emphatically notes, "[t]o name is to know; to know is to control." As Horii (2000: 107) rightly argues, despite best intentions of reformers, "a prison is a prison is a prison" and that the "structure of [correctional] authority that produces the oppressed and the oppressors alike is the key to understanding the problem."

Horii (2000: 107) goes on to take aim at the disguising of punishment and cruelty under sanitized euphemisms which fail to tackle the power structures underlying corrections. She argues that:

[t]he language of the oppressor, those reams of rhetoric and countless nice-nellyisms that effectively mask the barbarity of imprisonment behind policies fronted by cardboard people and programs are tools of this structure which must be disabled. Overlooking the covert power of euphemisms becomes blind acceptance.

I unequivocally concur with those authors and activists who pay close attention to the deconstruction of oppressive corrections language (such as 'treatment', 'clients', 'offender', 'cognitive behaviouralism'). However, it is recognized that such contributions from feminist academics and practitioners have been limited and therefore more forceful efforts are needed in order to uncover the systematic processes of labelling women as deviants and offenders in the first place (Schur, 1984). Myths and stereotypes surrounding women's criminal involvement need to be dispelled so that the capitalist, patriarchal, and racist foundations of the correctional system's treatment of women can be exposed. As Faith (1993: 59) convincingly articulates:

Given that labels are culturally invested with ideological significances, and applied with 
prejudice, it is best to avoid them. Certain women are criminalized, through social processes, and these women are then labeled female offender, delinquent, woman in conflict with the law, criminal or, most courteously, lawbreaker. When we recognize the contextual bases of illegal actions and the discriminatory nature of criminalization processes as applied to either men or women, and when we demystify labeled women by showing their diversities as well as the commonalities they share as women in a gendered power structure, we lose the need for labels, or for gendered stereotypes.

From a careful analysis of women's involvement with the criminal (in)justice system, it becomes clear that women are often criminalized by agencies of the state. That is, the law and the criminal justice system are actually in conflict with women. The majority of female crime is directly related to women's economic oppression and their roles as primary caregivers in society (Welch, 1997). The criminal (in)justice system creates additional barriers to women's economic and social equality by criminalizing poverty, mental illness, past histories of abuse, and race/ethnicity. In Canada, the criminalization of these systemic inequalities is clearly evidenced by the over-representation of Aboriginal women in prisons. Similarly, the increasing criminalization of women with mental illnesses, due largely to massive government cutbacks and deinstitutionalization in the health sector, further oppresses a group of women already on the fringes in society. Particular groups of women, based on race/ethnicity, poverty and mental illness, as well as other disadvantaged populations (i.e., youth, elderly) suffer untold hardships in the wake of cuts to social spending and health care, welfare reform, and housing.

Labels assigned to depict women's criminal involvement, such as those described above, fail to contextualize the gendered nature of women's crimes. For example, while women comprise only a very small percentage of the total number of violent inmates in Canada, these violent acts are usually a result of abuse suffered at the hands of their male partners (DeKeseredy et al., 1997). This idea that the law is more often in conflict with women needs to be more closely 
addressed. It is an idea that is grappled with throughout my research when examining the nature and types of crime women engage in and the gender-specific inequities precipitating their criminal activities. While it is noted that discussions on the rethinking of language used to describe women's experiences with the criminal justice system are still in their infancy, it should be a core area of concern to any serious feminist research investigation. ${ }^{14}$ For my research, I adopt the term "criminalized women" to emphasize the social, economic, political, 'psy-entific', and cultural processes which coincide and contribute to the labelling of women as 'lawbreakers' and 'offenders' (Schur, 1984).

\section{'Penal Industrial Complex'}

Canada, like other industrialized nations, is sentencing women to prison at an alarming rate. As of July 2003, there were 374 women incarcerated in Canada under federal jurisdiction (Canadian Human Rights Commission, 2003). This number represents a marked increase from 1989-1990 when there were 203 women in federal institutions in Canada (Canadian Association of Elizabeth Fry Societies, 2003b). Similarly, the rate of incarceration in provincial prisons in Canada has risen $102 \%$ since the 1980 s. Women are most notably affected by neo-conservative and neo-liberal strategies which have waged wars on drugs and welfare in Canada. In particular, racialized, young, poor women and women with mental and cognitive disabilities are overrepresented among this group (Canadian Association of Elizabeth Fry Societies, 2003a, 2003c). It

${ }^{14}$ While I acknowledge the necessity of serious interrogations of the language used to describe women's criminal involvement, it is beyond the scope of this study to sufficiently deal with this issue. It is brought to the reader's attention in order to raise sensitivity to the importance of language and related gendered power structures that further oppress women. 
is important to note that while the number of men admitted annually to federal custody for a first federal offence has decreased over the period from $1997-98$ to $2001-02(3,087$ to 2,774$)$, the numbers of women sentenced annually to a federal penitentiary on a first federal offence has increased during this period (181 to 188) (Solicitor General Canada, 2002).

The 'corrections' enterprise in Canada, as in most industrialized nations, amounts to big business (e.g., Christie, 2000). The expansion of the 'prison industrial complex' is marked by increasing rates of incarceration and, subsequently, exuberant amounts of money that contribute to the maintenance of this industry (Sudbury, 2004; Davis, 2003; Hallinan, 2001). As Davis (2003: 84) notes:

[t]he term 'prison industrial complex' was first introduced by activists and scholars to contest prevailing beliefs that increased levels of crime were the root cause of mounting prison populations. Instead, they argued, prison construction and the attendant drive to fill these new structures with human bodies have been driven by ideologies of racism and the pursuit of profits.

Davis (2003: 85) further encapsulates the notion of a prison industrial complex which insists on

[u]nderstandings of the punishment process that take into account economic and political structures and ideologies, rather than focusing myopically on individual criminal conduct and efforts to "curb crime."

Stemming from neo-liberal ideologies and corporate globalization, the prison industrial complex represents the growing move toward prison privatization (Van Wormer, 2003); corporate interest and exploitation of 'human misery markets' (Hallinan, 2001); the evisceration of social programs and offloading of government responsibilities onto individuals (Comack and Balfour, 2004); and the racialization of prison populations (Sudbury, 2004). As Davis (2003: 9495) points out, the racial composition of US prisons today rivals the proportion of black to white prisoners during the era of the southern convict lease and county chain gang systems. Similarly 
disturbing rates of racial criminalization exist in Canada with a disproportionate number of Aboriginals behind bars in this country.

The corporatization of prisons and the hidden profit-motivated agendas behind prison expansion is an area in need of critical and sustained interrogation. However, it is important to point out that in classifying the 'prison industrial complex', once again the subsidiary business of community-based corrections gets overshadowed. As we know, 93 percent of all prison inmates are eventually released (Petersilia, 2003). Therefore, the continuation of profit-making from the corrections enterprise is an ongoing corporate windfall in our communities. Furthermore, given that almost 50 percent of prisoners under state or federal jurisdiction in the United States are African American (Davis, 2003), entire communities are directly targeted by the corrections industry. Returning from prisons to communities characterized by poverty and retrenched inequalities means criminalized populations remain under the effective controls of corporate and racist agendas and therefore continue to be excluded from society (Young, 1999). By virtue of having served time in prison, these racialized groups are further marginalized by their experiences of prison, their removal from families and kinship supports, and their denial of productive engagement in their communities (i.e., labour force, education, families).

Canada is certainly not exempt from its mass embracement of the penal industrial complex and is increasingly following the lead of American multinationals in the business of locking people up. In 2001-02, for example, the annual expenditures on federal corrections in Canada totalled an estimated $\$ 1.55$ billion (Canadian Centre for Justice Statistics, 2002). This represents an increase from 1995-96 (in both current and constant dollars) when the expenditures amounted to an estimated $\$ 1.1$ billion. Likewise, provincial/territorial corrections expenditures 
are enormous, totalling approximately $\$ 1.26$ billion in 2000-01 (Solicitor General Canada, 2002).

The majority of federal correctional expenditures are consumed in the maintenance and operation of prisons. In 2001-02, the annual cost of incarcerating a woman was roughly $\$ 155,589$, almost double that of men $(\$ 79,538)$. The comparable daily costs of warehousing men and women are $\$ 217.91$ and $\$ 426.27$, respectively. On the other hand, the costs of supervising an individual on community release ${ }^{15}$ during 2001-02 were dramatically lower than incarceration, averaging \$18, 678 per annum (Solicitor General Canada, 2002). As Horii (2000: 107) eloquently argues, the "correct" description for the "business" of the Correctional Service Canada (CSC) is the Penal Services Among Canada (PSAC). This acronym doubles for the Public Service Alliance of Canada (PSAC), the largest public service union in the country, and draws the clear link between "jails and jobs".

In keeping with prison expansion, institutional corrections for federally sentenced women in Canada have undergone significant overhauls in the last decade. The most noteworthy of these changes took place in 1990 with the appointment of a federal task force to investigate the conditions of women in prisons. Public awareness of the problems that criminalized women face in our criminal justice system led to increased pressure on the government to change the current system of incarcerating women in this country. One of the major consequences of this pressure was Creating Choices: Task Force on Federally Sentenced Women (1990). The Task Force was designed to help remedy the problems of inadequate research on women's prisons and to suggest alternatives to incarceration. The mandate of the Task Force was:

${ }^{15}$ Community supervision includes day parole, full parole, or statutory release, as well as those who are temporarily detained or paroled for deportation (Solicitor General Canada, 2002). 
to examine the correctional management of federally sentenced women from the commencement of their sentence to the date of warrant expiry, and to develop a policy and a plan which would guide and direct this process in a manner that is responsive to the unique and special needs of this group (Creating Choices, 1990: 88).

The Creating Choices Task Force attempted to integrate the interests of a number of groups involved in the correctional process, including Correctional Services of Canada, the Canadian Association of Elizabeth Fry Societies (CAEFS), the Aboriginal Women's Caucus, and inmates at the Prison for Women. Unlike previous reports, Creating Choices was based on the belief that a holistic approach to the management of criminalized women was necessary to address concerns facing this population. On the surface, it was driven by a 'woman-centred' approach and looked at issues such as poverty, racism, wife battering, and sexual abuse as central issues in examining female involvement in crime.

The findings and recommendations of the Task Force were based on insights gained from extensive consultations and the results of a number of research projects. Areas of concern included over-classification $^{16}$, geographic dislocation and isolation, separation from families, inadequate programming, cultural ignorance particularly with respect to aboriginal healing practices, and the high incidence of self-injurious behaviour among inmates at the Prison for Women (P4W). There was also concern over a lack of community-based responses for federally sentenced women and the need for educational and vocational programs that would foster marketable job skills. Finally, there was a recognition that the absence or shortage of services for

${ }^{16}$ This refers to prisoners being classified as high risk, which does not accurately reflect their crimes or the 'threat' they pose to society. It is the conflation between 'risk' and 'need' which contributes to women's over-classification. A much higher percentage of women tend to be classified as maximum security compared to their male counterparts (Hannah-Moffat and Shaw, 2001). 
women, especially aboriginal and immigrant women was problematic and needed to be addressed (Hannah-Moffat, 1994).

The Task Force put forth several recommendations to the federal government (April 1990) including the call for the wider use of community release strategies for women. A few months later the government announced that it would be implementing many of these recommended changes to the penitentiary system. The major long term reform was the closure of Canada's only federal prison for women ( $\mathrm{P} 4 \mathrm{~W}, \mathrm{Kingston})$ and the construction of four smaller regional prisons and an aboriginal healing lodge. Programming at each of these prisons would concentrate on individual and group counselling that would supposedly be sensitive to women's needs. On-site child care facilities were to be made available. The aboriginal healing lodge would address the needs of federally sentenced aboriginal women through native teachings, ceremonies, contact with elders and children, and interaction with nature (Task Force on Federally Sentenced Women, 1990).

The Task Force also recommended that the government develop a community release strategy that would expand and strengthen residential and non-residential programs and services for federally sentenced women on release. It was recognized that women need support services in their communities upon release from prisons. Unfortunately, as has been the case with so many recommendations originating from task forces and commissions, they have not been acted upon in a manner consistent with the philosophy and principles of Creating Choices. Indeed, many scholars and advocates have argued that the plight of federally sentenced women in this country has regressed, whereby the well-meaning contributions of community groups and feminist scholars have been misappropriated and integrated into a prison rationale. The result is the 
mangling of this correctional ideology into the broader and more powerful penal rationale favouring punishment as its guiding principle. Subsequently, ongoing human rights violations by state officials are pervasive against the backdrop of a legitimation process whereby the supposed adaptation of a 'woman-centered' approach has been translated into correctional ideology and material practices which advance a 'law and order' agenda. ${ }^{17}$

Certainly, failings of the Task Force's recommendations have been evidenced at the level of the community. Proposed developments of community release strategies adhering to the principles of the Task Force have been lost. Moreover, it is argued here that the assignment of a woman-centered approach to corrections has been never made it past the prison gates. The focus on empowerment, meaningful and responsible choices, respect and dignity, supportive environments, and shared responsibilities ${ }^{18}$ are clearly absent in the community blueprint for change.

Despite the ongoing neglect of community strategies emanating from the Task Force, four in five criminalized adults under the authority of the federal correctional system in Canada are being supervised at the community level (Canadian Centre for Justice Statistics, 2002). Considerable debate and controversy have accompanied the widespread development of community sanctions. Proponents argue that community corrections provide a more humane

${ }^{17}$ An example of this legitimation process by the state is the inclusion of 'control talk' (Cohen, 1985) which replaced the language used to describe the work of front-line prison workers, formerly known as guards or correctional officers, with the supposed gender sensitivity of a re-classification wherein staff are now known as 'primary care workers'.

${ }^{18}$ Creating Choices outlined a model of woman-centeredness based on these five guiding principles. For a more in-depth discussion of the shortcomings and limitations of this approach within a custodial setting, see Hannah-Moffat and Shaw, 2000. 
approach to punishment, are cost-effective, and facilitate rehabilitation. On the other hand, critics argue that community options are widening the net of correctional supervision and control and are merely supplements to incarceration (Cohen, 1985). Despite the opposing viewpoints, community corrections continue to expand with little empirical evidence supporting their success.

Furthermore, the research which does exist is based on the experiences of criminalized males while the experiences of women and community corrections are once again consistently ignored or considered the same as their male counterparts (Micucci et al., 1997).

Since the late 1960 s, community corrections have become a major part of the criminal justice apparatus in Canada. Today, there are an endless range of community programs available, including everything from community service orders and probation to boot camps and electronic monitoring. While the number and type of community options have expanded, so too have the numbers of individuals involved in these programs. Correctional personnel or systemic netwidening ${ }^{19}$ and offender net-widening ${ }^{20}$ are evidenced as the number of prisons have grown alongside the number of women under community controls.

In Canada, five new federal prisons for women have been built since 1995 at an estimated capital cost of $\$ 54.6$ million. ${ }^{21}$ (Correctional Service Canada, 1995). Prison operations for women were regionalized in the 1990 s and now operate to maximum capacity in Truro, Nova Scotia;

${ }^{19}$ Correctional personnel or systemic net-widening focuses on the added costs associated with social network expansion, specifically in the form of additional staffing personnel and program service delivery (Mainprize, 1992).

${ }^{20}$ Offender net-widening refers to bringing more offenders into the correctional system who would otherwise be eligible for less intrusive 'alternative' sanctions, such as probation and parole (Mainprize, 1992).

${ }^{21}$ These costs do not include annual operating budgets nor do they account for the costs associated with warehousing of federally sentenced women within men's prisons. 
Joliette, Quebec; Edmonton, Alberta; Maple Creek, Saskatchewan; and Kitchener, Ontario. As an obvious consequence of new prison construction and regionalization, the numbers of correctional staff needed to work inside these prisons has grown congruently.

Debates surrounding the success of community-based corrections are not new and have existed in the criminological literature for decades (Greenberg, 1975; Solomon, 1976; Scull, 1977; Rothman, 1980; Christie, 1981; Chan and Ericson, 1985; Cohen, 1987; Matthews, 1987; Carlen, 1990; Blomberg, 2003). The crux of the opposing arguments can be broken down to reflect a longstanding practice of viewing community sanctions as 'alternative' sanctions. This implies that imprisonment is the norm and that all other measures are secondary. These so-called alternatives are included in a scale of punishment with prison as the toughest comparator (Joutsen and Zvekic, 1994: 2). All other custodial and non-custodial sanctions are measured in direct relation to the imposition of punishment meted out by the prison. Christie (1981:1) formulates the reasoning that:

[I]mposing punishment within the institution of law means the inflicting of pain, intended as pain. This is an activity which comes in dissonance to esteemed values such as kindness and forgiveness. To reconcile these incompatabilities, attempts are sometimes made to hide the basic character of punishment. In cases where hiding is not possible, all sorts of reasons for intentional infliction pain are given... None of the attempts to cope with intended pains seems, however, to be quite satisfactory. Attempts to change the lawbreaker create problems of justice. Attempts to inflict only a just measure of pain create rigid systems insensitive to individual needs. It is as if societies in their struggle with penal theories and practices oscillate between attempts to solve some unsolvable problems.

Christie (1981) calls for the advancement of 'alternatives to punishment'. In doing so, the rationale is to inflict as little pain as possible and "reduce to a minimum the perceived need for infliction of pain for the purpose of social control." He believes that "social control should be genuinely decentralized; systems of expertise and knowledge should be broken up; the 
euphemistic language of 'treatment' should be abandoned; and the state should take on a minimal role" (cited in Cohen, 1985: 254). Viewing community alternatives in this light means shifting the focus away from the prison and the concomitant urge by well-intentioned reformers to situate the range of non-custodial sentencing alternatives along a continuum of punishment which tend to use them as alternatives to one another, rather than as alternatives to imprisonment (Carlen, 1990: 6). Punishments are often cleverly disguised by euphemisms such as 'community alternatives' which garner support from those concerned with cost-savings, on the one hand, and appeasing 'get tougher', neo-conservatives, on the other.

On the monetary side of the debate, Scull (1977) argues that the 'decarceration' movement is itself tied primarily to economic considerations by the state in an attempt to control the escalating costs of incarceration. However, as Chan and Ericson (1985) maintain, communitybased corrections have not been effective in meeting their economic goals but rather have contributed to a substantial growth of the criminal justice apparatus and therefore have resulted in increased correctional costs. This issue of net-widening is central to discussions of community corrections. Consequently, a major concern surrounding an increased use of community-based programs for women is precisely that it brings more women into the correctional apparatus (netwidening) under stricter and more onerous state controls (net-strengthening) (Maidment, 2002).

While it is understood that both parole and probation are back-end sanctions and therefore do not contribute to net-widening per se, my earlier research documented recent emergent trends taking place in community corrections whereby traditional sanctions (parole and probation) are enhanced using electronic surveillance technologies (e.g., electronic monitoring devices, global positioning systems). Use of such technologies strengthen the correctional net and further 
undermine efforts to contribute to 'community' re-entry (c.f., Maidment, 2002). For my research, the term 'net-widening' expands outside the criminal justice system to include other state-run and community initiatives that control the lives of women probationers and parolees, such as mental health organizations, social services, child protection, and non-profit service agencies (Cohen, 1985). In this context, net-widening is closely aligned with 'transcarceration' which refers to the blurring between public and private system boundaries. Both these concepts are further discussed and applied in the theory and data analyses sections.

Critics of community corrections have also argued that the behavioural restrictions imposed on criminalized individuals in the community make such 'alternatives' less humane than they were designed to be. As Cohen (1985) argues, community-based programs tend to reproduce in the community the very same coercive features of the system they were designed to replace. The term 'community' has become a political vortex constructed by governments to satisfy their own organizational interests despite their lack of a clear and concise definition of the term. As noted by McCormick and Visano (1992: 287):

[T]he "community" is an elusive concept that has been too easily appropriated by the state to engineer support for limited initiatives that fail to grapple with fundamental inequalities in corrections. This term is contextually determined and discursively constructed to satisfy organizational interests. Without reference to the context of power, the community concept has become a pretext for intervention and exclusion.

This research explores the blurring of 'community' boundaries as it relates to women 'prisoners' and 'ex-prisoners' in the province of Newfoundland and Labrador. As will be discussed, it becomes increasingly difficult to distinguish the break between state-run programs and those administered by 'community agencies' who receive their funding from the government and therefore stick close to the 'control talk' and 'behaviouralist' agendas of the state (Cohen, 
1985). It also advances the argument that the community can be as repressive a site for punishment and social control as the prison, based largely on undercurrent penal theories and rationales which fail to depart from the traditional goal of punishment.

\section{Penal Trends at Research Locale}

Newfoundland and Labrador has the distinction of the lowest crime rate in Canada. In 2001 , police-reported crimes for this province was 5,635 per 100,000 population, compared to the Canadian average of $7,747^{22}$. Over a five year period, from 1997-2001, crime rates have decreased in Newfoundland and Labrador (from 5,653 to 5,635), alongside the overall Canadian average (from 8,453 to 7,747). Despite decreasing crime rates, Canada's incarceration rate is high relative to other Western countries, ranking among the top five in this grouping. In 2001, the incarceration rate in Canada was 116 per 100,000 general population.

Notwithstanding the slight decrease in incarceration rates overall from 1997-2001 (131 to 116 respectively), the numbers of women incarcerated in this country are steadily climbing and Newfoundland and Labrador is no exception to this trend. In 1997-98, there were 56 custodial admissions for women in Newfoundland and Labrador, representing 3.9\% of all prisoner admissions. In $1998-99$, the number rose to 80 , representing an overall increase to $5.3 \%$ of the total custodial population ${ }^{23}$ (Newfoundland and Labrador, Department of Justice, 1999). In 2000-

22 These numbers are based on official statistics from the Uniform Crime Report and therefore do not include victimization and/or self-report surveys. We need to exercise due diligence in making statements based on official data only.

${ }^{23}$ The Corrections and Community Services Branch, Department of Justice release their divisional reports on a bi-annual basis. However, the most recent statistical report (2000-01) does not contain custodial breakdowns based on sex (Newfoundland and Labrador: Department of 
01, the percentage increase of women in the total admissions population again climbed, reaching $8 \%$ (Canadian Centre for Justice Statistics, 2002).

Newfoundland and Labrador has one provincial prison for women. The Newfoundland \& Labrador Correctional Centre for Women (NLCCW) is a medium-security facility located $175 \mathrm{~km}$ west of St. John's ${ }^{24}$ and is the only correctional centre in the province which receives female prisoners, including those remanded in custody, females who have received provincial sentences (two years less one day), as well as low-security females sentenced to federal terms and held under the Exchange of Services Agreement (ESA) ${ }^{25}$ (Newfoundland \& Labrador, Department of Justice, 2001). The NLCCW opened in Clarenville in April 1996, retrofitted from a minimum security men's prison. From 1982 to 1996 , the NLCCW had been situated in Stephenville ${ }^{26}$, on the province's west coast. Prior to 1982, women were warehoused in a wing of the men's penitentiary located in St. John's (The Evening Telegram, May 6, 1995). The NLCCW accommodates a maximum of 22 women, who come from all areas of the province, including remote locations in Labrador.

Newfoundland and Labrador also has five regional lock-ups which continue to confine criminalized women for temporary and remand purposes. Over the past decade, the St. John's city

Justice, 2001).

${ }^{24}$ See Appendix F for a map of Newfoundland and Labrador.

${ }^{25}$ Federal-provincial Exchange of Service Agreement (ESA) allow some federal prisoners to serve their sentences in their home province. ESAs contribute significantly to the province's correctional budget. For example, in 2000-01, the province was reimbursed by the federal government $\$ 3,114,700.00$ for the detention of federal inmates (both males and females) (Newfoundland and Labrador: Department of Justice, 2001).

${ }^{26}$ Stephenville is located on the province's west coast, 724 kilometres from St. John's. 
lock-up has come under close scrutiny, particularly by women's advocacy groups, who maintain that the conditions at this facility are draconian and unsuitable for even short term stays, much less the longer periods for which women are being detained there. Complaints by women about lock-up conditions include lack of privacy, lengthy stays and poor ventilation and lighting 27 (Woodrow, 1998).

In recent years, considerable local attention has focussed on the plight of criminalized women in this province including the lack of adequate living facilities, cramped space, poor air quality and ventilation at the municipal lock-up, inadequate medical attention, and the growing numbers of women with mental health needs (Monster, 2000; Rossiter, 2001). There has been considerable pressure on the government to address the concerns of criminalized women although their response to date has been minimal. Stemming from this public awareness campaign, the establishment of a local Elizabeth Fry Society ${ }^{28}$ was launched by a coalition of women's advocacy groups (Western Star, May 10, 1997).

Responding to public concerns, relocating the prison closer to St. John's was regarded by senior government bureaucrats as a way of dealing with some of the problems at the lock-up. Similarly, the establishment of community-based sanctions was touted as a remedial measure to

${ }^{27}$ This situation led to a heightened awareness of the inadequate prison conditions for women in this province and a renewed interest in the establishment of a local chapter of Elizabeth Fry. Subsequently, in February, 1997 an E-Fry Working Group was formed.

${ }^{28}$ The Canadian Association of Elizabeth Fry Societies (CAEFS) is an "organization which works with, and on behalf of, women in conflict with the justice system" (Mission Statement). Local societies are autonomous community-based agencies offering services and programs to marginalized women, advocating legislative and administrative reform and offering public forums on aspects of the justice system which affect women. In Canada, there are 26 local Elizabeth Fry societies. For more information on the workings of this organization see: http://www.elizabethfry.ca/caefs_e.htm 
deal with this situation. In 1994, for example, an electronic monitoring program was implemented with a major goal being the inclusion of more women into that program. While the frequency of conditional releasing and probation dispositions has been stepped up in the province, the numbers of women in prison also continue to swell.

The historical lack of attention and services provided to criminalized women in Newfoundland and Labrador is promulgated by the same set of conditions that exist for women across the country, including their small numbers in comparison to men, and remote prison locations with an inadequate number of resources to address the growing issues of women's poverty, mental health problems, and substance abuse. Recently, in Newfoundland and Labrador, reports have been surfacing from the courts whereby women are requesting federal sentences in lieu of the lesser provincial terms of two years less a day ${ }^{29}$ so they can access treatment services and counselling programs which are only available, albeit in a limited fashion, at federal penitentiaries (The Telegram, June 24, 2003). This trend is an alarming reflection of the dire state of provincial prisons which grossly lack the resources to deal with criminalized women and, in particular, women with mental disabilities. While community corrections have been advanced as a panacea to deal with many of these issues, it is highly questionable and largely unknown at this

${ }^{29}$ Canadian corrections operate a two-tiered system: federal sentences are managed by the Correctional Services of Canada (CSC) and include sentences of two years or more. In the community, the federal government also has responsibility for statutory release and parole supervision. The National Parole Board (NPB) has jurisdiction in all provinces except Ontario, Quebec, and British Columbia where provincial parole boards have been established.

Provincial and territorial governments are responsible for all other corrections services including sentences of less than two years, remand prisoners, other forms of temporary detention (i.e., immigration holds), and supervision in the community (probation, electronic monitoring, conditional sentencing) (Canadian Centre for Justice Statistics, 2002). Probation and conditional sentencing are court-ordered and supervised in the community, while parole and statutory release into the community are part of a custody sentence. 
point how women are coping in the community.

As stated, community release programs cannot be looked at in isolation of prisons. The prison experience plays a major role in how women adjust (or not) to their period of community release. This research focuses on how women deal with the "pains of imprisonment" (Sykes, 1958). It also examines the "pains of probation" which includes the transition from prison back into the community, reconnecting with families and children, dealing with substance abuse issues, stigmatization by families, peers, and community members, interactions with mental health and other social service agencies, mandatory programming, counselling, and attempts to gain re-entry into the paid workforce (Goff, 2003).

The accumulation of women's experiences within the prison system sheds light on the challenges of readjusting to life in the community after having endured the pains of imprisonment. The latter are well documented to have long lasting effects on the physical, psychological, economic, and social well being of inmates (McGee, 2000; Martel, 1999) and cannot be ignored in a study which looks at women's experiences of community reintegration. Indeed, respondents in this study placed a huge premium on their prison experiences as directly related to their reintegration efforts. Additionally, the research at hand explores certain characteristics of prison life, as identified by the women, that contributed to their avoiding a return to custody. These factors include rehabilitative programming, employment counselling, substance abuse counselling, structured living environment both within and outside the prison, release to a halfway house, and peer supports. In all, considerable attention is devoted to women's experiences of incarceration and its carryover effects back into the community. 
Given the increasing trend toward imprisoning women and the resultant numbers of women serving time in the community, focus needs to be shifted onto community factors which converge to either facilitate or block women's successful reintegration. We know the majority of women prisoners return to their home communities at some point during her sentence. We also know that women have a relatively low recidivism rate. However, we know very little about the reasons for women's greater 'successes' in the community, especially given the plethora of social, economic, political, and cultural inequalities which contribute to their criminalization. It is to a broader understanding of the socio-political climate of criminalizing women that I now turn. 


\section{CHAPTER 3: \\ SOCIO-POLITICAL CONTEXT OF CRIMINALIZING WOMEN}

The problems of recidivism and post-release mortality have less to do with the character and actions of individual women than with the intolerance and neglect shown toward women prisoners, their particular circumstances, and their needs. (Davies and Cook, 1999: 272)

It is imperative to understand the constrained structural and economic parameters within which women are forced to operate on a daily basis as we know from the literature that conditions of poverty are often amplified once women exit the prison. We can reasonably expect the economic disenfranchisement of women to become even more pronounced once she has served a prison term and been effectively removed from the labour market for a considerable period. Therefore, broader structural forces surrounding women's criminality are discussed below and include an exploration of both neo-conservative and neo-liberal strategies of governance which have resulted in a dismantling of the welfare state; the offloading of collective responsibilities onto the shoulders of individuals and families; and social constructions of 'disorderly' populations. This broad focus is followed up by discourse analysis surrounding the prevailing ‘equality versus difference' debate which has dominated correctional ideology and material practices for women over the past several decades.

\section{Neo-liberal and Neo-conservative Strategies of Criminalization}

Critical criminologists (e.g., DeKeseredy et al., 2004; Renzetti et al., 2001; Raphael, 2000; Young, 1999; Parent, 1998) and legal theorists, (e.g., Daly, 1994; Comack and Balfour, 2004) provide a compelling analysis of the power of the state to reproduce a particular kind of order based on race, gender and class inequalities. Critical criminology, a term which has been in use since the 1970s, is defined as "a perspective that views the major sources of crime as the 
class, ethnic, and patriarchal relations that control our society..[and] regards major structural and cultural changes within society as steps to reducing criminality" (DeKeseredy and Schwartz, 1996: 239).

Critical criminology, based both in its origins and contemporary writings, draws heavily from the notion of exclusivity (Young, 1999). An 'exclusive society' in late modernity has been created and functions on three levels: economic exclusion from labour markets; social exclusion between people in civil society; and exclusion by the criminal justice system (Young, 1999: vi). Beckett and Western (2001: 36) point to an inherent feature of the exclusionary society wherein "welfare and penal institutions comprise a single policy regime aimed at the governance of social marginality." They point to the variations of these regimes according to their inclusionary or exclusionary agendas:

Inclusive regimes emphasize the need to improve and integrate the socially marginal and tend to place more emphasis on the social causes of marginality. These regimes are therefore characterized by more generous welfare programs and less punitive anti-crime policies. By contrast, exclusionary regimes emphasize the undeserving and unreformable nature of deviants, tend to stigmatize and separate the socially marginal, and hence are more likely to feature less generous welfare benefits and more punitive anti-crime policies (Beckett and Western, 2001: 36).

Underlying both policy regimes are neo-liberal and neo-conservative political ideologies. Neo-liberalism is "premised on the values of individualism, freedom of choice, market security and minimal state involvement in the economy. [It] marks a dramatic shift in emphasis from collective or social values towards notions of family and individual responsibility" (Comack and Balfour, 2004: 40). The outcome of neo-liberal strategies of governance have been a:

[R]etreat from any professed commitment to social welfare. Instead of formulating policies and targeting spending on programs that would meet the social needs of the members of society (education, health care, pensions, social assistance), governments now focus on enhancing economic efficiency and international competitiveness. With the 
'privatization' of responsibility, individuals and families are left to look after themselves (Comack and Balfour, $2004: 40$ ).

The political ideology behind a neo-liberal agenda, referred to as "social Darwinism",

[a]rgues for a survival-of-the-fittest reliance on market forces. The state should get out of the way of the forces that decide which regions, and which people, prosper and which don't. The only assistance the state should provide are 'incentives' to work. The policy results of these views is a dramatic shrinking of the social safety net (Martin, 2002: 92).

Neo-conservative policies, on the other hand, shift the focus towards a 'law and order' agenda. As Hermer and Mosher (2002: 16) point out, policies targeting the underclass have become a governing tool in the arsenal of a neo-conservative regime.

A central aspect of how the Ontario government has successfully carried out neoconservative reforms is through its ability to construct "disorderly people". Squeegee kids, welfare cheats, coddled prisoners, violent youth, aggressive beggars are part of a modern rogues gallery that has been used by the Ontario government to justify sweeping changes in the public character of government. Disorder and the people embodying disorder have become a central resource of political power in Ontario, one that is produced and managed as an essential feature of neo-conservativism across a wide range of government activities.

Neo-conservatives argue that the family (and the church) should be the source of charity

and support for the unfortunate (Martin, 2002: 92). This shift toward singling out the poor and disenfranchised groups is not a new state strategy, however. As Hermer and Mosher (2002: 16-

17) make clear:

[w] hat is new and radical about the type of disorder manufactured by the...government is that it is intentionally designed to dismantle the welfare state. In other words, making up a disorderly set of people has come with an erosion of some of the central principles that have underpinned the democratic and equitable character of our institutions, diminishing the ways in which we are made to feel responsible for each other. And what is most disconcerting about this shift,...is that it has taken place at the very sites in which the government is responsible for some of the most vulnerable and marginalized in our society-those with mental-health issues, the young, the poor and disabled, and a disproportionate number who are in correctional facilities.

Social and criminal justice policy outcomes under both neo-liberal and neo-conservative 
regimes result in a weakening of social service provisions for the most vulnerable in our society and a 'social Darwinist' approach to governing. The fallout of both fiscal agendas increases the social and economic divide between the upper and lower classes. Martin (2002: 97) sums up the divisive qualities of each regime:

Under a neo-liberal fiscal agenda, for example, private security, policing and correctional services expand, and treatment and social services are privatized, while public institutions face cuts and private charities remain the preferred means to deliver services to offenders and victims. On the other hand, in aid of a neo-conservative moral agenda, a law-andorder retributive approach to social disorder and dysfunction is offered to reinforce hierarchical/patriarchal social disorganization. The former claims to celebrate the autonomous individual and thus argues for all the elimination of all but the most essential intrusions by the state onto freedom of choice and action, while the latter insists on a combination of punishment and the charitable "rescue-and-reform" model for the few social services that survive.

This targeting of already disenfranchised and powerless groups in our society under a neoconservative banner is perhaps most acutely evidenced in this country by recent Ontario legislation which criminalizes youth who otherwise would be trumpeted under an entrepreneurial banner for their efforts to eke out a living on street corners and intersections offering a marketable customer service. 'Squeegee kids' have been hard hit by the Ontario Safe Streets Act. As

O'Grady and Blight (2002: 39) point out, the 'politics of exclusion' come down hard on these youth.

The act of censuring squeegee cleaning in Ontario can be interpreted as being part of a more global phenomenon. In other parts of Canada, and in the United States and England, recent years have been witness to more and more legal controls being targeted against the poor. The ever-expanding activities of the criminal justice system, persistent cutbacks to social spending, skyrocketing costs of housing in large urban centres and growing gaps of income inequality show us that society is becoming more exclusive (Young, 1999). The reaction to squeegee cleaning in Ontario is a clear example of how a marginalized and relatively powerless group are being squeezed to the point of exclusion.

Neo-conservative and neo-liberal strategies have contributed to the off-loading and 
dismantling of the welfare state which, in turn, lays the blame squarely on the shoulders of individuals for their 'wrongdoings'.

Taken as a whole, the legislative framework, the policies, the practices and the accompanying discourse operate to construct the poor as persons who don't deserve to be in control of anything; rather they are persons who need to be controlled, disciplined and reformed by others. Single mothers in particular represent disorder, since they stand outside the structure of both the hegemonic nuclear family and often, the labour market. Welfare recipients, and especially single mothers, are constructed as persons who ought not to possess any expectation of privacy; they are in effect, cast as objects, to be reformed by the "public" for the betterment of the "public." Thus privacy is preserved for others, for the economically privileged (Mosher, 2002: 49).

Single mothers existing on welfare have been demonized and stripped of any privacy rights under neo-conservative government policies. The coveted divide between 'public and private' space is eroded under this regime whereby targeted groups come under stricter enforcement and surveillance through mandatory drug/alcohol testing, unannounced home visits by welfare cops in search of violators ('spouse-in-house' rhetoric), and other such draconian policies which violate privacy rights. It is against the tide of such neo-conservative regimes which women find themselves trying to negotiate a balance between their right to privacy and a dependence on the state for their livelihood and the maintenance of their families. Failing to strike that illusory balance, women often find themselves in opposition to these structures and criminalization results. Entanglement in the criminal justice system brings with it a whole other set of contradictions and discriminatory treatment. It is to the organizational outcomes of criminalizing women that I now turn.

\section{'Equality Versus Difference' Paradigm}

An increasing amount of research on women and crime has proliferated over the past 
several decades (Adler, 1975; Simon, 1975; Carlen, 1988; Faith, 1993; Boritch, 1997;

DeKeseredy, 2000; Chesney-Lind, 2002, Carlen, 2002; Kendall, 2004). Recommendations on how to deal with women in the correctional system vary widely. On the one hand, some feminist scholars argue that women should be treated equally to men. That is, the range of programs and services available to incarcerated males should also be made available to incarcerated females. Proponents of the 'equal treatment model' oppose legislation that treats men and women differently by arguing that "while equal treatment may hurt in the short run, in the long run it is the only way to guarantee that women will ever be treated the same as equal playing partners in economic and social spheres" (Chesney-Lind \& Pollock, 1995).

Critics of the 'equal treatment approach' argue that women's situations are acutely different from those of their male counterparts and therefore, women should be treated differently by the criminal justice system. Proponents of this model argue that "because equality is measured against a male standard, women will always lose" (Chesney-Lind \& Pollock, 1995). The result is the 'separate but equal argument' which does not necessarily suggest that females should be treated any better or worse, just different. Historically, however, this 'differential needs model' has translated into glaring deficiencies in rehabilitative services and programs provided to meet women's needs. Different for women in that sense has meant less. Recent commentary on the situation for women prisoners observes:

The history of Canada's treatment of women prisoners has been described as an amalgam of: stereotypical views of women; outright barbarism and well-meaning paternalism... [F]rom the beginning, the welfare of women prisoners was secondary to that of the larger male population (Arbour Report, 1996).

Chesney-Lind \& Pollock (1995) point to the weaknesses inherent in both models by suggesting that both accept the dominant male definitions. They argue: 
Equality is defined as rights equal to those of males; and differential needs are defined as needs different from those of males. In these cases women are "other" under the law: the "human bottom line" is a male one.

To counter the equality versus difference paradigms, Chesney-Lind \& Pollock (1995) posit a third model which takes a 'social justice approach' to women's inequality, thereby enabling them to avoid some of the pitfalls of the androcentric parity/difference debate. They point to the work of Carlen (1989) who argues in favour of a 'women-wise penology' which emphasizes a number of structural factors contributing to women's involvement with the criminal justice system. These include privileging women's roles as mothers, encouraging economic and emotional self-sufficiency, reducing the number of prison beds for women and increasing the use of non-carceral sentencing options. In short, this approach begins from a 'woman-centered' framework rather than the one currently adopted by legislators which judges women against the male norm.

A brief overview of this ongoing debate is presented as it attempts to locate the unique needs of criminalized women. Historically, women have been a correctional afterthought and much of the ideological and material practices surrounding their incarceration and treatment have been reflective of this stance. Therefore, the proposal by Chesney-Lind and Pollock (1995) of a 'social justice approach' has particular interest for this study as it places an important emphasis on the structural factors which contribute to women's criminal involvement. As a starting point for my analysis, this approach is merited by its establishment and recognition of a policy framework for women which seeks to accommodate the unique needs of women stemming largely from their economic, social, cultural, and increasingly medical marginalization in society.

On the basis of the neo-conservative/neo-liberal regimes as well as the 'equality versus 
difference debate', women's involvement in the criminal justice system is often considered in direct proportion and relation to that of their male counterparts. Adopting this comparative framework for analysis, we know that consistently women commit disproportionately fewer crimes than males (Chesney-Lind, 2002; Boritch, 1997). Therefore, female crime is relatively rare compared to crimes committed by males and a smaller proportion of females are incarcerated each year. Canadian data for 2001-02 indicate a total of 355 women sentenced to federal penitentiaries, representing $4.9 \%$ of all admissions for that year. This number represents an increase from previous years when the incarceration rate for federal females was $3 \%$ (Solicitor General Canada, 2002). Women constitute a slightly higher proportion of those admitted to provincial/territorial institutions. In 2000-01, women represented $9 \%$ of admissions to provincial/territorial prisons in Canada. The majority of these provincial sentences for women are six months or less, and almost 40 per cent are 14 days or less (Canadian Centre for Justice Statistics, 2002).

The majority of women's criminal activity is directly related to their disenfranchised socio-economic status in society and has appropriately been dubbed 'survival crimes'. Research has shown that women's participation in property crime is linked to their disadvantaged socioeconomic position in society. Many more women than men in Canada continue to live below the poverty line, to be dependent on welfare, to be unemployed or underemployed in low-paying, semi-skilled jobs with few or no benefits, and to be the sole supporters of children (Canadian Council on Social Development, 2004).

Due to the neo-liberal social policies which rupture the social safety net, especially for welfare mothers, the concurrent rapid increase in female-headed households and the stresses 
associated with poverty, increasing numbers of women are being charged with shoplifting, cheque forgery, and welfare fraud. Consequentially, the proportion of poor children living with single mothers has grown substantially in recent years. In 1980, the figure was 33 percent. This number rose to 39.4\% in 2000 (Statistics Canada, 2001a). Much of the economic disparity between women and men is directly connected to the fact that women constitute the overwhelming majority of single parents. In Canada, in $2001,81 \%$ of all lone-parent families were headed by women, a figure that has remained relatively constant since the mid-1970s. Of this number, more than half $(53 \%)$ had incomes which fell below the Low Income Cutoffs (LICOs) ${ }^{30}$ (Statistics Canada, 2001d). Women continue to make up a disproportionate share of the Canadian population with low incomes. In 2001 , females accounted for $55 \%$ of all Canadians classified as having low incomes. The average earnings of employed women still fall far below those of men. In 2002 , the estimated earned income of women was $\$ 22,964$, a figure far below the $\$ 36,299$ average for earned income of men (including part-time) (Human Development Index, 2004). Table 3.1 outlines the 'unofficial poverty rates' in Canada. Based on these calculations, an unattached person in the Census Metropolitan Area (CMA) of St. John's with an income below $\$ 13,160$ would be poor. No woman in my sample had an income anywhere close to this amount.

${ }^{30}$ Statistics Canada determines whether a family is low-income by "comparing the income of an economic family to a low-income cutoff (LICO), which varies according to family size and the size of the area of residence. The LICO values are chosen by estimating at what income families spend 20 percentage points more than average on food, shelter and clothing" (Statistics Canada, 2002b). 
Table 3.1: Canadian Low Income Cutoffs, Based on Population Size, 2003

\begin{tabular}{|c|c|c|c|c|c|}
\hline $\begin{array}{c}\text { Family } \\
\text { Size }\end{array}$ & $500,000+$ & $\begin{array}{c}100,000 \\
499,999\end{array}$ & $\begin{array}{c}30,000- \\
99,999\end{array}$ & $\begin{array}{c}\text { Less than } \\
\mathbf{3 0 , 0 0 0}\end{array}$ & Rural \\
\hline 1 & $\$ 16,348$ & $\$ 13,160$ & $\$ 13,558$ & $\$ 12,389$ & $\$ 10718$ \\
\hline 2 & $\$ 19,948$ & $\$ 16803$ & $\$ 16,544$ & $\$ 15,118$ & $\$ 13,079$ \\
\hline 3 & $\$ 25,230$ & $\$ 21,252$ & $\$ 20,924$ & $\$ 19,120$ & $\$ 16,542$ \\
\hline 4 & $\$ 31,424$ & $\$ 26,469$ & $\$ 26,061$ & $\$ 23,814$ & $\$ 20,603$ \\
\hline 5 & $\$ 35,122$ & $\$ 29,584$ & $\$ 29,127$ & $\$ 26,616$ & $\$ 23,028$ \\
\hline 6 & $\$ 38,820$ & $\$ 32,699$ & $\$ 32,193$ & $\$ 29,418$ & $\$ 25,453$ \\
\hline $7+$ & $\$ 42,519$ & $\$ 35,814$ & $\$ 35,259$ & $\$ 32,220$ & $\$ 27,878$ \\
\hline
\end{tabular}

Notes: This table uses the 1992 base. Income refers to total post-tax, post-transfer household income. Source: Canadian Council on Social Development (2004).

In direct comparison to the LICOs figures, Table 3.2 shows the social assistance rates for both unattached individuals and lone-parent families throughout the province. Clearly, single women and single-parent families fall far below the low income cut-offs. Several important stand alone points are also identified in this table, most notably: average benefits for lone-parent and unattached individuals have remained constant over the five-year period since 1999; average benefits for lone-parent families have not kept pace with inflation rates; average benefits for unattached individuals have actually decreased since 1999; and the average duration for reliance on social assistance benefits have remained constant for lone-parents families while they have increased for unattached individuals. The overall picture is one of a deepening entrenchment of poverty levels amongst single-parent families and single persons, a majority of whom are women. 
Table 3.2 Social Assistance Rates and Population for Unattached Individuals and LoneParent Families in Newfoundland and Labrador, 1999-2003

\begin{tabular}{|c|r|r|r|r|r|}
\hline & $\mathbf{1 9 9 9}$ & $\mathbf{2 0 0 0}$ & $\mathbf{2 0 0 1}$ & $\mathbf{2 0 0 2}$ & $\mathbf{2 0 0 3}$ \\
\hline Total Lone-parent and unattached & 29300 & 28930 & 27480 & 27205 & 27900 \\
\hline Average benefits & $\$ 5,300$ & $\$ 5,400$ & $\$ 5,100$ & $\$ 5,100$ & $\$ 5,300$ \\
\hline Average duration (months per year) & 9.1 & 9.2 & 9.3 & 9.3 & 9.3 \\
\hline Lone-parent families & 9255 & 9085 & 8485 & 8150 & 8175 \\
\hline Average benefits & $\$ 7,200$ & $\$ 7,300$ & $\$ 7,400$ & $\$ 7,300$ & $\$ 7,400$ \\
\hline Average duration (months per year) & 9.4 & 9.4 & 9.4 & 9.4 & 9.4 \\
\hline Unattached individuals & 20075 & 19850 & 19000 & 19055 & 19725 \\
\hline Average benefits & $\$ 4,500$ & $\$ 4,500$ & $\$ 4,200$ & $\$ 4,200$ & $\$ 4,400$ \\
\hline Average duration (months per year) & 8.9 & 9.1 & 9.2 & 9.3 & 9.3 \\
\hline
\end{tabular}

Source: Strategic Social Plan (2004). Community Accounts Profile. Government of Newfoundland and Labrador.

Further analysis of the particular economic situation in Newfoundland and Labrador point to consistently high rates of unemployment and seasonal/part-time employment. Table 3.3, provides recent unemployment figures for the nation and the provinces. As identified, Newfoundland and Labrador has unemployment rates more than twice the Canadian average and, by far, the highest amongst all the provinces. 
Table 3.3: Unemployment Rate (\%), Canada \& Provinces, 1997-2003 Annual, Seasonally Adjusted

\begin{tabular}{|l|l|r|r|r|r|r|r|r|}
\hline \multicolumn{1}{|c|}{ Province } & $\mathbf{1 9 9 7}$ & $\mathbf{1 9 9 8}$ & $\mathbf{1 9 9 9}$ & $\mathbf{2 0 0 0}$ & $\mathbf{2 0 0 1}$ & $\mathbf{2 0 0 2}$ & $\mathbf{2 0 0 3}$ & Jan-04 \\
\hline Canada & 9.1 & $\mathbf{8 . 3}$ & 7.6 & 6.8 & 7.2 & 7.7 & 7.6 & 7.4 \\
\hline Newfoundland & 18.6 & 18 & 16.9 & 16.7 & 16.1 & 16.9 & 16.7 & 16.5 \\
\hline Prince Edward Island & 15.4 & 13.8 & 14.4 & 12 & 11.9 & 12.1 & 11.1 & 10.8 \\
\hline Nova Scotia & 12.1 & 10.5 & 9.6 & 9.1 & 9.7 & 9.7 & 9.3 & 9.7 \\
\hline New Brunswick & 12.7 & 12.2 & 10.2 & 10 & 11.2 & 10.4 & 10.6 & 10.4 \\
\hline Quebec & 11.4 & 10.3 & 9.3 & 8.4 & $\mathbf{8 . 7}$ & $\mathbf{8 . 6}$ & 9.1 & 9.1 \\
\hline Ontario & 8.4 & 7.2 & 6.3 & 5.7 & 6.3 & 7.1 & 7 & 6.6 \\
\hline Manitoba & 6.5 & 5.5 & 5.6 & 4.9 & 5 & 5.2 & 5 & 5.2 \\
\hline Saskatchewan & 5.9 & 5.7 & 6.1 & 5.2 & 5.8 & 5.7 & 5.6 & 5.6 \\
\hline Alberta & 5.8 & 5.6 & 5.7 & 5 & 4.6 & 5.3 & 5.1 & 5 \\
\hline British Columbia & 8.4 & 8.8 & 8.3 & 7.2 & 7.7 & 8.5 & $\mathbf{8}$ & 7.1 \\
\hline Source: Statistics Canada, Labour Force Survey, February 2004 & & & & \\
\hline
\end{tabular}

Furthermore, certain groups of women are over-represented amongst the ranks of the poor, based on race/ethnicity. For example, the average income of Aboriginal women is $\$ 6,000$ less than that of other Canadian women or of Aboriginal men, and they are much less likely to be employed (Hadley, 2001). In light of these economic disparities, it is not surprising to find a disproportionate number of female inmates in Canada are also Aboriginal. While Aboriginal women constitute only $2.8 \%$ of the adult Canadian population, they represented $29 \%$ percent of federally sentenced women in 2003 (Canadian Human Rights Commission, 2003). These numbers are even more pronounced in the Prairie Region (Manitoba, Saskatchewan, and Alberta) where Aboriginal federal women inmates comprise $53.6 \%$ of the total female population in custody (Monture-Angus, 2002). Moreover, the number of Aboriginal women sentenced to federal custody is increasing steadily, at a pace that far outnumbers the male population. From 
1996-97 to 2001-02, the number of federally sentenced Aboriginal women rose by $36.7 \%$, compared with 5.5\% for Aboriginal men (Solicitor General, 2002). It has been noted repeatedly that:
Aboriginal women and their children suffer tremendously as victims in contemporary Canadian society. They are victims of racism, of sexism and of unconscionable levels of violence against women. The justice system has done little to protect them from any of these assaults. At the same time, Aboriginal women have a much higher rate of over representation in the prison system than do Aboriginal men (Report of the Aboriginal Justice Inquiry of Manitoba, 1991: 475).

The quantity and quality of vocational programs at female institutions have been found to be wholly inadequate as compared to those in male institutions. Research shows that most of the existing vocational programs offered in women's prisons reinforce traditional middle-class female roles that reflect and exacerbate the gender inequalities found in the wider society. As a result, cosmetology, clerical work, food services, laundry and sewing are typical of the programs found in female institutions (Faith, 1993). Over two decades have passed since the first Canadian Human Rights ruling (1981) found that criminalized women were being discriminated against on the basis of sex because of restricted and limited access to programs within the prison setting. Still, programs for female inmates continue to be defined by traditional stereotypes and fail to reach parity with the number and type of programs offered within male institutions. This situation is even more bleak for provincially incarcerated females who have considerably less access to programs and services than do their federal counterparts. The existence of a two-tiered prison system in Canada has important implications for this study and will be elaborated on in much greater detail in a later section.

Another reality for criminalized women is that an overwhelming number are mothers (roughly three-quarters) and $66 \%$ of mothers had primary responsibility for their children prior to 
their incarceration. While some prisons for women purportedly permit visiting by children, efforts to encourage and enable visitation are often lacking. Many women never see their children during their incarceration because the distance between the prison and their home community makes travelling between sites near impossible. On the federal scene, the regionalisation of prisons for women in Canada was intended to help alleviate the geographic separation between women and their children. Arguably, the regionalisation of prisons has had little impact on most inmates and their families who continue to experience the difficulties involved in being located several hundred kilometres away from one another. For most inmate's families, travelling to Kingston, Ontario or to a neighbouring province is equally difficult, if not impossible, due mainly to financial reasons which restrict or prohibit visitation. ${ }^{31}$ In many ways, the establishment of regional prisons is more problematic for women who can no longer seek support for the claim that being located several thousand kilometres away from their home communities is a major problem for them during their period of incarceration. There was very little public sympathy or institutional support for such claims when women were centrally located in Kingston much less at their present locales, geographically closer to their homes.

In terms of accessing programs and community services, the regionalisation of prison facilities has worsened the situation for federally sentenced women. For instance, the decision to locate the Atlantic regional facility in Truro, Nova Scotia was a political manoeuver that did nothing to enhance the range of services available to women incarcerated there. Undoubtedly, the prison would have better served the needs of the inmate population if it were located in a larger

${ }^{31}$ The distance from St. John's, Newfoundland where a majority of federally sentenced women and their families reside, to Truro, Nova Scotia is 1315.19 kilometres. 
urban centre with greater access to programs and services. ${ }^{32}$ Provincially, the problem created by the distance between home communities and prisons pose similar challenges for the families of women inmates. Given that most Canadian provinces have only one facility for women serving provincial terms, the opportunity to remain in close contact with family members and children is almost nonexistent.

Culminating in the ongoing discrimination of women on the basis of sex, race, and disability and despite the purported re-forms of Creating Choices, the Canadian Association of Elizabeth Fry Societies (CAEFS), in conjunction with a number of other equality-seeking women's groups ${ }^{33}$, launched a complaint to the Canadian Human Rights Commission in May 2001:

$[\mathrm{O}] \mathrm{n}$ the grounds that the manner in which women prisoners are treated is discriminatory, [and] contravenes several of the prohibited grounds articulated in s. 3(1) of the Canadian Human Rights Act. CAEFS is concerned about the discrimination on the basis of sex that is faced by women throughout the system. In addition, we are very concerned about the discrimination on the basis of race that is the particular experience of Aboriginal women and other racialized women, as well as discrimination on the basis of disability that is experienced by federally sentenced women with cognitive and mental disabilities (CAEFS, 2003a).

${ }^{32}$ Truro is a remote rural area of Nova Scotia with little community infrastructure to serve the needs of women prisoners. The larger centre of Halifax would have been much more conducive to accessing resources, as well as facilitating family visits given that the centrality of its location in Atlantic Canada.

${ }^{33}$ On March 8, 2001, International Women's Day, the Canadian Association of Elizabeth Fry Societies (CAEFS), in conjunction with the Native Women's Association of Canada (NWAC) urged a broad-based systemic review, pursuant to Section 61(2) of the Canadian Human Rights Act, regarding the treatment of federally sentenced women. As part of the process of developing submissions to the Canadian Human Rights Commission (CHRC), CAEFS consulted with twenty-seven other national women's, Aboriginal, and justice groups. The CHRC circulated a discussion paper to individual and organizational stakeholders working on behalf of federally sentenced women. The coalition of equality-seeking groups each made submissions to the CHRC based on this report in May 2003. 
Based on these submissions, the Canadian Human Rights Commission (CHRC) undertook a broad-based review of the treatment of federally sentenced women on the basis of gender, race, and disability. In December 2003, the CHRC released its report finding that women prisoners continue to face systemic human rights problems in the federal corrections system. The report finds that:

[T]he correctional system needs to be more tailored to the unique needs and generally lower security risks posed by criminalized women. Specifically, the correctional system should take a more gender-based approach to custody, programming and reintegration for women offenders...[W]hile Correctional Service Canada has made some progress in developing a system specifically for women offenders, systemic human rights problems remain, particularly with regard to Aboriginal women and women with disabilities (emphasis added) (CHRC, 2003).

The report sets out a number of guiding principles in relation to the treatment of federally sentenced women, consistent with human rights' laws. These include:

federal women prisoners have a right not to be discriminated against and a right to correctional services as effective as those received by men; equality must be based on the real needs and identities of women inmates, not on stereotypes and generalizations; the duty of CSC is to promote and protect the human rights of women and means that they must take into account the fact that some of the reasons women offend, their life experiences and their rehabilitation needs are unique (CHRC, 2003).

The report put forth 19 recommendations for action, the most prominent of which include: the creation of a security classification scheme specifically for criminalized women which does not conflate issues of risk and need; harm reduction measures to deal with addictions; resource allocation to deal with mental illness; low and medium risk offenders be accommodated in appropriate security facilities; improving responses to the rehabilitation needs of women; appropriate and adequate community housing; community programs and services; and community release options for women. 
While the findings of this report are somewhat encouraging, cautious optimism is exercised as many of these same recommendations were made in many other government reports including Creating Choices (1990), the Arbour Commission (1996), the Public Accounts Committee Report (2003), and the Auditor General Report on the reintegration of criminalized women (2003), and have not been acted upon.

\section{Penal Responses to Criminalized Women}

The human costs of women's criminalization far outweigh any monetary costs in terms of the impact it has on women and their children. These impacts are difficult to quantify and vary in degree from one woman to another. Suffice it to say that the consequences of criminalization have detrimental effects on the well-being, mental health, and future life chances of former inmates and their immediate family (e.g. children). The personal costs associated with criminalization also extend to society as a whole. For example, imprisonment of single mothers places an increased demand on the need for foster care services. Earlier research shows that the majority of children of incarcerated women are placed in temporary foster care unless alternate arrangements can be made with other family members (Shaw, 1994; Boritch, 1997; Watson, 1995; MacLeod, 1986). A study conducted in England and Wales found that 90 percent of fathers in prison left their children in the care of their spouse while only 23 per cent of mothers in prison could do the same (Shaw, 1994). This is undoubtedly a concern unique to women in prison.

Children of criminalized women face untold hardships including the stigma associated with their mothers serving time, the physical separation and loss of a parent and the transient nature of foster care services. Often times, children are shifted in and out of a number of foster 
care arrangements during the length of their mother's incarceration which leads to further isolation and loneliness. It goes without saying that criminalized women themselves suffer tremendous hardships during their period of incarceration. Self-injurious behaviour, especially slashing, is very common amongst women in prison. Most women who injure themselves have histories of childhood sexual abuse and adult violence (Filmore et al., 2001). A common institutional response to this behaviour by correctional staff is the use of solitary confinement (Martel, 1999). Other forms of reprisal by correctional authorities have been the suspension or cancellation of visitation privileges.

Illustrations of the human tragedy of women's incarceration are all too prevalent in this country. For example, the prison riot (April 1994) which resulted in the brutal strip searching by an all-male emergency response squad against female inmates at P4W brought the horror and barbarism of prison life into our homes. Media coverage of this event highlighted the cruel treatment of inmates by correctional staff and led to the appointment of a commission of inquiry to investigate the situation (Arbour Report, 1996). This scathing report called for reform of the present system of segregating women for long periods of time, of employing male riot squads in prisons for women, and of strip searching women against their will. The Arbour Report also called for financial compensation for those women who were subjected to this inhumame treatment.

It is easy to lose sight of the human costs of women's criminalization when examining statistical profiles, government-sponsored commissions and inquiries, and other secondary documents. However, recent media attention surrounding the tragic death in Ontario of Kimberly Rogers, places the human costs in chilling perspective. In April 2001, Kimberly Rogers was 
convicted of welfare fraud for receiving student loans while collecting social assistance. Under the Government of Ontario's “Zero Tolerance" policy for welfare fraud, anyone convicted of social assistance fraud (on or after April 1, 2000) was deemed permanently ineligible for social assistance (Income Security Advocacy Centre, 2003). In Kimberly Roger's case, the welfare office determined an overpayment and she was automatically suspended from receiving social assistance benefits for three months. She was subsequently sentenced to six months house arrest (with no means to pay her rent); allowed out of her apartment only three hours a week (during a heat wave in Ontario); repayment of $\$ 13,468.31$; and eighteen months probation. At the time of her conviction, Kimberly Rogers was five months pregnant and suffering from a number of medical conditions for which she required prescribed medication. When her benefits were cancelled, her Ontario Works prescription drug card was also cancelled.

On May 14, 2001 Kimberly Rogers launched an important case under the Charter of Rights and Freedoms that challenged the constitutional validity of the Ontario Works regulations that cancelled her benefits after her conviction. Tragically, on August 9, 2001 Kimberly Rogers and her unborn child were found dead in her apartment before her application could be heard. A Coroner's Inquest to investigate the conditions surrounding her death began in Sudbury, Ontario on October 15, 2002 (Eden, 2002). Two months later, the jury released a number of recommendations including the elimination of the zero tolerance lifetime ineligibility ban; the insurance of adequate housing, food and/or medication be provided to persons serving a custodial sentence of house arrest; assessment of the adequacy of social assistance rates; the establishment of a committee to develop a model for assessing whether cases of welfare fraud should be referred for prosecution; and benefits for drug therapy for life-threatening conditions not be 
discontinued during any suspension of welfare benefits (Eden, 2002). The case of Kimberly Rogers is a clear example of the fallout of draconian state-sponsored policies which threaten the lives of women and their children through the evisceration of social and economic programs. This case also focusses attention on the futility of community corrections programs (i.e., house arrest) in the face of such dire economic conditions, all to common amongst criminalized women.

In addition to the human costs of processing women through the criminal justice system, the financial price tag is also alarming. In the year before the release of Creating Choices (1989), there were 203 women in federal institutions in Canada. By 2002, this figure had increased to 355 women which represents a $65 \%$ increase in the population of federally sentenced women (Canadian Association of Elizabeth Fry Societies, 2003b). Part of the reason for this dramatic increase might well be attributable to the creation of five new federal facilities for women in Canada. It is evidenced that court judges are now more likely to sentence a woman to a federal term knowing that there is a prison located within the region. This observation is based on the 'build it and they will come' principle which dictates that if additional prison space exists it will be filled to capacity.

In 2001-02, as noted, the average annual cost of incarcerating a federally sentenced woman was estimated at $\$ 155,589$. This represents an amount that is more than fifteen times the annual income of a single mother on social assistance. It has been convincingly argued by many feminist scholars that if women's poverty issues were adequately addressed there would be little need for existing prison facilities or future prison construction and would actually result in enormous cost savings to governments and taxpayers in the range of millions of dollars annually. The situation of women in the corrections system has been fraught with a unique set of 
historical circumstances, reflective of women's small numbers relative to men and, consequently, their 'invisibility'. Four major and often inter-related areas are characteristic of most criminalized women including physical and sexual abuse issues, low levels of education and job skills, histories of substance abuse, and parenting problems. The majority of criminalized women have been victims of abuse and trauma in their families of origin or with their intimate partners. One study found that 82 percent of the women surveyed at $\mathrm{P} 4 \mathrm{~W}$ and 72 percent of those women surveyed in provincial prisons under Exchange of Service Agreements (ESA) reported being survivors of physical and/or sexual abuse (Shaw, 1990). Prisons for women have been negligent in providing adequate programming or counselling for abuse victims (Comack, 1996). Furthermore, these issues are consistently more prevalent among Aboriginal women who report histories of physical and/or sexual abuse in the 90 percent range (Shaw, 1990).

Second, women's low levels of education and job skills are inextricably linked to their involvement with the criminal justice system. Their offences are often tied to their strained socioeconomic circumstances which too often include absolute poverty. Most criminalized women are poor, lack marketable employment skills and are single parents, solely responsible for child care. Over 40 percent of incarcerated women are classified as functionally illiterate. In prison, there are severe limitations in gaining access to vocational programs that are designed to develop marketable job skills to assist women upon their release back into their communities (Canadian Human Rights Commission, 2003).

Substance abuse is also a common problem for women in the correctional system. Research indicates that women are more likely to have a different range and type of problems related to their substance abuse than do their male counterparts. There is accumulating evidence 
that eating disorders, major affective mood disorders (depression) and a history of abuse are highly prevalent in women with substance abuse issues. Further, criminalized women are more likely than males to have been diagnosed as mentally disordered, prescribed medication and hospitalized in the past (Motiuk and Blanchette, 1998).

Finally, parenting is a major issue for criminalized women. Many mothers have tremendous concerns over lost custody of one or more of their children and report that contact with their children, regardless of age, is essential to their personal well-being. The majority of mothers indicate a need for programs that address issues around parenting skills and coping effectively while incarcerated with the realities of being separated from their children. All of these areas previously identified in the literature were common amongst the women in my study and will be further discussed and elaborated on in subsequent chapters.

\section{Summary}

The situation of women in the corrections system has been fraught with a unique set of historical circumstances, reflective of women's small numbers and, consequently, their 'invisibility'. Women, both in prison and in the community, are often relegated to the position of 'second class offenders' based on their small numbers, the unique socio-economic nature of their offences, and their direct comparisons to men. Furthermore, Aboriginal women and women with mental health diagnoses are increasingly marginalized in the corrections system with a disproportionate number ending up behind bars. The plethora of issues facing criminalized women has been a source of frustration due largely to a lack of serious and meaningful consideration by policymakers during this past century. A review of Canadian correctional history 
reveals that efforts to accommodate women in prison have been based largely on a male model which is insensitive and neglectful of the distinct realities of women's lives. Attempts to make theoretical sense of such realities and locate the broader societal forces which contribute to the criminalizing of already disenfranchised women marks the focus of the next chapter. 


\section{CHAPTER 4: \\ THEORETICAL INFLUENCES}

... [W] hat has come to be known as criminology was actually the study of male crime, and largely, male victimization. Predictably, theorizing about crime and justice followed much the same intellectual trajectory, and theories that were generated to discuss "crime", "victimization", and "crime policy" were actually theorizing male deviance and criminality, in the main....[S]o severe has been this distortion that some feminist scholars have wondered, aloud, as to whether feminist criminology is not, in fact, an oxymoron." (emphasis added) (Chesney-Lind and Faith, 2001: 287).

This research is driven by a grounded theory approach to data analysis. However, it is fundamentally informed by feminist thought, most notably socialist and standpoint feminisms which take into account the capitalist and patriarchal systems which structure women's experiences in the social and criminal justice domains and the exclusion of women from the knowledge legitimation process. Tied into an analysis of broader forces which structure the lives of women, discussions of feminist epistemologies and knowledge legitimation are brought into view. Finally, discussions of social control and transcareration are key theoretical influences from which my study results are framed and analyzed.

\section{Grounded Theory}

Grounded theory is the primary approach taken to inform and make sense of the research findings. The premise of grounded theory is that research should be directed toward the development or 'discovery' of theory. Theory which is generated from the data as grounded theory is "distinguished from theory logically derived from a priori assumptions and based on a touch of common sense, peppered with a few old theoretical speculations" (Glaser and Strauss, 1967: 29). Given the dearth of literature focussing on criminalized women in the community and, consequently, the exploratory framework used for my research, a grounded approach is necessary. Throughout the research, major themes and concepts emerged and directed subsequent theory 
formation, which include socialist feminism, standpoint feminism and social control theories. Such a non-restrictive approach at the outset was needed to allow for the establishment and identification of significant themes as identified by the respondents themselves. More in-depth discussions of the grounded theory methodology are taken up in the next chapter and outlines the steps and rationale behind this approach to theory development.

\section{Feminist Criminolog(ies)}

While adopting a grounded theory approach in my work, my research is heavily informed by feminist thought. This does not compromise a grounded approach as my previous work on criminalized women and a review of the extant literature in the area clearly reveal that criminalized women are marginalized in our society based on gender, race, class, sexual orientation, and mental disabilities. Women are further oppressed on all these dimensions by the criminal justice system. These factors cannot be overlooked when working within the grounded tradition. It is from this perspective that I begin to frame a theoretical understanding of women's attempts at community re-integration.

Over the past three decades, feminist criminology has gathered considerable momentum and attracted unprecedented attention from scholars who have carved a niche for this subdiscipline within the wider context of mainstream criminology. Where once there existed only a handful of feminist scholars devoting serious attention to the topic of women and crime, mainly in the United States and Britain, the discrete contributions of feminists to the larger study of crime continues to attract global attention. Research in this area has been expansive, with its concentration on women as offenders and victims, identifying gender discrimination within all 
aspects of the criminal justice system, positing theoretical perspectives on women's involvement with crime, and identifying methodological tools for conducting feminist research on women's lawbreaking. While these contributions have opened the debates and sparked discussions surrounding women's criminal involvement there are still many questions and gaps that remain.

One of the ongoing debates within this body of literature centres around the question of whether or not a singular 'feminist criminology" ${ }^{34}$ exists or whether what we are actually referring to are feminist perspective(s) within criminology or feminist criminology(ies). It is from this quandry over "feminist criminology as an oxymoron," that I begin to frame my discussions and interrogations of feminist contributions within the broader field of criminology. A major objective of my work is to examine the notion that a feminist criminology exists as merely a critique and adjunct to the already established body of 'malestream' criminological knowledge (e.g., 'add women and stir approach'). Moreover, I address the following questions, as articulated by Smart (1990: 83): what does feminism have to offer to criminology and, more importantly, what does criminology have to offer to feminism? This is an important line of inquiry as it forces a shift in focus toward the broader fundamentals of feminist thought. It also forces a critical analysis of the traditional and contemporary assumptions of criminology as an androcentric discipline that fails to take gender ${ }^{35}$ seriously by placing it at the periphery of inquiry and analysis.

${ }^{34}$ Although a core focus of my work is to critically assess the existence of a monolithic 'feminist criminology,' I employ the term to describe the varied contributions of feminist theories/methodologies in criminology and thus use the terms 'feminist perspectives' and 'feminist criminology(ies)' interchangeably.

${ }^{35}$ Criminology has also been criticized for its failure to examine the pivotal intersections of race and ethnicity, class, and gender. Recent attempts to address this shortcoming have been attempted by socialist feminism (see, for example, Messerschmidt, 1997; 1986). 
A common tenet of early feminist criminological research points to the gender-blindness of mainstream criminology. Like other social sciences, criminology is androcentric in its orientation to understanding the social world. The study of crime, then, is shaped by male experiences and continues to exalt men as the standard by which research and theory construction are premised. Women are seen as "other" (Cain, 1990), when they are taken into account at all. The 'legacy of sexism' inherent in mainstream criminology can be traced to early biological explanations of female criminality (Boritch, 1997). For example, Lombroso and Ferrero (1895) posited a theory of female criminality based on the faulty construction of criminalized women as "wicked" and lacking in virtue (DeKeseredy, 2000). The work of positivist ${ }^{36}$ criminologists like Lombroso and Ferrero (1895) provided ample grist for later criticism by feminists who pointed to the severe methodological and theoretical flaws within their work. The essentialist rootings of biological derivations based on sex are clearly inadequate and do not capture the wider social, cultural and economic forces that serve to construct gender realities.

Almost half a century after Lombroso and Ferrero (1895) we see a reassertion of the positivistic approach to the study of female crime in the work of Otto Pollak (1950) who introduces the 'chivalry' thesis by arguing that women are better able to disguise their criminal involvement by their cunning and deceit. Therefore, female crime is "masked" by the greater leniency with which female criminals are treated by chivalrous criminal justice personnel

${ }^{36}$ Positivism refers to the assumption that we can establish a "verifiable knowledge or truth about events: in particular, that we can establish a causal explanation which will in turn provide us with objective methods for examining events defined as problematic (Smart, 1990: 72). Feminism has raised significant questions about the role of power and knowledge and challenged grand theorizing which impose a uniformity of perspective and ignore the immense diversity of subjectivities of women and men. 
(DeKeseredy, 2000: 73). As before, feminists have criticized the work of Pollak and others based on their failure to consider the wider structural conditions (e.g., patriarchy, poverty, family violence) that account for gender differences in crime. In addition to the sexist nature of classical studies, such approaches have been criticized for being classist, racist, and heterosexist as their focus has been on white, middle-class, and married women as the standard by which all other women are judged (Belknap, 2001).

The works of Adler (1975) and Simon (1975) are widely regarded as the first feminist ${ }^{37}$ attempts to theorize about women's involvement with crime and the criminal justice system. The 'liberation/emancipation' thesis suggests that the women's movement has brought about unintended negative consequences, including an increase in the female crime rate. For example, Adler (1975) proposed that women's violent crime rates would increase as a result of their liberation while Simon (1975) argued that only property crimes would increase due to women's economic liberation (Belknap, 2001). While parting ways in their approach to how feminism would being played out, both authors posit that the women's liberation movement contributed to an increased involvement by women in criminal activities. Both authors rejected the biological assumptions that had been previously put forth to explain crime differences between the sexes. According to Adler (1975), as women's social roles expand to resemble those of men, so too does

37 The contributions of Adler (1975) and Simon (1975) have been heavily criticized by feminists. However, their contributions are no doubt important. As Laster (1996: 193) points out, "[c]riminology's failure literature forces us to confront the limitations of our own theories, methods and politics. Frequently, failure is the catalyst for the development of new (but not necessarily more successful) strategies for imagining crime and responses to it...[S]uccessfully proving failure creates space for new ideas and people. Feminist criminology's successes have come, in part, from its ability to capitalise on the failures of main (male) stream criminological theory." 
their criminal behaviour. Simon (1975), on the other hand, focuses more narrowly on the impact of women's increased participation in the paid labour force and proposes an 'opportunity model' to explain women's increased involvement in property crimes (Belknap, 2001).

Having been criticized heavily for their faulty assumptions about the influences of the women's movement on crime rates (e.g., increased economic and structural opportunities and that the feminist movement made women behave like men) Adler (1975) and Simon (1975) can be partially credited with opening the arena for debate and the subsequent growth of research on women's involvement with crime and the criminal justice system. This research was followed by a groundswell of feminist theorizing in criminology.

Feminist criminology cannot advance an understanding of women's involvement with crime and the criminal justice system without first probing the bases of feminist thought. Feminism itself, then, can be defined as, "a set of theories about women's oppression and a set of strategies for social change" (Daly and Chesney-Lind, 1988: 502). According to Danner (1991: 51), feminist theory "is a woman-centered description and explanation of human experience and the social world. It asserts that gender governs every aspect of personal and social life." While there are many variations of feminist theory, patriarchy is at the centre of each strand's explanation of women's oppression. Patriarchy refers to "a social, legal, and political climate that values male dominance and hierarchy" (Belknap, 2001).

Daly and Chesney-Lind (1988: 504) characterize five elements of feminist thought that distinguish it from other types of social and political thought. They include the following: (1) gender is a complex social, historical, and cultural product; it is related to but not simply derived from, biological sex difference and reproductive capacities; (2) gender and gender relations order 
social life and social institutions in fundamental ways; (3) gender relations and constructs of masculinity and femininity are not symmetrical but are based on an organizing principle of men's superiority and social and political-economic dominance over women; (4) systems of knowledge reflect men's views of the natural social world; the production of knowledge is gendered; and (5) women should be at the center of intellectual inquiry, not peripheral, invisible, or appendages to men.

First, that gender is not simply a product of biology but is much more complex is a cornerstone claim of feminist thought. On this point, feminists argue that there are crucial distinctions between sex and gender. ${ }^{38}$ Gender is a socially constructed phenomena that shapes and influences all spheres of social, political and economic life. Based on this distinction, criminological theories that place biological sex differences between men and women as the axis of examination are flawed. Second, an understanding of gender relations in all spheres of society is paramount. Accordingly, criminological research that fails to account for the social hierarchy of gender relations cannot adequately theorize men's or women's involvement in crime. Third, patriarchy is a consistent unifying element of feminist theory. Sexual, economic, and political control by men over women in society must be a central organizing feature in criminological theory. Fourth, knowledge production is based on men's views of seeing the world. Feminists have critiqued the knowledge-making and legitimation process as being androcentric and similarly critique criminological theories that argue objectivity and scientific rigour.

\footnotetext{
${ }^{38}$ Sex differences are biological differences, including differences in reproductive organs, body size, muscle development and hormones. Gender differences, on the other hand, are those that are ascribed by society and that relate to expected social roles. Gender differences are rooted in inequality and therefore social change is seen as necessary to achieve equality (Belknap, 2001).
} 
Subjectivities and experiences must feature prominently in research and subsequent theory construction. Finally, feminists maintain that women's experiences should be at the center of our attempts to understand the social order. Likewise, criminology as a discipline must reorganize its hierarchical structure to account for gender.

Based on the central organizing principles of feminist thought discussed above, several feminist criminological theories have been formulated. Arguably, there are at least a dozen strands of feminist criminological theory. ${ }^{39}$ My research draws upon two of these strands: socialist and standpoint feminisms. Each is discussed below as they bear particular application to the research at hand.

\section{Socialist Feminism}

Socialist feminism emerged largely as result of feminists' dissatisfaction with the essentially gender-blind character of Marxist thought which regards economic class relations as the primary source of women's oppression. According to Marxist feminism, the material basis of women's marginalization and inequality lies in the fact that as a group women work outside the labour economy. Women's labour is in the home and is reproductive, not productive. Therefore, it is argued that women do not create surplus value in the economy. For Marxist feminists, the oppressor is capitalism which exploits and benefits greatly from women's labour (Daly and Chesney-Lind, 1988). This over-reliance on economic class to the near exclusion of gender relations to explain women's oppression is hailed as a major shortcoming of Marxist feminism.

${ }^{39}$ For example, structured action theory (Messerschmidt, 1997); libertarian and cultural feminism; multicultural and global feminism; multicultural/multiracial theory (Chesney-Lind and Faith, 2001); psychoanalytic (Tong, 1998); existentialist (Tong, 1998). 
To overcome the inherent limitations of traditional Marxist feminism, socialist feminists "seek to explain the ways in which capitalism interacts with patriarchy to oppress women more egregiously than men" (Tong, 1998: 119). While concurring with the central thesis advanced by Marxist feminists that women's liberation depends on the overthrow of capitalism, socialist feminists maintain that capitalism cannot be destroyed unless patriarchy is also destroyed.

Socialist feminists argue that life experiences are shaped by both class and gender. Patriarchy, then, is seen as an equally important driving force behind women's oppression and is exercised and reinforced through such institutions as marriage, child rearing, and sexual practices. Patriarchy is a

set of social relations of power, in which men control the labor power and sexuality of women. It is this control- both in the home and in the labor market- that provides the material base of patriarchy (Messerschmidt, 1986: 32).

Strategies for change, then, rest on the overthrow of patriarchal relations which would permit women's sexual autonomy and obliterate the "oppressive nature of sexual and familial relations for women with their link to relations in the public sphere" (Daly and Chesney-Lind, 1988: 538).

While Marxism recognizes only labour in the productive realm, socialist feminism recognizes the inextricable and inseparable linkages between production and reproduction. As Messerschmidt (1986: 28) points out:

Relations of production and reproduction have varied historically, but in contemporary society, relations of production take the form of capitalist class relations and relations of reproduction take the form of patriarchal gender relations.

Socialist feminists recognize that familial reproduction and the nuclear family are as important to the needs of capitalism as production in the workplace (Chesney-Lind and Faith, 2001: 293). Moreover, they recognize that patriarchy affects the ways by which men control women's 
productivity. As Messerschmidt (1986) points out, turning back to horticultural societies, we witness the appropriation of labour by those with power over the subordinate group, in both productive and reproductive spheres. The appropriating group, as Jaggar (1983: 136) clearly describes, has:

(1) defined what work should be done and how it should be performed, (2) benefited disproportionately from the labor (both productive and reproductive) of the subordinate groups, and (3) used the labor performed by the subordinate groups to consolidate and extend its control over those groups.

Socialist feminists differ from their Marxist predecessors in that they view women's interests as inherent in, rather than subordinate to, the working class struggles. They recognize the gender factor as well as the economic factor in the division of labour and the distribution of criminalization (Chesney-Lind and Faith, 2001). It is the sexual division of labor which is key to a socialist feminist understanding of oppression.

Burstyn (1983: 53-56) has identified three integral characteristics of the sexual division of labor in a capitalist patriarchy. First, that the nature of labor performed by women and men is different. While men labor in the productive sphere, women labor in both productive and reproductive spheres. Second, "normative heterosexuality [i]s the major psycho-sexual organizing principle" of capitalist patriarchy. The sexual division of labor, "divides the sexes into two mutually exclusive categories, creating gender, and enjoining heterosexual marriage for economic survival and biological reproduction." Third, men control the "economic, religious, political, and military systems of power in society" which perpetuate the capitalist patriarchy. Therefore, "since the oppression of women and the working class is intimately related through the interaction of production and reproduction, the material base of society as $a$ whole needs to be transformed to end that oppression...[The call is for the creation of] a socialist feminist society, 
not just a socialist society (Messerschmidt, 1986: 31 ).

A socialist feminism understanding of crime therefore stresses that crime occurs for both men and women in an economic and male-dominated context. Increases in women's incarceration then would be seen as part of the larger 'prison industrial complex' that acts as a response to social problems (e.g., war on drugs). The state, acting on behalf of corporate interests, has targeted a massive spending increase on women's prisons. In turn, expenditures on welfare and education have dropped dramatically to fund the prison endeavour. Resources that were once used to support low-income women and their children and to enhance education efforts have been exchanged in favour of an expanding prison industrial complex for women (Chesney-Lind and Faith, 2001).

Foremost in a socialist feminist analysis are the intermeshing of class and gender in the reproduction of a capitalist patriarchy. However, it has been rightly argued by some that socialist feminism has not gone far enough in integrating racial inequalities into their analyses (e.g., Danner, 1991). Patriarchy, as it is argued, cannot be separated from capitalism just as racism is integrally connected to oppression. ${ }^{40}$ Another major criticism of socialist feminist theory is that it fails to account for agency, that is, an over-reliance on structural explanations (class-based inequality, patriarchal subordination of women, racial/ethnic inequalities) to account for gender inequality. It has also been argued by postmodern feminists that socialist feminism, like its radical predecessors, is guilty of exclusivity in that it appeals to a white, euro-centric, middle-class group of women. As Smart (1998:82) points out:

${ }^{40}$ It is recognized that socialist feminism still focuses largely on gender and class and does not adequately address race as a contributing factor to women's oppression. 
[T] he rejection of the one reality which arises from the 'falsely universalizing perspective of the master.' It refers to subjugated knowledges, which tell different stories and have different specificities. Thus the aim of feminism ceases to be the establishment of feminist truth and becomes the deconstruction of truth and analysis of the power effects which claims to truth entail. It is this recognition that knowledge is a part of power that underlines the claims made by feminist postmodernists.

\section{Standpoint Feminism}

Standpoint feminism relies on the notion that previous feminist attempts to integrate the varied interactions of race, class, and gender have been deficient. It is argued that, "[ $t]$ he field has particularly focussed attention on the fact that the predominantly white and middle-class women's movement had, in its focus on gender alone, essentially ignored the diversity of women's experiences, lives, and communities" (Chesney-Lind and Faith, 2001: 297). Smart (1990: 80), in her analysis of standpoint feminism states that:

[T]he epistemological basis of this form of feminist knowledge is experience. Feminist experience is achieved through a struggle against oppression; it is, therefore, argued to be more complete and less distorted than the perspective of the ruling group of men. A feminist standpoint then is not just the experience of women, but of women reflexively engaged in struggle (intellectual and political).

One attempt to value knowledge at the margins that lacks 'official knowledge status,' (i.e. legitimation), has been offered by proponents of standpoint perspectives (Haraway 1996; Collins, 1991, Smith, 1987). Smith (1987: 108) illustrates the connection between power and the legitimation of knowledge and the exclusionary nature of these processes as follows:

A standpoint in the everyday world is a fundamental grounding of modes of knowing developed in a ruling apparatus. The ruling apparatus is that familiar complex of management, government administration, professions, and intelligentsia, as well as the textually mediated discourses that coordinate and interpenetrate it.

The standpoint perspective is based on the assumption that one's positionality is crucial in 
gaining knowledge and understanding (Wolf 1996). Hartsock (1998) argues that due to women's positions within the sexual division of labour and sexist oppression, in general, women would have greater insights as researchers into the lives of other women. ${ }^{41}$ In other words, one's position in the social hierarchy potentially broadens or limits one's understanding of others. Members of the dominant group will have viewpoints that are partial in contrast to those from subordinated groups, who have greater potential to have fuller knowledge. Smith (1987) emphasizes that the only way we can know a socially constructed world is to know it from within. But since our knowledge and perceptions about reality are shaped by our own unique experiences and how we interpret them, there is little or no possibility for value-free and objective knowledge. In a similar vein, nobody's knowledge is worth more or less than somebody else's.

One of the major criticisms of standpoint feminism is that it has tended not to problematize masculinity. Many feminists recognize the importance of questioning what it is about masculinity that singularly makes it the most predictable variable of criminal involvement. Hegemonic masculinity also remains "defined as different and separate from, in opposition and superior to, femininity" (Danner and Carmody, 2001). Countering the criticism that standpoint feminism excludes masculinity studies, Smart (1990: 81) states that:

...[I]t is precisely because standpoint feminism in this area has risen from a grassroots concern to protect women and to reveal the victimization of women, it has not been sympathetic to the study of masculinity(ies). Indeed, it would argue that we have heard enough from that quarter and that any attempts by feminists to turn their attention away from women is to neglect the very real problems that women face.

${ }^{41}$ Contradictory evidence exists which refutes this claim by feminist standpoint theorists concerning the implications of males researching the experiences of female respondents (see, for example, DeKeseredy and Joseph, Forthcoming; DeKeseredy et al, 2004; Currie and MacLean, 1999; Websdale, 1998). 
However, given the claim by feminists that we need to deconstruct gender it is important to take account of this theoretical shortcoming while at the same time heeding Smart's warning of not falling into the androcentric trap of taking men's experiences as the starting point of analysis and subsequently the standard by which women's experiences are evaluated.

As elucidated from the above discussion, there is no monolithic feminist criminology. There exist a multitude of viewpoints about women's subordination and their subsequent involvement in crime. As Boritch (1997:78) points out, "[m]any feminists now take the position that to adopt any single definition of feminism, or approach to gender and crime, would limit the development of feminist perspectives in criminology." While some feminists have moved more toward an examination of social control issues that propel women into crime (e.g., Daly and Maher, 1998; Miller, 1998) others have argued that we need to move away from the traditional confines of criminology altogether (e.g., Cain, 1990; Smart, 1990) as it restricts an examination of central questions about women and fails to liberate them from their oppression.

Smart (1990: 70) argues that the "core enterprise of criminology is problematic, that feminists' attempts to alter criminology have only succeeded in revitalizing a problematic enterprise, and that, as feminist theory is increasingly engaging with and generating postmodern ideas, the relevance of criminology to feminist thought diminishes." She regards criminology as something of a siding for feminist thought, with feminist criminologists risking something of a marginalized existence-marginal to criminology and to feminism (Smart, 1990: 71). This challenges the modernist assumption that once we have the theory (master narrative) which will explain all forms of social behaviour, we will also know what to do and that the 'rightness' of this doing will be verifiable and transparent (Smart, 1990: 72). 
A large body of feminist empiricist literature which explores claims to objectivity, grand theory, and the deconstruction of knowledge now exist (see, e.g., Keller, 1996; Smith, 1987; Haraway, 1996; Hartsock, 1998). Feminist empiricism refers to a body of work which has criticized the claims to objectivity made by mainstream social science. It points out that what has passed for science is in fact the world perceived from the perspective of men, what looks like objectivity is really sexism and that the kinds of questions social science has traditionally asked have systematically excluded women and the interests of women. Feminist empiricism, therefore, claims that a truly objective science would not be androcentric but would take account of both genders. As Smith (1973: 77) points out, "to direct research at women without revising traditional assumptions about methodology and epistemology can result in making women a mere addendum to the main project of studying men. It also leaves unchallenged the way men are studied" (cited in Smith, 1987).

It is important to recognize that knowledge in the everyday world is socially constructed and that the political, economic, social, and cultural contexts of knowledge generation, acquisition, and transmission have to be taken into account. Whose knowledge comes to be accepted as the 'truth', who has a voice in the creation of knowledge, and what the intervening factors are that play into the legitimation process of knowledge, such as the 'relations of ruling'42 (Smith, 1987) are important tenets of feminist methodology. In this regard, issues surrounding who decides what becomes acceptable as knowledge in a particular spatial, temporal, and cultural 
context are paramount.

Before knowledge gets to be accepted in the everyday world it has to undergo a 'legitimation process' which results in an 'official' decision being made as to an explanation's legitimacy or lack thereof. If the decision-makers (patriarchal capitalists) perceive some knowledge to challenge the status quo, an approving assessment of this threatening type of knowledge might be withheld as a consequence and the finding will not be recognized as (legitimate) knowledge. Consequently, this leads to the marginalization of knowledge and many creators of subsequently marginalized knowledge have come from oppressed groups, such as women and non-white, including Aboriginal people. Conversely, much of legitimate/legitimized knowledge has come from members of the dominant group(s) - primarily white, heterosexual and male - who had (have) some affiliation with the ruling class.

Feminist writings on the value-laden and androcentric bases of scientific knowledge, such as those of Evelyn Fox Keller (1996), have pioneered the deconstruction of knowledge claims and have argued for the inclusion of feminist ways of knowing in the experimental design of (social) scientific research. Keller (1996) discusses the relationship between knowledge and power and notes that both are intermeshed -- knowledge is about legitimacy and legitimacy is about power. Recently, feminists critiques of the objectivity and legitimation of science (Keller 1996; Haraway 1991) have entered the criminological discourse as well (e.g. Naffine, 1996; Smart, 1990; Scraton, 1990).

Epistemological contributions that attempt to deconstruct and expose the value-laden assumptions of scientific knowledge have also sparked feminist writings in the area of research methodologies. Issues grappling with power relations inherent during the research process have 
been an integral part of the discussions and debates. While this may be the case, there is still a lot of work to be done in this area. On this point, Ristock and Pennell (1996: 68) argue that "feminist discussions of research have yet to describe fully the complexity of power and struggles with subjectivity in research."

Feminist methodologies and epistemologies are inextricably linked to subsequent theory construction. Before we can theorize from data, we must understand the knowledge construction/legitimation processes that guide our research. We need to recognize the subjectivities of the researcher and take account of the power that is institutionalized in a masculinist form throughout all aspects of the criminal justice system. As Scraton (1990: 15) points out, "If academic discourse and its patriarchal context is to be challenged it needs to be considered within a broader framework of how ideas gain currency, become transmitted and eventually become institutionalized or consolidated as knowledge." It is from this vantage that feminism offers its greatest potential to transform the criminological discourse. Naffine (1996: 4) elaborates on these feminists contributions to the criminological discourse by pointing out that:

Feminists have carried out the more conventional (but necessary) empirical work of documenting sex bias within the criminal justice system. Feminists have questioned the scientific methods deployed by criminologists, as well as their highly orthodox approach to the nature of knowledge. Feminists have engaged with criminological theory, across the range, questioning its ability to provide general explanations of human behaviour. Feminists have provided an abundance of data about crime from the viewpoint of women (to counter the more usual viewpoint of men), and feminists have also helped to develop new epistemologies that question the very sense of writing from the perspective of a woman (or, for that matter, from the perspective of a man).

It is precisely on this point that I argue criminology has a great deal to offer to feminism 
by asking what it is about the construction of masculinities ${ }^{43}$ that propel men into crime? Put another way would be to ask what is it about the construction of femininities that makes women law-abiding? An inquiry into why women obey the law would surely advance a criminological and feminist understanding of gender. However, as Naffine (1996: 8) points out, "the idea that an exploration of the lives of women might provide the [criminological] discipline with powerful insights into human behaviour has not been considered." She also acknowledges that such an approach to the study of crime would "allow women a degree of separateness and subjectivity that has not been accorded them by the discipline."

Following this line of inquiry, several other important questions can be raised: what would criminology look like if women were at the centre of inquiry? How can feminist methodologies 'transgress and transform' mainstream criminological traditions? How would the discipline of criminology transform and progress if gender deconstruction of both women and men were forefront? As Heidensohn (1987: 24) makes clear, gender as a central focus of inquiry in criminology needs to be a central objective. She states:

The deeper understanding which studying women and crime bring to criminology ought to result in a paradigm shift. Gender, and hence the explanations of gender-related patterns, should become central. That has clearly not happened. Instead, there is now a vast store of material on women offenders, women and crime and women and penology which is, no doubt, taken seriously and widely used for its impact on women. But the importance of gender for criminality is only perceived in terms of victimology...A central question therefore remains about gender: how can it be built into criminology to play the central part in explanation and analysis it must?

In examining the myriad of factors that propel people into crime (men) and, likewise, the

${ }^{43}$ A plethora of research on masculinities and crime has been advanced over the past decade (see, e.g., DeKeseredy and Schwartz, 2004; Barak, 2003; Schwartz and Hatty, 2003; Hatty, 2000; Messerschmidt, 2000; Bowker, 1998; DeKeseredy and Schwartz, 1998; Websdale and Chesney-Lind, 1998; Connell, 1995; Newburn and Stanko, 1994). 
social control mechanisms in place that restrict criminal involvement (women) we need to move beyond the boundaries of criminology in many ways and look toward the broader social, economic, political, and cultural issues that contribute to the construction of gender in society. We also need to critique the knowledge-making and legitimation processes as being androcentric and similarly critique criminological theories that exclude women from their research and analyses and then argue objectivity and scientific rigour.

\section{Social Control and Transcarceration}

The term 'social control' has been bandied about in the sociological literature for decades. It sometimes appears as a "term to cover all social processes to induce conformity" (Cohen, 1985: 2). These social processes include education, family relations, and peer-group interactions. Carlen (2003: 119) notes that 'social control' is a vacuous term implying anything from "conspiracy theories" which view every social practice as part of the social control process, to a very narrow definition referring only to the state's official mechanisms of controlling crime. In other sociological interpretations, the term is applied to all state-sponsored social policies, including health and welfare, and is strictly adaptable to the 'coercive apparatus of the state'. Cohen (1985: 3 ) defines social control as somewhere in between these two poles and more general than the 'formal legal-correctional apparatus for the control of official crime and delinquency'. His focus is directed toward:

[t] hose organized responses to crime, delinquency and allied forms of deviant and/or socially problematic behaviour which are actually conceived of as such, whether in the reactive sense (after the putative act has taken place or the actor been identified) or in the proactive sense (to prevent the act). These responses may be sponsored directly by the state or by more autonomous professional agents in, say, social work and psychiatry. Their goals might be as specific as individual punishment and treatment or as diffuse as 'crime 
prevention', 'public safety' and 'community mental health'.

While I concur with Cohen on the necessity of broadening the purview of social control elements outside the criminological domain, I conceive of a more encompassing definition which extends itself beyond the official/formal delivery agents of the state. In particular, a gender-based analysis of social control must be invoked. There is nothing coincidental about the nature and types of social controls exerted on girls and women who end up as the targets of official/formal correctional controls brought about by the criminal justice system. It extends far beyond these parameters. While much of my analysis is premised on Cohen's broader interrogations, gender remains at the forefront of my analysis surrounding women's involvement with formal control agents. A grounding in the work of social control theory acts as a starting point for my discussions of women not only entangled in the criminal justice system, but for those 'at risk' of criminalization and, women for whom the criminal justice system represents only one force along a broader continuum of controls which have pervaded their lives.

Drawing on the work of Carlen (2003: 119), an alternative lens for analyzing the different types of "controls" experienced by women is invoked through the term "antisocial control", defined as:

a generic term for a variety of malign institutionalized practices that may either set limits to individual action by favouring one set of citizens at the expense of another so as to subvert equal-opportunities-ideologies in relation to gender, race, and class (or other social groupings), or (in societies without equal-opportunities ideologies) set limits to individual action in ways that are antisocial because they atrophy an individual's social contribution on the grounds of either biological attributes or exploitative social relations.

The major advantage of adopting this 'antisocial' definition of control is that it takes into account the different ideological, political, and economic conditions in which control is exerted. In particular, Carlen (2003) draws on control agents outside the purview of the criminal justice 
system when analyzing the (anti)social control of women. These sites of control include: (1) the 'antisocial family' wherein historically women are expected to subject themselves first and foremost to the family. The powerful ideology that "good mothers make good families make good societies" and that the family, in turn, "must forever be at the service of the military, the markets, and the man" (Carlen, 2003: 122) extends the discussions of control over women's lives; (2) the 'antisocial state' is interconnected to women's assumed domesticity wherein defiance of these expected roles subjects women to exclusionary and more formal measures of obedience and; (3) 'antisocial masculism' which is achieved by physical exclusion of women from public spaces, public institutions, and workplaces, managed primarily through law, the economy and tradition (Carlen, 2003: 124).

Additionally, as Carlen (2003: 125) makes clear, a further subjection of women has been achieved through beauty myths and body image norms which target conformity. For women unable to cope, there have been the (overprescribed) tranquilizers and the (oversubcribed) mental hospitals. Official regulatory agencies such as the courts and prisons are but the end result of the antisocial targeting of women's conformity achieved through various other converging social institutions. Keeping these various other antisocial control mechanisms in full view, the power of the courts and laws to then criminalize women's 'disobedience' must be placed into this wider context. In adopting an antisocial control framework, however, it is to the grounding of 'traditional' control theories that the deconstruction of 're-integration', 'decarceration', and 'transcarceration' within the criminal justice system takes place.

Central to the analysis of community-based reforms which have taken place over the past several decades, both in the criminal justice and mental health spheres, convincing arguments 
based on empirical evidence point to net-widening in these systems. Decarceration attempts have failed to bring about their desired goals of closing down institutions and locating 'clients' in their communities. Cohen (1985:37) comments on the results of this failed movement.

Instead of destructuring, however, the original structures have become stronger; far from any decrease, the reach and intensity of state control have been increased; centralization and bureaucracy remain; professions and experts are proliferating dramatically and society is more dependent on them; informalism has not made the legal system less formal or more just; treatment has changed its forms but certainly not died.

Scull (1977:1) outlines the historical context of the decarceration movement that took place in mental hospitals and prisons during the 1960 s and 1970 s. He notes that decarceration is

shorthand for a state-sponsored policy of closing down asylums, prisons and reformatories. Mad people, criminals, and delinquents are being discharged or refused admission to the dumps in which they have been traditionally housed. Instead they are left at large, to be coped with "in the community"

There is widespread disagreement among policymakers and the public about what the 'community' actually encompasses and very little empirical support that it is effective in meeting its intended goals of rehabilitation, cost-savings, and increased humanity. In practice, Scull (1977) maintains, community-based 'alternatives' are ripe with euphemisms, such as 'personal care homes' and 'treatment centres', which effectively camouflage the reality of one's precarious existence in the community. Scull (1977: 2) maintains that:

Decarceration thus forms yet one more burden heaped on the backs of those who are most obviously the victim of our society's inequities. And it places the deviant in those communities least able to care for or cope with them.

The shift to deinstitutionalize mental patients and prisoners, Scull (1977) argues, is driven by advanced capitalist market economies seeking to disaggregate social control models which are far too costly; by the advent of the therapeutic millennium and psychoactive drugs; and an alleged concern with the more humane provision of 'treatment' services in the community. Decarceration 
efforts have been a failed attempt to shut down, or at least reduce, the size and expanse of institutions. "An apparently radical decarceration strategy ends up only shifting custody from the state to local level and becoming a revenue sharing carve-up between local agencies" (Cohen, 1985: 96).

Resistance strategies employed by middle and upper class communities to housing the 'mad' and the 'bad' in their neighbourhoods have forced the situating of these makeshift and halfway residences in transient, deleterious, deteriorated urban locales. 'Treatment' under these conditions of restraint are no more conducive or empowering than they are in the rightly criticized confines of the institution.

From a purely economic stance, reducing expenditures by means of deinstitutionalization means doing less with less. The 'treatment' services and housing arrangements made available to ex-mental patients and ex-prisoners, for example, are heaped onto the private sector which are largely free of state regulation and inspection and are more often circumvented into conforming to state-based ideologies. It amounts to little more than the 're-packaging of misery'. As Scull (1977: 152) points out:

It is scarcely surprising to learn that decarceration in practice has displayed remarkably little resemblance to liberal rhetoric on the subject. Indeed, the primary value of that rhetoric...seems to have been its usefulness as ideological camouflage, allowing economy to masquerade as benevolence and neglect as tolerance.

Cohen (1985: 53) also makes clear the extent of community co-optation by decarceration strategies by identifying that:

[I]ntervention comes earlier, it sweeps in more deviants, is extended to those not yet formally adjudicated and it becomes more intensive. And all of this takes place in agencies co-opted into the criminal justice system (but less subject to judicial scrutiny), dependent on system personnel for referrals and using more or less traditional treatment methods. 
Commenting on the blurred boundaries between prison and the community, Cohen (1985: 58$)$ asserts that:

[I]t is by no means easy to know where the prison ends and the community begins or just why any deviant is to be found at any particular point... [t] he term community treatment has lost all descriptive usefulness except as a code word with connotations of 'advanced correctional thinking' and implied value judgements against the "locking up" and isolation of offenders.

The community then becomes the site of offloading by the state and the further blurring of private/public space. In order to survive, private community organizations must count on state funding to maintain their operations and subsequently become "co-opted and absorbed into the formal state apparatus" (Cohen, 1985: 65). What is clear is

that a probable outcome of this blurring is...the creation of a hidden custodial system, under welfare or psychiatric sponsorship, which official delinquency statistics simply ignore. This is the real, awful secret of community control. Not the old closely guarded secrets of the penitentiary (the brutality, the chain gangs, solitary confinement). These things occur in the community-and this is, by any measure, progress. The secret is a much less melodramatic one: that the same old experts have moved office to the community and are doing the same old things they have always done. Once again, we do not know what they are doing, not because they are hidden behind walls but because they are camoflauged as being just ordinary members of the community (Cohen, 1985:62-75).

Much has been written on the institutionalization and decarceration of mental patients (c.f., Goffman, 1961; Scull, 1977) and provides powerful evidence of the stakes by professional interest groups and the growth of whole industries in whose favour it is to keep the numbers high. 'Social control entrepreneurship' (Warren, 1981:724-40) describes the rationale behind this expansion. "To keep your job, to justify your existence, to attract grants and subsidies, you must keep on expanding" (Cohen, 1985: 167). Commenting on the continuum of controls exhorted over psychiatric patients, Cohen (1985) writes:

The mental-health network contains its own hard-soft bifurcation exactly parallel to that in the criminal justice system. At the core remains the classic asylum, relegated by the 
ideology of community to a dumping ground for chronic clients and favouring drug and behaviour therapy. In the next circle comes the community mental-health services and clinics, taking in a mixture of the old decarcerated patients and an increasing number of newer cases brought in by the net-widening ideology of preventive psychiatry and community mental health. These patients receive a mixture of drug therapy and traditional but watered down psychodynamic modalities (Cohen 1985: 153).

Net-widening is at the centre of the social control network and can be characterized as an endless tautology of re-cycling 'clients' back and forth from one 'help' system to another. Once entangled in this web of state-sponsored control, it becomes near impossible to break free from the host of sponsors who maintain stakes in keeping the cycle revolving.

Control leads to more control.. Almost the entire alternatives, diversion and community movements can be seen as loop...new systems being created to deal with the damage done by the old systems, but then inflicting their own kind of 'damage' from which clients have to be further saved, diverted, delabelled or decategorized. Diversion agencies loop clients away from the criminal justice system, then screening procedures have to be developed to loop the 'wrong' clients away from the diversion agencies. Theoretically, there is no end to this process (Cohen, 1985: 171-72)

Building upon the tenets of social control theory, transcarceral strategies of social control are characterized by institutional mobility wherein 'clients' of the criminal justice system are "pushed from one section of the help-control complex to another" (Lowman et al., 1987: 9). By managing and supervising individuals within the community, the correctional apparatus expands to include welfare, mental health agencies, social services, child protection agencies, educational resources, halfway houses, treatment centres, et cetera.

Agencies within the criminal justice system might compete over the same potential clientele, or clients might be tracked and retracked between crime, welfare and psychiatric systems...boundaries between these systems are now less clearly defined and therefore gains and losses are virtually impossible to estimate. The flow occurs in both directions: former offender groups are retracked into welfare or mental health system and previous patients (notably decarcerated mentally ill adults) come into the criminal justice system (Cohen, 1985: 54-55)

In situating a transcarceral model of social control, Lowman et. al., 1987, build upon 
much of the earlier analyses of control theories but advances the arguments even further. In

developing an interpretative framework for transcarceration they are dealing with:

a peno-juridicial, mental health, welfare and tutelage complex in which power structures can be examined only by appreciating cross-institutional arrangements and dynamics. Thus, 'privatization', 'decontrol', 'deinstitutionalization', 'decentralization' and so on, have consequences for security, courts, corrections, probation, parole, welfare and mental health...For control agents, this means that 'control' will essentially have no locus and the control mandate will increasingly entail the 'fitting together' of subsystems rather than the consolidation of one agency in isolation from its alternatives (Lowman, et al., 1987: 9).

Focussing on the manifestations of social control on women, Davis and Faith (1987),

begin with an inherent assumption that mechanisms and rationales of control are gendered and that "sexist traditions and ideologies are rampant in both the formal and informal spheres of control'. The involvement of the state in controlling the lives of women permeates beyond the level of the institution. Women continue to be penalized for violating traditional sex roles (antisocial control) and defying the maintenance of social order. Patriarchal relations which serve as a basis for defining women as 'deviant' in sexually demeaning and dependent ways include pornography, rape, sexualization of women's crimes, and prostitution (Davis and Faith, 1987). Neo-conservative political agendas exert increasingly punitive and institutionalized controls over women for behaviours which counter the gender roles demanded of women and their opposition to these demands.

When this labelling occurs it neutralizes and obfuscates a political phenomenon by defining it as deviant. To institutionalize opposition in the name of health, welfare, treatment, penalty and public safety is to attempt to silence that opposition (Davis and Faith, 1987: 187).

Davis and Faith (1987: 172-73)) also make the important observation that certain groups of women are more vulnerable to instutionalized controls than other women (and men). 
Disobedient or runaway adolescent females, those who are sexually active or pregnant in violation of husband's or father's wishes, and the 'unfit' mother are far more likely to be candidates for intervention than disobedient, runaway, sexually promiscuous, or domestically-abusive males.

Placing gender at the forefront of discussions surrounding mechanisms of social control and models of transcarceration is a vital exercise. Doing so from the theoretical rooting of socialist and standpoint feminisms is the guiding framework for my research as it situates the broader systems of capitalism and patriarchy by privileging the voices of criminalized women in the knowledge legitimation processes.

\section{Summary}

This chapter provides a theoretical understanding of the socio-political and economic processes which structure the lives of criminalized women. Drawing from the tenets of socialist feminism which emphasizes the capitalist and patriarchal structuring of society; the interconnectedness of gendered divisions of labour (production/reproduction, paid/non-paid work); the division between work and family; and the public patriarchy of a paternalistic state, a broad-based interpretation of the inequalities which persist in devaluing the contributions of women throughout our society is analyzed.

Standpoint feminism is adopted to situate and bring attention to the neglect of women's perspectives and experiences in the production of knowledge as a source of gender inequality. The remedies offered from this theoretical perspective is the making of women central to research agendas, as researchers and as subjects. The contributions of standpoint feminism to my work begins with the reframing of research questions and priorities which place women's experiences at the forefront. It also contributes to the creation of a feminist paradigm for the production of 
knowledge. Social control theories and the closely aligned explications of transcarceration are central frameworks for analyzing my data. Before turning to an application of these theoretical positionings, a thorough detailing of the study methodology is in order. 


\section{CHAPTER 5: METHODOLOGY}

If you have come here to help me, you are wasting your time. If you have come here because your liberation is bound up with mine, then let us work together (Lilla Watson, cited in Faith and Pate, 2000: 147).

This chapter lays out the methodological groundwork for the research process. First, carrying on from the feminist epistemological tradition discussed in the last chapter, key operational and definitional issues surrounding the notion of 'success' are explored. Next, both the quantitative and qualitative methods used in this study are detailed. Issues related to the recruitment and selection of the sample population, gaining access to, and locating respondents, as well as interview procedures are then reviewed. Further discussions related to feminist methodologies and epistemologies are situated, along with discussions of a grounded methodology and its relation to how the research and subsequent data analyses are framed and analyzed. Finally, certain key limitations of this study's methodology are presented.

\section{Operationalizing 'Success'}

A cornerstone concept of corrections is predicated on the theory of risk management. Actuarial attempts to predict the likelihood of an individual re-offending have gained enormous currency in the Canadian corrections enterprise (Ross and Gendreau, 1980; Gendreau and Ross, 1987; Andrews, 1989; Bonta, et al., 1995; Gendreau et al., 1996; Blanchette, 1997; Andrews and Bonta, 1998; Motiuk and Blanchette, 1998). Underlying the 'logic' of risk management is the concept of 'cognitive behaviouralism'. This approach "assumes that a person's thinking or cognition affects his or her emotions and behaviour...[therefore] behaviour can be altered by changing one's thinking"' (Kendall, 2004: 54). As Kendall (2004: 56) elaborates, cognitive behaviouralism in the context of corrections: 
works on the assumption that offenders have faulty or deficient thinking which causes them to engage in immoral or criminal behaviour. Programmes, therefore, aim to 'remoralise' or 'ethically reconstruct' offenders by teaching them to think 'pro-socially'.

Rooted in the work of Canadian psychologists (Don Andrews and James Bonta) at the 'Ottawa School', risk prediction scales such as the Level of Service Inventory - Revised (LSI-R) have gained international success as "part of an escalating focus on managerialism, efficiency, and accountability in correctional systems and a movement away from concern with individual cases" (Shaw and Hannah-Moffat, 2004). Actuarial assessments satisfy a neo-liberal agenda concerned with individual responsibilities, as well as providing a heightened measure of accountability for correctional staff (Kendall, 2004).

Andrews and Bonta (1998) claim to have developed a 'psychology of criminal conduct' (PCC) characterized by cognitive deficiencies. With correctional cognitive behaviouralism at its rooting, this 'discovery' brought renewed promise to the fledgling rehabilitative ideal of the 1970s and "introduced a technique which allowed for offenders to be governed in ways commensurate with neo-liberalism" (Kendall, 2004: 79). Under the broad banner of 'cognitive skills', the 'psy' disciplines have reinvigorated the notion of individual responsibility for criminal conduct and provided neatly 'prepackaged modules' which can be delivered by prison staff to replace or reprogram an individual's faulty criminogenic thinking (Kendall, 2004).

Practically translated, cognitive behavioural therapies designed to 'fix' anti-social thinking and therefore divert individuals away from their criminal lifestyles are inextricably tied up in the correction's management tool of recidivism scales. At the outset of my research, it was fully recognized that the women (and by default men) who are the objects of these actuarial assessments are altogether excluded from the knowledge production which defines the parameters 
and outcomes of risk/need assessments and therefore the validity of recidivism prediction tools.

Researching 'from the margins', then, became the driving force behind this study. In every way, it is an attempt to research by, for, and with women. The margins, as best described by Kirby and McKenna (1989), refer to:

[T] he context in which those who suffer injustice, inequality and exploitation live their lives. People find themselves on the margins not only in terms of the inequality in the distribution of material resources, but also knowledge production is organized so that the views of a small group of people are presented as objective, as "The Truth." The majority of people are excluded from participating as either producers or subjects of knowledge (Kirby and McKenna, 1989: 33).

So it is that my research seeks to depart from, or at least question critically, some of the well-entrenched and taken as 'truth' knowledge claims about women and their encounters with the criminal justice system. One such sweeping and subjective claim is that of risk prediction validity. The most frequently used indicator of individual successes and, by default the overall performance of corrections ideologies and material practices, is the use of recidivism rates. As Bonta et al., (2003) claim:

Knowledge of the recidivism rate of released inmates is important because it is one of many indicators of success of a prison system's attempt to reintegrate offenders safely back into the community (Bonta, Rugge, and Dauvergne, 2003: 1)

The recidivism rate for imprisoned women is approximately 20 per cent, only half of which represents the commission of new crimes while the remainder is related to technical violations (administrative breaches or conditions of community release) (Bonta et al., 2003). Most women who are imprisoned are not high risk and do not pose a threat to public safety. However, they present a high degree of need. For example, a majority of criminalized women have been victims of physical and sexual abuse and many are emotionally and financially dependent on abusive male partners (Adelberg and Currie, 1993). The issue of risk-need 
classification has become a major focus of discussion amongst policymakers and academics alike (Feely and Simon, 1992; Hannah-Moffat, 1999; O'Malley, 2000; Chan and Rigakos, 2002; Hannah-Moffat and Shaw, 2003). Suffice it to say, however, that the hybridization of women's needs as risk markers has led to the over-classification of women. The provision of services required to assist women in dealing with their needs continues to present a challenge to androcentric risk-management schemes which are wholly deficient in responding to the needs of criminalized women.

Recidivism scales as a tool for accurately measuring program outcomes is quite problematic and there is no single measure of recidivism that does not carry with it certain disadvantages. The various measures that have been used all have serious shortcomings in terms of what they are purporting to measure and what they actually measure. Most outcome measures rely on re-arrest or re-incarceration data, both of which are problematic in that they count someone as having committed another crime when in fact they have not. An overwhelming majority of parole revocations result from technical violations of the conditions of one's release. In 2001-02, for example, 75 percent of women's parole revocations were for technical violations (Auditor General, 2003). Therefore, failing to report monthly to a parole officer or violation of a curfew would be counted in the same category as someone who commits a break and entry. Furthermore, recidivism rates do not distinguish between the types of crime which cause one to be returned to custody. Breach of probation falls into the same category as armed robbery in terms of counting success or failure.

Another problem with recidivism rates is the cut-off period used to determine success. Most recidivism calculations use two years from the date of release as the typical cut-off mark. 
Therefore, if an individual makes it past two years without a return to custody they show up in official statistics as a success or non-recidivist. This arbitrary time period is problematic for obvious reasons, most notably its subjectivity. Before designing a research project which focuses on criminalized women and their strategies for staying out of prison, it was necessary to first grapple with a conceptual understanding, and definition of, how success is defined. It was recognized at the outset that perceptions of success are highly subjective and vary widely depending on who is doing the defining. It was naturally expected then that women would have quite a different definition of success than those of state correction's officials. For instance, for a woman involved in the criminal justice system throughout most of her adult life, success could refer to staying out of custody for a much shorter time than the officially sanctioned recidivism rates would permit. It was critical, therefore, that women be given every opportunity to locate and name their own success and/or failure in the criminal justice system. As Kirby and McKenna (1989: 33) state:

Focussing on the world from the perspective of the margins allows us to see the world differently and, in many ways, more authentically.

This 'official versus marginal knowledge' conundrum became quite evident during the pre-testing of the Research Instrument. The 'corrections' knowledge legitimation processes and outcomes are unilaterally imposed on women who have no input or consensus on the factors which are used to predict recidivism. One woman interviewed, for example, clearly defined herself in successful terms based on the fact that she had remained out of the system for one month. Given her extremely high level of institutionalization, she proudly proclaimed her accomplishment during her most recent community release by setting herself up in an apartment, reconnecting with family members, and operating with some degree of autonomy in the 
community. Her reasons for going back inside had nothing to do with these official risk characteristics (dynamic and legal factors ${ }^{44}$ ). Rather, she felt that prison had become her home and life on the outside was 'too scary'. This is quite different from the 'success' indicators of recidivism proffered by criminal justice personnel.

For the purposes of my research then, the official definition of 'success' was only operationalized during the sample selection stage of my research. That is, the selection of a group of women who had not been re-convicted following a two-year period with a comparative group who had gone back into custody during this same period. At the outset, the strict adaptation of the term 'recidivism' was employed in keeping with official definitions by Correctional Service of Canada and provincial justice departments. Because correctional data-keeping, at both the provincial and federal levels, adhere to the 'two-year' mark as the official barometer of measuring recidivism, I opted at the data selection stage of my research to subscribe to this definition so as to ensure a degree of uniformity. I wanted to ensure that all women in both groups of 'repeatedly criminalized' shared similar experiences in terms of the frequency of their encounters with the criminal justice system. That is to say, I selected only those women who had repeatedly been transitioning back and forth to prison throughout a significant portion of their adult lives. ${ }^{45}$ Once the total sample was drawn and then matched I departed from any reliance on official measures to

${ }^{44}$ In the determination of an offender's risk level, Correctional Service Canada relies upon the integration of both legal and dynamic factors. Legal factors, for example, include one's length of sentence, severity of the offense and any history of violence. Dynamic factors include the one's willingness to comply, attitude, criminal associations and any evidence of substance abuse. Demographic factors such as age, education, and employment are also factored into determining risk levels.

${ }^{45}$ In sampling, I avoided selection of any woman who would have been involved with the criminal justice system at one isolated point in her life. 
characterize success.

Notwithstanding the problematic of defining recidivism, my research attempted to deal with this issue by adhering to a feminist methodology which allowed the women to define their own 'success'. Again, the imposition of any one particular definition was confined to the sample and selection stages only of my research. After that, it was left entirely up to the women themselves to characterize their own successes and/or failures. The balance of the research process then is centered around 'researching from the margins' where the concern is "how research skills can enable people to create knowledge that will describe, explain and help change the world in which [women] live (Kirby and McKenna, 1989: 33). As Stanley and Wise (1983) poignantly ascertain:

We need to reclaim, name, and re-name our experience and thus our knowledge of this social world we live in and daily help to construct, because only by doing so will it become truly ours, ours to use and do with as we will (Stanley and Wise, 1983: 205).

\section{Data Collection Methods}

This research relied on two primary sources of data. First, a SPSS database containing the socio-demographic history of all women sentenced in the province of Newfoundland \& Labrador during a 11-year period (1989-2000) was accessed $(n=359)$. Second, in-depth interviews with two groups of women comprised of official 'recidivists' $(n=11)$ and 'non-recidivists' $(n=11)$ were conducted between January 2003 and September 2003. The bulk of the interviews took place between January 2003 and April $2003(n=18)$. However, difficulty in locating a number of 'nonrecidivists' prolonged the interviewing process. Not surprisingly, it proved much more difficult to locate this sample of women given that they were no longer under correctional supervision and therefore were not as easily tracked. Also, a few women in this group $(n=2)$ declined my request 
for an interview citing their desire to 'leave the past behind and move on with their lives.' It is known, for example, in the case of one woman who has been out of the criminal justice system for over two decades that her adult children were not aware of her criminal history and she did not want to jeopardize that secrecy.

In retrospect, it was highly advantageous to have conducted the interviews over such a prolonged period as it allowed ample time for theoretical memoing and reflexivity. It allowed me to pull back from the data and gain some distance (Lofland and Lofland, 1984). Also, it is openly acknowledged that at many times the interview process proved to be emotionally exhausting and, in some cases, left me feeling puzzled and quite frustrated as to the direction of patterns which were emerging. It allowed sufficient time between interviews to step back and reflect on certain key themes which were followed up in subsequent interviews. Indeed, it was during these periods of absence from the interviews that key themes and patterns were identified.

Based on the work of Memorial University sociologists ${ }^{46}$, a database was constructed using SPSS (Version 11.0) which provided a socio-economic overview of the total provincially and federally sentenced female population for a 11-year period (1989-2000). It was discernable from this database that the number of sentenced women in the province during the period from 1989-2000 inclusively stood at $359^{47}$ (Rossiter, 2001). This database was compiled from a review of files of all criminalized women in the province. Selected social, economic, and health variables were constructed and placed within a SPSS data file for subsequent analysis. The eleven

${ }^{46}$ Access to this database was made available by the principal investigator, Dr. Larry Felt, Memorial University of Newfoundland, Department of Sociology.

${ }^{47}$ This number includes all women who received a court-imposed sentence (federal or provincial prison term, probation or conditional sentence). 
constructed variables include: AGE, EDUCATION, OCCUPATION, OFFENCE, SENTENCE

LENGTH, REPORTED PSYCHIATRIC PROBLEMS, PREVIOUS INCARCERATION, MARITAL STATUS, TYPE OF ADMISSION, ETHNICITY, and REPORTED

\section{ALCOHOL/DRUG PROBLEMS.}

This database was instrumental in locating a sample population of women who have been consistently returned to custody following sustained periods of incarceration and community release. It was determined that the total number of women deemed to be 'repeatedly criminalized' stood at 24 , based on a major defining criterion which included only those women who had more than four prison admissions during this eleven-year period. ${ }^{48}$ In fact, most of this number had significantly more than four prison admission with several women reaching as high as 12 readmissions. From this total number $(n=24), 11$ women were tracked for study participation ${ }^{49}$. Of the total identified sample of repeatedly criminalized women: two refused participation; one woman was unavailable for interview as she now permanently resides in a psychiatric facility; three women could not be located in the province; and seven women had moved outside the province of Newfoundland \& Labrador. Given the limited budget of this study, I was not in a

${ }^{48}$ The major criterion for my sample was 'four or more prison admissions over a 11-year period'. Because the majority of imprisoned women are serving a first-time sentence, I did not want to capture that group of women who may have had a one-time, isolated run-in with the criminal justice system and 'naturally' migrated away from the prison system. My target group was those women for whom prison played a significant role throughout their adult lives. This selection of four prior admissions yielded a sample size of 24 .

${ }^{49}$ It proved much less difficult to locate and secure study participation from this group given the fact that many of them were incarcerated during the time of the interview $(n=4)$ or were still under the supervision of correctional authorities $(n=7)$. It was made clear, however, that study participation was completely voluntary and that the researcher was not offering any incentives (other than monetary) that would assist them in any way with institutional conduct reports or early release. Understandably, most members of this group were a 'captive sample'. 
position to travel to other Canadian centres to conduct interviews. It is certainly recognized though that the experiences of those criminalized women who move away from this province in search of employment opportunities would enrich the study results. ${ }^{50}$

Based on the number of repeatedly criminalized women identified above and agreeing to take part in this study ( $\mathrm{n}=11)$, a further sample of repeatedly criminalized women who had not managed to stay out of prison following a two-year community stint were matched $(n=11)$ based on nine of the above-noted social, economic, and custodial variables contained within the SPSS database. The variables constructed to account for reported psychiatric problems and reported alcohol/drug problems were excluded for the purposes of sample generation for my study. ${ }^{51}$ Following the production of a comparative sample of women who have stayed out with those who have been consistently returned to prison, I matched the identification numbers from the SPSS database to the woman's name ${ }^{52}$.

Semi-structured interviews were conducted with both groups of women $(n=22)$ over a 8month period. The total number of women selected for participation in this study is based on several important factors including: (1) the number of provincially sentenced women in this province is small to begin (roughly 30 women sentenced annually); (2) attempts to locate a

${ }^{50}$ This is a project that would best be conducted on a national scale, in conjunction with the Canadian Association of Elizabeth Fry Societies.

${ }^{51}$ These variables were excluded for two main reasons. First, these categories are considered highly subjective by the researcher as they are formulated based on the opinions of correctional and mental health staff. They are not self-reported by the women themselves. Second, these two categories proved to add little value in the selection of my two comparative groups.

${ }^{52}$ Following a written request for study support, the Director of Adult Corrections granted access to the names of potential respondents. 
sample of women who have successfully completed their period of conditional release (i.e., stayed out for a minimum of two years) reduces the numbers even further ${ }^{53}$; (3) some women did not wish to participate or could not be located.

The time period from 1990-2000 was selected for several important reasons. First, the year 2000 was selected as the cut-off period for access to women's prison files due to the fact that my research focuses, in large part, on those women who have stayed out of prison for a minimum two-year period. This allowed for the requisite time lapse needed to draw the comparative sample of 'non-recidivists'. Second, attempts tọ locate women who were imprisoned prior to 1990 would present important practical problems (i.e., many have moved out of province, changed addresses and name, memory recall problems). Third, access to a database compiled by Memorial sociologist, Dr. Larry Felt, covering this 11-year period was made available for the purposes of my research.

Following a written request outlining the intent of my proposed research on criminalized women in the province of Newfoundland and Labrador, a series of meetings were held with the Director, Adult Corrections and Community Services, Department of Justice during the Fall of 2002. ${ }^{54}$ These meetings outlined the goals and limitations of this study and were intended to elicit

${ }^{53}$ One of the major reasons for the dearth of literature on women who stay out of the criminal justice system after a period of incarceration is the difficulty of tracing women once they are out of prison. Often times, women deliberately make themselves hard to find. Some move substantial distances to start anew, away from old lifestyles (Davies and Cook, 1999: 276). Indeed, this is a major strength of my study in tracking down and soliciting participation from a relatively large sample of women, in comparison with their small numbers overall.

${ }^{54}$ Two face-to-face meetings were held with the Director to discuss the nature and scope of the project. During these meetings a number of relevant secondary materials were passed onto myself. As well, considerable dialogue about the current trends in women's incarceration (i.e., criminalization of mental health) took place. Several follow-up telephone conversations and email correspondence also took place during this period. 
support from the Department of Justice to provide access to relevant secondary documents related to the sentenced female population and recent correctional trends. Following these meetings, a Letter of Support ${ }^{55}$ (Appendix E) was provided along with the co-operation from the Department to assist in any way with the research project at hand. From here, contact was made with the Classification Officer at the $\mathrm{NLCCW}^{56}$ who was apprised of the study parameters and who agreed to assist the researcher by initially contacting potential respondents. At this point, I had the names of potential respondents only. I did not gain access to their criminal files ${ }^{57}$ which contained such

${ }^{55}$ It is interesting to note in this letter the emphasis placed on a willingness to seek reforms for criminalized women based on the "disproportionately high rate of Divisional resources" they consume, in relation to their small numbers.

${ }^{56}$ It was suggested during my meetings with the Director that the Classification Officer at the NLCCW was the most suitable person to assist with initial contact of potential respondents as several of the women were currently imprisoned at that institution. As well, case files including last known address and telephone number were available to her on site at the prison. A similar process then was followed wherein I provided this staff person with a detailed outline of my proposed research, along with a copy of the Letter of Information (see Appendix A) and the Informed Consent Form (see Appendix B).

It was made clear to the Classification Officer that this study was independent of the Department of Justice and participation by respondents was voluntary. Subsequently, the classification officer contacted and informed the imprisoned sample population about the nature of the research and provided potential respondents with the name and telephone number of the principal investigator, should they wish to participate in the study. This allowed the principal investigator access to only those women who had agreed to participate in the study and ensured corrections' officials were not privy to the names of those women who did wish to participate (See Appendix D, for further details on ethical concerns of anonymity and confidentiality).

${ }^{57}$ I did not request or gain access to women's prison files as it was felt that all necessary and relevant information needed for this study could be gleaned first-hand from the women themselves. It was also felt that any additional information from official prison files would be tainted in certain areas from the subjective views of correctional staff writing in these files. Overall, I wanted to document the voices of women first hand. However, the benefits of having first-hand access to prisoner files is recognized as a tool for substantiating and verifying certain key relevant information documented from the interviews with women. For example, in many cases it proved difficult, if not impossible, for women to chronicle their complete criminal histories due to memory problems and the sheer complexity of their criminal records. In 
information as their last known address and telephone number.

The task of locating potential respondents was fairly straightforward for the group of women who were still involved in the criminal justice system. That is, those women who were still under court sentencing were easily contacted either by their presence at the prison or in the community under the supervision of a parole or probation officer. However, the task of locating the sample of women who had officially ceased their involvement with the criminal justice system proved much more difficult to pinpoint and track down. Given that these women were no longer required to report to correctional authorities, the last known address on their files was often no longer current. In this case, assistance in locating several women from this group was sought from the Executive Director of the Stella Burry Corporation. This organization operates a community residential centre in St. John's with two parolee beds for women. A high number of women in both my samples had either been released directly to Emmanuel House after prison or had spent some time there in mandatory day treatment programs. Emmanuel House also operates a 'former resident' program wherein they provide ongoing counselling services to women who had previously resided there on conditional release from prison. Also, this organization services the needs of the mental health population in St. John's, many of whom in my sample are currently involved. The mandate and operation of this facility will be discussed further in the data analyses chapters as it is an important community-based organization through which many criminalized women continue to have involvement.

Prior to finalizing the Interview Guide, (See Appendix C: Research Instrument), a pre-test hindsight, accessing women's prison files for this select purpose would have been beneficial
overall to rounding out women's criminal, economic, and institutional histories. However, given
the remote location of the prison where all prison files are kept and the budgetary constraints of
this study, this exercise did not prove feasible. 
of the draft instrument was conducted with two women selected from each group. Given the dearth of literature exploring women's experiences of community release and therefore an absence of prior research which would potentially guide and identify important areas of focus to the study, it was important to pre-test the interview schedule and elicit feedback from women regarding their perspectives into issues they identified as relevant areas affecting either their perceived success or failure in staying out of prison. The exercise of pre-testing the instrument proved invaluable in targeting key areas which contributed to a much broader understanding of the total lives of criminalized women. For example, I had not originally conceived that women's earlier life experiences outside the criminal justice system would play such a prominent role in shaping their subsequent encounters with the law. The 'layering of social control' theme was formulated at the pre-test stage when women recalled how childhood physical and sexual abuses initially drew them into a sustained web of state interventions, most notably child protection services and foster care.

Pre-testing is critical in keeping with the tenets of feminist methodologies (e.g., voice, reflexivity, positionality) whereby women are given every opportunity to frame the central focus and direction of the research in all areas they identify as important. Following the initial pre-tests, the interview schedule was revised considerably to reflect the areas of importance and concern identified by the women. Finally, the Interview Guide was reviewed by my doctoral committee members who provided important feedback regarding content and length.

Interviews lasted from 45 minutes to 3 hours (average 90 minutes). I met with each woman individually before interviewing to introduce myself, explain the nature of the project, and generally develop a rapport (See Appendix A: Letter of Information). Most interviews took 
place at either the respondent's home $(n=12)$, the NLCCW $(n=4)$, Emmanuel House $(n=4)^{58}$, or at the psychiatric hospital $(n=2)^{59}$. All interviews were tape-recorded with the permission of respondents. It was felt that the use of a tape-recorder would better ensure the accuracy of documenting women's voices as it could be reviewed and reflected upon at a later time that allowed more distance by the researcher. It was also important that I pay close attention to what the women were saying and not be preoccupied with writing and jotting of notes during our conversations. Due to the intensity of many of these life stories and the need for probing questions, the use of a tape-recorder greatly enhanced the accuracy and depth of interview transcriptions. ${ }^{60}$ Finally, I offered a monetary incentive ${ }^{61}$ for women to accommodate their time

${ }^{58}$ In three cases, interviews took place at Emmanuel House where 'former residents' were employed on a casual basis for a variety of duties including cleaning and catering.

${ }^{59}$ One interview took place at the Waterford Psychiatric Hospital where a woman has been confined since her release from prison.

${ }^{60} \mathrm{It}$ is important to note that in several cases, major themes were identified by myself only upon reviewing (often as many as three times) and transcribing verbatim the tape recordings.

${ }^{61}$ It is quite interesting to note the mixed reactions I encountered in relation to paying the women for the interviews. For the most part, monetary payment was met with resistance. Many women felt they were 'prostituting' themselves by telling their stories in exchange for money. Others felt that just by telling their stories they were somehow 'paying back' to society for their crimes. Still others stated they wanted to help other women in similar situations and viewed me as a conduit to this goal. Overall, payment interfered with the intended egalitarian relationship between interviewer and participant which is espoused by 'research methods from the margins'.

However, the situation has to be put into the context wherein I was already familiar with a large number of these women $(n=8)$ who saw me as a friend/acquaintance (through my residence in St. John's as well as my involvement with Elizabeth Fry) and therefore as someone who was genuinely interested in their stories. The introduction of a monetary incentive was perceived as a shift toward a power imbalance. They also saw me as a student and felt uncomfortable about taking money from someone who was herself struggling. Several women refused to take the money and preferred instead to donate the interview proceeds to women in prison who were deemed to need it more than those women on the outside. 
spent during the interview process (based on a rate of $\$ 10$ per hour).

Issues of confidentiality and anonymity were stressed throughout the research.

Respondents were made aware that this research was being conducted independent of the provincial Department of Justice and Correctional Services Canada. I met with respondents before actual interviews took place to answer any questions or address any concerns they had about participating in this study. Respondents were also strongly encouraged to ask questions of myself, which many of them did. ${ }^{62}$

To ensure anonymity of respondents, women were assigned pseudonyms which were attached to their respective interview schedules. A log matching respondent's pseudonyms with their real names, contact numbers, and addresses was kept in a locked safety deposit box separate from interview tapes and transcripts, accessible only by myself. The names of participants were coded with a number and a list of codes were matched with names and secured in a locked box by the principal researcher separated from the interview data. Pseudonyms were then assigned to the participants and any revealing situations were altered to avoid identifying any individual experiences. Tape-recorded interviews were erased following transcription while written transcripts have been retained for an indefinite period to facilitate future research and analysis.

\section{Grounded Theory Methodology}

A grounded theory methodology is adopted as the major guiding tool for conducting this research. Grounded theory requires a concept-indicator model of analysis, which in turn employs

${ }^{62}$ Many women wanted to know about my academic program; the current status of E-Fry in the province; and personal queries (e.g., if I was married and/or had children; if I had ever been to prison or convicted of a criminal offence). 
the method of constant comparison (Glaser and Strauss, 1967). Empirical indicators from the data (in this case, actual words of respondents) are compared, searching for similarities and differences. From this process, underlying uniformities in the indicators are identified and coded and categories or concepts are produced. Concepts are then "compared with more empirical indicators and with each other to sharpen the definition of the concept and to define its properties" (Schwandt, 2001:110). Theories are then formulated based on the proposition of plausible relationships among concepts and sets of concepts (Schwandt, 2001:110).

This approach proposed by Glaser and Strauss (1967) has been elaborated on by Kirby and McKenna (1989) to "give priority to two essential components of research from the margins': intersubjectivity and critical reflection on social context. Intersubjectivity refers to "an authentic dialogue between all participants in the research process in which all are respected as equally knowing subjects" (Kirby and McKenna, 1989: 129). In keeping with the constant comparison approach espoused by Glaser and Strauss (1967), intersubjectivity requires that priority be given to the voices from the margins throughout the management and analysis of the data. Constant comparisons are made from existing documentation and theoretical approaches and linked with data findings.

Critical reflection on the social context requires an awareness and understanding of the context in which the research participants' experiences have occurred. As Kirby and McKenna (1989: 129-130) make clear:

It only makes sense that if we are to fully understand that data and effect change, we must try to understand contextual patterns and how they are sustained and controlled...Giving priority to intersubjectivity and critical reflection on the social context throughout the analysis ensures that we are able to hear and affirm the words and experiences of the research participants and at the same time be able to critically reflect on the structures that influence the actualities of their lives (emphasis added). 
The links between the structures which influence women's lives (e.g., the economy, the family, state controls) and the research findings themselves will be identified and analyzed within their specific social context in the data analysis chapters which follow.

Adopting a grounded methodological framework, six main stages in the research process were followed (Ferguson, 1997:30, cited in Dell, 2001) and include:

1. Collection of Research Data

(Semi-structured interviews with 22 women prisoners and ex-prisoners).

2. Coding the Data

3. Identification of Categories

4. Identification of Core Variables

5. Generation of Theoretical Memos

6. Generation of Substantive Theory

\section{Coding the Data}

A key process in theorizing from data is the categorization and sorting of information known as coding. Coding is a common aspect of all social research. Typically, codes for variable categories are established prior to data collection, and the data are interpreted within a particular theoretical frame of reference. In grounded theory development, on the other hand, the codes are developed from field observations. Thus, it is inappropriate to approach the field with preconceived notions or precoded protocols detailing how the world is to be understood. Instead, codes are generated as a part of making sense of the world (Singleton et al., 1988).

Coding is "a procedure that disaggregates the data, breaks it down into manageable segments, and identifies or names those segments...[C]oding requires constantly comparing and contrasting various successive segments of the data and subsequently categorizing them 
(Schwandt, 2001:26). In keeping with a grounded theory methodology, the process of coding begins with an inductive, context-sensitive scheme to make sense of the data. Here, "[a]nalysts work with the actual language of respondents to generate the codes or categories and...[w]ork back and forth between the data segments and the codes or categories to refine the meaning of categories as they proceed through the data (Schwandt, 2001: 26-27).

Strauss (1987) identifies three sequential stages of data coding: open coding, axial coding, and selective coding. The first stage involves locating themes and assigning codes to them. Codes are defined as "tags or labels for assigning units of meaning to the descriptive or inferential information compiled during a study" (Miles and Huberman, 1994: 56). The objective of the first stage of coding is simply "to identify, formulate, and analyze all ideas, themes, or issues they suggest" (Emerson et al., 1995: 143). Open coding is done by "scrutinizing the field note, interview, or other document very closely: line by line or even word by word. The aim is to produce concepts that seem to fit the data" (Strauss, 1987: 28). For my research, codes emerged from two primary sources: previous literature on women and corrections, more generally, and women being released from prison, more specifically. Second, codes predominantly emerged from respondent's verbatim interview transcripts, the context of these interviews, and interpretations of their experiences.

The second stage of coding, referred to as axial coding, involves organizing themes into groups that represent key concepts and conceptualizing about the various linkages between them. Axial coding is:

[T]he process of relating subcategories to a category. It is a complex process of inductive and deductive thinking involving several steps. These are accomplished, as with open coding, by making comparisons and asking questions. However, in axial coding the use of these procedures is more focused, and geared toward discovering and relating categories 
in terms of the paradigm model (Strauss and Corbin, 1990: 114).

Finally, selective coding is completed once the major categories have been established and "when all other subordinate categories and subcategories become systematically linked with the core (Strauss, 1987: 69).

The data was manually coded as opposed to reliance on a computer-assisted software package, such as NUD*IST, for several important reasons. First, there is often an implicit assumption that because computer-managed analysis is by definition more algorithmic, systematic, and rigorous, that it is therefore better. However, this claim has little support. For example, the developer of ETHNOGRAPH, one of the more popular programs, notes several pitfalls of qualitative software tools including: a) an infatuation with the volume of data one can deal with sacrificing resolution for scope; b) a reification of the relationship between researcher and data wherein the researcher assumes that data are 'things out there' that can in a relatively simple and straightforward manner be discovered, identified, collected, counted and sorted, thereby ignoring the fact that data are artifacts of complex processes of identifying, naming, indexing, and coding that, in turn, are shaped by theoretical and methodological assumptions; and c) a distancing of the researcher from the data (Schwandt, 2001:28).

Manual data coding was the preferred method for this study as it allowed a high degree of interaction and familiarity with the data. It did not restrict the creativity, objectivity, and reflexivity which facilitated the development of key concepts and themes which emerged throughout the research process. Manual coding also allowed for the practice of 'hurricane thinking' described by Kirby and McKenna (1989: 146-47) as one strategy for understanding the links between categories. It is a visual strategy for making sense of the emergent categories by 
using index cards moved around a core research question which is displayed in the centre of the page ('eye of the hurricane'). It allows the researcher to see patterns of relations which describe the data. ${ }^{63}$

\section{Identification of Core Categories}

The main categorizing strategy in qualitative research is coding, discussed above. The major goal of coding is to "fracture" the data (Strauss, 1987:29) and "rearrange it into categories that facilitate the comparison of data within and between these categories and aid in the development of theoretical concepts" (Maxwell, 1996: 78-79). A category is a "classification of concepts...discovered when concepts are compared one against another and appear to pertain to a similar phenomenon" (Strauss and Corbin, 1990: 61).

Strauss (1987: 36) outlines six specific criteria for determining the presence of core categories. These principles include: centrality (related to as many other categories and their properties as is possible); frequency (denoting a stable pattern); relatability (the core category relates easily to other categories); implications for a more general theory; the appreciable movement forward of theory; and maximum variation (core categories allow for building in maximum variation into the analysis).

According to these defining criteria, several core categories emerged at various stages of the data analysis. In the beginning, these categories were central to both groups of women in the

${ }^{63}$ It was originally conceived in my research proposal that I would employ the computer software NUD*IST for data analysis. However, this strategy was abandoned given many of the reasons cited above and due to the small number in my sample. However, I fully intend to compare my manually-generated output with those generated by a qualitative computer package. I am interested to contrast the results according to the respective methods, and therefore provide further insight into the knowledge production and legitimation processes. 
sample and related to experiences both before and during their prison sentence. Furthermore, development of core categories also emerged from the comparative findings of both groups of women thus forming a major area of analytical interpretation and theoretical speculation.

\section{Identification of Core Variables}

The identification of core variables is a continuous process throughout the data collection and analysis phases of the research and is a series of 'back and forth steps' (Glaser and Strauss, 1967). Core variables emerge from the three sequential stages of coding (open, axial and selective) and are constantly being re-organized and re-shaped to make theoretical sense of the data. Throughout the coding processes, core variables attaching to the broader categories dealing with women's experiences prior to prison, during imprisonment, and post-release emerged somewhat naturally. In other instances, the practice of theoretical memoing (Glaser, 1978), concept mapping (Maxwell, 1996), and hurricane thinking (Kirby and McKenna, 1989) were invoked to bring these core variables to light.

\section{Generation of Theoretical Memos}

An important tenet of the constant comparison approach in grounded theory is the use of theoretical memos. This analytical procedure (Glaser, 1978) is used for:

[E]plaining or elaborating the coded categories that a field-worker develops in analyzing data. Memos are conceptual in intent, vary in length, and are primarily written to oneself. The content of memos can include commentary on the meaning of a coded category, an explanation of a pattern developing among categories, or a description of some specific aspect of a setting or phenomenon. Memos capture the thoughts of the inquirer while he or she is engaged in the process of analysis. Typically, the field analysis and interpretation are based on integration and analysis of memos (Schwandt, 2001:156-157). 
Closely related to the concept of theoretical memoing discussed above, Kirby and McKenna

(1989:49) discuss the notion of 'conceptual baggage' and describe the process as follows:

[T] he record[ing] of the experience and reflections of the researcher that relate to the focus of the research...Since all research is done by someone, it is essential that "someone" is identified in some way and accounted for in the research...In all research, it is necessary to record both information sought and gathered (the content) and how the research is done (the process). In researching from the margins, conceptual baggage is a big part of that record. It consists primarily of jotting about the topic or the process and ongoing reflections throughout the research enterprise.

Throughout the data collection process, the practices of theoretical memoing and recording of conceptual baggage were adhered to. I kept a cryptic account of ideas, thoughts and, more often, frustrations I experienced related to the seeming lack of commonalities expressed by women in recounting their experiences of staying out. I realized early on in the research that I fully expected to find a clear pattern that, neatly packaged, would reveal a 'how-to' approach for staying out of prison. However, I quickly concluded this was not a straightforward and apparent theme. The strategies and life experiences were as unique as the women themselves and did not fit neatly into concise and monolithic categorical patterns. However, through the process of theoretical memoing and recording of conceptual baggage I was able to more fully articulate certain categories and integrate these findings within the context of the interviews. These reflections will be elaborated more fully at various junctures in the data analysis sections.

\section{Generation of Substantive Theory}

Substantive theory refers to theory "developed for a substantive, or empirical, area of sociological inquiry" (Glaser and Strauss, 1967: 32). This differs from formal theory which is "developed for a formal, or conceptual, area of sociological inquiry (Glaser and Strauss, 1967: 
32). Both types of theory are conceived as "middle-range". That is, they fall between the "minor working hypotheses" of everyday life and the all-inclusive "grand theories" (Glaser and Strauss, 1967: 33).

Substantive theory is developed from the categorized data and help to describe and explain the research focus. Glaser and Strauss (1967:3) maintain that theory must be able to assist in the production and explanation of behaviour; the theoretical advance of sociology; the provision of a perspective on behaviour (a stance on the data); the provision of and guide for a style of research on particular areas of behaviour and; the understanding of practical applications (cited in Kirby and McKenna, 1989: 138). As discussed in the preceding chapter, substantive theory for my research is generated through the integration of two major strands of feminist theory (socialist and standpoint) along with a gender-based analysis of social control theories and transcarceration to make theoretical sense of the research findings. Application of each of these theoretical influences takes place throughout the remainder of this work.

\section{Applied Feminist Methodologies}

Positionality, as earlier discussed, refers to the attempt by researchers to locate themselves within the context of their research and to share much of this standpoint with their readers. This was achieved throughout the data collection process by sharing much of my own personal background with the women and locating myself in the context of their research. Positionality helped identify my own personal biases and social position and how these related to the research findings. For example, I needed to question and look closely at the issues that I identified as important throughout the interviews, while women may have identified additional or completely 
different issues as more relevant.

Another goal of feminist researchers to garner a more complete understanding of women's experiences is achieved through the process of reflexivity. One example of invoking the practice of reflexivity was apparent early on in the data collection. It became very clear to me how taken up I was in listening to women's life histories and experiences (particularly the lack of family supports, histories of foster care, and histories of abuse) and how courageous and strong I considered these women to be. I marvelled at their 'survival strategies' and began to query women on how they managed to overcome or, more precisely, how they sustain themselves in the face of ongoing adversity and hardship. This line of questioning was propelled by my own mind set at the time, having just lost my father at a young age to prostate cancer in the months prior to conducting this research. For me, this major life event represented an unparalleled level of pain and anguish. I was very much struggling to keep the faith and enthusiasm I once took for granted and succumbed to a bout of depression which left me feeling very isolated and hopeless. Consequently, I was truly captivated by the strength and resiliency of these women who had endured such tremendous pain throughout their lives while still managing to cope and maintain a sense of themselves and the world around them. This theme, generated from my own personal reflections and positionality at that time, no doubt added another layer to the research which would not have been so readily apparent if I had not taken the time to reflect and position myself alongside these women. In turn, survival and resiliency became prominent themes in my research. Another major goal of feminist research is the attempt to extrapolate the voices of women on the margins. The goal is to shift the focus of standard practice from research concerned with men's agendas in order to bring in the locations and perspectives of all women. Throughout the 
research process, DeVault (1996) argues, it is imperative that we listen to the voices of our respondents and not selectively hear or document what fits neatly with our own subjective orientations. Failing to listen to the voices of our respondents runs the risk of recreating knowledge that suits our own personal, theoretical, or political agendas. The decision to taperecord the interviews was based largely on this imperative to accurately document the voices of women. It is interesting to note that many themes which were introduced throughout the interviews were only subsequently 'heard' by myself upon listening to the recordings and reading through the transcriptions. Often times there was quite a lot of information to absorb and, given the emotional nature of some testimonies, I found myself getting caught up in the moment and therefore often times missed processing some key valuable information.

In keeping with the presentation of women's voices at the forefront of this research, the data analyses sections (Chapters 6, 7,8,9, and 10) contain extensive use of direct quotations from respondents. I make no attempt to curtail what are often times quite lengthy verbatim quotes if it is felt that in doing so women's stories and experiences are captured in their truest form. Finally, I made every effort to represent the voices of the women and their unique perspectives by allowing them access to their own interviews and the opportunity to elaborate on issues that they defined as important. For example, follow-up contacts were made with several respondents $(n=6)$, either via telephone or in-person, to verify and elaborate on certain key points of discussion which were unclear or underdeveloped in the initial interview ${ }^{64}$. Further, throughout the dissertation,

${ }^{64}$ It is important to note that during the relatively brief time between the initial interview and subsequent attempt to contact women for further clarification and/or discussion of some issues (ranging anywhere from 3 to 9 months), many women had already moved from the place where the interviews took place (in many cases women interviewed in prison had already been released) or had relocated from their former place of residence. Further attempts to track this small sample of women were abandoned. However, it does speak to the problems inherent in 
respondents are quoted liberally to illustrate common themes and to ensure that their voices are adequately heard.

\section{Limitations of Study Methodology}

Two major limitations of this study methodology are readily apparent. While the findings generated provide a detailed description of criminalized women in Newfoundland and Labrador, it is acknowledged that results may vary if women who have relocated to other Canadian provinces were included in this sample. This conclusion is based primarily on two observations. First, economic opportunities in this province ${ }^{65}$ are considerably reduced compared to other Canadian provinces, where a large number of islanders relocate (i.e., Ontario and Alberta). As Table 5.1 shows, Newfoundland and Labrador has the lowest percentage of lone-parent families with earnings amongst all the Canadian provinces. Single mothers who relocate to other provinces in search of employment might fare better economically than those who remain.

doing feminist collaborative research with a group of women who are often times quite transient.

${ }^{65}$ Newfoundland and Labrador is a province with relatively fewer well-paid work force opportunities as compared to some other Canadian provinces. This economic relationship to women's criminal involvement has been briefly touched upon and will be the subject of more focussed attention in the data analysis chapters. 
Table 5.1: Proportion of Lone Parents ${ }^{66}$ with Earnings, Canada, Provinces and Territories $(1980,1990,2000)$

\begin{tabular}{|c|c|c|c|}
\hline & 1980 & 1990 & 2000 \\
\hline & \multicolumn{3}{|c|}{$\%$} \\
\hline Canada & 64.7 & 68.3 & 74.0 \\
\hline Newfoundland and Labrador & 47.7 & 58.9 & 53.1 \\
\hline Prince Edward Island & 64.3 & 73.6 & 86.5 \\
\hline Nova Scotia & 59.4 & 60.4 & 64.2 \\
\hline New Brunswick & 49.6 & 62.0 & 69.2 \\
\hline Quebec & 51.4 & 65.0 & 73.9 \\
\hline Ontario & 69.7 & 68.5 & 75.3 \\
\hline Manitoba & 72.8 & 67.1 & 72.4 \\
\hline Saskatchewan & 72.1 & 71.4 & 73.7 \\
\hline Alberta & 79.1 & 75.8 & 83.1 \\
\hline British Columbia & 72.6 & 74.1 & 71.1 \\
\hline Yukon & 81.4 & 82.8 & 89.6 \\
\hline Northwest Territories & 79.4 & 81.2 & 77.7 \\
\hline
\end{tabular}

Source: Poverty Lines. Canadian Council on Social Development. (2004).

Also, the whole notion of 'community', which is central to this study, would invariably differ according to geographic location (for example, urban versus rural areas). Several women in my sample remarked that given the relatively small size of the St. John's ${ }^{67}$ area, protecting

${ }^{66}$ Lone-parent families with at least one child under 18 years.

${ }^{67}$ The total population of Newfoundland and Labrador is 512,930 . The population of Labrador is 27,864 . St. John's, the capital city of Newfoundland and Labrador has a population of 99,182, while the census metropolitan area (CMA) has 172,918 (Newfoundland and Labrador 
anonymity proved quite difficult. Subsequently, an increase in the labelling process which goes along with living in a smaller community such as St. John's, would negatively impact one's attempt to 'start over'. This situation could be averted in a larger urban centre, such as Toronto, where anonymity could be protected and detection and surveillance by state and community agencies would be minimized.

A second major limitation of this study is that it does not include an adequate representation of Aboriginal women or other racially/ethnically marginalized groups. While it is known at a national level that Aboriginal women are disproportionately over-represented in the criminal justice system, especially in the Canadian Prairies, this study fails to elicit the voices of Aboriginal women and to document their stories of rebuilding after a period of incarceration. Cultural differences would certainly lend themselves to markedly different ways of adjusting to life following a period of incarceration. Also, in terms of the major findings from this study, patterns of institutionalization throughout the lives of many women who eventually become entangled in the criminal justice system would be even more pronounced for Aboriginal women given our Canadian history of colonization and residential schooling.

Similarly, in Atlantic Canada, black women are over-represented amongst criminalized populations. At present, black women account for approximately 15 percent of the total federally sentenced population at Nova Institution, the regional Atlantic prison for women. This is in stark contrast to the numbers of black women in the overall population of Atlantic Canada which is roughly 1 percent, the majority of whom reside in Halifax, Nova Scotia (Personal Communication, Warden, Nova Institution, September 2004). On a local level, we know from the Statistics Agency, 2004). 
data set of all women sentenced in this province $(n=359)$ over an 11 -year period that $8.2 \%$ of women are Aboriginal ${ }^{68}$ and reside in remote areas of Labrador. Given that the bulk of community services, albeit as limited as they are, take place in the city's capital centre, this places Labradorians ${ }^{69}$ at a disadvantage if they eventually desire to return to their home communities which lack the resources to effectively deal with women coming out of prison (and men for that matter). Also, the whole notion of 'community' and its cultural meanings for Aboriginal (especially those living on reserves) and other non-White populations, would invariably differ based on the cultural significances of kinship relations and governance practices.

Given the dearth of empirical research examining the lives of women post-prison in Canada as well as the complete lack of provincial data on criminalized women on conditional release, my exploratory study marks a significant contribution to opening the discussions on women's lives post-prison and raising a number of important methodological and theoretical questions. In terms of the generalizability of my research findings, despite the economic and cultural differences which have already been highlighted, the major research findings examined throughout this study are typical of nationwide trends for criminalized women (increased criminalization of mental health, increasing criminalization of racial minorities and immigrant women; feminization of poverty; over-classification of women prisoners, etc.) it is suggested that while important differences would no doubt exist in terms of defining one's community in a

${ }^{68}$ The ethnic breakdown of the total sample is as follows: Inuit $(7 \%)$; Innu $(0.9 \%)$; Metis (0.3\%); African American (0.3\%); European descendants (89.6\%); Other (2\%).

${ }^{69}$ Labrador is home to three peoples of Aboriginal ancestry: the Inuit, the Innu, and the Metis. Newfoundland is home to the Micmac peoples of Conne River, a status Indian Reserve on the province's west coast. 
larger urban centre or remote rural areas, the central thesis remains the same. Women continue to be marginalized in all spheres of public and private life. Their economic marginalization into low-paying, part-time and casual labour, their role as primary caregivers for their children and the lack of a federal day care program are national socio-economic problems that are not unique to the study province. These factors are taken up and explicated in the next chapter.

\section{Summary}

This chapter provided an overview of data collection methods, sample selection and recruitment, and interview techniques. The major purpose of this section is to detail how respondents were recruited for inclusion in the study and the criterion used to match two comparative samples according to previous convictions and community release. A step-by-step examination of the grounded theory process was detailed including the processes of data coding, identification of categories and subcategories, and the generation of theoretical memos and substantive theory. As well, feminist methodologies which are brought to bear in achieving the broader goals of objectivity, and 'research for women' were discussed. Key operational and definitional issues were presented, most notably the context in which 'success' is employed throughout the research. Finally, methodological shortcomings and their important implications for this study were detailed. 


\section{CHAPTER 6: \\ GETTING IN: PATHWAYS TO PRISON}

"I do what I have to do to survive. I am not all that criminal. I don't even think of myself as one anyways" (Rebecca)

The following issues are examined through data analyses spanning the next five chapters respectively: pathways to, and experiences of, imprisonment; transitions back into the community; how women perceive and define their own 'successes' post-prison; agents of social control in women's lives upon release; and internal/social resources women draw upon to stay out. To begin the criminalization trajectory, this chapter deals explicitly with women's pathways to prison. In this regard, it is important to look at some of the common themes that have been well documented in the literature on women in prison and which women in this study collectively identified as contributors to their criminalization. These major categories include: poverty trap, substance abuse, histories of physical and sexual abuse, histories of state control (foster care, child welfare, social services, mental health), and defiance of gender norms. First, a description of the socio-demographic characteristics of the total sample of women $(n=22)$ is presented along with a comparative analysis of the two groups.

\section{Socio-Demographic Overview of Respondents}

The socio-demographic profile of the total sample population is presented in Table 6.1. This gives the reader a general overview of the characteristics common amongst both groups of 'repeatedly criminalized' women. Socio-demographic variables presented here include age, education, primary source of income, employment status prior to sentencing, marital status, and ethnicity. Each of these is explicated below. 
The average age for the total group is 36.68 years. The range is $23-50$ years. This is slightly higher than the national averages for federally sentenced women who tend to be younger than 35 years of age. However, the average age of the adult federally sentenced women population has increased over the years from 1981 to 1998 . The proportion of women over the age of 35 years increased from $31 \%$ in 1981 to $51 \%$ in 1998 (Dell et al, 2001). With specific reference to my sample population, the slightly higher age grouping may be explainable by the fact that both groups are comprised of women who have had lengthy histories of criminal convictions and therefore have been cycling in and out of prison for a number of years. That is to say, there were no first-time prisoners in my sample which would conceivably lower the overall age of the group. The education levels of respondents ranged from Grade 3 to high school completion with a mean of Grade 9 . Not surprisingly given the low levels of education, the majority relied on social assistance as their primary source of income (59\%). Previous work histories were sporadic and comprised typically of part-time, low paying, 'pink ghetto' jobs which consisted primarily of housekeeping, cashier, food services, and elder care.

The majority of the women were single $(72.27 \%)$. There was no distinctions made in this category between women who were single due to having never married, those who are widowed, and those divorced/separated. The category of 'single' was characterized as such by the women themselves and was primarily an economic determinant. That is, they defined themselves as 'single' based on the fact that they did not rely on a partner for financial support. Finally, the overwhelming majority of respondents were European descendants (95.4\%). 
Table 6.1: Socio-Demographic Profile of Total Sample

\begin{tabular}{|c|c|c|}
\hline Age & Percent & $\mathbf{N}$ \\
\hline $18-29$ & 18.1 & 4 \\
\hline $30-39$ & 40.9 & 9 \\
\hline $40-50$ & 40.9 & 9 \\
\hline Education & 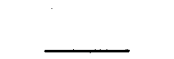 & $\ldots$ \\
\hline High School Completion & 36.3 & 8 \\
\hline Some High School (Grade 9-12) & 27.2 & 6 \\
\hline Less than Grade 9 & 36.3 & 8 \\
\hline Major Source of Income & {[} & 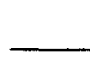 \\
\hline Paid Employment & 13.6 & 3 \\
\hline Social Assistance & 59 & 13 \\
\hline No Income & 22.72 & 5 \\
\hline Other & 4.5 & 1 \\
\hline Employment Status Prior to Sentencing & - & ב \\
\hline Employed & 0 & 0 \\
\hline Unemployed & 100 & 22 \\
\hline Marital Status & - & $\ldots$ \\
\hline Single & 77.27 & 17 \\
\hline Married/Common Law & 22.72 & 5 \\
\hline Ethnicity & $\ldots$ & $\underline{.}$ \\
\hline European descendants & 95.5 & 21 \\
\hline Aboriginal & 4.5 & 1 \\
\hline
\end{tabular}

When we begin to break down both groups using these same variables some important findings arise. The average age of recidivists and non-recidivists, 36.27 and 36.18 years respectively, was not significant. Education levels were slightly higher for the non-recidivist group (Grade 8.45 for recidivists; Grade 9.54 for non-recidivists). While the majority of women in both groups relied primarily on social assistance, the 'No Income' category was higher for the 
recidivist group. This is explained by the fact that a number of these women were incarcerated during the time of the interviews $(n=4)$. All women in both groups were unemployed at the time of the interviews. The majority of women in both groups were single ( 72.7 recidivists; 81.8 nonrecidivists). Finally, the overwhelming majority of respondents were European descendants (90.9 recidivists; 100 non-recidivists).

Table 6.2: Comparative Socio-Demographic Profile

\begin{tabular}{|c|c|c|c|c|}
\hline & \multicolumn{2}{|c|}{ Recidivists } & \multicolumn{2}{|c|}{ Non-Recidivists } \\
\hline & $\%$ & $\mathbf{N}$ & $\%$ & $\mathbf{N}$ \\
\hline \multicolumn{5}{|l|}{ Age } \\
\hline $18-29$ & 27.2 & 3 & 9.0 & 1 \\
\hline $30-39$ & 27.2 & 3 & 54.5 & 6 \\
\hline $40-50$ & 45.5 & 5 & 36.3 & 4 \\
\hline \multicolumn{5}{|l|}{ Education } \\
\hline High School Completion & 27.2 & 3 & 45.5 & 5 \\
\hline Some High School (Grade 9-12) & 27.2 & 3 & 27.2 & 3 \\
\hline Less than Grade 9 & 45.5 & 5 & 36.3 & 3 \\
\hline \multicolumn{5}{|l|}{ Major Source of Income } \\
\hline Paid Employment & 0 & 0 & 27.2 & 3 \\
\hline Social Assistance & 54.5 & 6 & 63.63 & 7 \\
\hline No Income & 36.3 & 4 & 9 & 1 \\
\hline Other & 9.0 & 1 & 0 & 0 \\
\hline \multicolumn{5}{|c|}{ Employment Status Prior to Sentencing } \\
\hline Employed & 0 & 0 & 0 & 0 \\
\hline Unemployed & 100 & 11 & 100 & 11 \\
\hline \multicolumn{5}{|l|}{ Marital Status } \\
\hline Single & 72.7 & 8 & 81.8 & 9 \\
\hline Married/Common Law & 27.2 & 3 & 18.18 & 2 \\
\hline \multicolumn{5}{|l|}{ Ethmicity } \\
\hline European descendants & 90.9 & 10 & 100 & 11 \\
\hline Aboriginal & 9.1 & 1 & 0 & 0 \\
\hline
\end{tabular}


Based on a comparative assessment of these six variables, there were very little differences reported between both groups. There was a slightly higher number of 'non-recidivist' women in the 30-39 age bracket and this group tended to have slightly higher level of education. Overall, however, socio-demographic differences tended to be insignificant. This is an important finding in and of itself. The fact that respondents in both groups tended to be mirrored on sociodemographic variables points to more significant differences taking place on other levels. These other levels (nature of criminal conviction and child care responsibilities) also need to be explored.

Table 6.3 demonstrates the comparative nature of women's criminal convictions. Not surprisingly, the majority of women were convicted on non-violent offences. Based on national statistics, women's crimes tend to be primarily concentrated at the property level. In terms of specific offences, the most frequent crimes are theft (27.2\%); violations of Provincial Liquor Acts (12.4\%); assault (11.5\%); and fraud (9.7\%). Some noteworthy differences emerged, however, in the two categories of women. The major difference was the higher percentage of women charged with theft, fraud and forgery in the recidivist category. Otherwise, there tended to be little major outstanding differences based on criminal offences between both groups. This is an interesting finding in and of itself as one might expect greater variation based on type of criminal conviction. Overall, property-offences were the major category represented among both groups of women. Despite moral panics invoked by the media, there has not been an increase in violent crimes committed by women. In fact, official crime data show a decrease in women's violent crime (Dell and Boe, 1998). Furthermore, when we contextualize women's rates of violence very often it takes place as an act of self-defence against an abusive male partner (DeKeseredy, 2000). 
Table 6.3: Comparative Nature of Criminal Convictions ${ }^{70}$

\begin{tabular}{|c|c|c|}
\hline & Recidivists & Non-recidivists \\
\hline & $n=11$ & $n=11$ \\
\hline
\end{tabular}

\begin{tabular}{|l|c|c|c|c|}
\hline Type of Offence & Percent & $\mathbf{N}$ & Percent & N \\
\hline Theft & 63.63 & 7 & 36.3 & 4 \\
Fraud & 63.63 & 7 & 45.5 & 5 \\
Assault & 36.3 & 4 & 36.3 & 4 \\
Assault with a Weapon & 27.2 & 3 & 36.3 & 4 \\
Break and Enter & 36.3 & 4 & 18.18 & 2 \\
Breach of Probation & 81.8 & 9 & 81.8 & 9 \\
Impaired Driving & 27.2 & 3 & 18.18 & 2 \\
Mischief & 27.2 & 3 & 27.2 & 3 \\
Uttering Threats & 45.5 & 5 & 27.2 & 3 \\
Sexual Assault & 9.0 & 1 & 0 & 0 \\
Forgery & 54.5 & 6 & 18.18 & 2 \\
Uttering Forged Documents & 36.3 & 4 & 18.18 & 2 \\
Fossession of Stolen Property & 27.2 & 3 & 18.18 & 2 \\
\hline
\end{tabular}

${ }^{70}$ Overall percentages exceed the sample size given that all women had more than one criminal charge on their most recent conviction and/or their combined criminal histories. Also, each separate Criminal Code conviction was counted only once for each woman. 
Table 6.4 displays the breakdown of women in the total sample with children. This is important for later discussions on the role of mothering and the associated socio-economic realities which are closely linked to women's criminal histories. It is interesting to note, though, that of the number of women who had been single mothers at some point in their lives (most often prior to their incarceration) a significant number had their children removed from their care and placed in foster arrangements $(n=6)$. This is important for later discussions of control exerted by child protection services in the lives of criminalized women.

\section{Table 6.4: Comparative Child Care Responsibilities}

\begin{tabular}{|c|c|c|}
\hline & Recidivists & Non-recidivists \\
\hline $\mathrm{n}=11$ & $\mathrm{n}=11$
\end{tabular}

\begin{tabular}{|c|c|c|c|c|}
\hline & Percent & $\mathbf{N}$ & Percent & $\overline{\mathbf{N}}$ \\
\hline With Children & 63.63 & 7 & 63.63 & 7 \\
\hline \multicolumn{5}{|l|}{ Number of Children } \\
\hline 1 & 9.0 & 1 & 27.2 & 3 \\
\hline 2 & 45.5 & 5 & 18.18 & 2 \\
\hline 3 & 0 & 0 & 9.0 & 1 \\
\hline 4 & 9.0 & 1 & 9.0 & 1 \\
\hline \multicolumn{5}{|l|}{ Age of Children ${ }^{71}$} \\
\hline $0-2$ & 9.0 & 1 & 0 & 0 \\
\hline $2-5$ & 9.0 & 1 & 9.0 & 1 \\
\hline $6-10$ & 9.0 & 1 & 18.18 & 2 \\
\hline $11-17$ & 54.5 & 6 & 45.5 & 5 \\
\hline $18+$ & 36.3 & 4 & 45.5 & 5 \\
\hline \multicolumn{5}{|l|}{ Single Mothers } \\
\hline & 18.18 & 2 & 27.2 & 3 \\
\hline
\end{tabular}

${ }^{71}$ The total number of children for all 14 mothers is 26 


\section{Pathways to Crime}

The first major category identified throughout the interview process was that of women's pathways to prison. This was most often the starting point in our discussions and was a theme which persistently ran throughout the interviews. Identical questions were asked of women in both groups in an attempt to identify similarities and differences in women's experiences prior to their entry into prison. Overall, women's pathways into criminal activity were remarkably similar. The major emergent core variables included in this category were: poverty, physical and sexual abuse, histories of state controls, and defiance of gender norms. An in-depth exploration of each of these core variables forms the nexus of the remaining chapter.

\section{Poverty Trap}

All too often, the common denominator amongst criminalized women is a chronic cycle of poverty and dependence on welfare (Faith, 1993; Adelberg and Currie, 1993; Boritch 1997; DeKeseredy, 2000). Moreover, education, sex, age, and geographic location are strongly correlated to poverty. In a recent study by Statistics Canada (2004), for example, those workers with high school education or less were approximately three times more likely to live below the poverty line than those with a university degree. Consistently, women are more likely to be employed in low-paying, part-time jobs relative to men. Age of workers is also strongly correlated to the incidence and prevalence of poverty in Canada, as elsewhere. Women aged 1624 experienced low-paying jobs almost twice as often as those aged 25-34. Compounded with these aforementioned demographics affecting poverty rates, workers in the Atlantic provinces had the highest incidence of low weekly earnings in Canada (Statistics Canada, 2004). Given that 
criminalized women are generally mirrored on all these demographic variables accounting for an increased concentration of poverty, it is not surprising that poverty plays such a major role in women's criminal pathways.

The criminalization of poverty has become an international trend for women. As articulated by Wacquant (2003), 'prisons of poverty' are due to:

the increased use of the penal system as an instrument for managing social insecurity and containing the social disorders created at the bottom of the class structure by neo-liberal policies of economic deregulation and social-welfare retrenchment.

While Canadians often hold the misguided perception that homelessness and poverty are nowhere near the levels of our southern neighbours, as DeKeseredy et al., (2003: 2) point out, the percentage of Canadians living in concentrated urban poverty parallels, and in many instances, exceeds that of our US counterparts. In fact, Canada now has one of the highest rates of family and child poverty in the developed world, with an increase of 33.8 percent amongst poor populations between 1990 and 1995 (DeKeseredy et al., 2003: 5).

Evidence of the criminalization of poverty are being felt in all advanced capitalist societies where those at the bottom of the class structure are penalized by draconian state policies targeting the poor. In Ontario, a lifetime ban on social assistance eligibility for anyone convicted of welfare fraud is just one example of neo-conservative strategies to penalize already disenfranchised populations, largely made up of single mothers and their families. The realities of poverty are most acutely felt by single mothers in their often failed attempts to eke out a living on their meagre and wholly inadequate welfare incomes.

The numbers of single-parent families headed by women in Newfoundland and Labrador 
has grown by 13 percent since 1991, now comprising roughly one-fifth of all families with children $(23,000)$. Undoubtedly, lone-parenting and its almost sure-fired equivalent of poverty was cited as a major factor to women's criminal pathways thus becoming a predominant theme throughout our interviews. Countless commentaries were made by women in describing these links. As Sarah remarks, social assistance benefits do not even come close to covering the basic costs of living:

[S]ocial services will not look after a single person. They give you dirt, shit money. You know it's not worth the paper it's wrote on for what you get... They'll pay you up to $\$ 433$ a month for rent. You have you to pay your own bills. Electricity bill right now if you got a small child that child has to bath every night and you have to shower yourself every night. Just a quick one before you go to bed or anything so that drives up your light bill. I have not seen an electric light bill under $\$ 200$. Never in the winter months. You wouldn't get a flop house for the money [they give you].

For many women like Sarah, their experiences of poverty were directly linked to attempts to provide for their children and the stressors associated with trying to manage the basic survival needs of a family.

You are way below the poverty line living on social services and a woman to go out and have to buy extra fruits and vegetables and things for a child to eat to keep a child healthy they cannot do that on the budget they are living on. You take it, like when [my son] was gone from me [into foster care] I was getting \$179 every two weeks. Now I was struggling with that. To buy your groceries and...[ $t$ ]hen you got a child going to school and they get in there and [you] can't afford to buy things. And then if someone comes around and things are stolen and says "Want to buy a pair of jeans for $\$ 20$ ?" and they fit my daughter, yes, I'll take them.

Affordable housing presents an ongoing burden for many women in the province. In a recent gender-based analysis of housing policy in Newfoundland and Labrador, the Status of Women Council (2003: I) points out that almost half of the tenant households in this province spent 30 percent or more of their gross income on shelter and thus were classified as 'core 
housing need' as defined by Canada Mortgage and Housing Corporation (CHMC). Low-rental housing is in scarce supply in many areas of the province. As this report notes, there are lengthy wait-lists for social housing; many rentals are in poor condition; there is a lack of short-term housing for abused women and their children; a lack of emergency shelters; and not enough accessible and supportive housing for people with disabilities and seniors.

Increasingly, single women and their young families are fast becoming part of the 'hidden homeless', staying temporarily with friends and relatives ('couch-surfing'), or in shelters (Status of Women Council, 2003: I). This burgeoning trend was clearly reflected in an interview with Nicole, who described the affordable housing crisis in St. John's.

Most one-bedrooms wants $\$ 400$ or $\$ 500$ a month. They want damage deposits on top of that. Then they wants you to pay your own utilities. It's going to be costly to set up. It's still $\$ 350$ or $\$ 400$ for a bedsitting room. $\$ 300$ is the lowest I have seen and they still want a damage deposit. I've seen them around a little cheaper but they are all taken so fast. You're just getting a single room for all that money.

As Rebecca succinctly puts it, when people have to choose between eating and paying rent, little choice remains.

I have gone out on days and just stolen enough stuff to put food in the house for the kids. And I don't care. I will be 90 years old and if I don't have food in my house I will go and get it one way or another. If my kids are hungry, I am going to go and get it. Plain and simple. Just enough so I can feed the kids. I do what I have to do. I am not all that criminal. I don't even think of myself as one anyways.

Persistent comments on the cycle of poverty and the lack of incentive to join the ranks of the working poor created by a substandard minimum wage were heard. Charmaine provides an economic rationale for her criminal involvement.

The only real way I can explain it is like I said when I started out shoplifting it was for survival. But now...[1]ike to go out and pay $\$ 90$ for a pair of jeans when I can get them for 
nothing. I'd go out for half an hour and I'd have myself three or four hundred dollars and people are out there working their ass off for two weeks for that. Which is pathetic?

The dependencies created by social services were not lost on these women. For many women, the availability of a drug plan through Social Services was an invaluable feature of the welfare program that they would not have if employed at a minimum wage job where the provincial rate, as of November 1, 2002 stands at $\$ 6.00$ per hour, the lowest in Canada. Victoria provides an example of this trap and her cycle of dependency on welfare benefits.

I am asthmatic. My inhalers is $\$ 100$ and something dollars a month. I get a drug card through social assistance. I wouldn't be able to make it [without that]. That's why I am hanging on to this welfare. I want to work. It makes me feel better. I don't want to be on welfare for the rest of my life.

The feminization of poverty is an ever increasing reality for women wage earners who now earn 65.2 percent of the incomes of their male counterparts (Statistics Canada, 2004). Women are more likely to be concentrated in low-wage service jobs with little job security and benefits and are over-represented in part-time, temporary work. Three-fourths of part-time workers in Canada are female (Statistics Canada, 2004). The bulk of these part-time jobs are lowpaying at the substandard minimum wage. Women in my sample, like Rebecca, were well aware of this economic trap and saw little incentive to join the ranks of the ever burgeoning working poor.

There is no incentive to work for minimum wage. Maybe it's alright for a single person, living at home but it ain't no good for a family. I'd be worse off than I am now if I went that route.

It is also critical to point out that Aboriginal women are even more disadvantaged in the labour market where the average total income for Aboriginal women was $\$ 13,305$ and $\$ 18,221$ 
for Aboriginal men. The non-Aboriginal equivalents were $\$ 19,348$ and $\$ 31,404$ respectively. (Canadian Association of Elizabeth Fry Societies, 2004). Overall, Aboriginal people and loneparent families were more likely than any other Canadians to be poor (Heisz and McLeod, 2004).

Housing is also an urgent need for Aboriginal people across Canada. In Labrador, most of the housing in Aboriginal communities is in desperate need of repair. Three to ten percent lack bathrooms and running water; up to one-fourth have unsuitable drinking water; houses are smaller than the Canadian average, more overcrowded, and often shared by several families. Fully one-half of Aboriginal households in Canada are in core housing need (Callaghan et al., 2002: 3345). It is therefore not surprising that an Inuit woman in my study was strongly opposed to returning to her home community in Labrador based on the rampant poverty and substandard living conditions, none of which, as she clearly pointed out, would lend itself in any way to her re-integration.

Poverty and the lack of affordable housing are considered major factors facing women upon their initial release from prison when the stakes are highest in an attempt to 'go straight'. Transitions from prison back into the community will be taken up in much greater detail in subsequent sections. Suffice it to say, though, poverty and core housing needs are themes which run the entire gamut of women's lives before and after incarceration. Sadly, for some women, prison is the only viable 'housing alternative'.

The psychological consequences of being poor were certainly not lost on these women. Many women, like Rachael, connected the emotional anguish of poverty to a decline in their physical and mental health.

I guess being poor and not having a lot leads to overall depression...[a]nd of course the 
depression leads to not having any money. So that's why so many people drinks and gets involved with drugs because you can afford it. Most drugs you can afford. Like a gram of weed that lasts hours and hours is only $\$ 20.00$. And you stay so high that you don't really know if you are in the world and you are so happy. That is why people does it because you are so depressed you would rather go into another world than face the fact that they are on welfare, got no job, and everything seems to be falling apart.

The cycle of poverty is retrenched for many of these women by state-sanctioned impediments to climbing out of poverty. We know that one of the strongest correlates to poverty is low levels of education. In 2003, for example, families headed by individuals who did not graduate high school were at least twice as likely to fall below the Low Income Cut-Offs as those headed by people who had either a university degree or college diploma (Canadian Council on Social Development, 2004).

The oft expressed desire to return to school and 'make something of themselves' was waged against the reality that in doing so women would be cut off from their only source of income, therefore making the goal of higher education virtually unattainable. Jessica discusses the short-sightedness of the provincial government's fiscal policies with regard to the welfare trap.

I had to quit school because Student Aid didn't come through. You are trapped there [on welfare] and you got no way out of it. You are stuck there and you are staying there. You are not getting anywhere else. If they sat back and said, o.k. fine, go to school and then maybe in a year or two they would be rid of me altogether. They don't look at it like that. There is no choice.

Unrealistic expectations were also placed as stumbling blocks for criminalized women already living in absolute poverty when it came to payment of fines. Many women drew parallels between their prior convictions and an inability to pay the court-imposed financial penalties. Similarly, many women who would otherwise have managed to stay out of prison by all other accounts, were awaiting upcoming criminal charges for fine default. Rebecca articulates the 'no- 
win position' in which she finds herself.

They got it set up now that I am just waiting for a call and then for someone to come and take me out of here and put me in jail for my fines. They give me a fine when I can't make ends meet here now. (Laughs). Then they slap a fine on me. Sure they are only asking for me to come back. They give you a fine so that in a couple of years they can come back and get you again.

Charmaine also flags the ridiculousness of levying a fine on those least able to pay.

I've got fines that have accumulated over the years. Now they are looking for their money. They give a shoplifter a fine knowing that they are constantly back and forth to court. Obviously I am out there making money because I don't have enough to live off. That is why I am out there. I don't have anything fancy around me. I don't even have a couch. I will make do without all of that but I will keep doing it...[I] don't want to go back to prison but I can't afford not to.

For those women expressing a will to seek paid employment, albeit at substandard and low-paying service jobs, the presence of a criminal record was cited as a major impediment to achieving this goal. Rebecca, in exploring her options, again points to this stumbling block:

There is no second chances here. You got a record no one will look at you. I can't even work at Tim Horton's or nothing because I am not bondable.

Poverty for many women also creates dependencies on male partners, most of whom are the family breadwinners. In a recent study connecting abused women and their experiences of the welfare system in Ontario, Mosher et al., (2004) clearly denounce the neo-conservative policies which drive women further under the control of their abusers by stating that:

[W]omen who flee abusive relationships and turn to welfare seeking refuge and support frequently find neither. Women's experiences of welfare are often profoundly negative... They encounter a system that is less than forthcoming about their entitlements, and about the multiple rules with which they must comply...They are often subjected to demeaning and humiliating treatment from workers within a system in which suspicion and the devaluation of recipients are structured into its very core. For many the experience of welfare is like another abusive relationship...Disturbingly, the decision to return to an 
abusive relationship is often the 'best' decision for a woman, in a social context of horrendously constrained conditions (Mosher et al., 2004: v).

Remaining in unhealthy and abusive relationships with an intimate male partner due to economic constraints was also echoed by several women in this study. Corrina describes her 'structured choice' in this regard:

You wonder why everybody is scamming welfare. I'll tell you why. They won't let you get ahead at all. They won't give anybody a break. They get you in the rut and they keep you there. I am stuck here now 15 years in an abusive relationship and I am sick of it. They try and keep you down...[I] don't know what I would do if he [partner] ever left me. I wouldn't be able to make it here alone without him. Otherwise, I'd be gone out of here for long ago.

Jamie recalls her attempt to flee an abusive relationship with two young children, the consequences of which landed her in prison.

I had two kids to raise and I stayed in an abusive marriage because I had two kids. I did it for them and I couldn't put up with it any longer when they got six years old. First time I got in trouble my husband went to court and filed a joint custody of one of them and wanted custody of the other one so I packed up the kids and took off.

For many young women, the departure from their parents' home at a young age results in an immediate entry into a heterosexual relationship whereby the expectation exists for the male partner to look after the woman's economic needs. This financial dependency on a male breadwinner is often not the desired route for women. However, it is sometimes the only viable (and non-criminal) means of economic security. Failing to take this route, many like Victoria find themselves living on the streets or turning to crime to support themselves.

I did stupid stuff because I did not want to go back [to my parent's] home. I went to [university] for a while. I wrote cheques to have a place to stay in B\&B's and hotels. I didn't want to go home because my family background was so dysfunctional and I didn't want to ask people for things. You don't do that right. You are supposed to make it on 
your own. You're not supposed to screw up. So I wrote cheques. That was my first offence. After the first time going inside I learned about how to get prescriptions and stuff and then I started writing prescriptions, fraud, whatever I could. Then I moved in with him and things went downhill from there.

Charmaine talks about her unwilling dependence on her partner for economic survival and the inherent stressors of living in such an unhealthy situation.

I wouldn't be able to live in this apartment if me and him split up because I definitely would not have enough to live off. I got to scam to get ahead. But I tell him to leave and then I am worse off. I would have only $\$ 600$ a month to live and that's not enough to pay my heat and lights. I am damn well not going into some bedsitter. No way. No. Then I would be out of my mind altogether.

Clearly, the lack of legitimate opportunities created by absolute poverty leaves women with few options to financially support themselves and their families. This recurrent theme structured many of the 'choices' women had to return to school to upgrade their education, to leave abusive relationships, and to secure safe and affordable housing.

\section{Physical and Sexual Abuse}

The high prevalence of criminalized women with past histories of physical and/or sexual abuse has been well-documented in the literature. The Task Force on Federally Sentenced Women (1990), for example, found that over two-thirds of women interviewed $(n=191)$ had been physically abused as children or adults; over half this number (53\%) had been sexually abused at some point in their lives. These figures are considerably higher amongst the population of Aboriginal women where $90 \%$ had been physically abused and $61 \%$ sexually abused (Heney and Kristiansen, 1998).

Comack (1996: 37) found similarly alarming results from a study of provincially 
sentenced women in a Manitoba jail where, overall, 78 percent of women interviewed reported a history of physical and/or sexual abuse during their lifetimes $(n=565)$. Again, the incidence of abuse among Aboriginal women, who comprise a disproportionate number of prisoners in Prairie prisons, was even higher ( 81 percent). Similarly high and disturbing patterns of abuse were evident in the experiences of women in my study. The links between trying to cope with abuses (past and present) and criminalization are clearly evident. Kathleen describes her situation of living in an abusive relationship.

I've got to start dealing with all the shit that is going on and deal with [childhood] sexual abuse issues. I'm 33-years old now and I can't take this anymore. I've got to get away from my common-law. I have left him before but he was in jail when I left him. He got a load of assault charges but he never gets any big time for it. A few months here and there in weekends and then I writes a cheque for $\$ 52.80$ and I gets eighteen months. Figure that one out. The highest sentence he ever, ever had was 13 months for assault. I don't know but it is just a homicide waiting to happen. I've got to get away from him [common-law partner]. When I get out things are alright for a little while. Then things start to get abusive again and I start using [drugs].

Valarie draws the connections between her past abuse and her present-day addiction to prescription medications.

I never dealt with my [sexual] abuse really. You forgive but you don't forget and you go on. I could not communicate. I keep it all bottled up and turn to the pills.

For some women, like Emily, their 'troubles' with the criminal justice system began later in their lives, often as they began their journey towards a realization that the sexual abuse they suffered was not a 'normal' way of life.

I never drank until I was thirty-one [years old]. I had been doing stuff growing up but I hadn't realized until 7 or 8 years ago that that was a way of coping with things that happened when I was growing up. I never knew that. We were always taught that wrong was right and there was no arguing. To be raped and molested and all that was normal. Anybody who wasn't raped or molested there had to be something wrong with them. 
For some women, once they began to deal with their past histories of abuse, their anger and hurt got redirected and they began lashing out at various authority agents who they deemed had failed to protect them as young children. Jennifer is one such example of this backlash against authority figures. As she describes, her entanglement with child protection services and the anger she felt at the prospect of having her own child taken away because she was labelled 'unfit' led her to directing her rage and hostility toward to the police.

I was told that my child was going to be taken away [by Child Welfare] as soon as it was born because of my history [in foster care and custody]... If you are not given the freedom to talk about things it just builds up and builds up in your mind and eventually you are going to blow. And for me unfortunately I always took it out on people in authority. They were the only ones it seemed that were [correct]. So I went in last time for assault of a police officer.

Another means of coping with the pain of abuse is to inflict harm upon oneself (Filmore et al., 2001). Self-injury is all too common amongst women prisoners. Heney (1990) found in her study of women prisoners that 59 percent had engaged in self-injurious behaviour (slashing, headbanging, starvation, burning and/or tattooing). Heney (1990: 4) maintains that "self-injurious behaviour is a coping strategy that manifests itself as a result of childhood abuse (usually sexual)". As Faith (1993: 242) makes clear, a lack of support systems and a sense of absolute powerlessness within a prison environment exacerbate the impulse to inflict pain upon oneself. The most fundamental dynamic underlying both child sexual abuse and incarceration is the structural distinction between the powerful and the powerless (Heney and Kristiansen, 1998: 32). Yvonne, who spent close to 30 years cycling in and out of prisons and psychiatric institutions, speaks to the self-injurious behaviour as a way of releasing the anger she felt from having been sexually abused while under the 'care' of the state. 
I used to slash up and not even feel it. I had so much anger in me from all the abuse. When I used to slash up it used to relieve the anger and not even feel it. People didn't understand that release.

Past abuse is often times the marker for early state intervention in women's lives. When women come forward to report their abuse, many times it results with intervention from child protection services and the start of a downward spiral of state-sponsored control in their lives. Jennifer chronicles this pattern as she talks about the cycle of foster care and mental health interventions in her young life as a result of her sexual victimization.

My first suicide attempt was at 11 years old. We lived in this big old two-story house and the boys were in one room and the girls were in another but because there was no room in the girl's room for me I was put in the boy's room with the boys. He [live-in relative] used to come in and do a lot of things and it wasn't until I made the suicide attempt he [abuser] was kicked out of the house. Then, of course, unfortunately child protection got involved... I ended up in the Janeway [Children's Hospital]. I don't remember how long I was there but I was going back and forth for counselling for years. And then when I was $14 \mathrm{I}$ was admitted to the Waterford Hospital ${ }^{72}$. To this day I am the youngest person ever admitted to the Waterford Hospital.

The emotional trauma of childhood sexual abuse left many women struggling to maintain any semblance of healthy adult relationships. As Olivia describes in the following passage, her relationships with men have been complicated by the lingering effects of her sexual abuse. To this day, she struggles with issues of sexuality and trust.

${ }^{72}$ The Waterford is the primary psychiatric hospital located in St. John's and "offers acute, rehabilitative and continuing care to those 16 and older with mental health problems and mental illnesses." This historic hospital located on Waterford Bridge Road in St. John's was first opened in 1854 as the Hospital for Mental and Nervous Diseases. It was renamed the Waterford Hospital in 1972. During the 1960's, the Waterford had more than 1,000 patients in residence. Today, the Waterford Hospital continues to function as the base of mental health operations and provides mostly acute care at the facility. Roughly 200 'clients' occupy beds at any time in the Hospital, as well as numerous outpatient and community-based services (Health Care Corporation, 2003). 
I married when I was 18 but it was kind of hard because it was kind of hard in a sexual way because he was trying to get my clothes off and going down around my crotch and stuff. Oh God. Thinking back then it was hard. I got in the bed with my clothes and all on and turned in. He was there like trying to turn me out and trying to get my clothes off. Oh, come on now. We just got married. But he didn't know [about my past sexual abuse] so I turned around and I told him so.

In the end, Olivia faced the additional trauma of discovering that her then husband was sexually abusing family members. The discovery of this abuse eventually led her to violence towards this man. She explains:

When I was married I found out after 7 years that my husband was a child sex offender. You know because at the time then the reason I was going to leave him was because it was two of my nieces that he was trying to get a hold to. Six months old and the other one was 9 years old. He was caught feeling them up and everything...So after I grabbed the gun and I went from there. I was going to shoot him and shoot myself...Then a few years after all that I ends up with another guy I was going with for four years and lo and behold he was up on charges from [Little Island] for sexually assaulting kids. I said every man I gets involved with is always a child molester. I said every man I goes with in the past, no I am finished with men. I'm telling you. It seems like every one I am after going with is a child molester. So I am after going through a lot.

Olivia goes on to talk openly about the pain she continues to suffer as a result of her horrific

experiences of sexual abuse and her inability to reconcile the constant torment.

To tell you the truth I have been going in so many different directions, wrong directions. I am reaching for the bottle. I am reaching for someone to put their arms around me and say yes by I understands exactly what you are going through. What I wouldn't give. There is nobody on this god-earthly world who can ever take the pain away. It's just myself. I am the one that got to go to sleep and I am the one who got to face it the next morning. And to tell you the truth there is no bottle and there is no medication that can help that. This is the first time that someone has come in and it is actually being recorded what I am saying right. You know. When I was younger I used to screech until my heart would drop right out of my soul. I wanted so badly for someone to hear what I was going through. That means a lot to me to have someone to hear me.

Olivia talks at some length about the longstanding emotional implications of sexual abuse on her overall social functioning and the interplay with state agencies. 
I am after losing a lot because of that [sexual abuse]. I couldn't concentrate on learning when I was going to school. My mother was after putting me in four or five different schools. I remember one day she brought me in to the children's hospital to get tests done on me like you know brain scan and they couldn't find anything. Every night I used to go to bed and pee in my clothes. I used to wake up screaming and balling that he [abuser] would be there. In my dream he would be there after me in the dark and everything. Now today here I am at 46 and you ask the guards. I will not go into that room by myself and I will not go to sleep with that light off. The light got to be on...To me, I am after turning a few times to the doctors in the hospital but they didn't understand exactly what I was going through. I lost my education. I lost my home because I ended up in hospital a few times. They turn around, back in them days, they say I was unfit to look after a child. [They said I] was in the Waterford quite a few times. So they used that against me and took my child away. So then I turned more to the bottle and more to the pills and everything.

A large number of criminalized women have longstanding alcohol and/or drug addictions (Pimlott and Sarri, 2002; Burke, 2002). Well over half of women in prison report substance abuse or addiction concerns (Morash and Schram, 2002). In my combined sample, the overwhelming majority cited alcohol or drug dependencies as a key factor involved in their criminal offending. Drug use is often used as a means of temporarily escaping the enduring realities of being poor. For many women, their realities were comprised of cyclical poverty, depression, and histories of abuse. Leanne characterizes her connection between drugs and crime.

Where I live [in public housing] there is a lot of people addicted to OxyContin ${ }^{73}$. My best

${ }^{73}$ A recent epidemic of OxyContin abuse in Newfoundland has resulted in the creation of a provincial task force to "identify the nature and extent of the problem related to OxyContin abuse and... [m]ake recommendations to limit unauthorized access and inappropriate use of OxyContin and other related narcotics" (Government of Newfoundland \& Labrador, Department of Health, December 15, 2003). OxyContin is a prescribed drug used in acute pain management of cancer patients. Because of its controlled-release property, OxyContin contains more oxycodone and needs to be taken less often than other oxycodone-containing drugs. This feature of the drug has led to a $400 \%$ increase in the quantity of OxyContin tablets prescribed in the province from 2000 to 2003 (OxyContin Task Force Report, 2004). 
friend is on them the past year. It is hard for me to stay off the drugs when I am living life like this. What have I got to look forward to?

Turning to drugs and alcohol was often a 'damage control technique' (Comack, 1996: 42)

to help women cope with the pains of past abuse. Olivia describes her attempts to medicate the

hurt she has endured and the lack of support received from 'help' agencies:

I did the wrong things. Facing the bottle. Facing pills. Taking four or five of this kind, this kind and that kind. And before you know it I am all loaded down with different kinds of pills. You figure that them two things, the bottle and the pills are you biggest friends. In the long run you are hurting yourself. And in the long run it don't make any sense because you say, "Is they worth it?" You know. These people who hurt you, are they worth hurting yourself for? But in the meantime you just don't care. You got to turn to something because some of these people on the outside don't understand exactly what you are going through. Right. And then you feel hurt and you feel hate and you feel pain and everything. And it's times you got things in your mind that shouldn't even be there, right.

Olivia goes on to make the point that no amount of deterrence tactics or punishment inside or outside the prison could take away the pain of her past abuse.

Even in here [prison] you figure that the pills are going to help you get through a day. To make you a little bit stronger. Now at first when you start doing it. Oh yes. It made me feel lots of energy to get up and go. You know. But the pills and the drugs they was the two things I turned to. Now some people turns to more things. People turns to cocaine, acid, and all kinds of drugs that would ease the pain. Just ease the pain a little bit. Just, you know, try and forget. Try and forget some things that happened in your past. Right. Just try and block it out. But next thing you know you end up doing something stupid and next thing you know you are in here. Like I said, I would be lying if I turned around and said to you there is no way in bloody hell that I will end up back in here, in this hell hole. They could turn around and they could put you in one of those fancy [restraint] chairs $^{74}$ they got in there and they could beat the soul right clean out of you. But that's not going to change anything.

For many women, their addictions were closely tied to the commission of criminal

${ }^{74}$ Recently, a "restraint chair" has been brought into the NLCCW as a means of confining women who 'act out'. Needless to say, the introduction of this controlling technique is a clear illustration of the barbaric and draconian measures in many provincial (and federal) prisons. 
activities in the first instance. In Canada, 69 percent of federally sentenced women indicate that drug and/or alcohol played a major role in their criminalization (Canadian Association of Elizabeth Fry Societies, 2004). That is, either crime was a means to obtaining drugs or drug money or it acted as a catalyst for crimes which were committed under the influence of narcotics. This pattern was borne out in my sample. Leanne describes her pattern of crime:

I have been drunk every time I've done anything [criminal]. The first time I was incarcerated was a week before my seventeenth birthday. I turned eighteen in Whitbourne $^{75}$ and I was eighteen when I came here (NLCCW). It's all for shoplifting and two break and enters. It's all a big cycle of drinking and drugs and shoplifting with me. Needing to get money for drugs since I was seventeen.

Long before patterns of criminalization are established, young girls many of whom have been victims of childhood abuses, encounter various other state control interventions stemming from dysfunctional family backgrounds. This 'layering of social control' is discussed next.

\section{Layering of State Controls}

One of the most striking commonalities for criminalized women, arising in large from the above discussions, is their often longstanding and layered experiences with state agents of social control prior to their period of incarceration. Most women who end up in penal custody have been under state supervision at an earlier age and usually for non-penal reasons (Carlen, 2002: 126). These formal agents of control predominantly included child protection services, mental health

${ }^{75}$ The Newfoundland and Labrador Youth Centre (NLYC) located in Whitbourne (78 kilometres outside St. John's), was operationalized in 1992. The NLYC has been deemed the primary secure custody facility for youth in the province. It is a 60-bed institution and accommodates young persons sentenced to secure custody, as well as those remanded for psychiatric assessment, trail, or sentencing (Government of Newfoundland and Labrador, Department of Justice, 2001). 
agencies, foster care, and social services.

Carlen (1988: 74) discusses the prominence of foster care in the lives of criminalized women. In a study of thirty-nine women prisoners, Carlen found that nearly two-thirds had been through the 'care/custody mangle'. She points out that a disproportionate number of young women go directly from foster care into prisons. This pathway to prison was clearly present among the women in my study who had not managed to stay out of prison for any considerable period of time. Yvonne talks about her path from foster care into custody.

Well where my criminal history comes in, it comes from my past abuse and I where I have been in foster care all of my life and where I have been, physically, sexually and mentally abused which led me into the criminal justice system. Getting involved with breaking the law. Because from my past abuse I had a lot of anger which causes violence which caused me to a lot of emotional issues which I had this negative attitude about life. I said to myself people don't care about me and I don't care about them. So anyway, from my past, all the abuse I have been through led me to a lot of anger. I was a very angry person. For a good fifteen years of my life I have been in and out of prison.

For some women, their abuse began once they entered into fostering arrangements.

Maggie tells of her horrific experiences of state 'care'.

I have been in foster homes since I was six months old. Every day I was beat and beat and beat. I was ignored. No communication. I would get beat around all the time. Then my foster father sexually abused me. I couldn't stand up for myself. I went through a hard time. There is a book out called Suffer Little Children ${ }^{76}$. I was in that home. I know first hand. If anyone across Canada ever read that book you would know exactly where I am coming from and what I have been through. I was in the same foster home.

Following a lengthy history of being bumped around from one foster home to another,

Yvonne talks about her attempts to escape the abuse and how this led to subsequent criminal

${ }^{76}$ This shocking autobiography of a foster child uncovers the abuses by the Roman Catholic church in the delivery of foster 'care' services, written by a former resident of Mount Cashel Orphanage in St. John's (O’Brien, 1991). 
activity.

At 16, I start running away. Then I got into a girl's home and that's where it all started. The violence actually started in there. For the next 15 years I was in and out, in and out, in and out [of prison]. I didn't care. The abuse numbs you. You can't think. What am I doing? You can't think. It takes a while to heal. It's a state of mind.

In the following passage, Christine describes the culmination of a number of social support systems which failed her throughout her life including education, mental health, foster care, child protection, and the criminal justice system.

At eleven years old I was taken out of my parent's home. I was put in foster care. The first time I was in a juvenile jail I was twelve years old. It started off when I was mentally ill one time when I was in a foster home and I went out to K-Mart. I stole some products. A fifty cent eye pencil I got caught with. I was supposed to write a letter of apology but I couldn't because I was dyslexic and they couldn't understand that so they shoved me juvenile. I couldn't explain to them why I couldn't write the letter because I write backwards and I didn't know how to do the apostrophes and they didn't understand.

Admissions to psychiatric institutions are all too often a precursor to women's criminal pathways. As Valarie points out, going to prison was for her the lesser of two evils when directly weighed against the prospect of spending the rest of her life in a psychiatric ward.

I went into the youth centre in Pleasantville ${ }^{77}$ for girls and boys when I was 13 . I was in a psychiatric unit when I was 11. I've mostly been in hospitals, institutionalized. I would go to court and they would put me in hospital on a normal ward. Whatever you call normal in there. So I got in trouble in BC [British Columbia] and they put me on a forensic unit. I was always in hospitals until 1996 or 1997 . That was the last assault with a weapon. They wanted to do a report with the psychiatrist and I wouldn't do it because I knew what would happen. I would spend the rest of my life in a forensic unit.

Child protection agents also played a significant role throughout the lives of many

${ }^{77}$ The 10-bed Pleasantville Youth Centre is the only other secure custody facility in the province, besides Whitbourne. It primarily serves the greater St. John's Census Metropolitan Area (CMA) and accommodates young persons temporarily detained by the police, short-term remands, or those awaiting psychiatric assessments. 
women. Either women were wards of the state during their own childhood or they had encounters with child welfare as mothers. In Maggie's case, child welfare intervened in her young life as she was removed from her family home, placed in foster care, and subsequently diagnosed with a psychiatric illness. Because of her 'mental instability' child welfare agents deemed her 'unfit' to look after her own child.

When I was $18 \mathrm{I}$ had my first child. They [child welfare] took my child away because I was in the Waterford a few times and they used it against me...[T]he welfare turned around and took him away on me. I tried to get him back but no, no. They used the same thing on me as before. I was an unfit mother. I shouldn't have him and blah, blah, blah. Two days before Christmas child welfare came to my door and said your son passed away. Then I tried to commit suicide.

While under the control of the state, any act of perceived defiance of authority can have very serious consequences and often results in disciplinary action. As Maggie describes below, her resistance as a young girl in open custody to those in positions of authority landed her further criminal charges and a persistent record of violence for which she was subsequently classified as maximum security in the adult prison system.

When they put me in open custody, I done some violent acts at the juvenile jail. They were trying to put me in a suicide watch cell to calm me down. And they were trying to rustle me to the cell and so $I$ hit them to get away from them. They charged me for when they were trying to rustle me to the cell and I touched them and they took my clothes off and put me under suicide watch. So they charged me with that and I got months added on. If I was in open custody I would say, 'I'm not fucking listening to you. You know, you're not my mother or you're not my father so go to hell." They would tell me to go to my room. I would say, "I'm not fucking listening to you. Go to hell or I'll fucking kill you." They thought I was serious but it was only a figure of speech. All my anger and my mental illness. I am not using my mental illness as an excuse but that's just the way my mind worked, my adrenaline.

Not surprisingly, there is nothing linear about women's varied experiences with confinement in state and community-run agencies and their past abuses, addictions, and mental 
illnesses. Maggie is quoted at some length as she describes her history of cycling in and out of formal control systems.

I was in a mental hospital for three months first ... [I] know nobody believes me. I was hearing voices saying burn that unit down and you will die. They will evacuate everyone else and you stay in your room and they will think that you are gone and you will die in the fire while they're gone. So they didn't believe me. They obviously extinguished the fire and they found me in the room after. That was my first crime as an adult...After that, about a year and a half later I was feeling sick again. I was in the midst of [an abusive relationship]. I got married to a really wrong man and I was after having a child. I was having problems with post-natal depression and psychotic depression. So I thought in my own eyes anyways. Then I married a man after I lost my child to adoption. I married a man who was physically and mentally abusive. And the other way too [sexually abusive]. And so we separated after he beat me. He was after beating me that day. So I went to the Waterford and asked them for admission and they wouldn't admit me. Mom was gone. My father wouldn't talk to me. The Waterford wouldn't admit me. [Halfway house] wouldn't talk to me because I had been away from the [criminal justice] system for years. And I had nowhere to go so you have to do what you have to do. So I went down to the phone by the Waterford hospital and I called them and told them I had a gun but really it was only a plastic toy thing I had in my hand. I was crying out for help. I little gun I had held on for years. A little plastic thing you get in a surprise package type of thing. And I told them I had a gun. I was trying to do it so they would shoot me to kill me. To give them a reason to shoot and kill me because I didn't want to live. I was basically trying to show the [system] that I was sick.

Countless other stories related to young girl's entanglement with foster care providers and

their subsequent criminalization were recorded. Leanne chronicles her 'custody-care' continuum:

I've been seeing a psychiatrist and a psychologist since I was 16 . That was all through my experience in foster care. I was in foster care when I was 15 and 16. My mother and I didn't get along. That was how I first started getting in trouble because I was always running away from home.

Rachael also recounts her sense of hopelessness and despair of having her daughter taken from her care because of her childhood involvement with state care.

My second crime [as an adult] when I went federal was because I lost my daughter [to Child Welfare] and I just had enough of it. They said I couldn't take care of her because of my past. I was dealing with a lot at the time. My family, my friends and overall my 
daughter being taken I just couldn't deal with it. I couldn't take it anymore. I lashed out. I purposely wanted to get caught.

The 'layering of social control' experienced by many of these women as children and young girls continues to be a major force in their lives not only through the criminalization process but also upon their release back into their communities. Attempts to 'go straight' are strongly influenced by the nature and extent of these control mechanisms and will be discussed again when the focus moves into women's re-integration attempts.

\section{Defiance of Gender Norms}

Gender norms are a powerful societal tool for ensuring conformity (Andersen, 2003). These informal processes of routine social interaction through which women are personally discredited or "put in their place" often result in 'labeling women deviant' (Schur, 1984). Women's deviance, then, is a social construct which results from a particular kind of definition and response. As Howard Becker (1963:9) argued:

[s]ocial groups create deviance by making the rules whose infraction constitutes deviance, and by applying these rules to particular people and labeling them as outsiders. From this point of view, deviance is not a quality of the act the person commits, but rather a consequence of the application by others of rules and sanctions to an "offender."

Becker (1963: 17) goes on to note that labels are applied unequally and are largely a matter of some persons or groups (in this case men) imposing their rules on others (women). Deviant designations get assigned by those who hold the political and economic power. Women who 'offend' specific gender system norms by behaving in ways deemed inappropriate for females receive the label of 'deviant'. 
Beauty norms are one such example of the antisocial control (Carlen, 2002) exerted over young girls and the associated pressures to conform to gender norms. Beauty norms govern the visual objectification of women and, as Schur (1984: 68) makes clear:

[p]hysical appearance is much more central to evaluations of women than it is to evaluations of men; this emphasis implicitly devalues women's other qualities and accomplishments; women's "looks" thereby become a commodity and a key determinant of "success" or "failure"; the beauty norms used in evaluating women are excessively narrow and quite unrealistic; cultural reinforcement of such norms conveys to the ordinary woman a sense of perpetual "deficiency."

Failing to satisfy the stringent requirements associated with physical appearances can lead to a dual designation of deviance. That is, violation of beauty norms, for example, results in a deviant label in and of itself. For some women, though, attempting to re-negotiate these boundaries leads to 'secondary deviance'. Women often seek out other ways to exert themselves in contestation of these informal norms and, in doing so, are 'doubly deviant'. Several examples of women in defiance of beauty norms were cited. In Corrina's case, her attempts to re-negotiate the boundaries associated with physical appearances led her to sexual "promiscuity" and a further violation of sexuality norms. She explains:

I never considered myself very pretty. Now I look at myself and if someone don't like me they don't have to look at me. But back then I was a teenager and I wanted to be like everybody else. Small and pretty. So what I could do to fit in I done. That was my humor. And doing whatever, bend over backwards, doing whatever anybody wanted me to do. That included being taken advantage of by all the guys [for sexual purposes].

Other women employed resistance strategies to the informal gender norms by turning to 'formally sanctioned deviance.' That is, in order to permeate the trappings of gender role expectations, they turned to illegal activities. Rachael, for example, who admittedly did not conform to proscribed beauty norms took steps to compensate for her 'deficiency' and sought 
alternative means of gaining acceptance. In her case, this translated into becoming a 'runner' for her peers which included the ongoing provision of stolen goods.

All my life I was told I was ugly. That I would never get anywhere. That I would never amount to anything. So I took it in my head that I would have to do things a bit different. Do what I had to do to get accepted. And that's just how it went.

Kathleen also describes her non-conformity to female appearance norms which were specific to a certain class and urban setting. She describes her situation moving from a small town to a metropolitan centre where she did not fit in. A turn to criminal activity was her way of gaining the acceptance of her peers, negotiated through the acquisition of same-style clothing and other outwardly material signs of female conformity.

It was wicked. It's like you are different. You move into a place where you didn't grow up. And then to come in and move into [public] housing right off the bat you're an outcast. So you are going to do whatever you can to fit in and I did. I done everything in my power. I fit in all right... That's when I started shoplifting. I would go down to the mall and steal what I needed...After that, I got kicked out of school. I got pregnant. I done everything...Yeah, I fit in. I made myself fit in. I was fitting in one way or another.

Another powerful tool for ensuring gender norm conformity is the notion of women as 'passive' and 'nurturing'. A 'masculine character structure' requires self-confidence, independence, boldness, responsibility, risk-taking, and aggression/violence (Messerschmidt, 1986: 40). Such characteristics are shunned for women and, transgressing these boundaries, results in a deviant designation. In my study, several women spoke about the consequences of violating this norm. For Katharine, her aggression and 'tomboyish' ways led to her being ostracized and outcast by her family.

I was basically on the other end of any abuse. I was the aggressive person. Men, I didn't bother with them. Boyfriends came and went at that point. I was one of the guys. I was out beating around. We had our fun and I was out beating around and I had a really bad temper. And growing up in [Mundy Pond] there was a lot of people to meet. I was just out 
having fun, just like the guys but because I wasn't a guy I drew a lot of attention. The wrong kind of attention.

Non-conformity to heterosexual relationships becomes another form of antisocial control

for women who fail to satisfy gender norms. Speaking to the objectification of women, MacKinnon (1982: 533) asserts that "sexuality is the linchpin of gender inequality." She further argues that:

[a] woman is a being who identifies and is identified as one whose sexuality exists for someone else, who is socially male. Women's sexuality is the capacity to arouse desire in that someone (MacKinnon, 1982: 533).

Homosexuality then becomes a major site of exclusion and isolation for many women who violate sexuality norms. In my study, lesbians told of having to 'compensate' in many ways for their denouncing homosexuality and therefore sought out other forms of social approval. Often times, this took the form of turning to drugs or alcohol to resist their sexuality-based exclusion from society.

Another of the pivotal regulators of women's conformity are maternity norms (Welch, 1997; Schur, 1984). Maternity norms govern what is often viewed as women's primary traditional role, that of mothering. Despite changing family patterns and society's claim of loosening the traditional family construct, women are still expected not only to bear children but also to do so within the approved context of conventional marriage. As Schur (1984: 83) points out:

[t]he very terms used for childbearing outside of marriage-"unwed" or "unmarried" motherhood, and also "illegitimacy" itself- indicate both the character of the normviolation and the strong social disapproval attaching to it.

This is uniquely a motherhood 'offence'. Jessica speaks directly to her resistance of maternity 
norms when she had her first child as a single teenage mother.

It all started when I got 17. It was like my life was over kind of thing [because I just had a child] and now I was supposed to go a certain way that I didn't want to go...I was expected to stay home and look after a youngster. So, I just didn't care.

April also talks about her rebellion to maternity norms and chronicles her 'breaking out' period.

I wasn't a hard kid growing up...I mean I was only young when I got pregnant and I more or less said, fuck, like my life is gone now anyways. So, just do what we can. I was young. I was free. Even though I had a child I didn't want to be tied down. So I just continued to live a teenage life and I got twisted.

\section{Summary}

Women's trajectories into prison are marked by often longstanding patterns of poverty, abuse, drug addictions, histories of formal social controls, and defiance of gender role norms. These factors converge in ways which are clearly non-linear. That is to say, often times these conditions overlap with one another to produce a lifestyle of (often unwanted) dependencies on the state. In turn, these dependencies become further entrenched in a criminal justice system which fosters a culture of dependency and does nothing to contribute to women's economic and social empowerment. It is the compounding effects of incarceration on the lives of women who have, for the most part, been excluded by society based on their class, gender, sexuality, and cultural differences which form the focus of the next chapter and take us along the path to deconstructing the notion of re-integration. 


\section{CHAPTER 7: \\ DOING TIME ON THE 'INSIDE'}

"It's the system that's crazy, not the women." (Maggie)

It is critical in a study on pathways out of prison to examine women's experiences in prison. Carceral experiences are inextricably tied to women's attempts to rebuild their lives upon release. The findings presented below were familiar to women in both groups in this study and included: two-tiered corrections system (provincial versus federal; women versus men); criminalization of mental illness; lack of programming for women; institutionalization; and associated pains of incarceration. Each of these broad-reaching categories is discussed below in relationship to the overall impact it has on women's lives post-release.

\section{Two-Tiered 'Corrections'}

As noted, the Canadian correctional system operates on two distinct levels. A majority of women in both sample groups had experienced 'doing time' in both provincial and federal institutions. A major theme which developed was the imbalance which existed between the two systems. Discussions of a two-tiered corrections' system featured prominently for women in connecting their successes or failures. A second theme surfaced around a dual corrections' system and the distinctions between 'treating' criminalized males and females. This 'equality versus difference' paradigm, making men the comparator group upon which correctional programs and services are based, was not lost on these women, despite the recent rhetoric of a 'woman-centered approach'. Both themes are discussed in turn.

In Canada, women sentenced to terms of imprisonment of two years or more serve their 
sentences in federal prisons, by virtue of s. 743.1 of the Criminal Code. Sentences under two years result in a provincial prison term. As mentioned earlier, in some instances, a woman may be permitted to serve a federal sentence in a provincial prison, under the Exchange of Services Agreement. There are a number of reasons why a woman would choose to remain in her home province, most notably to be closer to her family and children. Apart from geographic considerations, a most disturbing trend has been identified recently in the provincial justice system in Newfoundland and Labrador. Many women appearing in court are requesting federal sentences in an effort to avail of the wider range of programming and treatment services offered therein. This trend is startling against the backdrop of earlier discussions chronicling human rights' abuses in federal prisons in Canada, most notably the recent systemic review launched by the Canadian Association of Elizabeth Fry Societies (CAEFS) and other equality-seeking groups.

This trend was echoed throughout my interviews by women who noted the two-tiered correctional system in Canada. Jennifer describes her request to 'go federal'.

When I went to my last charge I asked the judge for over two years and he gave it to me. I felt in my own heart that the justice system in Newfoundland wasn't doing anything for me. Wasn't offering me the help I needed or the programs I need to get me back on my feet. In a way I was kind of saying to him, "Like what is the sense of putting me back in Clarenville and staying there a while and getting out and not handling it and then going back again." Like if I was getting counselling or programs or something like that then maybe I would be able to stay out. But there is none of that here in Newfoundland. Not for women anyways.

Corrina discusses the 'merits' of the federal system and relates an incident at the provincial prison which led to her request a transfer to the federal prison part way through her sentence so as to continue her studies at the local college.

If I went, if I was foolish enough to do something and the judge looked at me and gave me under two years I'd have to punch someone out in the courtroom to try and get over two 
years. I would never be able to go to Clarenville again. Never. Like I was going to school in Clarenville taking a carpentry course from CONA (College of the North Atlantic) and I was studying for a really, really big test one night and one of the girls she put the place up. It was a sin because she was on all kinds of medication. But the more she screamed the more they bugged her. So I was up all night. I went in to do the test and I forgot everything. I lost it right in the middle of the school room. I flipped out. Having anxiety attacks. They had to give me Ativan. After that I got transferred.

Rachael comments on the reality for many women prisoners who lack family supports on the outside and which effectively exclude any need they may have to remain in a prison based on its closer proximity to their places of origin.

When I went to court I was only getting I think 12 months and I asked for 24 months... Like I had no visitors. If I had done a provincial term I would not have had any money, no tobacco, none of my family was in support of coming for visitation so there was no reason for me to stay in town and that is why I wanted to go away.

Jennifer, who has been in and out of provincial/federal prisons and psychiatric hospitals for almost 20 years talks about recent regressive changes which have taken place at NLCCW which propelled her request for a federal term.

When I assaulted that police officer they told me I might get a year and I approached my family and I never done that before. I said I am going to ask to go two years or more. That's when my brother said you have to start talking about why you don't want to go back to Clarenville because you practically grew up there. I knew I wasn't going to get the help I needed in Clarenville. I spent more time in the chair, the restraint chair, than I did out with the other inmates. I beat up three guards there in one morning who were trying to restrain me.

Rebecca focuses on the benefits of getting 'fast-tracked' through the federal system which serves as an incentive for some women to request federal time.

Women are asking judges for federal time. Well that's what my sister did. Her lawyer asked for federal. It was the only way she could get programs. She could work and get money to support herself up there. And she was automatically fast-tracked. If you get a federal sentence and you stay in provincial prison you lose all your federal rights. You don't get fast-tracked and you lose a lot of other things. Stupid. 
For some women like Nicole, the availability of community support systems in place in

areas surrounding federal prisons was an attractive feature.

When I was on parole they [parole officers] didn't want to help me go to school. They couldn't even give me a bus pass or nothing. You are just there. I mean I asked them about programs and stuff but there was nothing [in the community]. Now when I was in Nova Scotia, Halifax, on parole for one month I did programs in Antigonish. Thirty-one day programs for addictions. I broke my glasses in jail and I told my parole officer about it and he picked them up right way and got them fixed. Down here they don't do any of that.

The opportunity to generate some income while incarcerated is a very real issue for prisoners, like Nicole, who often times do not have financial supports on the outside.

They [federal and provincial systems] are both completely different. If you are in federal prison your time is taken up. You are doing stuff. They pay you for it too right. You get your canteen every two weeks because you are working. If you are in provincial and you don't have family you don't get nothing right.

Jennifer also points to the fact that the cost of tobacco and other canteen-related products are cheaper in federal prisons, a disturbing yet real reason for federally sentenced women to forfeit their rights under the Exchange of Services Agreement.

One of the advantages of Springhill too is that they have a big canteen and they only charge about six bucks for a pouch of tobacco or whatever. Because there are so many prisoners up there and they are making their money anyways. I know that in Clarenville you can only get tobacco at the drugstores. They charge a fortune. Regular prices.

Programming availability, albeit limited, was often cited a major reason for wanting to 'go

federal'. Nicole highlights the range of programming she availed of while federally imprisoned.

I did a lot of anger management and Survivors of Sexual Abuse and Trauma in Truro. I went to school there, did upgrading. I did horticulture up there. I did some AA. There are a lot of things you can do up there. It is all provided for you. You didn't have to go anywhere. I did find them helpful, especially the SLE [Structured Living Environment] program up in Nova. You are living there and they give you [all kinds of help].

The situation at the NLCCW in terms of limited space and lack of mental health services 
was cited as major problems for women. Laura explains:

Were you ever there [in Clarenville]? Do you know how small it is? It takes your life away. That's what it does. I was taking pills. Trying to cope. You weren't allowed to do anything unless they said. It's just too hard. It's too small. I couldn't have stayed in Clarenville to serve my federal time. I would have cracked up with that little bit of space. So I made my choice to go federal.

A lack of mental health services was also cited as a catalyst for requesting federal time.

One day one of the girls, she was handicapped, and another girl said something to her about shaving her legs and I lost it! I flipped. I walked out into the office and said if I don't get transferred today I am going to kill someone. Everyone is here trying to do their time and the ones here with mental health problems gets fucking picked on. I said it's disgusting. I want out of here.

Conversely, many women talked about getting the much sought after help they needed to deal with their issues in a federal prison, which was otherwise unavailable to them through other non-penal agencies. Yvonne talks about first starting to deal with her abusive past while in a federal prison.

I did federal time. Two years plus a day. In Kingston. I got a lot of help up there too. That helped me benefit the most. Dealing with all my abuse and stuff started up there. That's where it started. Like I had a lot of behavioural problems through anger. I still carries that but I am getting a lot better. I am getting help that was not there at first. When I went federal time I finally started to get some help.

A two-tiered corrections system was also evidenced in relationship to the availability of services, programs, and physical space between for female and male prisoners. Rebecca comments at some length in describing these differences.

There's a lot of difference between men and women. For instance, if you are out in Clarenville and you are cursing on someone you are locked down. Down at $\mathrm{HMP}^{78}$ they

${ }^{78}$ Her Majesty's Penitentiary (HMP) is a provincial male facility located in St. John's. 
wouldn't do that. The Pen[itentiary] has more. You can get paid at HMP...The men [guards] out there is a fucking pain too. That should never, never, never be. They should never put a male guard in a women's prison. They can roam up and down those halls and you could be in the bathroom. The men have a lot more programs. There is not a thing in this town for women. Everything is for men. There is no focus on employment and education. You can't even get a TA [temporary absence] to do anything. There is nothing out there to do anything else. It's just somewhere to shove you. They got nothing out there just one big empty room. They took it all away from the women and gave it to the men and the women got the shaft. And the men had the nerve to complain because at the lockup we had a fucking TV. Wow. Try looking at what you got compared to what we got.

For Rebecca, the revolving door of the prison is exacerbated by the lack of supports in place for women to deal with many of the underlying issues which brought them into prison and which co-exist to keep them coming back.

Out there [NLCCW] it's just one big fucking empty space. You are in the woods almost. You are right off the road. There is nothing. At least men down at the pen, if there are outside AA meetings they could go to them. Anger management is outside the building and they go. They can at least go out and do a bit of work out around.

Clearly, there is a major shortage of gender-specific programming in women's prisons. Programs which are available (for example, peer support and substance abuse programs), albeit in dire limited supply, are available in federal prisons only.

\section{Criminalizing Mental Illness}

Lurigio (2001) examines the mental health service needs of individuals within the corrections system. In doing so, three major policy shifts contributing to the criminalization of mental health are identified. First, deinstitutionalization of mental health patients from psychiatric hospitals into community-based centres. This policy, however, was never properly implemented and failed to provide adequate or well-co-ordinated out-patient care. "In other words, the 
unsuccessful transition to community mental health care had the most tragic effects on patients least able to handle the basic tasks of daily life" (Lurigio, 2001: 447). Second, mental health law reforms have placed restrictions on the procedures and criteria for involuntary commitment. Therefore, only the 'most dangerous and profoundly mentally ill are hospitalized, resulting in greatly increased numbers of mentally ill persons in the community who may commit criminal acts and enter the criminal justice system (Lurigio, 2001: 448). Third, the compartmentalization of mental health and other treatment services has resulted in patients with 'dual diagnoses' being refused acceptance into one or both programs/centres.

Based on these same policy shifts, an alarming trend is occurring in women's corrections in Canada in recent decades. The number of women entering our prison system with mental health diagnoses is increasing at a disturbing rate (DisAbled Women's Network, 2003). Leanne comments:

I think there are a lot of women in jails who are depressed or got anxiety and didn't even know it. There is not enough talk about it with doctors or anyone to say what is on your mind. [The] psychiatrist, he is only in once a month. If you do get to see him it's for about 10 minutes and that's it.

The lack of appropriate treatment facilities and personnel to attend to the unique needs of mental health detainees was a major source of frustration for both the 'mental health women' themselves and other prisoners who felt that these women should either not be imprisoned in the first place, or should have special provisions for their stay. Sarah talks about the volatility of having mental health inmates mixed in with the general population.

There should be a separate place for mental health. They are saying they are fit to stand trial. I've seen it where they would smack someone right in the head with the broom. Walking around, big smiles on their face, don't talk very much but then pick up a TV and smash it against the floor and then go after people for no reason. Down in the dining room 
eating and there's cups flying and you're ducking and they are splitting their fucking heads open. And then they are putting them in segregation for months. And why? That person has got a mental problem. They don't know they are doing these things or why they are doing it. They are thinking probably you are trying to do something to hurt them. They should not be there. They [guards] have not got the training.

Sarah also talks about the inadequacy of confining women with severe mental health problems in a prison.

I seen a girl in there for the same length of time as me, six months, and out of six months she spent five and a half in her room and the rest of it crying and singing out and saying her prayers saying, "Please help me. God help me. These people, I don't know what they are doing to me." Then she starts crying and everyone has to get out of the dining room because this person is yelling out and screaming. Then there are people who are suicidal, blankets up over them. You can't let them out of your sight for a second. These kind of people should be in a [separate] place. They should have, like they got down to the men's prison, where all MHA's ${ }^{79}$ are in one section doing their time together, PC's [Protective Custody] are doing their time.

Jennifer highlights the differential treatment of psychiatric women in prison.

If I even got a little upset I was put in what they call the hole or segregation. And so I spent most of my time there isolated from everyone else. That's the way it has been the way for me $90 \%$ of my life. I try and do something that is going to make me better but something always gets in the way. But like I was only 11 when I had my first suicide attempt so I've been in the psychiatric system ever since. Either way it goes.

Corrina further discusses the 'treatment' of mental health prisoners and the deleterious impacts of incarceration to their psychological well-being.

I used to see a psychiatrist on a regular basis. When I transferred to Nova I was on fourteen different kinds of pills. Anti-depressants. All different kinds. I've heard it said that the highest rate of people taking medication in Nova comes from Newfoundland. There is more people with mental health in Clarenville than there is people just out doing normal crime. They haven't got the space. The guards are not equipped to handle it. What are they going to do? Strip them down, hog-tie them to a chair and male guards at that

\footnotetext{
${ }^{79}$ MHA is the acronym used for criminalized women detained under the provincial Mental Health Act.
} 
helping? It's gross. These people don't need it. There is an imbalance somewhere in the brain. Why do they have to put up with that? I've seen them put [name of mental health inmate] in that [restraint] chair for hours and hours tied down to that chair, in the hallway by her room door. They wonder why she is up screaming all night. They had her hog-tied to a chair for God's sake. Make no wonder she is the way she is.

Charmaine brings into focus the unique needs of this population of women, many of whom cycle back and forth from prisons to psychiatric hospitals and have never known life outside these institutions.

[It's the system] that is crazy, not the women. In Clarenville, you are all put together in one little room. You do everything in that room. Make no wonder there is always fights and people always flipping out. MHAs put in with the regular population. I am not saying they are any different but they have greater needs. They should not be there.

Valarie provides a chilling example of the abuses which take place inside institutions and the reality that prison sometimes represents a 'safer' place than mental hospital.

I never had no where to go [when I got out of prison]. I used to take overdoses just to get in the hospital. I sued the Health Care a few years ago too. I was sexually assaulted while I was in hospital. It was hard and very scary being paranoid and all that shit. I don't think I was ever dependent on prison [unclear]. I think the hospital had more control over me than the prison.

Again, disturbing parallels were drawn between treatment women received in mental health institutions and the prison system wherein placement in the latter was often the preferred choice. Yvonne compares the treatments she received in both institutions.

Honestly, I was treated better in Clarenville than I was treated in the Health Care system. They didn't lock me down. In the Waterford I was locked down for three months in a hole. Shit and piss on the floor and live in it. Shock treatments. No chance, needles. Slap your food down. Wouldn't let you use the washroom. They treated me good out there [prison] compared to the hospitals. I've got to be honest. In the Waterford I didn't eat for 40 days and 40 nights.

There was also a high degree of incongruency between the institution-based psychiatric diagnoses 
women received and their self-reports. Valarie explains:

I have been off medication now two years. I was told all my life that I was bipolar. [Doctor] even said that I am going to need my medication again. That I am going to fall. Two years now have passed and I am better than I ever was on medication. I haven't been at the Waterford for years. I hate to go in there. As soon as I walk in I get ill. I see [my psychiatrist] at his office.

Institutional responses all too often retreat to over-diagnosing and over-medicating women prisoners. Jennifer relates her experiences in this regard.

[Psychiatrist] still don't believe that I had a very serious drug problem. He said I was bipolar. I think it's starting to sink in now that I did have a drug problem. I remember at the Waterford and patients wouldn't take their pills. I would line up and take their pills for God's sake. Or they'd slip it under their tongue and give it to me. I didn't mind being out of it.

Valarie, who has been out of the prison system now for almost three years, talks about coping with her past abuses without the aid of prescription medications, which she was first introduced to via the psychiatric hospital and then through the prison system.

The only problem I had going off my medication is that now I had feelings. It was hard for us for a while [her partner] because I couldn't communicate right. Medication always blocks it out. That's what everybody believes. Everyone thinks if you take your medication all your problems are gone. Same as taking drugs. To numb out the pain. Same as slashing. It's gone for a few minutes and then it's back. I do believe that getting out of the system is a big part of it [recovery]. I was totally institutionalized.

Similarly, for some women like Leanne, their initial psychiatric diagnoses began at an early age through residence at various state custodial agencies.

I used to always get heart palpitations. Look at my hands. Sweaty, clammy. Nervousness. A lot of it is social anxiety. When I am around a lot of people I feels like a panic attack. It must be like, I am diagnosed with a depression but I don't feel depressed. When I was 17 they diagnosed me with that. When I was in Whitbourne, that's when they put me on drugs. Paxil. 
For others like Jamie, their cycle of depression began as a result of dealing with the pains of abuse.

It all started [depression] about 21 or 22. I got married because I was pregnant and it was the wrong thing to do. I just got sicker and sicker and sicker. I was into an abusive marriage that I didn't want to be into.

Several women spoke about resisting the administration of prescription medications offered to them by prison psychiatrists. Rebecca is one such example, as she explains her rationale for doing so.

They [prison psychiatrists] offered me pills. They said I was overly compulsive. Overly compulsive got nothing to do with it. They wanted to put me on meds. That would make more problems for me. Sure you are only getting rid of the problem for a little while. Medicate you and keep you quiet while you are inside.

For many women, their mental illness was self-reportedly situational. That is, there is a tendency to over-prescribe and over-medicate women within institutions. Jamie explains:

A lot of people get addictions once they get inside. There was a young girl out there and I am telling you we could not eat with the woman. The food was dribbling down her face. She couldn't keep her eyes open she was pilled up that much. I met her three years ago. She got a baby as bright as can be. All they done was medicate her to shut her up. Give her a few pills and you won't have to deal with her. That is their way of dealing with things. To up her medication because she is flipping out. Instead of finding out why. That girl came out and I am telling you she is just like a normal girl walking down the road. And I thought there was something seriously wrong with her when we were locked up.

Rebecca talks about depression and other mental health diagnoses brought about by the very conditions of imprisonment.

It's normal to be depressed when you're locked up. That's normal. So why give you depression pills? They tell me I should be on depression pills. I don't want it. I haven't got no chemical imbalance. I am depressed, yeah. Let me go back to school and I wouldn't be depressed. Put me in school and you would see a different person here. Completely different. Instead of saying is there something we can do to get you out of trouble they drug you up. 
For other women like Leanne, a diagnosis of mental illness was only made once they entered into the prison system.

[Recently] the doctor diagnosed me with an anxiety. I was having panic attacks. So he gave me anti-depressant, anxiety pills. I forget what they were called. I found that I did need that because since I started taking it I see a difference in myself. I was always kept to myself and felt like the walls were caving in and stuff. I think that was a big part of why I was drinking and taking drugs so I didn't have to feel that way anymore. Now that I am medicated for it and I am feeling better I got to continue taking that when I am out.

\section{Lack of Programming and Counselling}

Despite earlier discussions 'favouring' the wider availability of programming and psychiatric services at federal prisons, there was no shortage of commentary which was highly critical of the lack of appropriate, gender-based programming at both levels of the institution. Again, even though the quantity and quality of programming at federal prisons was seen as somewhat more of an 'enticement' for women seeking to avail of such support services, it was a 'lesser of two evils' rationale. Clearly, appropriate support services are lacking in both federal and provincial institutions. Sarah comments on this situation.

They haven't got anything for women [in prison]. Well, they've got an old nun that's out there [NLCCW] and she don't know the first thing about it. How would she know about anger management? Like if I were really, really pissed off, if I was angry and I said I am going to tear someone's head off. I am going to go out there and I am literally going to bang them to the wall and I am literally going to kill them on the floor or something. So they are probably going to take me and put me some place up there with the lifers. You are saying it out of the blue because you are mad.

Jennifer raises the issue of long waiting lists to avail of psychiatric services in prison and the lack of appropriate responses to deal with mental health prisoners.

In Clarenville if you get really agitated they take you to the hospital and get a shot and then bring you back and put you in the restraint chair until you fall asleep. In Springhill there is always a doctor there...The justice system is so different all across Canada. I was 
there for thirteen months at one point and I never so much as seen the psychiatrist. Half the time you would go 4 or 5 months without seeing any doctor.

For Charmaine who has been coming back and forth to prison for almost two decades for shoplifting charges, programming specific to her offences was lacking.

They don't have it [STOPLIFTERS ${ }^{80}$ ] here in St. John's and they should. For the women or the men too, there is a lot of men shoplifters but most of these men do have alcohol or drugs problems and I'm not condemning them and there is a lot of women out there with alcohol and drug problems who shoplift too that contribute to their habit. But there is a lot of women out there too who shoplift because it's an addiction. They probably started out for survival but it ended up as an addiction. Like me, all the times that I went to jail I got nothing out of it. I got no programs, I got nothing. Sit down and eat, smoke, drink Pepsi all day long. That's all we done.

Rebecca relates the need for more meaningful programs for women which will assist them

upon their release.

There needs to be programming here [for women] because there is none. They [women] need more counselling groups in here. Like group sessions. One on one groups and some way to continue those groups when you get out. And probably an employment counsellor who can look at your goals and work out a plan for when you get out. If you are not getting the help you need from alcohol and drugs you got no other choice but to go out and commit crimes to feed your habit. You got no other choice. You are going to end up back in here anyways.

\section{Institutionalizing Women}

For many criminalized women, patterns of institutionalization began long before their

initial entry into prison. Prison represents just one more journey in and out of state-sponsored institutions, including psychiatric hospitals and foster care. It is important to explore women's institutional experiences and dependencies because it is inextricably tied into their attempts to

${ }^{80}$ STOPLIFTERS is a shoplifting intervention program operated by several provincial Elizabeth Fry Societies across Canada. 
negotiate their independence upon release back into the community. It stands as an important marker between those women who 'make it' on their release and those who continue to be drawn back into one control system or another. Valarie, for example, has been in institutions for over thirty years and describes this vicious cycle of 'retrenched dependency' on state-imposed norms and regulations.

I have been institutionalized since I was 11 . That's all I have ever known. I've never known what it's like to be out living like a normal life. I was always hurting myself. I never ever hurt anyone in my life. I always cut myself up or overdosed. I even apologized to the judge that day. When I went to Clarenville I had to see a priest. I had to. I never ever hurt no one. It was the first time I ever hurt anyone and I was so drugged up.

For Jennifer, normal functioning and expressions of one's feelings, whether negative or positive, are met with punishment in an institutional setting.

I have been institutionalized for the past 25 years. I never even had the opportunity to say I was feeling a bit down and I was carted off in a cop car somewhere. Plus the school didn't help me very much. I ran away and things like that. I was gone for days just sitting in the country in the woods smoking cigarettes. I was only ten when I started smoking.

Sadly, for many women like Nicole, institutional life offers a degree of familiarity and comfort which they have never known on the outside.

After so long I kind of got used to the system and it seemed like it was starting to [feel like home]. Being out here [community] it is kind of hard. When you are walking around you can still see the bars and stuff. You can still see the Seg and the steel doors and [hear the guards] and stuff. It is hard to get away from it. Out here it seems like nobody in the world [cares]. I don't know how to verbalize it. I just feel it. I don't know how to talk to anybody cause in there at least out there [prison] your life is laid out for you. I have looked for a place out here but right now I am thinking about going back to Nova again. At least that was my home. There I have everything. There's nothing out here. If you got a criminal record nobody is going to hire you. I don't have the training. There is no housing and stuff. If you don't want to go back and you want to stay clean it's almost impossible. I just wish I was back [in Truro]. There is nobody out here to talk to. Everyday is a struggle. 
Leanne, who has been out of institutions (prisons and psychiatric hospitals) for the longest period in her adult life, expresses her frustrations and isolation on the outside.

I got nothing right now. I am looking for a place at the moment. I have been here [halfway house] six months. I just want to go back at Nova. Out here you need a damage deposit, you need housing, a place that is warm, a place to call your own. Out here it is impossible. You can't do it. I can't do it by myself.

Similarly, for Jamie, life in prison effectively removes the loneliness she encounters living in the community. She weighs the benefits and shortcomings of both the prison and the community.

I don't know if it is a safe place [in prison] but there's lots of company. Lots of different people to talk to. At home, there is no one to talk to. It is lonely.

Maggie, who has been out of the prison system for a number of years recognizes the detrimental effects of locking someone away in an institution and the debilitating consequences of this isolation.

If they had to keep me in the prison system past three years and I had to keep on with the hard crowds and learning all the prison terminologies and then put me out on the streets ten years later to be honest with you I probably could kill somebody. With all the anger I would have built up inside. I am angry now but if I had to let that anger build up. If my mother had to die or my father had to die while I was inside and when I came out I would have went looking for that judge and I would have spit in his fucking face.

A hierarchy of institutional 'preferences' was a key theme for many women. Quite disturbingly, as Nicole identifies, prison represents a 'safer' place than confinement in a psychiatric hospital.

I was going back and forth to the Waterford Hospital for years but I just couldn't handle it. It's just so cold in there. Like the nurses and the doctors, they are supposed to be there and be caring and stuff but I found it so cold. Don't seem like it is a hospital. I had so much abuse in there [hospital] I can't even begin to tell you. That's the last place I want to go.

Most disturbingly, for many women time spent in psychiatric hospitals are as traumatizing and even more so, than prison. Jennifer speaks to the abuses which occur in psychiatric 'care'. 
There have been times when I have got upset and they had to put me in what they calls their TQ room (Therapeutic Quiet). It's just a room with a mattress. Same practically as that down at the lock-up. They [Waterford staff] are like prison guards who can do a lot to you when they are not on camera. They can and they don't hesitate.

Jamie has also been out of prison for several years and is now a regular in-patient at the

Waterford. She talks about her life inside psychiatric hospitals.

I have been to hell and back again you could call it. Been to hell and back again. My life growing up in the hospitals was way worse than it is in jail. I mean in here [hospital] there is no freedom. You can't go and come when you feel like it. That's the hardest part about being in here but depression and stuff. That's something else all together that is.

The connection between prolonged involvement in state-controlled institutions and a woman's chances of 'making it' one the outside are clear in the following statement by Yvonne.

I am totally institutionalized. I am only out a day or two and back again. I am back and forth to the Waterford for 14 years. If that's not institutionalized I don't know what is. I have never lived a normal life.

Nicole highlights the lingering psychological effects of institutionalization which inhibits reintegration efforts on the outside.

After a while, you get so used to being inside that it becomes second nature to you. Your senses get all dulled out and you are afraid to make a decision on your own, afraid that you might get in trouble for making the wrong one. You go around in a daze most of the time and then you come out here and don't know which way is which. Prison is like my home. In there, everybody knows me and knows what I am all about and I know what they're all about. There's no big surprises.

Because of past abuses and fears associated with living alone in the community with a psychiatric illness, Maggie sums up the sad reality of independent community living.

It's hard to look at someone and tell them you feels safer in prison than you do outside. But that's the way it is for me. 


\section{Pains of Imprisonment}

Much has been written on the pains of imprisonment in relation to women prisoners (c.f., Morash and Schram, 2002). The well-noted separation from children and geographic isolation are undoubtedly very traumatic. While women in my sample reiterated these concerns, pains were more often expressed in terms of physical and emotional treatment within the prison. Maggie shares her memory of a singular incident, while noting that such inhumane practices are commonplace.

You know what broke my heart one time in Springhill. There was this doctor nurse and he bought me a teddy bear. Someone to hug and he made me feel safe. One time I acted up and they put me in segregation and they took it on me. They told me if I didn't quieten down they were going to rip the ears off it. You know what they did? They opened the window and they ripped him up and they stuffed him on me. I have nightmares about that. I even had a name on him. It was "Little Positive Buddy". They must have thought there was something wrong in Springhill to give a teddy bear to a grown woman.

Several women made mention of the recent introduction by provincial corrections

authorities of a 'restraint chair' which is now being used in the prison. Jennifer describes 'the chair?.

A couple of weeks ago the chair made the news. It's like an electrocution chair. They used to put a hockey helmet on my head. And they would put me in the chair and there would be a guard there just staring at me until I fell asleep...[T] hey would make arrangements for the cops to come and take me to the hospital and then get an injection, bring me back in the chair until I fell asleep. Then the same thing would happen over and over again.

For many women like Laura, the emotional distress of being locked and separated from their children impacts on physical well-being.

I came in and 14 or 16 days later the psychiatrist came in she said I heard you haven't been eating, you haven't been drinking, you haven't been getting any sleep. So she gave me some nerve pills. You are just constantly thinking about home, your kids. 
Sarah also comments on the mental anguish of being separated from children and the inability to provide care for them.

The hardest thing about being out there doing your time is your children and who is looking after them and it goes through your head, you know, did he fall down and get hurt, who is hugging him when he cries. I went through fucking hell and back and thinking about him and he was only seven years old and his father is drinking.

Jennifer, a woman with severe mental health problems, describes a situation at the federal prison

which led to her launching a formal complaint against prison staff.

They [correctional staff] were notified that evening that I had planned on catching fire to myself and they never confronted me or made any attempts to talk to me or anything like that and then when I did it of course they didn't take me to hospital. I was just left there in the cell for two days until the Minister came in talking to me and I showed her my sides and my arms and she went out and made some calls and next thing I knew I was taken to the hospital and flown to a burn unit and I had six surgeries and then they came and told me I was being transferred to Saskatchewan...But when I think I had two months left I went back to Springhill. That was when I made the decision I was never going back there again. Never. They made it hell for me the last two months I was there. Because they were being investigated and that don't look too good on them.

Coping with prison life very often results in new found dependencies on drugs. Sarah

talks about this connection.

I'd say [substance abuse is] $98 \%$ [of getting through prison]. Because when you go in there you can't cope with it unless you got something for your nerves to keep you calm. Then you can't sleep, you need a sleeping pill. So if you are there any length of time by the time you come out you are addicted to the drugs. And then when you go back they say you got a problem with drugs. Well, who put me on these drugs?

Similarly, Victoria traces her addictions to her initial prison entry.

I tried smoking up and coke and stuff but I wasn't heavily into it. I got into pills once I walked through those prison doors in 1995. I didn't know about taking pills, getting high. Swallowing pills to me, I would urge taking an aspirin. [Then I got into] Demeral, Morphine, Valium, Percocet. Anything to give you a high even if it was a downer. Like Valium is a downer. It relaxed me. It took everything away from my mind. I was happy. I would take whatever I could get. I liked downers too. I guess it killed all the pain. I didn't 
have to deal with things. You didn't really care. You were relaxed and happy-go-lucky.

Jennifer puts into focus the psychological difficulties of trying to cope inside prison.

The first time you say don't eat for a few days they say you are depressed and suicidal. You've heard of lock-downs and they can go on for days. Thinking about everything. Everything is going through your head. Sure that is enough to put anyone over the edge.

It is quite clear from investigating women's experiences of incarceration that prison does not contribute to empowerment (Hannah-Moffat, 2000; Pollack, 2000). Quite the contrary. The isolation, depravation, loss of liberty, infantilization, and medicalization are all features of the penal apparatus. Given the pathways into prison and the fundamentally disempowering impact of prisons, where do women begin to rebuild once they are physically released from the pains and realities of prison existence? Getting out and trying to regain some semblance of normalcy against the inhumanity and cruelty which characterizes the prison forms the focus of the next two chapters. 


\section{CHAPTER 8:}

\section{GETTING OUT: COMMUNITY TRANSITIONS}

For almost any woman, the relief of getting out of prison is quickly replaced by the anxiety of being out (Faith, 1993: 170, emphasis in original).

The transition from prison back into the community is often a very difficult and anxious

time for women. The challenges facing women upon release are compounded by their prison experiences. As Eaton (193: 56) describes:

Whatever disadvantages the woman suffered from before prison she now faces the world with the added disadvantage of a prison experience and a prison record. She is a prisoner and she brings this knowledge, this identity, out into the world. The prison experience will affect her response to the outside world, the prison record will affect the response of others to her. When she comes out, she brings something of the prison with her.

Most women commented on the level of intimidation, disorientation, and trepidation they felt over their release and the pressures of trying to resume their pre-prison identities. Yvonne describes her fears in this regard:

Believe me it was really hard coming out [of prison]. It was really scary. I wanted to go back in again. You can get institutionalized very easily and what makes you institutionalized is the safety you feel inside. You know what I mean? I've been back and forth between prison and the Waterford for 15 years. It's a scary world all around.

Nicole reiterates the psychological adjustment one feels upon leaving the institution, where attitudes of incompetence and low self-esteem are fostered.

It's like you're on the bus and you think it's written on your forehead that you just came out of prison. It's terrible it is. You got no one around. It's much easier in prison because all the guards were around. They cared about you somewhat. Out here it just seems like you are by yourself. Just thrown out. And you are always being judged.

Everyday tasks such as banking and shopping, which become all too taken-for-granted, now pose major stumbling blocks for women upon their immediate release. Maggie describes her initial 
experience at the grocery store.

I went up there and I was frightened to death. I didn't know what to do and then I got into the wrong line-up. The woman told me I had too much stuff and I got panicked. I ended up telling her I just got out of prison. Then they wanted I.D. to change my welfare cheque and all I had was my parole card. I just left the cart and got out of there.

\section{Safe and Affordable Housing}

One of the most immediate concerns facing women upon their release into the community is the often arduous process of securing safe and affordable housing (O'Brien, 2001; Richie, 2001). Much is dependent on getting settled in a place of one's own in order to qualify for welfare benefits which require a fixed and permanent address. Reuniting with children is also hinged on the woman securing suitable accommodations. For most women living in poverty, finding an affordable place to live proved difficult enough prior to entering prison let alone having the added burden of declaring your recent whereabouts to potential landlords.

For many women, the road out of prison often leads back to cohabitating in former relationships characterized by abuse. Corrina, for one, describes in considerable length her ordeal with inadequate housing arrangements and how this contributed to further abuse and isolation.

My daughter was [with me when I got out]. We were in a shelter for a while and then I got a place with a girl I met in there [shelter] and we shared an apartment. Then, Christmas came and one of our friends punched me in the face. I had him charged. He is like 6' 2 " and a couple of hundred pounds...That started the Percocet [pain killers] then. After that I went to a shelter for abused women in [southern Ontario]...Then [lived] with a friend, then with a guy I met because I had nowhere else to go. I took a job at [coffee shop] to get enough money to leave to come home [to Newfoundland]. I got on the bus to come home, got stranded in Halifax, ran out of money there. I stayed at a shelter in Halifax. I didn't want to go to welfare because I would have had to change shelters.

For those women who managed to secure decent accommodations it often meant the difference between staying out during that crucial few months of release and going back inside. 
Victoria managed to qualify for and secure satellite housing.

Housing is a big issue. I struck luck because the woman who used to live here, she has [respite] workers that come in with her she needed a bigger place. So I got this parole house.

All too often, women ended up in undesirable neighbourhoods, characterized by poverty

and violence, in accommodations which were wholly inadequate. Victoria describes her place.

You don't have a lot of decent housing here. For some people that isn't an issue to go back but for some women it is. When I came here the carpet was filthy. I was stressed to the max. And you know something? You might not think it is a big thing but it was dirty. I don't like dirt. I was so stressed out. I was like I got to move. That stressed me out.

Slum housing becomes the all too familiar last resort for many women like Yvonne.

Some of the places they put you in are not fit. That's what leads people back into jail. They are not fit at all. They shouldn't be allowed.

For women from rural areas of the province, the affordable housing crisis is even more pronounced. Emily describes this ordeal and her plight to alert policymakers of this problem.

I've been in touch with some politicians and they told me there was no housing problems in rural communities in Newfoundland. In small communities houses are handed down from generation to generation but what about the fact that there are children now adults living with parents or some relative because they don't have a house to go to. But saying you don't have a housing issue is saying you are willing to allow the abuse. You can call it silent abuse but the only reason it is silent is because everyone in the community is going to keep it quiet.

Leanne, a young unattached woman, notes the low housing priority given to single women.

I just don't have the money to go and get my own place. Welfare is not going to give me my own place because I don't have any kids. I got to stay with somebody and everyone I knows lives up around that area and the same friends I got, they got.

Housing arrangements specific to Aboriginal women and their families are almost nonexistent in this province, especially on the island. Nicole, an Aboriginal woman, notes the irony 
in this situation:

I heard there was housing [at the Native Friendship Centre]. It's supposed to be for men and women but they don't take anyone out of prison. Half of the people who are Native got a criminal record!

Emmanuel House, a co-ed and multi-purpose housing centre in St. John's was often

a stop-over, temporary housing arrangement for quite a large number of women in my sample.

While many women prefer women-only accommodations (Eaton, 1993) this was not an option.

Emily describes this situation.

There's two beds here at [Emmanuel House] in all of St. John's for [women] parolees. Compared to the number of Newfoundland and Labrador women in need that is not very good odds.

Because Emmanuel House is a co-ed, multi-purpose facility, arrangements specific to the needs of women more generally, and criminalized women specifically, were notably absent. Sarah remarks on this shortcoming.

There should be some other kind of place in this city to house women who are not high risk so their kids can come down and they should have visits every evening after supper even for an hour in the evening and weekends. If they had a house like Emmanuel House and it had a lot of bedrooms for the women coming out, five rooms for little girls and boys and they could live in that place with their kids and a counselor 24-hours around the clock and those people had a home and that would be there.

For some women, securing any type of housing proved unsuccessful. Homelessness was the only viable alternative. Jennifer recalls her time spent on the streets of St. John's.

I lived on the streets. One night the cops picked me up down on Quidi Vidi Lake and I was unconscious in the gazebo. I was going back and forth there for months. It was so cold I guess I passed out from the cold. If you lose your apartment by going to jail you have to wait for 30 days to get another place.

Again, poverty is inextricably linked to the limited availability of housing alternatives for women. 
Rachael describes the endless cycle she faces.

Poverty is the biggest factor because I mean when you come out [of prison] and you got no money. When I first got released I had no where to go. I had to stay in a hotel. Like I only had $\$ 300$ to my name [from working in the prison] and I had to pay that in hotels. I had a bedsitting room first and then that fell apart because I didn't have enough money to keep that going. That's the thing. If you're on Social Assistance, they don't give you a lot like down here [Newfoundland] and you are shagged. Basically once you are finished, you are finished with the [criminal justice] system. Like once you are on your release date they can't help you and that is why I kept going back so many times because I had nowhere to go.

\section{Meaningful Employment}

Criminalized women are amongst the most disadvantaged in terms of marketable job skills and levels of education. It is women's position within the capitalist patriarchal structure, rather than their inadequacy as individuals, which accounts for their poverty and unemployment. As we know, joblessness is a key correlate of crime (DeKeseredy et al., 2003). However, even those with full-time employment working for the minimum wage are 'paid to be poor'. In a recent series profiling trends and economic realities of minimum wage workers in this country, some well-known trends including the gender wage gap, correlation between education and earnings, concentration of women in low-paid, part-time employment, and the impossibility of surviving in any Canadian centre on minimum wage earnings, were revealed (Canadian Broadcasting Corporation, 2004).

In Canada, for example, 53 per cent of the working poor (around 900,000) who remained 'trapped' in low-paid work in 2001 tended to be older women and those who had only high school education or less. These individuals were more likely to be working part time for small, non-unionized organizations. Furthermore, while the gender gap for income has been closing for

the last 20 years, women still earn 64 cents for every dollar men make. Women also accounted for 
almost two-thirds of minimum wage workers in 2003 (CBC, 2004).

In 2003, one in 25 employees worked at or below the minimum wage set by their respective province. Furthermore, four out of 10 minimum-wage workers did not have a high school diploma, continuing to point to the correlation between education and income. One of the hurdles the working poor in Canada are facing is the so-called "casualization of the work place" a term used to describe the move towards part-time and temporary employment. Women consistently occupy positions in the casual labour force which lack benefits such as sick leave, holidays, and medical coverage.

Income is inextricably linked to affordable housing access. In 1998, for example, the United Nations's Committee on Economic, Social and Cultural Rights expressed grave concerns about housing in Canada and stated that "provincial social assistance rates and other income assistance measures have clearly not been adequate to cover rental costs of the poor. In the past five years, the number of tenants paying more than 50 per cent of their income towards rent has increased by 43 per cent."

For single mothers, access to even minimum wage employment is blocked by the lack of national day care program. Daycare costs in every province in Canada (except Quebec which has government-subsidized child care that amounts to $\$ 5 /$ day) have increased in the last 10 years. The average cost of daycare in Canada is $\$ 551 /$ month (Canadian Broadcasting Corporation, 2004). This amounts to roughly half a month's minimum wages. The working poor in this country are 'nickel and dimed' (Ehrenreich, 2001) into extreme poverty and substandard living conditions and then made to feel, according to neo-liberal ideologies, that "being poor is a crime in and of itself' (Gilliom, 2001: 44). 
Furthermore, as Eaton (1993: 71) points out in her study of women after prison, men's and women's jobs are segregated both horizontally (into different occupations) and vertically (with women occupying subordinate positions within the same occupation). Women's paid employment tends to be clustered around low-paying service work. Gender-based job segregation was evidenced in my study in the context of government-sponsored parole release job programs. Sarah talks about an extension of this gendered division of labour in community corrections.

Like they had that place out there in Bull Arm and in each division they had so many places reserved for men on parole for work. Now they were out there making a killing. They were good-paying jobs. Now what's here for women to go at? Nothing. The government should fund something for women when they come out [of prison] if they want to go back to school and they get paid while they are going to school. And I mean good pay. Bring them above the poverty line. But there is nothing here for women when you got a police record. Like if women came out and had a chance to go to Bull Arm to work and someone to help with their kids, they would make money, enough to keep them going. They would be able to pay their rent, buy their groceries.

Charmaine also comments on gender role stereotypes which presume a male wage-earner.

[There needs to be] some kind of work programs for women. Somebody should be able to have something to put women into some kind of job program or something. I know if I had been working I would have never been in prison. Definitely not. They have them for men but not a damn thing for women. They thinks that men are the main breadwinners.

No doubt, the possession of a criminal record further narrows a woman's chances of securing employment. Corrina remarks on her recent situation of interviewing for a job.

A criminal record makes it hard to get a job. I got interviewed for a job down to the mall before Christmas last year. I never even heard back. Not so much as a no, we have everyone hired. I just stood out different from the rest of the girls. It was a group interview. I stood out more than anyone else there. I was more nervous.

Charmaine also comments on the necessity of employment, not only as an economic means but for psychological well-being. 
What would keep me out would be work. It's a big thing. Everybody needs work. People with criminal records. They can't get jobs. If there was some kind of job program for people coming out of prison. Idle hands only gets you in trouble.

Jennifer explicates the quandry she faced when searching for employment and the decision of whether or not to disclose her criminal record.

You try to get a job and first thing they ask is if you have a record. I was going around for about a week trying to get my cheques changed and I couldn't get it changed because I didn't have a picture ID...I had to show them my parole card!

Unable to secure employment, Sarah talks about alternative measures of making ends meet on the wholly inadequate social assistance rates. Faced with the enduring reality of poverty, options become limited.

I live on my own. I got to take in two girls to help me pay the rent so I can go out and buy groceries and a new pair of jeans, sneakers, gym clothes or a new winter coat for them [children]. It's not really expensive but something they would like. A single woman would never make it in an apartment [on her own]. You need help. If you can't get help and if you get someone to come and stay with you like a boyfriend or something to help you out then they cut your cheque off because he's got money. That's not fair. This is you. You are not married to this man. He is not obligated to give you anything.

Olivia highlights her lack of marketable skills given that the majority of her life has been consumed with the unpaid and undervalued labour of child care.

If I could work instead of going back home and sitting on my ass all day. But I mean even if there were jobs out there. How many people in the name of God are going to take somebody who got no experience of work? That's all I knows is looking after babies and looking after homes, right. You know.

On the other hand, Yvonne, raises an objection to the rationale that employment alone keeps women out of prison.

Employment is a big thing but you can't blame it on that. I don't have enough money but that's no reason to end up in prison. That's not a good enough reason to end up back in jail because you are not getting enough from welfare. Nobody is getting enough. You 
don't need to break the law. There's people out there to help.

\section{Lack of Community Supports for Women}

The well-noted lack of gender-based supports for women in prison is replicated in the community. Due to the lack of gender-specific programming, women were often mandated to attend counselling programs centered around the needs of men. For Rebecca, a program to deal with her history of shoplifting would have been highly beneficial. Instead, she has attended anger management sessions each and every time she has returned to her community.

I don't want to keep doing the same garbage I've been doing. I am wasting my time and their time by going to a program that I've already done 10 times. It done nothing for me.

Valarie remarks on the lack of women-only programming in the community and her forced attendance at group counselling sessions on sexual abuse which was clearly targeted toward male sex offenders and not their victims.

They [Emmanuel House] take women coming out of prisons. And they take sex offenders and everything for God's sake. Why should I give credit to Emmanuel House for helping me when they didn't? And since I am doing well they all look at you different and I ain't paranoid either. When you're well you see things that others who are medicated or half out of it don't see it. And all their groups are addictions and abuse and that's it. There's nothing like journalling, which helped me a lot. I had to do that myself.

Yvonne also criticizes programs which include both sex offenders and victims and the level of anxiety she felt in this group.

They have a lot of women coming there with abuse issues. I found it very difficult when I first went there [mandatory counselling group] and you are in a group and you have sex offenders sitting across from you and you had to try and talk about abuse. I met one guy up there who was a sex offender and staff told him to lie. So what are they running? Do they take sex offenders or don't they?

The availability of culturally specific programming was non-existent. Nicole describes the 
only native-run program in the city and the experience she had there.

I went up there [Native Friendship Centre] for two minutes. They were o.k. when they were on Casey Street. The doors were unlocked and you could go and have a smoke and a coffee. But once they got a new place on Waterford Bridge Road, their staff are behind closed doors and they have the glass in the window. It don't seem like no friendship centre. I dropped up and dropped back out again. It seems worse than prison in there. It is supposed to be a friendship centre. It is not supposed to be run like a frigging prison.

Victoria sums up the current fiscal situation and the off-loading of state-run programming onto the community, which lack the human and monetary resources to effectively deal with the individual populations they are mandated to service.

There's not enough services out there. Emmanuel House is swamped. They cannot take everyone at one time. People on wait lists. There's not enough things for people. And inside there is nothing. It's ridiculous. If they want to save money from people doing crime put something in place to help people. I guess they have got to keep their jobs too. Staff and jobs and buildings.

Rachael, a young single mother, comments on one particular program geared toward the educational and financial needs of single parents which she independently sought out at the expiration of her parole.

If they had more programs, like SPAN [Single Parents Association of Newfoundland]. At least you are doing something productive that makes you feel good about yourself. Like I know myself once I start paying bills, like when I paid my phone bill like that was the best feeling I ever had, compared to having him (son). It makes me feel like I am doing something in society. I am not depending on other people to get what I need. I am doing it on my own even though the money is coming from them [SPAN]. Now that I am getting a bit of money from them [SPAN], going to classes, and I got a babysitter there is a possibility [of staying out]. It just makes me feel good.

Yvonne comments on the lack of trained professionals and gender appropriate spaces in the community to effectively deal with the myriad of issues facing women.

I really feel that women should have their own place [apart from men]. It's a separate issue. You could relapse for sure in a place with sex offenders. I think men got more 
facilities anyways. They've got a couple of places already. What's a woman got to come out to? Nothing. You also need counsellors who understand. Not just professionals. A degree is no good without [lived experiences]. A degree is only a piece of paper. You need to understand to be able to help them, to walk in their shoes. Some of them haven't got a clue where I am coming from. I don't want to talk to someone like that. It is very frustrating.

Community supports which address the systemic issues facing criminalized women were notably absent. As Rebecca comments, programming in and of itself is futile when women are continually faced with issues of cyclical poverty and abuse.

There is nothing here for women where you have a group on how to stay out. How to live outside. No education groups here at all. You are just being stuck. You are not allowed to go to school. There is not a program here in Newfoundland for shoplifting. Not one.

Another disturbing trend identified by the women in this study is the situation whereby parole releases are denied by the institution based solely on the lack of supports available to women in the community. Kathleen comments on this situation.

Out here [community] there is nothing. When I had my parole hearing my parole officer never even recommended me for release because there is nothing out here for women.

\section{Police Surveillance}

One major area of concern raised throughout the interviews was police intrusion and surveillance of women post-prison. Often times the police are the first agents of the state to impose formal social control. Efforts to break free and stay out of trouble were often inhibited by the constant scrutiny of the police. Sarah explains:

The police. They are a big part of it. They don't leave you alone. They see you walking along the street, they stop and say, "What are you at tonight [Sarah]? Are you under any restrictions?" In front of everybody, you know. "Are you drinking? Are you under any kind of court orders or anything?" 
Jamie relates first-hand how police interference continues to pervade her life.

Sure I am telling you, I have come out of the shower to run out and answer the phone and there would be a paddy wagon that would pull in right there [points to the front window] on the wrong side of the road and me standing up there with a towel around me, there's two men in a paddy wagon staring at me. They [police] were having meetings at the [town hall] for all the break and entries and stuff in the area and one man I was renting from told me he heard horror stories and people told him not to associate with me.

Attempts to avert the glare of the police were formulated by Corrina who, to say the least, expresses her distrust of the authorities.

They [police] put the spotlights on us. They would come down the road and slow down at our place and all heads are turning and looking. Police will not leave us alone. If you do time and you come out and if there is a similar type of crime [to the ones I committed] they will always go back to that person. Even if it was 10 years later. Now they are trying to get this DNA in for people who done high crimes. I don't agree with that. They could turn around and plant a hair sample or anything and there are bad god-damned cops.

Leanne also articulates her frustration of rehabilitation efforts inside prison which are

negated and counteracted in the community.

Police don't say you got your time done and that you paid back your debt to society. That's what it's all supposed to be about. What groups you got inside the prison they don't know about. Anger management and people skills and you could be the best kind of a person. They don't know and they don't want to know. They just treat you the same way they did when they picked you up for doing whatever you done. And that's the way it is.

Reverse discrimination by police forces were articulated by Maggie.

A few weeks ago I had someone break into my house and I called the police. They didn't even come by. They said they searched the area and that was it. They didn't even come by to take a statement.

On the other hand, Emily recounts how police relations have recently changed for her now that she is 'on the other side of the law'.

I couldn't pull the car out of the driveway without them [police] pulling me over. At one 
point one night I had been out with a friend of mine at two or three o'clock in the morning and they had me hauled in. There was a time when I laid a complaint against an officer and generally if you lay a complaint against one of them they are all over you. I can get along with them now because I am in this position [of responsibility]. Sometimes I think it is hilarious. The same cops who were trying to arrest me are trying to work with us (laughs). It's nice to know that when they come here they won't be drawing guns.

Police scrutiny and interrogation extended beyond the purview of the women themselves and onto their families. In Sarah's case, her teenage children were now being targeted by the police based on her past criminal history.

I was sentenced to the armed robbery-two and a half years. Then there was an armed robbery [later] in this area and so they [police] come in and busted my door in the morning and I am there and the youngsters are there. The door falls in and knocks my youngster over a flight of stairs and my son [name] is up against the wall trying to catch his breath. I said, "Get away, leave me alone. That is my child. There is something wrong with him. He does not know you. He needs his mother. Leave me alone."

Similarly, for many women with a reported history of theft, private security agents posed resistance in their attempts to 'go straight'.

When I go to the mall all the floorwalkers knows me and I gets followed around everywhere I goes. When I go down on George Street all the police officers knows me even though I don't remember them. I got more of a chance of getting caught or arrested.

For many women with psychiatric illnesses, their first encounters in a crisis situation in the community are with the police. Therefore, the police play a significant role in determining whether a woman is brought back into custody or a psychiatric hospital. Jennifer describes a recent experience she had in this situation:

Like when the cops came here the other night and the [respite] worker wanted me to go the hospital. I wasn't after sleeping for four days and I was really agitated and I didn't want to go to the hospital because I was afraid they would say oh look who is back. Apparently, they came into the hospital to visit me, my workers, the same ones that called the police. When they first arrived here the first thing they said to me is, "Get your boots on. We are going to the lock-up." I said, "Why are we going to the lock-up? I know I have 
to go and see someone but why do I have to go to the lock-up?"

Continuing on from the focus on police and private security surveillance, the labelling process brought on by the criminal justice system remained an ongoing reintegrative struggle for many women like Sarah.

If you went to court on a shoplifting charge with me for the same thing you would get probably probation and a fine and you are gone home. I would get time and I would not get bail. Because of my name. Because of my name [my kid] is up in Whitbourne now and he is not able to get bail now because of me.

Sarah reverted back to her maiden name so as to avoid one aspect of the labelling process.

I went under my maiden name with the armed robbery stuff because I didn't want the kids to be going to school [and hearing about it]. But they got it anyway.

\section{Re-Negotiating Relationships}

Relationships play a major role in women's lives post-release (Eaton, 1993; O’Brien, 2001). Primary relationships included immediate family members, intimate partners, and professional staff. Each is discussed below.

\section{Familial}

Very few women in my sample had supportive family networks. This can be traced back to a number of sources already discussed and include: histories of physical and sexual abuse by family members; dissolution of kinship relations upon entering foster care arrangements; and the breakdown and disassociation of family relations experienced upon entering prison and other institutions. For those small number of women who had strong and supportive family networks, 
this proved to be an invaluable source of support at all stages of their criminalization, especially when it came to 'making it' on the outside. Sarah, a young single mother recognizes the level of family support which is so vitally important in women's lives.

Oh my God. I don't know how I would get through it without my own family. They should have a program for women in prison who have no family where you can adopt their child just by sending them so much money a month. Adopt them, do crafts, spend time with them. Everyone needs to have someone to care for them.

Jessica also speaks to the importance of family supports throughout her life.

I would never have been able to do it without my family. I mean I had excellent, excellent, excellent family support all the way through. I had two children before I was twenty years old. I mean you know I had a lot of help through the years. I was very fortunate. Many of times if I wanted to just leave and go away for the weekend I could go. I didn't have to worry about having to find a babysitter. I didn't even have to make arrangements. If I wanted to go I just went. And that was my escape goat too. I was lucky for that you know. I find some people get stressed out with youngsters. They can't go. They can't do anything. I was lucky enough that I could.

Valarie recognized the invaluable support she received from her foster family once she made the decision to 'go straight'.

I just started to get my family back when I changed my life. My adopted mom is back in my life. I got my sister who came to visit me two years ago. I got my son. My foster parents have been in my life. They have been there since I was 17. They found it hard when I changed my life. They didn't want nothing to do with me. They found it very difficult because I wasn't there. They were always there when I was in a crisis like if I needed money they had money for me.

Positive familial relationships was one area which differentiated those women who 'made

it' in the community and those who continued to cycle back and forth into prison or other institutions.

Conversely, the absence of positive family supports and role modelling was often a reality for those for whom institutionalization has played a longstanding and prevalent role in their lives. 
For some women who maintained some semblance of familial relations throughout their incarceration and release, this proved more often than not to be a major source of frustration and disharmony in their lives. Corrina, for one, talks about her longstanding troubled relationship with her mother.

It wasn't good [parental relations] and it's still not. Sometimes I gets angry. Sometimes I won't answer the phone (when Mom calls). It's like I haven't got the head space to be sitting down and talking to this woman without getting angry and I don't want to be getting angry at her either. There was never an "I Love You" or anything like that. I am 33 years old now. I don't need it now. I could care less.

Jennifer completely lost contact with her family of origin upon entering a psychiatric institution at the age of 14 years.

My family turned on me for a lot of years. Matter of fact, I didn't even know my mother was dying. They couldn't locate me. They didn't know where I was living or nothing. It was fluke that one of the nurses working in at the hospital that was working in on my unit that week and she and I were talking and when she went home she heard they were looking for me. By the time I got home my mother was already dead.

Yvonne describes initial contact with her mother upon her release from prison.

I got on the bus on July $13^{\text {th }}$ to come home, got stranded in Halifax, ran out of money there. I stayed at a shelter in Halifax. The churches paid my way across on the boat to Port-aux-Basques. I stayed there overnight and then Salvation Army paid my way by bus into town. When I got off the bus I never had a cent to get a taxi or nothing. It was pouring and I mean pouring. I got this taxi driver to dispatch the office and call Mom to see if she had enough money for a cab to get over there. She said she didn't have enough money to pay for a cab. Can you imagine that?

\section{Intimate}

Intimate relationships were often a major source of turmoil and abuse in women's lives.

Corrina, who has been out of prison now for over one year, talks about her current relationship.

I fuck up relationships big time. I am in one again now with a guy I have known for 13 years. He's at the halfway house. I don't know how that's going to work out. I'm not 
going to get my heart right gung-ho into it because I have been there and back with him 100 times before. When I wasn't in jail, he was. It's a big cycle. So we're trying it now and see what happens.

Intimate relationships were all too often characterized by abuse. Corrina describes her history of heterosexual relationships.

All the relationships I've been in [with men] have been abusive one way or another. Abuse of drugs, abuse of alcohol, abuse of relationships, mental abuse and physical abuse. Money-wise, everything. It's been a big cycle of abuse every which way except for sexual, that's the only one. It's over and over and over again. I guess where I never had a father figure. I never met my father until I was 21 . So it was just this thing about needing the male companionship. It was just like I had to have it.

Corrina recounts an experience she had with her former boyfriend upon entering prison.

I lost everything [when I went to prison]. [A friend] went down and took what she could, like my daughter's bed and stuff. But then the guy I was going out with at the time went down and had a big old party and decided to take my cheque and change it. He was a nice guy but he was an alcoholic. He drank too, too much but he was a nice guy other than that. And he changed my cheque and got charged with fraud. He called me a couple of months later. I got his number and used it to run up his phone bill. So when his phone bill was $\$ 700$ I said, "Here's a return for the favor.'(Laughs). So I got my money back one way or another.

On the other hand, some women, albeit very few, described supportive intimate relationships which were a major source of assistance throughout their prison terms and, consequently, upon their return back home. Victoria tells of the support she receives from her same-sex partner.

The only supports I really have is my partner and my foster parents because [halfway house] don't give a fuck. They are just as bad as anybody else. When you are doing well you notice things that you wouldn't normally see if you weren't well. When you are medicated you don't see anything. I couldn't even talk right when I got out of prison. My speech was very slurred. They had me blown up on pills. I didn't have clothes. I didn't have food when I first got out. I had no money and what I did have I spent it on drugs. I would never have done it without her [partner]. 
Rebecca attributes her sobriety, in large part, to the support of her partner.

Drugs are not an issue for me anymore. Now, before when I first started I was really nervous and I used to take Valium. I got off of them. I'd say if it wasn't for her support [partner] I would probably be back on my pills.

While Jennifer acknowledges the emotional support of her partner, she realizes that this does not go far enough in dealing with the economic realities of poverty which many criminalized women continue to face upon release.

I get support from [my partner] and the kids. But he is getting sick of it. I keeps telling him there is nothing I can do about it. I am not going to sit here and be hungry. No way.

Histories of physical and sexual abuse often left women struggling to develop trusting and egalitarian relationships with men. Victoria describes this ongoing cycle.

Relationships is big thing. You've always got to have something. Being so dysfunctional all your life and being so screwed up from your background I guess you always got to have something there even if you are doing so well. You are always getting involved in something negative. Which I am doing now because I am in this relationship. It is not good because it could land me right back in jail. I know that. I see that. I do understand it. I am trying to get out of it slowly.

However, same-sex relationships were not exempt from the difficulties involved in trying to cope with histories of abuse. Victoria reflects on her current relationship.

All [my relationships have been] negative. Even this one is negative. This is not a healthy relationship. We have been in it a year in February. A very unhappy relationship. We broke up and were kind of still seeing each other. I don't know. It's not a healthy relationship. I've got to make some decisions. I can't be around this.

For many single mothers, relationships with their former partners were marked by a total lack of financial and emotional support in caring for their children. Sarah talks about the struggle to make it without the support of the children's father. 
[Former husband] is here in town but he does not take part in the children's lives whatsoever. Like he has four daughters of his own [and he can't even take care of them]. At Christmas time I used to have to shop for them and I wouldn't have money enough to get it but I would make sure they had what they wanted [through shoplifting].

\section{Professional}

For many women with a longstanding history of institutionalization, primary relationships developed over a number of years with professional staff (probation and parole officers, psychiatric staff, counsellors, etc). These relationships are not always positive and are often characterized by a level of mistrust. Due to the nature of professional relationships and issues of confidentiality which are often surrendered in a prison or community-run centre, women did not feel comfortable sharing certain aspects of their lives. These relationships are often hinged on a duty by professional staff to report certain information which may be perceived as threatening to the lives of women or others. This is very much the case in an institutional setting whereby frontline staff double as 'keepers' and counsellors. Jamie describes this complication.

Well it would be alright if they [corrections staff] asked you what was bothering you and try and help you about that but it seems like they are always asking you how you feel. I don't know. They just don't get to the bottom of the problem. Never did get to the bottom of mine anyways...And I never did get any help... [Psychiatrist] comes in here [prison] but I don't find they help a big lot. I've been seeing a psychiatrist from the time I was 17 until I was about 32. And I have been in and out of psychiatric wards all that time and doctors never ever helped me much.

Jennifer, who established a close relationship with her parole officer over a number of years, describes how the completion of this relationship affected her emotionally.

I tell you what else was really funny and helped me complete my parole without even so much as a violation of any kind was my parole officer. Like she would come down and me and her would go out for a coffee and a drive somewhere. A couple of days before I finished parole and she came down and said look I am filling up the tank and anywhere you wants to go we are going. O.k. I said I tell you where I want to go and that's to Ferryland to see my nephew's grave. I have not been there in 15 years. And she said o.k. 
[Then] she said you know I have to come down and say good-bye to you. I felt like I lost my best friend. I really did.

Maggie also describes the close relationship she had with her former parole officer.

I got out of the parole system three years ago. I really cared about [my parole officer]. I learned how to read and write all over again just for her. I would write her poems. I got into painting and drawing pictures for her. She didn't even appreciate it by writing me back. I can't handle being abandoned. That makes me really hurt. When people go out of my life like that it really hurts. She had a big impact on my life.

Jennifer takes note of the significant differences positive relationships with professional staff can make in a woman's life.

There was this one guard in Springhill and no matter what the other guards said she always treated me really good. If any clothes came in she always made sure I had first choice at it. Even the day I was getting released on parole she was the one that brought me to the airport and stayed with me until my flight was ready and stuff like that. Me and her had a long talk and she told me if you goes federal any more you knows you are going for a long time. So I think that is one of the things that is probably keeping me straight.

Prolonged dependency on professional staff was a major part of women's lives who had

either been institutionalized or did not have any other supports in terms of family or partnerships.

Jennifer explains her fear in losing this support network she built up over a number of years.

I know that will happen [my home care supports will get reduced] but I also know that it will not be a shock. It will be something that is gradual. You know eventually I have to get used to being on my own again. One thing I am worried about that could put me back in again is what kind of relationship I am going to have with this new probation officer. Am I going to get along?

Maggie also talks about the need for professional supports on the outside to assist women who have been confined in institutions for most of their lives.

We need counsellors and people to come in to slowly integrate us into society. When we do learn how to do some of these things again we need people to show up periodically. You can't just abandon us altogether. Before that person goes away on us slowly get us used to another person. We just can't be left on our own. Certain people can do it. But 
people like me I know cannot make it on our own, by ourselves. I am too institutionalized. For the rest of my life and the rest of my days. If not people like me will spend the rest of my life in prison.

Olivia expresses her opinion of psychiatric/counselling professionals and the artificial and imbalanced environment created between the 'helper' and the 'helped'.

I would love to sit down with a psychiatrist but what turns me off is you go into this fancy office, here they are wearing this fancy suit, crossing their legs and their shoes so shiny and here they are with a little marker in their hand scribbling down a few little words and then I will see you next week. They thinks they knows what you are going through but they don't because they have never been through it.

Maggie also echoes the concern raised by several women about the medicating of their problems by psychiatric staff.

[What I need to stay out] well for one thing when I do get out is to find help for one thing. Maybe join up AA. Go to doctors. The ones who are going to help me. Not the ones who are going to give me a pile of pills, fifteen minutes, mark down a couple of words and we'll see you next week.

Olivia makes the point that male professionals, either in prison or in the community, are incapable of empathizing with her history of sexual and physical abuse, thereby providing little guarantee that she will not return to prison if she doesn't deal with her past abuse.

I can't say I won't be back. I can't say that. I am not going to say I am not going to go out there and hit the bottle, right. But on the other hand, I am going to ask God to keep me strong. I am going to ask the good Lord to keep me strong. I am definitely going to ask the Lord to keep me strong. But I think once I gets out in that place in town (Emmanuel House) once I'm there and they are talking with me. It's like to me, to tell you the truth, if I had a powerful staff person, like a female, I think she would understand me a little bit more. She is more warmer, you know. But with a man it's like he's there with crossed legs and (laughs) it's like he don't understand right.

\section{Summary}

This chapter touched upon the immediate challenges facing most women upon their 
release from prison. Tangible areas included securing safe and affordable housing, searching for employment, reconnecting with family, and negotiating relationships. Undoubtedly, these are important challenges to overcome upon release from prison. However, once these goals have been met, the struggle is by no means over and the obstacles to staying out remain. The next chapter further break downs the challenges women face in trying to stay out of prison once these initial targets have been met. 


\title{
CHAPTER 9: STATE AND COMMUNITY CONTROLS
}

\begin{abstract}
'You are never out of the system once you're in it. You are never ever out of it. I don't care what anyone says. Like I am out of it now but I am still not out of it. I am still doing time [on the outside]."
\end{abstract}

A major finding of this research centres around the 'layers of social controls' which characterize the lives of criminalized women. That is, the more layers of formal state control a woman has encountered prior to her coming into prison, the less chance she has to break away from the criminal justice system upon release. Furthermore, institutional responses to criminalized women are replicated at the community level whereby transcarceral strategies of social control push 'clients' of the criminal justice system "from one section of the help-control complex to another" (Lowman et al., 1987: 9). By managing and supervising individuals within the community, the correctional apparatus expands to include state controls (psychiatry and mental health, welfare, child protection) and community controls ('home care', mandatory programming, and residential centres). My research seeks a broader exploration of the formal and informal social control mechanisms that govern the lives of women and include the intersections of state control agents and community-sponsored controls. In the case of community-run corrections, the offloading of state responsibilities in the name of economic prudence has meant a scramble by community groups to obtain core government funding to continue operations. This often means co-opting their missions and principles to accommodate state-imposed policies and practices.

\section{Psychiatry and Mental Health}

For the almost two-thirds of women in my study who have been 'successful' in avoiding a 
return to custody within a two-year period, they are now as tightly entrenched in community-run psychiatric and mental health agencies as they were during their institutional stays in prison. While they have stayed out of prison, they are now either resident in a psychiatric hospital or receiving full-time 'respite care' in their homes. Jennifer describes what her life has been like since coming out of prison over three years ago.

There is nothing I haven't done. I have caught fire to myself. I have jumped off the bridge. I have jumped into St. John's harbor. Ran in front of cars. There is nothing I have not done. Basically it comes back to them saying she is looking for attention. So, like I could honestly say that I might have been able to stay out [of prison] this past couple of years or more but it hasn't been easy. One day she [home care worker] came into the house when I was after swallowing down about $20-30$ bottles of pills. She said to me I am going to have to call the police. I hauled out the knife and said it is too late to call the police. She grabbed the knife and cut her finger. And I told her to get out. She went and called the police. They came and charged me with assault causing bodily harm. So, I had a choice. Plead not guilty and try to fight it but with my history? I plead guilty so they put me in at the Waterford Justice Unit from June to September. When I got out I told them I didn't want anymore home care workers. And so they weren't happy with me being there by myself so they put me back into the Waterford and that's where I was until now.

Yvonne recounts her cycle of psychiatric admissions over the years and the reality that it was only through her encounters with the criminal justice system that she began to get the psychiatric help she needed upon release.

I have over 100 admissions there [Waterford Hospital]. It's hard to break out of that cycle too. That's what happened to me. The mental health system refused me but the prison system couldn't refuse me. That's a fact. It's hard to get some help. I got more help in the prison system than I got in there [Waterford]. I only got abused in there. I never got any help from the Waterford. I got slapped to death and drugged to death and abused. You name it. I have been abused everywhere. They went together anyway, the justice system and the Waterford. That's still to this day.

Maggie talks of the desperation she feels in the community and her reliance on mental health agents since coming out of prison.

The Crisis Centre wouldn't talk to me. I was feeling like I didn't belong in the house. I 
didn't belong at the Waterford. People are telling me death is not the answer and prison is not the answer. I didn't know what the answer was and I didn't really want to die so I thought taking the pills would just put me brain dead with just lying in the bed and people seeing my face. Maybe being there in the bed being hooked up to all these fucking wires would make them happy. I still don't feel any happier than I did the other night...[I feel happy] when people are around. I do feel pretty good after certain people are around. Like the worker who was here today. She pissed me off because she wouldn't loan me money for smokes because she knew you were coming and I was getting paid. I told her I didn't want to take any money from you. I was just delighted that you were coming.

Rebecca speaks to the continuum of mental health which is all too familiar to many criminalized women.

It's much more than the criminal justice system. It's the mental health system. It's social services. It's every other system that plays into it. They got sick of them at the Waterford and shoved them out. They didn't want to deal with them anymore. Those are people who can't cope and they keep throwing them in jail.

Locking women up under the Mental Health Act is often the first course of action taken by the police in responding to a woman in crisis. Jennifer recalls her most recent experience in this regard.

I am in the process of going up against the mental health system right now. A few weeks back I went to the hospital to talk to a doctor because I was not feeling well and I was refused to be seen. And because I was refused to be seen the police came and took me to the lock-up and I was down there for 16 hours on a mattress and that same night I was refused treatment another person was also refused treatment and went over and jumped off the bridge by the Waterford. He's still in critical condition in hospital. The reason the nurse gave me that night on call at the Waterford was that the doctor who was on didn't know me plus they had no beds. She didn't see the purpose of me being seen by a doctor who didn't know me. Then I was taken to St. Clare's and the doctor there would not even come in and see me. So that was when the police came and told me they had no other choice to take me to the lock-up.

Jennifer, who had earlier been detained at the lock-up under the Mental Health Act, also describes her resistance to hospitalization.

The police weren't comfortable in me coming back home [from the lock-up] even though I had a worker here with me. The next day a psychiatrist came into the lock-up and told 
me he was the head of all the hospitals here in the city and he told me I was going to Waterford. I told him I didn't want to go and he told me I had no choice. He was signing the papers saying I had to go. I said they have no beds and he said to me when I want a bed I get a bed. So 3 o'clock that next afternoon I was admitted to the Waterford.

Jennifer connects the psychiatry/prison continuum that has pervaded her life and continues even though she has not been to prison in over three years.

You are never out of the system once you're in it. You are never ever out of it I don't care what anyone says. Like I am out of it now but I am still not out of it. I am still doing time [on the outside]. Like when I left Springhill no one even gave me the benefit of the doubt that I was going to stay out. And they figured I would be in a breach of parole at any time. I guess I fooled them (laughs). It was no confidence. None at all. I considered it they were there for the cheque and that was it. So, you know, I think if people really took a look at the criminal justice system in Canada they would be shocked. I was in Springhill a year when I caught fire to myself. And then I was transferred to Saskatchewan psychiatric unit.

Despite the fact that Yvonne has been out of prison for two years, she is quick to realize that her

psychiatric illness can continue to draw her back into the system at any time.

Like either way I am getting hauled back in (the system). It's either the prison or the hospital. I didn't think that was still an issue except for the other night when they came here and they said we are taking you to the lock-up. I did also find out something that made it a bit easier. It doesn't matter if you are on probation or whatever they can take you to the lock-up if they think you are trying to hurt yourself or something like that. They are not going to charge you, just hold you. They can only hold you until you are seen by a doctor and then once you are seen they got no other choice but to either take you to a hospital or release you. There is also something there. See, I have made an agreement with my doctor that if I need to come in for a night or something then that is o.k. We had a meeting yesterday and we all agreed with my workers that if I am not feeling well and I need to see someone then that's o.k. So, it's like a big difference.

Jamie has also been out of prison for several years and is now a regular in-patient at the

Waterford. She talks about her life inside psychiatric hospitals.

I have been to hell and back again you could call it. Been to hell and back again. My life growing up in the hospitals and stuff the way I felt back then is really confusing. It is worse than it is in jail. I mean in here there is no freedom. You can't go and come when you feel like it. That's the hardest part about being in here but depression and stuff. That's 
something else all together that is.

The 'penal industrial complex' was by no means lost on these women who

recognize the business of corrections and psychiatry in the community. Valarie talks about the exploitation of women by some community-run agencies.

They are not even qualified counsellors. A lot of them up there got Grade 12 and they're doing counselling on abuse! Some of them have a few criminology courses. They've got this thing with $\$ 62.50$. You've got to work. You've got to get 24 hours every two weeks. What's that? About $\$ 2.00$ an hour? I did my cooking course and I love cooking. I did catering for them. Here I found out they were paying the staff out of it. We did catering jobs for Mental Health and Justice and here they were paying staff out of the money that I was earning! And they had this other thing where you stuff envelopes for $\$ 5$ an hour but where I was on this 24 hour thing they had me doing it and working for half that wage. They get a lump sum payment from the Cancer Society and pocketing that money and just giving the workers the $\$ 62.50$. Where is all the money going from what we make from catering?

The continuum of dependency on prescription medications is often exacerbated and enabled by agents of the criminal justice system who force mandatory drug compliance on women, especially those with mental health diagnoses. As Valarie describes, monitoring of her prescription intake for a diagnoses of 'bipolar disorder' was a legislated condition of her probation. It was only once she had satisfied the terms of her probation order that she managed to re-negotiate her own mental health needs according to what she deemed as appropriate.

I had to take my medication. That was a part of my probation. I wasn't allowed to do drugs but I was allowed to drink. That makes sense [laughs]. I had to see a probation officer and [Emmanuel] House was involved. I had respite workers which I didn't want but I had to have them. They were like pill-pushers...[W]hen I got off probation I threw my pills in the toilet. I told my probation officer that I was doing that. I had to take my pills or they would have put me back in prison. Part of the conditions.

Supports for women upon their immediate release from prison and while still under the control of probation or parole, in terms of reporting and regular home visits, are diminished as 
she nears the end of her sentence. Maggie explains:

Well first [when I got out of prison] I was involved in a lot of church activities. I had people supporting me. Counseling. I had Emmanuel House understanding me but now I feel a lot of people at Emmanuel House are after abandoning me. I was mentally well but now my physical illness. I have a lot of physical problems right now. I am worried. I have to go and get surgery done. I am worried about not knowing if people are going to be there if I have to get surgery. Right now I am worried because I am that big now that when I go to the washroom I can't even wipe myself I am that fucking big. I get into the bathtub and I get stuck. I can't even wash myself down below. I can only wash up here. I can't wash my own back. I can barely wash my own head. It makes me depressed. So I run to the institution. The Waterford. Then they make me angry and upset. If they went to grab me and put me in TQ [Therapeutic Quiet] I am liable to hurt someone. I don't want to. I have no plan to hurt nobody but if they wants to calm me down by putting me in TQ then I will go [smacks her hands together]. Then they will think I had that planned and then the next thing you know I am behind bars again. But it's not that. I am not planning to hurt anyone. Honest to God. I love to see people helping. But it's like an adrenaline, it rushes to the head like an empty feeling. A fuzzy feeling in my head. It rushes to my head and they don't understand that. It's something in my head like a rush goes to my body. It's like my head is working 28 hours out of 24 hours. Spinning.

Maggie talks about her recurrent admissions to the psychiatric hospital despite being out of prison for three years.

Frankly what I think [for women in prison] it's a lack of understanding of mental illness. [I]n the past three months I have been in there [Waterford Hospital] 19 times. And in the past three weeks I have been in there six times. I got out of there yesterday. Like the other day I was in ICU with something down my throat and I couldn't breathe. I goes in hospital and they discharges me yesterday. After OD'ing. They sends me home with more prescription pills! Here, have some more pills!! Do us a favour (and kill yourself). In Newfoundland, you will find that women were institutionalized at a young age at the Waterford. At the Janeway [Children's Hospital]. Doctors overloaded them with medication. Misdiagnosing. Misunderstanding. Not interacting with Child Welfare to take children out of the home at an earlier age when they were being abused. Teachers getting away with covering things up for families.

Jennifer speaks to her ongoing reliance on prescription drugs to medicate the pains of past abuses, which, as she points out quite succinctly, did not cease upon the expiration of her conditional sentence. 
Believe it or not for 25 or 26 years [slashing] was a way too of not hurting someone else. It was to hurt myself first. Sad part about this is that for almost a year I didn't know what it was like not to hurt myself and that was the longest time I ever went. All of a sudden last week things just got too much and the first thing I wanted to do was hurt myself. I didn't want to die or anything I just wanted to feel pain...There was a lot of things going through my head. I kicked my workers out because I just wanted to be by myself. That was the first night I had spent in the apartment by myself.

Leanne, who developed her addiction to prescription medications while inside the prison, recognizes that she must now continue taking her medication to avoid falling back into the trap of crime. Having said that, she also recognizes this is only one piece of the puzzle, with poverty being the main contributor to her past crimes.

[The biggest challenge for me staying out is] I have to stay on the medication I am on. I have to not drink and not do drugs. Stay away from certain people and make them changes in my life. I'm 25 now and this has been the longest time I have been off the drugs. But in terms of shoplifting I think, I know I am going to do that again.

An 'assertive case management' model has been adopted by community organizations in dealing with criminalized women who have psychiatric labels. This model provides "intensive supervision to those severely and persistently mentally ill persons whose needs are not met through regular case management" (Luther, 2003: 165). Jennifer explains the piloting of this new approach.

I don't know if you know this but I am the first one in Newfoundland that they tried this with [assertive case management model]. I don't consider myself a criminal half the time. I consider myself sick and I am being treated like a criminal. But you don't know where to turn. Like my worker couldn't understand the other night why the police came and took me to the hospital. Why would you be glad the police came and got you? Because I knew I was not being violent and I didn't want to hurt them and I knew I would get there safely and stuff like that. So I mean that was a big thing. That's why I knew then that I wasn't going back. I could have got in that car that night and kicked up a big stink and hit one of those cops. I wouldn't be going to the Waterford. I would be going to the Waterford Justice Unit and then bought to jail. That's the other thing. 


\section{Child Protection}

Criminalized women, many of whom are single mothers, are routinely subject to the gaze and intervention of child protection agencies. For some, child protection was already a wellestablished layer of social control in women's lives prior to their incarceration. For others, their maternal fitness became the subject of ongoing intrusion and surveillance post-prison. During their period of incarceration, several women had their children placed into temporary foster care arrangements and mother-child reconciliation became a source of constant monitoring by the state following their release.

Not surprisingly, relationships between women and child protection officials are marked by high levels of suspicion and distrust. Olivia, for example, recounts a breach of confidentiality by child protection agents which was used against her at her sentencing.

When I was trying to get my second child back what they done this time is they went to the Waterford and took out my files. The doctor took out my files without my permission and used that in court. I don't think there was any need of that. I didn't think they was allowed to do that.

Since returning to the community and her home, Olivia has been subjected to ongoing intrusions by child protection services.

When I had my home and my child that was really a good time. But after one day all that was taken away. They say I was unfit but they were the ones who drove me there. I mean I used to wash out the clothes twice a day. You could be able to eat off that floor...Social Services would get calls to come in and I was getting pissed off. And I had the house spotless. Spotless. And the next thing you know a knock comes on the door. Lord God. A knock comes on the door and that was Social Services. There was two of them there and they had a police officer and they said we are after getting more calls again. "What now?", I said. Well, we got calls saying your child is sore and you got a hole in the mattress and a bucket beneath the bed and I said Lord God. I got fed up with it and I said come on in. By the time the week finished they had the house wrecked. I grabbed the sheets and throwed them on the floor, got the mattress and tore it off. I said, "Look. Do you see a bucket there?" They said no. I took them into the front room. I took off the chesterfield cushions. 
I said, "Look do you see any buckets there?" Oh, my God, I tell you. It's wicked.

Sarah talks about her ongoing struggles with child protection agents who continue to invade her privacy and label her as an 'unfit mother'. She recalls a confrontation with child protection which highlights her position that her children received inadequate care while temporarily residing with their father during her period of incarceration. Despite her contestations, Sarah's criminal record continues to interfere with her best efforts to regain custody of her children.

Child protection had a big problem with [my criminal history]. And then when I came home [from prison] I said I am taking my kids back. And they looked at each other and I said, "You can look all you want because I said take a look at that. That's what is down in my basement because it fell down up on a beam. The dryer was shaking and they were rocking and rolling and here's a picture of the woman next door giving my husband a fucking blow job." And my kids would be up throwing rocks at the window the next morning trying to wake him up because they would be over in the house by themselves and trying to get a bit of money to go get breakfast. [He'd say] "Here, go down to the park and get a hotdog and a coke." Get a hotdog for your breakfast? Then by the time they would get home at lunch, there would be no meals..[My daughter and granddaughter] were there and they [guardians] were loaded drunk. They would sit on the step in the morning waiting for the liquor store to open to phone a cab and bring it up to him.

After much ongoing intervention by child protection services throughout her life, Nicole, a middle-aged woman returning to the community from a three-year federal sentence, placed her children up for adoption.

I had my children with me up until 1996 and then I put them up for adoption because I thought that was no life for them. They were in foster care and all that. I thought it was bad enough for the little children to live there and I wanted to give them a chance so I put them up for adoption. At first it was hard, yes. They were in foster care for 8 months before they got adopted.

Rachael, who also had her daughter taken out of her permanent custody, connects the loss of her child to subsequent criminality. 
She [daughter] is in Child Youth and Family Services. She got apprehended once I got sentenced to two years she was taken away. But she wasn't in my care. She was in temporary wardship with Child Youth at the time and I went out and they said they were taking her permanently and of course I did not agree and I flipped out and that proved to them again more or less that I wasn't capable or wasn't ready to take care of a baby, to be a mother, and of course when they got that order [apprehension order] that is when I ended up getting in trouble with the law again.

Despite being out of prison for over two years and upon the birth of her second child, Rachael is still subject to routine investigations and home visits by child protection workers.

Child Protection is still involved with me today of course because of my past with [my daughter] but they don't have no reason to have any concerns at this point. I have been doing good. I haven't had any trouble with the law. I am basically going to my counselling appointments and I am showing no signs that I am starting to go back to my old self. Well not to my old self but to them, getting in trouble [is my old self]. They don't have no risk concerns at this time.

Mistrust of child protection agents was a common theme amongst mothers. Olivia elucidates the basis of this lack of trustworthiness.

Ever since they took those files out and used them against me I don't feel trustworthy of them anymore. To take out my files, walk into a court room and use it against me and everything. I mean it was strangers in this court. I didn't know nobody. But you know what was strange I was sitting there in a chair [in the courtroom] and he knew everything about me but I didn't know nothing about him [refers to the judge]. That was a real blow to me like when she got up and took out my file and said [she] is not capable of looking after her kids because she was sexually assaulted blah, blah, blah, blah. My God, I said to myself that is supposed to be confidential. Maybe things have changed now. That was the [19]70s. I certainly hope they have changed.

\section{Social Services}

Quite similar to the nature and extent of intrusion by child protection agents, welfare officers continue to play an important role in women's lives after their release from prison. Reliance on social assistance benefits keeps women entangled in a system of controls wherein regular reporting and check-ups are routine. Jennifer provides one such example of this level of 
control and intrusion in relation to the monitoring of her prescription medications and cites this surveillance of her drug card as a reason why she is staying out of prison.

Another thing that is probably keeping me out too is finally after so many years of going to Social Services and getting a drug card and loading up on pills and overdosing they finally realized I am costing them a lot of money. So now my drug card is restrictive and only my home care workers can pick up my pills. My pills are locked in a safe so I cannot even access my pills. So I cannot overdose or anything like that. I guess in a way that is a big benefit. It seems like reality has set in me plus everyone else.

Monitoring the prescription medication intake of welfare recipients is a routine occurrence.

Additionally, the generation of any income outside the regular welfare payments must be reported to welfare officers. Any change in address or conditions of supervision by parole services must be reported to social services. Finally, recipients are subject to unannounced home visits and intrusion by 'welfare cops' employed to detect any fraudulent activities, which include checking up on women to ensure that she is not cohabitating with a male partner. Breach of any one of these stringent regulations could result in criminal charges of welfare fraud and undoubtedly was an ongoing source of stress for women.

\section{Community Agents of Control}

As discussed earlier, 'community' is a term invoked by governments, reformers, feminists, and academics but seldom do these groups concur on its meaning. As Worrall (1997) maintains, "the term community [h] as become a thoroughly promiscuous word, attaching itself to almost any activity formerly regarded as a responsibility of the state." My research addresses the extent of the community which incorporates a number of state agencies (social services, child protection agencies, criminal justice system, mental health agencies) that do not necessarily 
represent a forum for rehabilitation and reintegration. Similarly, the community for women parolees often represents further repression and (in)formal social controls in their lives. Having said that, for some women like Yvonne, the level of community supports they now have in place is only as a direct result of their incarceration and entanglement with the criminal justice system.

The support is out there for me that was never there before. The support is there to help me deal with my anger and issues which was never there before. I had to break the law several times just to get this help. It's pretty bad I had to break the law to be where I am today because of my crimes.

Maggie, who has been out of prison for over three years, talks about the need to differentiate community services for women with major mental health needs. Because her master status is that of ex-prisoner, services provisions are based foremost on this status and not on her mental illness.

The government should have a place funded for people like me who have a mental illness. They should have people hired for people in the prison system with a mental history. People who have difficulties with the law. Just regular correctional people don't understand. They need someone hired who understands. I am stable now. I am just after getting out of hospital and I am on new medication now. Medication helps me stay out of prison is number one. But what if I forget my medication? What if people stop coming around? What if I lose my apartment from getting in with the wrong crowd because I can't say no? What if I start hallucinating and the new doctors don't believe me? What if I am not representing myself appropriately or inappropriately and they don't know what to believe? They don't know if it is the manipulative side of me coming out or the sick side of me coming out? Sometimes I am manipulative. Sometimes I am telling the truth and sometimes I am not. What do they do if they don't know what to believe? These days I know I am being the most truthful person of my life and they still don't believe me. What do I have to do? Shed my blood for the system? People like me, all they want to do is lock them up and throw the key away when initially it is cheaper to hire someone to put in my home than keep them on the street and spending millions upon millions in the prison system and locking them up behind bars.

Yvonne credits, in part, her 'recovery' to the consistent level of community support she has received over the past number of years. 
I got community support care on the go to help me cope on the outside. So I could live comfortably on the outside not in and out of prison. I just made up my mind that enough was enough. I don't belong in prison. Why should I break out windows and stuff like that just to get in jail? Why am I doing that to myself? So I said enough is enough. I am not punishing myself anymore. I said I am going to stay out of jail. I just made up my mind to stay out. And with the help of counselling from here at Emmanuel House, from community support care, I just never went back and that's it. Don't get me wrong. I've got emotional problems from a lot of anger but I get it dealt with now. I have enough sense now to go to my counsellor and helps me deal with it. I just turned around my life. I said I've got to stop punishing myself because that is exactly what everybody is doing to me. It's usually through some form of abuse that a woman would end up in jail. Anger built up in themselves. It causes low self-esteem. So you have been through so much abuse that has caused you to go back and forth to prison and you don't really stop to think, why do we keep punishing yourself? Put ourselves back and forth to jail. Now I've got a different attitude on life now.

Jennifer also attributes her staying out to the 'assertive case management model' which provides constant 'support' through full-time respite workers in her home and counselling services in the community.

I think the thing that is the biggest difference is the amount of support I have gotten this time since I have been out. Like I had a lot of people who confronted me with ideas on how I could better myself. Not to be judged so much by other people because that was the biggest problem with me. Being judged by other people. Professional and unfortunately because I had such a hard time I lost my family for quite some time. Since I came out this time and went to Carew Lodge and did well for months I have gotten some members of my family back. That was an added bonus to me because I was in prison a lot of times and I never heard from my family ever. So sometimes it works to your advantage to let other people help.

On the other hand, Jennifer who developed major a psychiatric illness throughout the course of her institutional life, relates the suspicion she encounters from the medical community and her subsequent failure to secure the services of a general practitioner.

One of the biggest problems is that I have been here over two months and they still can't find me a family doctor because as soon as they contact the doctor the first thing they ask them is do I have a psychiatrist? And they said yes and then they say oh she is probably only looking for some narcotics. So I seen my psychiatrist yesterday and the first thing he asked is if I had a family doctor yet and I said no. And he was questioning me and I told 
him why and he said he would write a letter to verify. I have diabetes so I do have to be monitored by a GP. As of last year, psychiatrists are not allowed to write diabetes or anything anymore.

For many women like Jennifer, issues of trust and confidentiality were still major barriers to seeking counselling and community supports.

One thing about me is that I was being hurt so much. I didn't trust. The trust was gone. Even though people were offering me these opportunities I was more or less afraid to let it happen. And I got to tell you that I have had my ups and downs even since I have been out. Like I don't think, I am on probation now, and I don't think I will go back to prison because like I have gained so much now that I just don't feel like I need the surroundings now and I did before. It was like a safety place. Right?

Jennifer also notes a sad irony inherent in one's discontinued involvement with the criminal justice system and that is the removal of these major support networks which come about as a result of institutionalization.

That's one of the disadvantages of not being in the [criminal justice system] because when I was at Carew Lodge I had family doctors, psychiatrists. [E-Fry staff] was always flying down to see me. Counsellors galore and everything like that. The minute you are finished with the [criminal justice] system it all goes away.

\section{'Home Care'}

For many women, particularly those falling into the 'assertive case management' model, their daily lives are characterized by the presence of 'home support workers' to assist them in their daily rounds. Maggie talks about this trajectory and the dependencies it has created for her.

I won't even go outside now. They [respite workers] expect me to bath every day. Wash my clothes every day. Clean my house every day. How do they expect me to do that with four fucking hours? There is no fucking way. I need more hours. More than likely I am going to end up 102B. That's my parole number. 
The high turnover in respite staff and the imbalanced professional relationship which exists

between worker and client poses a number of problems related to trust and relationship building.

Maggie explains her situation in this regard.

I had [respite care] all along but it was consistent. Now it's not as consistent anymore. They are hiring new workers. All new faces. Workers are cancelling out at the last minute. They are lying to me. They are deceiving me. When I told the boss a couple of months back that there was a worker talking about me and stealing from me and another client, they didn't believe me but they believed the other client. They say, "Oh [Maggie] is upset today so we will give her a pack of cigarettes to shut her up." But I don't want material things. I want someone to sit down and talk to me. Material things mean nothing.

Jennifer provides an example of the rationale for her recent increase in 'support staff'.

The most hours I have ever had in home care is four hours and now I got 14 hours a day, everyday. Ninety percent of my crimes were committed late in the night and now I have a worker with me every night. So I am never alone. So I don't even have time to think about that.

April also speaks to her dependency on 'support staff' and the lack of input she has to employ only female staff in her home.

I don't like to stay alone so I guess I will always need respite workers. I wouldn't want men [as respite workers] but you got no choice.

Jennifer is a product of the assertive case management approach and requires constant monitoring

in her life, due in large part to her psychiatric illness. She explains:

I have five different home care workers. I had a meeting yesterday and every week workers are given an opportunity to go to a meeting and discuss problems and concerns they are having. The only thing I got against me now is that I use the phone once too often (laughs). So if that's going to be the worse thing then I think I am going to do o.k. I mean $I$ know there are going to be times when I am possibly going to have to go back to the hospital for a couple of days or whatever but the other part is I have a good doctor now and when I go in to see him he doesn't just spend five minutes with me and then that's it. I will spend an hour or so with him. I also have a case manager which is something that I have never had. 
Reliance on 'home care' staff to take control of many aspects of women's lives is clearly evidenced in this quote from Jennifer who talks about money management.

I didn't have any security. I would go home at night and pass out on the floor and probably have a cigarette burn or something like that. Wake up the next morning, not even the next morning but a few hours later awakened by someone banging on my door because the house was full of smoke. I mean I even actually almost destroyed the house that my parents built in 1983. I think too now I was the one who decided that I didn't want my cheques coming in my name or to my address so the way we got it worked out is on cheque days my cheque would go to Emmanuel House and my worker would come and pick me up here and we would go up and do the things we have to do.

The continuum of control in the lives of criminalized women has been well established in this study, as elsewhere (c.f., Carlen, 1988). Women's pathways into prison are typically marked by 'layers of social control' that begin at a very young age. Quite apart from the criminal justice system, the myriad of state control forces in women's lives continue to play a major role in their lives post-release. It has been more than hinted throughout this study thus far that state-sponsored control forces continue to be present in women's lives long after their sentences have expired. For the most part, the majority of women who have successfully stayed out of 'trouble' and therefore have not landed themselves back in prison are now equally controlled by community-run control agents. Again, this finding is not new. It has been the subject of much writing by scholars such as Cohen (1985), Scull (1997), Carlen (2003), Blomberg (2003). The extended intrusion into the socalled private lives of women ex-prisoners has now been taken up by community agencies who receive their core funding from government sponsors and are expected to do more, with less.

The 'penal industrial complex' has largely escaped the scrutiny of prison abolitionists and other radicals who rightly point to the economic development opportunities provided by prisons. Through no real fault of these well-intentioned community organizations, we are now witnessing, 
at least in findings generated from this study, that the enormous costs associated with institutional maintenance are being downloaded onto community groups, with inadequate resources to effectively target the needs of women ex-prisoners. This is certainly the case with government per diem contributions to community groups operating residential centres for parolees.

\section{Residential Centres}

In addition to 'home supports' and ongoing intrusions by state officials (welfare and child protection) many women coming out of prison are required, as a condition of their release, to reside at a halfway house. An absence of women-only accommodations in the Atlantic region requires that women parolees accept space at a co-ed residential centre in the city's capital which foremost houses male sex offenders and former psychiatric patients. This practice is in stark contravention to the 'woman-centered approach' purported by Correctional Service Canada. While the use of such language has gained considerable prominence in the everyday vocabulary of governments, it is ill-defined and lacks consensual meaning.

In correctional discourse, the term 'woman-centered' was first introduced in Creating Choices and is supposedly the guiding philosophy behind institutional and community-based corrections in Canada. It is important to look more closely at this concept as it has been repeatedly pointed out that such an approach has failed at the institutional level. Having said that, the application of this philosophy has not even been attempted in the community. It is further argued the basic principles of 'woman-centeredness' are incongruent with correctional goals of punishment and surveillance.

The singular reference outlining the parameters of 'woman-centeredness' was prefaced as 
follows in Creating Choices:

The Task Force developed a woman-centered approach. It encouraged the empowerment of women throughout its work, and gained much insight because it valued the experiences of women. Accordingly, most Task Force members were women. All of the researchers were women. And, interviews and consultations held with most federally sentenced women in prison and with a large number on community release were an essential part of our work (TFFSW, 1990:1).

A number of concerns arise from this definition and its specific application to communityrun corrections for women. As Hannah-Moffat (1995: 36) argues, this approach is problematic from the start.

[C] urrent regimes and proposed visions of woman-centered corrections often fail to depart from traditional conceptualizations of punishment. The definition and constitution of a woman-centered regime is troublesome for the following reasons: It relies on the problematic category of "woman"; it is insensitive to wider social, economic, political, and cultural relations of power; it sets up a false dichotomy between the woman-centered and the male-centered regimes; and it denies the legal and material realities of imprisonment. Further...[w]oman-centered reforms rely on a flexible rationality of empowerment. The language of empowerment is used to legitimate both correctional and feminist strategies. The difficulty is that reformers and the state are working with different interpretations of empowerment.

Hannah-Moffat (1995) rightly contends that feminists have failed to address the meaning and criteria of woman centeredness and the implementation of the task force's recommendations. Subsequently, the definition of woman-centeredness has been left to the state with little external (feminist) input. Many of the above-noted issues become even more problematic in terms of community-run programs, paid for by the state, and not held accountable to upholding the guiding principles of such an approach. Therefore, what we are witnessing in the community in terms of housing and treatment programs is a reversion back to a male-centered model, based largely on economies of scale, to the detriment of women. Such is the example of mandating women parolees to reside in a co-ed facility, which does nothing to further their attempts at rehabilitation. 


\section{Mandatory Programming}

Attendance at mandatory group counselling sessions for women in the community also raised a number of pressing concerns with regards to confidentiality and opening up about past abuses in a group comprised of male sex offenders. Clearly, a multi-purpose approach to treatment and programming tends to replicate the very same problems cited previously which take men as the common denominator in program design and delivery. Again, a lack of accountability in the community to meeting the goals of empowering women has been lost. An emphasis on empowering women is another supposed component of women's corrections philosophy. Once more, this term is problematic and open to a wide range of subjective interpretations by the government, feminists, and criminalized women themselves. As Pollack (2000: 76) argues, "most models of empowerment prioritize an individualistic or psychological notion of empowerment, thereby minimizing the importance of social influences and oppression... [I]ndividualizing social issues can result in blaming individuals for problems that arise from being oppressed in various ways and may be further disempowering to them."

Cognitive-based treatment and assertive case management approaches such as those adopted in terms of mandatory treatment programs for women psychologize and individualize women's empowerment. The tensions arise when one is attempting to control women while at the same time attempting to empower them in an ultimately coercive and involuntary correctionsbased setting within the community.

\section{Summary}

This chapter demonstrates, through the voices of women themselves, the various state and 
community strategies which continue to pervade the lives of women post-release. For the women who managed to stay out of prison for the requisite two-year period, thus defining them in correctional language as non-recidivists, a large number suffer from psychiatric and mental illness which continue to draw them back into the web of social control sponsored by psychiatric hospitals or through intensive home supervision and 'assertive case management' models. Alongside structural factors which continue to pervade women's lives post-release, a range of internal and social resources play a major role in women's staying out. These resources are discussed in the next chapter. 


\section{CHAPTER 10: STAYING OUT}

"All I want is someone caring for me, loving me, and having respect." (Chloe)

This chapter continues the examination of women's lives post-incarceration with a focus on the internal resources women draw upon to negotiate their own 'success'. In addition to the structural forces which shape women's experiences of community reintegration, considerable focus evolved towards examining women's own agency in terms of staying out of prison. In particular, discussions with women who had been out of prison for a two-year period or for those reflecting upon their upcoming release from prison, many shared similar 'intrinsic' reasons for staying out or wanting to re-form their criminal past. These intrinsic reforms included frustration with a criminal lifestyle, a desire for independent living, and survival strategies. Extrinsic motivators were also discussed which included primary responsibilities for children, paying back to society, and a reliance on leisure activities. Each of these is discussed in greater detail below.

\section{Intrinsic Re-forms}

Thus far in analyzing women's pathways out of prison, attention has been focused exclusively on structural factors which either facilitate or block their successful exit out of the institution and back into their communities. While this is undoubtedly an area of paramount significance, women's own agency and resiliency strategies cannot be overlooked. While not attempting to deny or minimize the overwhelming structural compromises these women face, it is important to account for individual strengths and personal beliefs which guide women 'out of conflict' with the law at certain key stages of their lives. 
The terms 'resiliency' and 'survival' are adapted at this stage of analysis to move beyond the systemic impediments which women face and often overcome. 'Resiliency' is a term which develops from psychological and human development literature and implies that:

potential subjects are able to negotiate significant challenges to development yet consistently "snap back" in order to complete the important developmental tasks that confront them as they grow (O'Connell Higgins, 1994: 1).

Simply put, resiliency in this context refers to the extent to which someone can recover from adversity, trauma, and a 'cruel past'. An additional strength of the resilient individual is "their ability to acknowledge and experience significant psychological pain and still maintain their ability to love well'" (O'Connell Higgins, 1994: 2). 'Survival', on the other hand, often implies the act of just 'getting through' difficult emotional experiences. Both characteristics were identified throughout my study and contributed to women's breakaway from the criminal justice system.

\section{Seeking Independence}

At the outset of this research it was loosely hypothesized that age would be positively correlated with staying out of prison. That is, criminal activity is primarily the domain of the young and most adults 'grow out of crime'. However, this presumption was not borne out in my research findings. In fact, there were no significant differences based on age between those women who stayed out of prison and those who continue to cycle in and out of prison. Having said that, for many women who do stay out, the sentiment of growing tired and frustrated with their master status as prisoners was echoed. Victoria articulates this position as she chronicles more than a decade of criminalization and reflects on her past. 
I am just sick of being treated certain ways I have been treated. You don't get treated the best. I was sick of living the way I was living. Sick of jail. Sick of hurting my mother. I got sick of people telling me what to do and when to do it...I was sick of living like this. Every morning waking up to a cell door, one room. I got sick of it. I don't want to live like this anymore... I was scared, of everything. I couldn't picture a life not being in jail. I was starting to get institutionalized. I had my drugs there. I never had to make decisions. I didn't have to really cope with things [but] I just got sick of it.

While there was no significant evidence of age as a factor to staying out, a few women like

Corrina, did express the sentiment that they were 'growing tired' of cycling in and out of prisons.

I'm 33 years old. I am getting too old for this shit. What am I going to do? Be like an old maid, 50 and 60 years old and still going to jail. That's a bit pathetic. I haven't got the energy and the time for it anymore. Ever heard the saying tired of being sick and tired. That's me.

Victoria recalls feelings of guilt about her past and the hurt she inflicted on her family members.

I started to feel bad for the things I done. For the people around me. I never hurt no one like assault or anything but I frauded people in B\&B's and ran up their bills, their phone bills. I thought about it and thought what if that happened to me. I know if someone done it to me now I would be heart broken. I used to do this to people. I just couldn't do it anymore. I felt bad finally, which is good.

Victoria now recognizes the family support she has and is ready to accept help from others, a concession she had refused in the past.

It would probably kill her [mother] if I went back to jail. I think she would have a heart attack. I wouldn't do it. I think too much of her. I am starting to think too much of myself too. I deserve better than this. I always blamed the shitty upbringing I had which plays a factor but I kept blaming it and having an excuse. At the end of it it's you that's doing it and it's up to you. I had people there to help me. Not a big lot of support but if I had to reach out I am sure they would be there. I guess I wasn't ready.

For Valarie, a realization that she is ultimately responsible for her own happiness and healing was a sobering truth and a catalyst to her 'going straight'. 
What's been different this time around? I don't know. I got tired of the system. I'm older now. Nobody out there gives a fuck so you've got to look after yourself on the streets.

Emily also describes the 'breaking point' for her when she consciously decided to take a different path to deal with her abusive history.

It's just like you reach a point where you say I had enough. I know it's not that easy but to stay out of it. Like I said it's just a matter of deciding what you want to do. If you want to keep coming back and keep knocking yourself down, like what happened with me. If someone didn't knock me down I would knock myself down. That's a major factor.

In the end, Emily decided that she was not going to get the help she needed from the criminal justice system or mental health system and therefore she made a conscious choice to 'move on'.

It's only ourselves who can help ourselves out and realize that. Age hasn't got nothing to do with it. If I wanted to be doing it I could still be out there. But it depends on how you grew up and how strong you are psychologically. And your mental state. A lot of people I saw under the Mental Health Act, they are institutionalized. And if the Waterford wouldn't take them they were transferred to prison. That's the only two options that's for people out there. It's sad, but it's also for attention. Attention is a very big thing whether you have psychological problems or not. But the other side of it too is if you get out and you have been in the system for a long time society expects you to stay there. And even if part of society, like the government doesn't give you any options. Like there were times when I got out of prison and I thought like they [corrections] get a bigger chunk of the pie when people are in prison. It's major business... and a lot of it becomes a person getting very institutionalized because you get the attention. The government is not giving any attention. You have to go to hell and back sometimes several times over before you even get one person in there to listen.

'Doing time' inside is generally agreed to be much harder psychologically as the years go by.

Kathleen makes this point:

I can't do it (time) anymore. It is too hard on my head. The first couple of times was different right. I do hard time now.

Many women, through the help and support of family or partners sought a change in

lifestyle, one which departed from their former professional associates. Valarie, for example, 
recognizes her former dependency on agency staff and, with the support of her same-sex partner, began to seek out other outlets for coping with her life.

Not everybody wants to sit down and talk when they are feeling bad. Sometimes people benefit from going to a gym, going swimming. You can be over-programmed too. And you can be over-talked too. You can become too dependent on it too. Then whenever something goes wrong you go running to your counselor. That was my case. I just did it for attention. After a while you get so used to it.

For many women who have spent most their youth and adult lives under state-controls, the desire to live independently, free from the daily regime of institutional life, provided a major incentive to staying out. Victoria relates one example from her own recent experience.

It's a big thing for me to have my own apartment. That might sound like to others well you should have your own apartment that is a normal life. Well, I didn't know how to live that kind of life, a normal life.

Laura talks about seeking change from within herself and desiring a better life for her future.

Everybody thinks different. To find one thing that would suit one person is so hard. You have got to find it within yourself. You have got to want to change. You have got to want to do it yourself. There has got to be some reason within you to change. If you don't really care about yourself. I don't really care how many supports are out there, [you won't make it]. Once you get a taste of it [independence] and it's something you have never been used to, you want to get more of it.

Unable to deal with the hurt and torment of past abuse, Yvonne still recognizes the self-fulfilling cycle of 'beating herself up' and the impediments to living on her own, without the aide of professional counsellors.

You have to get somewhere comfortable in your life where you are willing to accept what happened and move on. I don't have to keep living this shitty life because I had a shitty life back then. Some people go to another abusive relationship because that's all they know. I guess they figure that's all they deserve or that's all you are ever going to know. You don't care what you do or what you do to get it. Because who cares? That's all I am used to anyways because that's all I know. I don't know how to live a normal life. That's scary when you don't know how to do that [live without booze and abuse]. It's a scary 
thing I am telling you.

Maggie, who has been living on her own in a small apartment in St. John's for the past three years, acknowledges that without professional supports she would likely not make it on her own.

I feel sometimes like I can't take care of myself. It's just as well to be in. The meals are provided. If I don't work at least I know there is some money provided for some smokes. I don't have to worry about budgeting money out for food. I'll always know there is people around me even if I am in my cell. But I know honestly, I feel like my mind, my chemicals are the same way they were in 1997. My chemicals have been down worse than I ever did. I am ready to lose it all together. I am praying. I am after calling every religion in the book and say Lord please send me somebody to stop it before it happens. Cause I know this time if I goes to prison I will get the Bitch, an habitual criminal.

\section{Survival}

One of the most striking themes that recurred throughout all the interviews was the survival skills of these women. I was constantly awed by the spirit and perseverance of these women to continue their struggles with poverty, abuse, and institutionalization. I probed quite often on this point to try and understand what keeps these women going in the face of such challenges. As Valarie remarked:

Well I am a survivor. I'll admit I am a survivor. I just turned 40 and a lot of people say to me they are surprised I am alive. Even girls who have been through the prison system. A lot of people don't remember me. I met up with one of the guards last summer and I don't think she could believe it was me. I think my biggest thing was coming off the pills. It was hard coming off medication. But I had to give it up. I didn't need it. I was diagnosed as bipolar but they didn't understand that I am a survivor of abuse since I was five [years old]. They didn't understand that. They didn't even have time to talk to a survivor. They look at you and they label you.

Yvonne talks about the survival skills she acquired throughout her life through living on the streets, dealing with abuse and addictions, and chronic institutionalization.

I think when you are a survivor of abuse you learn to deal with things. That's what makes you stronger. There is nothing that can crack us. You learn to build up a wall and it makes 
you stronger. Like all the things that happen to you in prison. You can deal with it. Really that is only small stuff compared to being abused.

Leanne marvels at her own success since coming out of prison.

My counsellor says she is surprised I saw 11 years old. Like my dad putting a gun to us and all this shit. I found it really hard turning 40 . I am alive. I couldn't believe it. But I've been doing well.

For Yvonne, the passage of time and what you do with that time allowed her to heal from her abusive past.

It all takes time. Time puts the anger away. It takes many years. I was the angriest person. I was so angry I was afraid of myself. But dealing with a lot of that I am much better now. I would never hurt anybody. I would just hurt myself. I was afraid to hurt anyone else because I had so much anger I didn't know what I would do. You've got to be a survivor.

\section{Self-esteem}

Rachael is quoted at length here as she draws the links between self-esteem, poverty, abuse and criminalization.

When you are poor and you got a low self-esteem and most families who grow up in the welfare system, and I am not prejudice or targeting the poor, but most homes you do not get a lot of healthy self-esteem. Eventually it comes to, when you don't have a good family background where you got a lot of love and support you go to drugs and eventually to relationships that are unhealthy because you don't care because you have such a low self-esteem, that someone paying attention to you it makes you feel better. Whether or not they are dirt themselves or they beat you, to you that's good because you got that all your life so what is the difference now? You go drinking because you don't want to deal with the fact that your partner is beating you and you don't want to live with him and you are so scared to go home and then, of course, your drinking leads you back out into the world of doing criminal charges. It's all linked together. It is a chain. It is the poverty, then it's the self-esteem, then the drinking and then the bad choices in relationships, your friends. Until you break one link on that chain you are always going to be doing the same thing...You just got to cut the links that's got you in the circle. 
In many ways, these women are no different from the rest of the population who seek

ways to improve their overall confidence and self-esteem. Rachael describes this quest.

It all goes back to self-esteem. I guess if you don't feel good about yourself, you are told you are gross all your life, that would cause you to go back too. As for what keeps people out, it is difficult to say because each person is different. You take one person could have been raped, could have been beat up all her life. For me it was all emotional, well up until I met my partners and then it was physical. All this leaves scars. But the bottom part of it is poverty. That is the main contributing factor. If you got no money what do you do? If you got a family home you've got to provide for them... It's pathetic. You go back and forth for robbing and [prostitution] to keep food and stuff for your kids.

Feelings of loneliness and abandonment are prevalent themes throughout the lives of many criminalized women. Corrina talks about her struggle to overcome loneliness.

I find it really, really hard being alone. The last five years I have always been with someone. A guy in a relationship or in jail or with a crowd of people or with family members. I was on my own in an apartment for a couple of months in [Ontario]. I don't know. I just finds it lonely by myself. Just me and [my daughter].

\section{Extrinsic Re-Forms}

Many women spoke to the presence of external motivators to their staying out of prison. Key amongst these motivators was the responsibilities women often have for caring for young children. Also, many women sought solace in caring for others, including giving back to society or caring for pets. Each of these external contributions are discussed briefly below.

\section{Child Care Responsibilities}

One of the most prevalent reasons proffered to staying out of prison was child care responsibilities. Rachael explains:

What is really keeping me out to be honest with you is my son. If I wasn't pregnant or I didn't have him I'd say I would be back in jail. Because the fact that I got a bond with him 
and I carried him for nine months I don't want to lose him like I lost my daughter. It's too painful. So he basically keeps me out because I works hard to keep him in my care but chances are if he wasn't with me chances are I would be back in the system again. Definitely.

Yvonne talks about the bond and unconditional love she receives from her daughter.

The responsibility of your children. That would be one for me. With me it was the fact that I never had anyone growing up. I was always by myself and now that I got a baby by my side it just makes me feel good as a person. Knowing that someone loves me for me and is not going to judge me or look at me any different. Is not going to throw me out in a snowbank because I does something wrong. It's unconditional love. That is one reason why I stayed out.

Corrina, who had been going back and forth to prison while trying to care for her daughter, now

realizes the impact of her absence.

My daughter [keeps me out]. Like I can't go back for the sake of my sanity. I'd end up in the Waterford [if I went back now]. And I don't know what she [daughter] would do. She came out of it pretty good. I looks at me when I was her age and she is like totally different. And I think if I done something now, would that change? Would she just totally turn over? Like my son just got out [of prison]. He was up there in Ontario and he just got out on Saturday. That's probably from growing up with parents in crime, in trouble all the time. Me and his father are no better than each, you know what I mean? We were both drinking a lot, out robbing, whatever. We both tried but the youngsters got the brunt of it.

Jessica, who had been criminalized since the birth of her two children, now accepts that she was

young and not ready for single motherhood.

Well for starters I got two children. That is the most important thing in my life. And that's basically, if I didn't have them I can't guarantee that I wouldn't be out. I want to be able to have a good life. To go to work and make a day's pay and come home and look after my children. I'm not interested in having any dealings with the police or anything like that. I think that I was young and it's not that I was in need of money because I really wasn't. It was just the money that kept my addictions going. And I guess I was irresponsible and immature. Because I live every day now always thinking about and trying to not get in trouble. Before I didn't care. Back then when I was younger I didn't care, right.

Jessica also credits her children with her staying out of prison. 
[My son] is almost 14 years old now and he is a joy. He is not one problem. And if I didn't have to change they would be in Whitbourne. I am sure of it. Because I am sure it was in them the same way it was in me. You just got to try and not let it come out. Everybody got it in them. We were all condemned.

\section{Leisure Pursuits}

Reliance on a number of leisure pursuits served as an alternative coping mechanism for some women in occupying their time spent at home and in the community. These included caring for pets, writing, music, and other newly discovered pass times. Valarie relates how important caring for her three dogs has become in her life.

I think my animals got a lot to do with it. I love these animals. I feed them with a fork. I microwave their food. I tell them to go upstairs and go to bed. Give them their treats and put them to bed. I had that attachment since I was a child. I told my dad I was going to be a vet. When I was young I had an Irish setter and when my dad used to beat me up he was my biggest support. I would take him and run into the woods.

Similarly, Maggie describes the unconditional love she receives from her two cats.

I would just like to have someone who really cares about me. Like that cat. When I wakes up in the morning the cat gives me a kiss after the night before I was yelling at her and she comes back and gives me a kiss. I know she really forgives me. But if I say to one of my workers to 'fuck off' and she says I forgive you I know she really don't forgive me. But I know when that cat kisses me I know she really means Mommy I love you. I loves them with all my heart. It puts a smile on my face. They are very affectionate.

Music was also a source of coping for many women like Valarie.

Music always helps me. I go downstairs and turn on the music and block it out. Ever since I was a child I turned to music. Even when I was a kid and beat up and shoved in my room I would turn the stereo on. Music is great. Like nature music.

Many other women found solace in writing poetry, short stories, or journalling as a means to release past anger and hurt. 


\section{'Paying Back'}

For some women who have been out of prison for a number of years, applying to have

their criminal record pardoned was an important building block to getting on with their lives.

Jessica describes her intentions in this regard.

It is important to me now because with school and stuff. Sometimes you can come across people who will take a chance on you but rarely that does that happen when you are going to work dealing with money and those type of situations. That's my biggest goal now. To get that Certificate of Conduct and to get school over and done with. Then try and get a full-time job and making half decent money.

Rachael also plans to re-apply for a pardon once she has paid the balance of her outstanding fines.

I am after applying for a pardon and I got turned down because I owed a surcharge to the court. So I am waiting for more time to pass now to re-apply. Which hopefully then I will be able to get it. I don't see any reason why I shouldn't get it now.

Emily talks about her attempts to regain her freedom through the erasure of her criminal past.

For the past years I have utilized everything, the legal system, social services, and now in October this year I will apply for a pardon. Then I will have my debt paid in full to society. And I have apologized for the things I did. I didn't do it because I knew I would feel better. I did it because I knew it was wrong. Having your security taken away from you is hell to get back.

For many women, paying back to society was an important goal in their lives since

coming out of prison. Maggie talks about her desired role here.

I would like to go to schools and universities and speak to people. I know I could do it and I think I could make a difference. I wouldn't want any money for it. I don't feel payment is the right answer. I would be speaking for all those people in that institution who are locked up days after days who are hurting. Feeling hard and hurt. Those people in there are being forgot about. Those people who guards probably spit at or kicked or screamed at and say stuff to. They are people. We are people with feelings. We have blood. When we clap our hands we have sound. We hurt inside. We think. We need a shower just like them. We get cold just like them. We have dignity and feelings and regrets. We have remorse. Believe you me I have remorse for the things I have done even though it took me 
years later to realize what I had done.

Olivia also wants to get involved by helping young teenagers who are dealing with the pains of abuse.

I would like to help a lot of teenagers who are going through a lot. My biggest goal is to help teenagers and what they are going through with their parents or being sexually assaulted or whatever the case may be.

Charmaine, who has a lengthy history of shoplifting would like to 'redeem' herself to those she has stolen from.

I would like to pay back, or repay something for all I have done to the stores. Not to show them because I want to show them but to contribute back the things I have stole from them. If that's the right way of saying it. I don't know I would just like to do something to help them for the damage that I have done to them. I don't know how to contact them or I don't have the nerve to go around from store to store. I am embarrassed of what I done.

\section{Summary}

For many women, staying out of prison had very little to do with external structural forces or community support networks made available through the criminal justice or mental health systems. In so many ways, these women are no different than the non-criminalized population who desire autonomy, respect, and meaningful opportunities to advance their independence. Throughout their lives, however, many criminalized women have had little opportunity to express themselves independently, free from the confines and restrictions of institutional life. Because a large number of criminalized women have struggled all their lives to achieve recognition, love and support, the idea that someone could actually care about them is wholly foreign to them. Seeking solace in leisure activities or through the companionship of pets was often a catalyst to their therapeutic healing and facilitated their psychological recovery from institutionalization. 


\section{CHAPTER 11: CONCLUSIONS}

While the term [community] may appeal to a warm, nostalgic sense of 'belonging' among the self-proclaimed, law-abiding, its promise of inclusivity can be interpreted in contradictory ways when applied to those who break the law and are criminalised. Far from demonstrating that it is resourceful, tolerant, and healing, the community is then rejecting, excluding and intolerantly punitive (Worrall, 1997: 47)

\section{Summary of Major Findings}

While this study confirmed some well-known pathways to women's criminality including a prevalence of poverty, sexual and physical abuse, histories of state controls, and defiance of gender norms, it also revealed several new findings which contribute to women's criminalization following a longstanding history of institutionalization. The foremost finding of this study reveals that the more 'layers of social control' a woman has encountered throughout her life, the less likely it is that she will stay out of prison. These 'layers of social control' include foster care, child protection, prolonged reliance on social assistance, and interactions with psychiatry/mental health agencies. A reliance on state-sponsored controls, often in the guise of community-run centres, continue to pervade women's lives long after their sentences have expired.

Second, success and/or failure are very subjective categories and do not coincide with official definitions. For some women who have stayed out past the official two-year cut-off, they did not consider themselves a 'success' in that they still struggled with histories of abuse, poverty, low self-esteem, and mental disabilities. Also, for some women not getting caught did not mean they were no longer involved in the 'survival crimes' which brought them into prison in the past. Others who were statistically non-recidivists were awaiting upcoming court charges, most notably for an inability to pay outstanding fines. Conversely, for some women who had not managed to stay out of prison for a sustained two-year period, they considered themselves a success 
nonetheless. For instance, one woman who had been institutionalized for 25 years, remarked that for her staying out on her own in the community for one month was a major accomplishment. She knew she could do it but, as she said, "all her friends and supports were inside." She ended up committing a nuisance crime to get back inside. Therefore, as a correctional management tool, recidivism rates are an unreliable indicator of women's overall performance and functionality in their communities. They tell us nothing about how women are managing through the course of their everyday lives and do a further injustice by labelling individuals according to a numeric scale which completely misses the human trials and challenges of community re-integration. These statistical scales camouflage a great number of issues which women face upon their release back to their communities (inadequate housing, poverty, abuse) and adhere to neo-liberal ideologies which place blame for 'failing to make it' back onto the shoulders of individual women.

Third, a most disturbing pattern was recognized amongst the group of women who had stayed out of the prison system. That is, an overwhelming majority have major mental health diagnoses and therefore are now confined in a psychiatric hospital or in their own homes with round-the-clock or full-time respite care workers. In this sense, patterns of dependency, medicalization and infantilization persist in the treatment of women in the community.

While the 'prison industrial complex' (Davis, 2003) was clearly evident throughout this research, the term was expanded to account for community involvement in the crime control industry. Not surprisingly, given the limited financial resources available to community-based organizations, non-profit groups are scrambling over the finite allotment of social service delivery monies. This results in community organizations attempting to operate under a multi-purpose 
banner and therefore offering themselves as candidates for several pockets of government dollars (CAEFS, AGM 2004).

An 'assertive case management' model to social service delivery, while applauded for its attempt to address the complex needs of many of its clients, often times ends up doing a disservice to certain vulnerable populations, including criminalized women and mental health users. Therefore, state agents of social control often become disguised in the community whereby community-run centres are reliant on core government-funding to operate not only correctionalbased programs but are now expected to be everything to everyone.

In this particular study, one of the major community-run organizations in Newfoundland and Labrador now operates a residential program which services male sex offenders, former psychiatric patients, and has two CSC beds for women, all under one roof. Similarly, several local Elizabeth Fry Societies across Canada have accepted contracts with Correctional Service Canada to provide direct parole supervision to halfway house residents. For the government, this means doing business at a cut-rate with non-profit agencies without interference by labour unions. For the non-profit organizations, surveillance now takes precedence over advocacy. For the women, this means a replication of control in the community and a diminished trust on behalf of halfway house staff who double as counsellors and enforcers.

Furthermore, critical investigations of 'punishment in the community' needs to be undertaken. As Worrall (1997: 48) states, "there is nothing in the appeal to community which offers any fundamental criticism of oppressive traditional sexual divisions of labour or social practices of racial intolerance and exclusion." The reality is that communities are also "fractured along divisions of age, race and gender." 
Fourth, federally incarcerated women stood a better chance of staying out of prison upon release. It is a sad reality that given the limited availability of gender-responsive programming for women in federal prisons and the scathing Canadian Human Rights Commission (CHRC) report released earlier this year which called for major reforms of the federal prison system for women, that the situation in our provincial prisons is even more dire and lacking in gender appropriate resources for women.

Finally, the well-known factors such as safe and affordable housing, meaningful employment, and supportive relationships, while cited as key contributors to women's staying out, were often not enough in and of themselves to keep women out of prison. It is also argued in this study that safe and adequate housing and meaningful employment should be a guarantee for women and should not pose as a risk factor which sets women up for failure in our society.

\section{Research Directions}

Prisons have now become the panacea for dealing with mental health populations. It is the only system which cannot turn women (and men) away from its doors. The criminal justice system continues to be the safety net used to catch those who fall through the ever-widening gaps in our social programs. As a result, women with mental illnesses, all too often brought about or exacerbated by the debilitating effects of institutional life, are trapped in a systemic spiral of 'help networks' which are not designed to deal with them or to accommodate their needs.

The criminalization of mental illness is marked by a number of key elements, as outlined by Kaiser (2004) and include an overrepresentation of people with mental health problems in the criminal justice system; dissonance between the purposes and services of the justice system 
compared to the needs of mental health detainees; exacerbation of symptomology and diminution of social functioning due to the ineptitude and insensitivity of the justice system; heightened likelihood of recidivism owing to the combined problems of an underfunded mental health care system and an unresponsive justice system. The Canadian Mental Health Association (CMHA) provides an understanding of this social phenomenon:

The mentally ill are being jailed rather than helped due to the lack of community mental health services... The trigger for police involvement is usually a nuisance offence, but the mentally ill are spending more and more time in police custody because local mental health services are insufficient and those that exist are over-burdened. In fact, once mentally ill persons are involved with the police, there is a $81 \%$ chance they will be apprehended again within a two-year period because they still have not accessed adequate services.

Prisons, with the primary goal of punishment and security, are ill-equipped to provide psychiatric care and treatment to mentally ill persons. Prisons are not treatment centres and should not lay claim to such. However, an increasing number of individuals with mental health diagnoses are ending up behind bars. A study focussed on the nature and extent of this phenomena, with particular attention paid to women, urgently needs to be undertaken.

Second, a study of the operations of a two-tiered corrections system in Canada warrants immediate attention. While the existence of a two-tiered corrections system in Canada is nothing new, this dual system has typically translated into an examination of governance and jurisdictional issues. The lived experiences of women prisoners doing time in both systems have been ignored. As this study clearly identified, the alarming trend toward sentencing women in this country to a federal term in an attempt to avail of the range of services available (albeit limited in its own right) needs to be addressed. There is a dearth of literature which examines the experiences of provincially sentenced women. Creating Choices (1990), for example, focussed 
exclusively on the plight of federally sentenced women. Likewise, the Arbour Inquiry (1996) made sweeping recommendations, specific and exclusive to women in federal prisons.

Notwithstanding the greater attention which has been paid to federally sentenced women and the plethora of human rights violations which continue to pervade federal prisons, systemic abuses continue. Given the current state of the Canadian literature in this area, one cannot help but be alarmed and disturbed by the voices of women who maintain that doing federal time is preferential to provincial incarceration. It speaks to the obvious level of inhumanity and systemic abuses which are taking place in provincial women's prisons. This is certainly an area of major concern and one which must be immediately addressed.

Third, transcarceral patterns of social control are clearly evidenced throughout this study and often have their rooting long before a woman is sentenced to prison. Incarceration in a penal institution represents another stepping stone along the continuum of formal social controls in the lives of many women. Shuffling from one institution to another throughout their entire lives, prison all too often represents the juncture at which 'help', albeit quite minimal, is found. Notwithstanding this sad reality, exiting prison in no way marks the end of a woman's period of incarceration. While much has been written about transcarceration and social control, placing gender at the forefront of such investigations is a critical exercise. Women are much more vulnerable to controls based on societal conceptions of family and motherhood and the proscribed roles of men and women. Women continue to be penalized for transgressing traditional sex roles and they are often subjected to controls which favour medicalized responses to conformity. 


\section{Policy Directions}

There are no shortage of policy recommendations generated from this study. However, while recognizing that a capitalist-patriarchal overthrow will not take place overnight, we have to be vigilant in the meantime and 'correct' the systemic-based inequalities which operate at the level of the criminal justice system and further marginalize, disempower, and neglect the needs of criminalized women. Therefore, policy suggestions are advanced on two distinct levels: 1) the criminal justice system; 2) a much broader social and economic equality-based level. Each is elaborated below.

\section{Classification Systems}

Actuarial classification schemes are the cornerstone of correctional management. However, it has been convincingly argued that classification systems are gender-blind and culturally insensitive (Hannah-Moffat and Shaw, 2002). A major definitional issue related to the subjectivities of 'risk' and 'need' evaluations has been the subject of much criticism (c.f., O’Malley, 1999; Feeley and Simon, 1992; Hannah-Moffat, 2000). One major problem with defining risk has been its focus on individual characteristics to the exclusion of broader situational and systemic factors. Another problem rests with the validity of these assessment tools for criminalized women which have relied on male-based input and outcomes.

The 'hybridization of risk and need factors' has resulted in "a substantial slippage between the concepts of risk and need" As Hannah-Moffat and Shaw (2003: 60) point out,

The resulting hybridization of risks and needs can lead to the identification of a "multitude of unrelated risk factors that in and of themselves provide no foundation for systemic rehabilitative interventions" (O'Malley, 1999:18). The term need then is both 
vacuous and enabling. It is a category that can be deployed to either extend the arm of the state or to reinstate welfare-based techniques of rehabilitation, which have an extensive history of medicalizing and pathologizing women's deviance (Hannah-Moffat and Shaw, 2003: 61).

While this issue of classification schemes and validation has received a great deal of attention in recent years, suffice it to say that the findings from this study pose some further considerations surrounding the subjectivity of actuarial assessments and the defining of women's needs and risks. The prevalence of criminalized women with mental illnesses is undoubtedly one major area which needs to be considered in actuarial assessments.

\section{Provision of Community Mental Health Services}

In December 2003, the final report of a public inquiry into the sudden deaths of two Newfoundland men with mental illnesses who were shot and killed within a period of 51 days by police officers, was released. The report clearly identified that the health, social and justice services in this province failed Norman Reid and Darryl Power. Mental health legislation has not been updated since its inception in 1971. As Judge Luther reports (2003: 1), "our province, to its utter shame, has by far the oldest Mental Health Act in the country."

Among the key recommendations put forth by Judge Luther, calls for the establishment of a Mental Health Division of the Provincial Court; a comprehensive new Mental Health Act; stringent criteria for certification to a psychiatric institution; provisions for a community treatment order and conditional leave with appropriate safeguards; additional funding for Health Boards to provide assertive case management of persons with mental illnesses; establishment of mobile health units to respond to mentally ill persons in crisis; core funding to the Canadian 
Mental Health Association, local chapter; and a comprehensive strategy to rid society of the stigma attached to mental illness. Based, in part, on the findings of the Luther Inquiry (2003) and the specific findings of this study in terms of mental health needs of women, a greater dedication of resources needs to be re-directed back into providing community mental health services. The impetus for change needs to take place long before individuals encounter the criminal justice system.

\section{Conditional Release Strategy for Women}

Women pose a relatively low risk to the safety of the community upon release. However, women are provided with far fewer opportunities for release especially on day parole where a requirement for residency in a halfway house is often imposed. There are no halfway houses for women in the Atlantic Region while only three exist in the Prairie Region. Overall, there are far too few spaces in women-only halfway houses across the country. The result is that many women have been released to halfway houses for men, which is inappropriate, not only for personal safety reasons, but also because they are marginalized and forced to adapt to the needs of the larger male population (Correctional Service Canada, 1998: 7).

The lack of spaces for women in halfway houses and residential facilities also further prejudices women with mental health and/or cognitive disabilities or other special needs, who may require more support upon release to meet the challenges of reintegrating into the community. Conversely, many women do not require the structure of halfway houses and day parole releases to their own homes should be recognized as an appropriate option for them. Release to halfway houses on day parole, which is the norm for men, is not generally required for women because of their lower risk to the community and lower recidivism rates. Options include establishing satellite apartments and day parole to their own homes (Canadian Association of Elizabeth Fry Societies, 2003) 
Funding for Provincial Elizabeth Fry Society

Gender-specific programming and services are sorely needed in Newfoundland and Labrador. In 1997, a provincial Elizabeth Fry Society was launched and a report recommending the nature and types of services needed to address the range of issues facing criminalized women was made public (Woodrow, 1998). However, due to political interference and a lack of commitment on behalf of justice officials, this society has never received any funding. As stated through correspondence with the Director of Adult Corrections in this province, criminalized women consume a disproportionate amount of divisional resources from the corrections budget. If we take the monies wasted to keep just one woman behind bars (roughly $\$ 120,000$ ) and infuse that into an organization mandated to service the needs of criminalized women only it will be money well spent. Overall, there needs to be a sustained and focussed commitment to criminalized women in this province.

Program and treatment approaches which fail to differentiate between the realities of women's lives and the unique set of individual and systemic conditions which pervade their lives must be dealt with. For example, placing women ex-prisoners in a multi-purpose residential program which predominantly caters to the needs of men is not an option. Likewise, mandating attendance at groups targeted to the criminogenic needs of men is not an option for women. Clearly, the unique needs of women identified in this study and elsewhere demands the provision of programs and services which are aimed at dealing with past histories of physical and sexual abuse, providing employment options for women, issues related to single parenting, and dealing with prolonged patterns of institutionalization. 


\section{Police Officer Training}

Given that police officers are often on the front lines of 'service delivery' in responding to mental health crisis, especially for those detained under the Mental Health Act, police officers should undergo intensive sensitivity education and training with regards to mental illness. This issue received inadequate attention by the Luther Inquiry (2003) which called for a one-day seminar to all members of the police force on the subject matter of mental health with "a minimum one hour presentation highlighting the most recently developed RCMP/RNC training on mental illness and appropriate police response." Other police-related 'solutions' to dealing with mentally ill persons in the community proffered in this report call for "the replacement of the long batons, presently in use, with collapsible batons" and the acquisition of "a minimum number of Tasers" (Luther, 2003:176-177).

Clearly, the recommendations in the Luther Inquiry miss entirely the complexity of policing members of our society with mental illness. Based on my research, it is clear that attempts at community re-integration are often inhibited by the continued surveillance and suspicion by police officers of further criminal involvement and a marked failure for law enforcement officials to adequately deal with mental health crises. A reversal of the trend wherein police officers resort to locking up women (and men for that matter) who display signs of mental illness needs to be addressed immediately. Police officers need to be guided by legislation which adopts prison as a last resort in dealing with the needs of mental health consumers. Prisoning this group of women should not be an option. 


\section{Broader Vision}

It is important to recognize that the policy proposals advanced above are specific to the mechanics of the criminal justice system and amount to little more than a mere tinkering with one part of a much wider system which is failing women. If we are truly serious about impacting the lives of criminalized women, we need to look to the broader capitalist patriarchy which characterizes and subverts the lives of Canadian women more generally. Undoubtedly, the key policy proposal advanced in this study is an ideological one. As DeKeseredy et al., (2003: 125) make clear, "ideological hurdles rather than economic obstacles account for the failure to mount rational campaigns to bring about social justice." Therefore, a much broader platform of social justice need to be adopted in dealing with criminalized women given the myriad of factors which converge to further disadvantage this particular group of women.

The feminization and subsequent criminalization of poverty are key findings of my research. Given that the overwhelming majority of women's crimes are property-related or 'survival crimes', issues surrounding women's increasing poverty and economic marginalization needs to be more closely addressed from the perspectives of the conditions which propel women 'into conflict with the law' in the first place while also assessing the role of women's economic marginalization in direct relation to their chances of successful completion of their parole terms.

Underlying the narratives of women's pathways into prison and their continued struggle to stay out is the failure of welfare policies to provide a decent living income. As Mosher et al., (2004: vi) remind us:

What is needed most urgently and most profoundly is a fundamental paradigm shift; a shift from viewing poverty as the failing of individuals, and those who are lazy, unmotivated and deceptive. To the extent that the welfare system...continues to operate 
from such a paradigm, there is really little hope that it will offer meaningful support to facilitate women's safe exit from abusive relationships. Women will continue to be subjected to demeaning, humiliating treatment; will be constantly regarded with suspicion; and will be subject to the control and discipline of the state. Women will continue to return to abusive relationships, women will not be safe, and women will not be equal citizens.

Along these same ideological lines, a call for a trangressive criminological approach is deemed appropriate. A major defining characteristic of transgressive criminology is that it starts from outside criminological discourse. As Cain (1990: 10) argues, feminist criminology "must explore the total lives of women, and there are no tools in existing criminological theory with which to do this." Furthermore, Cain (1990) contends that:

It simply has not proved possible to make adequate sense of what is going on in these areas of concern by starting from inside criminological discourse. Only by starting from outside, with the social construction of gender, or with women's experiences of their total lives, or with the structure of the domestic space, can we begin to make sense of what is going on (Cain, 1990: 10).

I interpret the work of Cain (1990) as a starting point for moving beyond the confines of criminology to look at the lives of criminalized women. I started this research on a reflexive note by posing the question, "What makes criminalized women different from many other working class women?" The answer, which revealed itself in many ways throughout this study, was clearly very little in terms of the broader social and economic inequalities characteristic of a capitalist patriarchy. On the other hand, the criminalized women in this sample are amongst the most marginalized in our society based on their increasing poverty as single mothers; their histories of physical and sexual abuse which results in a double victimization of women by the state; the layers of social controls which characterize their lives; the increasing criminalization of mental health; and women's defiance of gender norms which are met with resistance and punishment, 
both formally and informally in our society.

In terms of theorizing around women's criminalization, I am drawn back to the work of transgressive criminology because I fail to see what criminology in and of itself can offer to the lives of these women. Outside of tinkering with the correctional machinery, the real issues affecting the lives of criminalized women are no different than those affecting us all in a capitalist patriarchy. Feminist criminology, it is argued, exists as merely a critique and adjunct to the already established body of 'malestream' criminological knowledge (e.g., 'add women and stir approach'). The study of crime continues to be shaped by male experiences and continues to exalt men as the standard by which research and theory construction are premised. Women are seen as "other" when they are taken into account at all. Moving outside criminology, per se, forces a shift in focus toward the broader fundamentals of feminist thought and a critical analysis of the traditional and contemporary assumptions of criminology as an androcentric discipline that fails to take gender seriously by placing it at the periphery of inquiry and analysis.

If we start from a socialist feminist stance which sees life experiences as shaped by both class and gender then patriarchy is seen as a driving force behind women's oppression and is continually reproduced and reinforced through such institutions as marriage, child rearing, and sexual practices. Strategies for change under this line of inquiry rests on the overthrow of patriarchal relations which would permit women's sexual autonomy and obliterate the oppressive nature of sexual and familial relations for women. This broader feminist approach moves us away from a preoccupation with the corrections system in and of itself to more fundamental issues affecting the lives of all women. For example, expenditures on welfare and education have dropped dramatically to fund the prison endeavour. Resources that were once used to support 
low-income women and their children and to enhance education efforts have been exchanged in favour of an expanding prison industrial complex for women. We need to look to the evisceration of social programs under a neo-liberal government strategy which predominantly targets women and drives them further into poverty and despair rather than narrowing our focus to those women who get caught up in the machinery of the criminal justice system.

To come full circle back to my initial positioning and reflection on the lives of women who are the real voices of this work and who once sat as young friends in a classroom alongside myself, I am reminded of the quote often cited by Kim Pate (2003: 169), one of the leading activists on behalf of criminalized women in this country:
If you have come here to help me, you are wasting your time, If you have come here because your liberation is bound up with mine, then let us work together.

These words epitomize my position that the voices and experiences of women in this dissertation (and criminalized women more generally) cannot be neatly separated by their formal process of criminalization. There is a 'shadow line' between the directions in which these women's lives have gone and the directions in which they might otherwise have headed had it not been for the layering of structural and social inequalities which precipitated their encounters with the criminal justice system. Women's equality is a struggle we are all in together and therefore our collective liberation is truly what's at stake when researching the lives of women and, therefore, should be at the fore of any feminist criminological inquiry. 


\section{BIBLIOGRAPHY:}

Aboriginal Justice Inquiry. (1991). Justice on Trial: Report of the Aboriginal Justice Inquiry. Winnipeg: Queen's Press.

Adelberg, E., and Currie, C. (Eds.). (1993). In Conflict with the Law: Women and the Canadian Justice System. Vancouver: Press Gang Publishers.

Adler, F. (1975). Sisters in Crime: The Rise of the New Female Criminal. New York: McGrawHill.

Andersen, M. (2003). Thinking About Women: Sociological Perspectives on Sex and Gender. Allyn and Bacon.

Andrews, D. (1989). "Recidivism is predictable and can be influenced: using risk assessments to reduce recidivism." Forum on Corrections Research. 1 (2): 11-18.

Andrews, D., and Bonta, J. (1998). The Psychology of Criminal Conduct. Cincinnati, OH: Anderson.

Arbour, L. (1996). Commission of Inquiry into Certain Events at the Prison for Women in Kingston. Ottawa: Public Works and Government Services Canada.

Auditor General of Canada. (2003). Report of the Auditor General of Canada. Chapter Four. Reintegration of Women Offenders. Available at:

http://oag-bvg.gc.ca/domino/reports.nsf/html/200304ce.html

Barak, G. (2003). Violence and nonviolence: Pathways to understanding. Thousand Oaks, CA.: Sage.

Barnett, R. (2001). A Framework for Women-Centered Health. Vancouver/Richmond Health Board.

Beckett, K., and Western, B. (2001). "Governing social marginality: Welfare, incarceration, and the transformation of state policy." In Garland, D. Mass Imprisonment: Social Causes and Consequences. London: Sage. 
Belknap, J. (2001). The Invisible Woman: Gender, Crime, and Justice. Belmont, CA.: Wadsworth.

Blanchette, K. (1997). Risk and Need Among Federally-sentenced Female Offenders: A Comparison of Minimum, Medium, and Maximum Security Inmates. Research Report R58. Ottawa: Correctional Service Canada.

Blomberg, T. (2003). "Penal Reforms and the Fate of Alternatives.” In Blomberg, T., and Cohen, S. (Eds.), Punishment and Social Control. New York: Aldine de Gruyter. 417-431.

Bonta, J., Rugge, T., and Dauvergne, M. (2003). The Reconviction Rate of Female Offenders. (User Report 2003-02). Ottawa: Solicitor General Canada.

Bonta, J., Pang, B., and Wallace-Capretta, S. (1995). "Predictors of Recidivism Among Incarcerated Female Offenders." The Prison Journal. 75 (3): 277-294.

Boritch, H. (1997). Female Crime and Criminal Justice in Canada. Toronto: ITP Nelson.

Bowker, L. (Ed.). (1998). Masculinities and violence. Thousand Oaks, CA.: Sage.

Boyd, S. (1999). Mothers and Illicit Drugs: Transcending the Myths. Toronto: University of Toronto Press.

Burstyn, V. (1983). "Masculine Dominance and the State." In Miliband, R., and Saville, J. The Socialist Register. London: Merlin Press. 45-89.

Bush-Baskette, S. (2000). "The War on Drugs and the Incarceration of Mothers." Journal of Drug Issues. 30 (4): 919-928.

Burke, A. (2002). "Triple Jeopardy: Women Marginalized by Substance Abuse, Poverty, and Incarceration.” In Figueira-McDonough, J., and Sarri, R. (Eds.). Women at the Margins: Neglect, Punishment, and Resistance. The Haworth Press. 175-201.

Cain, M. (1990). "Towards Transgression: New Directions in Feminist Criminology." International Journal of the Sociology of Law. 18: 1-18.

Callaghan, M.., Farha, L., and Porter, B. (2002). Women and Housing in Canada: Barriers to Equality. Toronto: Women's Housing Program, Centre for Equality Rights and Accommodation. 
Canada. (2004). Labour Force Survey. Ottawa: Statistics Canada.

Canada. (2003). Parliament. House of Commons. Standing Committee on Public Accounts. Twenty-sixth Report of the Standing Committee on Public Accounts - Chapter 4 of the April 2003 Report of the Auditor General of Canada - Correctional Service of Canada Reintegration of Women Offenders. Ottawa: Public Works and Government Services. Available at: http://www.parl.gc.ca/infoCom/PubDocument.asp

Canada. (2002a). Adult Correctional Services in Canada, 2000-01. Canadian Centre for Justice Statistics. Ottawa: Statistics Canada.

Canada. (2002b). Low Income Cutoffs from 1992 to 2001 and Low Income Measures from 1991 to 2000. Ottawa: Statistics Canada.

Canada. (2001a). Women in Canada. Canadian Centre for Justice Statistics Profile Series. Ottawa: Statistics Canada.

Canada. (2001b). 2001 Census: Analysis Series, Income of Canadian Families. Ottawa: Statistics Canada.

Canada. (2001c). 2001 Census: Analysis Series, Aboriginal Peoples of Canada: A Demographic Profile. Ottawa: Statistics Canada.

Canada. (2001d). The Canada e-Book. Catalogue No. 11-404-X1E. Accessed at: http://142.206.72.67/02/02d/02d_001d_e.htm

Canada. (2000). Women in Canada 2000: A Gender-Based Statistical Report. Ottawa: Statistics Canada.

Canada. (1938). Report of the Royal Commission to Investigate the Penal System of Canada: Archambault Report. Ottawa: King's Printer.

Canadian Association of Elizabeth Fry Societies. (2004). Facts Sheets. Ottawa: CAEFS. Canadian Association of Elizabeth Fry Societies. (2003a). Submission of the Canadian Association of Elizabeth Fry Societies (CAFES) to the Canadian Human Rights Commission for the Special Report on the Discrimination on the Basis of Sex, Race and Disability Faced by Federally Sentenced Women. March. Ottawa: CAEFS. 
Canadian Association of Elizabeth Fry Societies. (2003b). CAFES' Fact Sheets. Ottawa: CAEFS. Canadian Association of Elizabeth Fry Societies. (2003c). CAEFS' Response to the Discussion Paper of the Canadian Human Rights Commission. April 10. Ottawa: CAEFS.

Canadian Association of Elizabeth Fry Societies. (1998). Position of the Canadian Association of Elizabeth Fry Societies (CAEFS) Regarding the Conditional Release Options Required by Federally Sentenced Women. Ottawa: CAEFS.

Canadian Centre for Justice Statistics. (2002). Adult Correctional Services in Canada, 2000/01. Ottawa: Statistics Canada.

Canadian Council on Social Development. (2003). Poverty Lines. Available at: http://www.ccsd.ca/factsheets/fs_lico03_at.htm

Canadian Human Rights Commission. (2003). Protecting Their Rights: A Systemic Review of Human Rights in Correctional Services for Federally Sentenced Women. Ottawa, ON.

Canadian Human Rights Commission. (1998). Annual Report. Ottawa, ON.

Canadian Mortgage and Housing Corporation (CMHC). (2003). 2003 Canadian Housing Observer. The State of Canada's Housing: An Overview. Available at: http://www.cmhc.ca/en/cahoob/stcaho/

Carlen, P. (2003). "Virginia, Criminology, and the Antisocial Control of Women." In Blomberg, T., and Cohen, S. (Eds.) Punishment and Social Control. New York: Aldine De Gruyter. $117-132$.

Carlen, P. (Ed.). (2002). Women and Punishment: The Struggle for Justice. Devon, UK: Willian Publishing.

Carlen, P. (1990). Alternatives to Women's Imprisonment. Milton Keynes: Open University Press Carlen, P. (1989). "Feminist Jurisprudence-or Woman-Wise Penology." Probation Journal. 36 (3): 110-114.

Carlen, P. (1988). Women, Crime and Poverty. Milton Keynes: Open University Press.

Cayley, D. (1998). The Expanding Prison: The Crisis in Crime and Punishment and the Search for Alternatives. Toronto: House of Anansi Press Limited. 
Chan, W., and Rigakos, G. (2002). "Risk, Crime and Gender." British Journal of Criminology. 42: 743-761.

Chan, J., and Ericson, R. (1985). 'Decarceration and the Economy of Penal Reform." In Fleming, T. (Ed.). New Criminologies in Canada: Crime, State and Control. Toronto: Oxford University Press. 223-241.

Chesney-Lind, M. (2002). "Imprisoning Women: The Unintended Victims of Mass Imprisonment." In Mauer, M., and Chesney-Lind, M. (Eds.), Invisible Punishment: The Collateral Consequences of Mass Imprisonment. New York: The New Press. 79-94.

Chesney-Lind, M., and Faith, K. (2001). "What About Feminism? Engendering Theory-Making in Criminology." In Paternoster, R., and Bauchnan, R. (Eds.). Exploring Criminals and Crime. Los Angeles: Roxbury. 287-302.

Chesney-Lind, M., and Pollock, J. (1995). "Women's Prisons: Equality with a Vengeance." In Merlo, A., and Pollock, J. Women, Law, \& Social Control. Allyn \& Bacon. 155-175.

Christie, N. (2000). Crime Control as Industry: Towards Gulags: Western Style. New York: Routledge.

Christie, N. (1981). Limits to Pain. Scandanavian University Press.

Cloward, R., and Ohlin, L. (1960). Delinquency and Opportunity. Glencoe, $\Pi$ : Free Press.

Cohen, A. (1955). Delinquent Boys. Glencoe, IL: Free Press.

Cohen, S. (1987). “Taking Decentralization Seriously: Values, Visions and Policies.” In Lowman, J., et al., (Eds). Transcarceration: Essays in the Sociology of Social Control. Aldershot: Gower. 358-79.

Cohen, S. (1985). Visions of Social Control. Cambridge: Polity. Collins, P. H. (1991). 'Defining Black Feminist Thought." Black Feminist Thought: Knowledge, Consciousness and the Politics of Empowerment. London: Routledge.

Comack, E. (1996). Women in Trouble: Connecting Women's Law Violations to their Histories of Abuse. Halifax: Fernwood Publishing. 
Comack, E., and Balfour, G. (2004). The Power to Criminalize: Violence, Inequality and the Law. Halifax: Fernwood Publishing.

Connell, R.W. (1995). Masculinities. Sydney, Australia: Allen and Unwin.

Consumers' Health Awareness Network Newfoundland and Labrador. (2002). Mental Health Consumers' Housing Advocacy Project: Final Report. St. John's: CHANNAL.

Correctional Investigator Canada. (2003). Annual Report of the Correctional Investigator, 2002-

2003. Ottawa: Public Works and Government Services.

Correctional Investigator. (2003). Response to the Canadian Human Rights Commission's

Consultation Paper for the Special Report on the Situation of Federally Sentenced Women. Ottawa.

Correctional Service Canada. (1999). Community Profile 1996: St. John's, Newfoundland. Ottawa: Correctional Service Canada

Correctional Service Canada. (1998). "Task Force on Reintegration of Offenders: A Summary." Forum on Corrections Research. 10 (1): 8-13.

Correctional Service Canada. (1996). Proceedings: National Workshop to Develop a Community

Strategy for Federally Sentenced Women. Ottawa: Correctional Service Canada.

Correctional Service Canada. (1995). Overviews: Correctional Service of Canada Regional Facilities for Federally Sentenced Women. Ottawa: Correctional Service Canada.

Covington, S. (2003). “A Woman's Journey Home: Challenges for Female Offenders.” In Travis, J., and Waul, M. (Eds.). Prisoners Once Removed: The Impact of Incarceration and Reentry on Children, Families, and Communities. Washington, D.C.: Urban Institute Press.

Currie, D., and MacLean, B. (1999). "Measuring Violence Against Women: The Interview as a Gendered Social Encounter." In Currie, D., Hay, D., and MacLean, D. (Eds.), Exploring the Social World: Social Research in Action. Vancouver: Collective Press. PAGE.

Daly, K. (1994). “Criminal Law and Justice System Practices as Racist, White and Racialized." Washington and Lee Law Review. 51: 2: 431-64. 
Daly, K., and Chesney-Lind, M. (1988). "Feminism and Criminology." Justice Quarterly. 5 (4): 497-538.

Daly, K., and Maher, L. (Eds.) (1998). Criminology at the Crossroads: Feminist Readings in Crime and Justice. Oxford University Press.

Danner, M. (1991). "Socialist Feminism: A Brief Introduction." In MacLean, B., and Milovanovic, D. (Eds.). New Directions in Critical Criminology. Vancouver: Collective Press. 51-54.

Danner, M., and Carmody, D.C. (2001). "Missing Gender in Cases of Infamous School Violence: Investigating Research and Media Explanations." Justice Quarterly. 18 (1): 87-114.

Davis, A. (2003). Are Prisons Obsolete? New York: Seven Stories Press.

Davis, N.J., and Faith, K. (1987). "Women and the State: Changing Models of Social Control." In Lowman, J., et al., (Eds.). Transcarceration: Essays in the Sociology of Social Control. Aldershot: Gower. 170-187.

Davies, S. and Cook, S. (1999). "Neglect or Punishment? Failing to Meet the Needs of Women Post-Release." In Cook, S., and Davies, S. (Eds.). Harsh Punishment: International Experiences of Women's Imprisonment. Boston: Northeastern University Press. 272-290.

DeKeseredy, W. (2000). Women, Crime, and the Canadian Criminal Justice System. Cincinnatti, Ohio: Anderson Publishing.

DeKeseredy, W. (1988). Woman Abuse in Dating Relationships: The Role of Male Peer Support. Toronto: Canadian Scholars' Press.

DeKeseredy, W., and Joseph, C. (Forthcoming). "Separation/Divorce Sexual Assault in Rural Ohio: Preliminary Results of an Exploratory Study." Violence Against Women.

DeKeseredy, W., and Schwartz, M. (2004). "Masculinities and Interpersonal Violence." In Kimmel, M., Connell, R., and Hearn, J. (Eds). The Handbook of Studies on Men and Masculinities. Thousand Oaks, CA: Sage.

DeKeseredy, W., Rogness, M., and Schwartz, M. (2004). "Separation/divorce sexual assault: The current state of social scientific knowledge." Aggression and Violent Behavior. 9:675-691. 
DeKeseredy, W., and Schwartz, M. (2003). "Backlash and Whiplash: A Critique of Statistics Canada's 1999 General Social Survey on Victimization." Online Journal of Justice Studies. 1 (1).

DeKeseredy, W., Alvi, S., Schwartz, M., and Tomaszewski, A. (2003). Under Siege: Poverty and Crime in a Canadian Public Housing Community. Lanham, MD: Lexington Press.

DeKeseredy, W., Schwartz, M., Saunders, D., and Alvi, S. (1997). "The Meanings and Motives for Women's Use of Violence in Canadian College Dating Relationships: Results from a National Survey." Sociological Spectrum.17 (2): 199-222.

DeKeseredy, W., and Schwartz, M. (1998). "Male peer support and woman abuse in postsecondary school courtship: Suggestions for new directions in sociological research." In Kennedy Bergen, R. (Ed.), Issues in Intimate Violence. Thousand Oaks, CA.: Sage. 83-96.

DeKeseredy, W., and Schwartz, M. (1996). Contemporary Criminology. Belmont, CA: Wadsworth.

DeKeseredy, W., and Schwartz, M. (1991). "British Left Realism on the Abuse of Women: A Critical Appraisal.” In Pepinsky, H., and Quinney, R. (Eds.). Criminology as Peacemaking. Indiana University Press. 154-171.

Dell, C. (2001). Correctional Service of Canada Ideology and Violent Aboriginal Female Offenders. Ottawa: Carleton University. Unpublished $\mathrm{PhD}$ Dissertation.

Dell, C.; Sinclair, R.; Boe, R. (2001). Canadian Federally Incarcerated Adult Women Profiles:

Trends from 1981 to 1998. Ottawa: Correctional Service of Canada.

DeVault, M. (1996). “Talking Back to Sociology: Distinctive Contributions of Feminist Methodology." Annual Review of Sociology 22: 29-50.

Eaton, M. (1993). Women After Prison. Buckingham: Open University Press.

Eden, D. (2002). Inquest into the Death of Kimberly Rogers: Jury Recommendations. Sudbury, ON. Available at: http://dawn.thot.net/Kimberly_Rogers/ 
Ehrenreich, B. (2001). Nickel and Dimed: On (not) getting by in America. New York:

Metropolitan Books.

Emerson, R. (1995). Writing Ethnographic Fieldnotes. Chicago: University of Chicago Press.

Faith, K. (1993). Unruly Women: The Politics of Confinement and Resistance. Vancouver: Press Gang Publishers.

Faith, K., and Pate, K. (2000). "Personal Musings and Political Activism: A Two-Way

Interview." In Hannah-Moffat, K., and Shaw, M. (Eds.). An Ideal Prison: Critical Essays

on Women's Imprisonment in Canada. Halifax: Fernwood Publishing. 136-147.

Feeley, M., and Simon, J. (1992). “The New Penology: Notes on the Emerging Strategy of

Corrections and its Implications." Criminology. 30 (4): 449-75.

Ferguson, (1997). Deconstructing Fetal Alcohol Syndrome: A Critical Inquiry into the Discourse Analysis Around Alcohol, Women, Ethnicity, Aboriginals and Disease. Ottawa: Carleton University. Master of Arts Thesis.

Filmore, C., Dell, C., and Elizabeth Fry Society of Manitoba. (2001). Prairie Women, Violence and Self-Harm. Winnipeg: Manitoba.

Gendreau, P., Goggin, C., and Little, T. (1996). Adult Recidivism: What Works! Research Report 1996-01. Ottawa: Ministry of the Solicitor General.

Gendreau, P., and Ross, R. (1987). 'Revivification of rehabilitation: evidence from the 1980s'. Justice Quarterly. 4: 349-408.

George, A. (1999). "The New Prison Culture: Making Millions from Misery." In Cook, S., and Davies, S. (Eds.) Harsh Punishment: International Experiences of Women's Imprisonment. Boston: Northeastern Press.

Gilliom, J. (2001). Overseers of the Poor: Surveillance, Resistance, and The Limits of Privacy. London: The University of Chicago Press.

Glaser, B.G. (1978). Theoretical Sensitivity: Advances in the Methodology of Grounded Theory. California: The Sociology Press. 
Glaser, B.G., and Strauss, A.L. (1967). The Discovery of Grounded Theory: Strategies for Qualitative Research. New York: Adline De Gruyter.

Goff, C. (2003). Criminal Justice in Canada. Nelson Thomson: Canada.

Goffman, E. (1961). Asylums: Essays on the social situation of mental patients and other inmates. New York: Anchor Books.

Greenberg, D. (1975). "Problems in Community Corrections." Issues in Criminology. 10 (1).

Hadley, K. (2001). And We Still Ain't Satisfied: Gender Inequality in Canada: A Status Report for 2001. Toronto: National Action Committee on the Status of Women.

Hallinan, J. (2001). Going Up the River: Travels in a Prison Nation. New York: Random House.

Hannah-Moffat, K. (2001). Punishment in Disguise: Penal Governance and Federal Imprisonment of Women in Canada. Toronto: University of Toronto Press.

Hannah-Moffat, K. (2000). "Prisons that Empower: Neo-liberal Governance in Canadian Women's Prisons." British Journal of Criminology. 40: 510-531.

Hannah-Moffat, K. (1999). "Moral Agent or Actuarial Subject: Risk and Canadian Women's Imprisonment." Theoretical Criminology. 3 (1): 71-94.

Hannah-Moffat, K. (1995). "Feminine Fortresses: Women-Centered Prisons?” The Prison Journal. 75 (2): 135-164.

Hannah-Moffat, K. (1994). "Unintended Consequences of Feminism and Prison Reform." Forum on Corrections Research. Ottawa: Correctional Service Canada. 6 (1): 7-10.

Hannah-Moffat, K., and Shaw, M. (2003). "The Meaning of 'Risk' in Women's Prisons: A Critique." In Bloom, B. (Ed.), Gendered Justice: Addressing Female Offenders. Carolina Academic Press. 45-68.

Hannah-Moffat, K., and Shaw, M. (2001). Taking Risks: Incorporating Gender and Culture into the Classification and Assessment of Federally Sentenced Women in Canada. Ottawa: Status of Women Canada. 
Hannah-Moffat, K., and Shaw, M. (Eds.) (2000). "Introduction.” In Hannah-Moffat, K., and Shaw, M. (Eds.). An Ideal Prison: Critical Essays on Women's Imprisonment in Canada. Halifax: Fernwood Publishing. 11-27.

Haraway, D. (1996). "Situated Knowledges: The Science Question in Feminism and the Privilege of Partial Perspective." Feminism and Science. 249-263.

Haraway, D. (1991). Simians, Cyborgs and Women: The Reinvention of Nature. New York: Routledge and Kegan Paul.

Harm, N., and Phillips, S. (2001). "You Can't Go Home Again: Women and Criminal Recidivism." Journal of Offender Rehabilitation. 32 (3): 3-21.

Hatty, S. (2000). Masculinities, violence, and culture. Thousand Oaks, CA: Sage.

Hartsock, N. (1998). The Feminist Standpoint Revisited, and Other Essays. Boulder, CO: Westview.

Heidensohn, F. (1987). "Women and Crime: Questions for Criminology." In Carlen, P., and Worrall, A. (Eds.). Gender, Crime and Justice. Philadelphia: Open University Press. $16-27$.

Heisz, A., and McLeod, L. (2004). "Low Income in Census Metropolitan Areas." Perspectives and Labour and Income. 5 (5).

Heney, J. (1990). Report on Self-injurious Behaviour in the Kingston Prison for Women. Ottawa: Ministry of the Solicitor General.

Heney, J., and Kriatiansen, C. (1998). "An Analysis of the Impact of Prison on Women Survivors of Childhood Sexual Abuse." In Harden, J., and Hill, A. (Eds.). Breaking the Rules: Women in Prison and Feminist Therapy. New York: Haworth Press. 29-45.

Hermer, J., and Mosher, J. (Eds.) (2002). Disorderly People: Law and the Politics of Exclusion in Ontario. Halifax: Fernwood Publishing.

Hertz, R. (1997). Reflexivity and Voice. Thousand Oaks, CA: Sage.

Income Security Advocacy Centre. Ontario Lifetime Ban Statistics. Toronto: ON. Available at: http://www.incomesecurity.org 
Jaggar, A. (1983). Feminist Politics and Human Nature. Totowa, N.J..: Rowman \& Allanheld. Jousten, M., and Ugljesa, Z. (1994). "Noncustodial Sanctions: Comparative Overview." In Ugljesa, Z. (Ed.). Alternatives to Imprisonment in Comparative Perspective. 1-42.

Kaiser, A. (2004). The Criminalization of People with Mental Health Problems: Joining Together to Find a Way Forward. NAACJ/Justice Canada/Public Safety and Emergency Preparedness Joint Policy Forum: Human Rights of People with Mental Disabilities and the Criminal Justice System. Ottawa: ON.

Keller, E. (1996). "Feminism and Science." In Keller, E., and Longino, H. (Eds.). Feminism and Science. New York: Oxford.

Kendall, K. (2004). "Dangerous thinking: a critical history of correctional cognitive behaviouralism." In Mair, G. (Ed.). What Matters in Probation. Devon, UK: Willian Publishing. 53-89.

Kendall, K. (2000). "Psy-ence Fiction: Governing Female Prisons through the Psychological Services." In Hannah-Moffat, M., and Shaw, M. (Eds.). An Ideal Prison: Critical Essays on Women's Imprisonment in Canada. Halifax: Fernwood Publishing. 82-93.

Kendall, K., and Pollack, S. (2003). “Cognitive Behavioralism in Women's Prisons: A Critical Analysis of Therapeutic Assumptions and Practices.” In Bloom, B. (Ed.). Gendered Justice: Addressing Female Offenders. Carolina Academic Press. 69-96.

Kirby, S.,and McKenna, K. (1989). Methods from the Margins: Experience, Research, Social Change. Toronto: Garamond Press.

Laster, K. (1996). "Feminist Criminology: Coping with Success." Current Issues in Criminal Justice. 8 (1): 192-200.

Lofland, J., and Lofland, L. (1984). Analyzing Social Settings. Belmont, California: Wadsworth Publishing Company.

Lombroso, C., and Ferrero, W. (1895). The Female Offender. New York: Philosophical Library. 
Lowman, J., Menzies, R.J., and Palys, T.S.. (1987). "Introduction: Transcarceration and the Modern State of Penality.." In Lowman, J., et al., (Eds.). Transcarceration: Essays in the Sociology of Social Control. Aldershot: Gower. 1-18.

Lurigio, A. (2001). "Effective Services for Parolees with Mental Illnesses." Crime \& Delinquency. 47 (3): 446-461.

Luther, D. (2003). Report of Inquiries into the Sudden Deaths of Norman Edward Reid and Darryl Brandon Power. St. John's, Newfoundland.

MacLeod, L. (1986). Sentenced to Separation: An Exploration of the Needs and Problems of Mothers Who Are Offenders and Their Children. Ottawa: Solicitor General Canada.

Maidment, M. (2002). "Toward a Woman-Centered Approach to Community-Based Corrections: A Gendered Analysis of Women and Electronic Monitoring." Women \& Criminal Justice. $13(4): 47-68$.

Maidment, M. (1999). In Conflict with Women: A Gendered Analysis of Electronically Monitored Offenders in St. John's, Newfoundland. Unpublished M.A. Thesis, Department of Sociology. Memorial University of Newfoundland.

Mainprize, S. (1992). "Electronic Monitoring in Corrections: Assessing cost effectiveness and the potential for widening the net of social control." Canadian Journal of Criminology. 34 (2): 161-180.

Mann, C. (1993). Unequal Justice: A Question of Colour. Bloomington: Indiana University Press. Martel, J. (1999). Solitude \& Cold Storage: Women's Journeys of Endurance in Segregation. Elizabeth Fry Society of Edmonton. Edmonton: Alberta.

Martin, D. (2002). "Demonizing Youth, Marketing Fear: The New Politics of Crime.” In Hermer, J., and Mosher, J. (Eds.). Disorderly People: Law and the Politics of Exclusion in Ontario. Halifax: Fernwood Publishing. 91-104.

Matthews, R. (1987). "Decarceration and Social Control: Fantasies and Realities." In Lowman, J., et al., (Eds.). Transcarceration: Essays in the Sociology of Social Control. Aldershot: Gower. 101-198. 
Mauthner, N., and Doucet, A. (1998). "Reflections on a Voice-centered Relational Method: Analysing Maternal and Domestic Voices." In Ribbens, J., and Edwards, R. (Eds.). Feminist Dilemmas in Qualitative Research: Public Knowledge and Private Lives. London: Sage.

Maxwell, J. (1996). Qualitative Research Design: An Interactive Approach. Thousand Oaks, CA.: Sage.

McCold, P., and Wachtel, B. (1998). "Community is Not a Place: A New Look at Community Justice Initiatives." Contemporary Justice Review. 1: 71-85.

McCormick, K., and Visano, L. (1992). “Corrections and Community (In)Action.” In McCormick, K., and Visano, L. (Eds.). Canadian Penology. Toronto: Canadian Scholar's Press. 275-290.

McGee, S. (2000). "The Pains of Imprisonment: Long Term Incarceration Effects on Women in Prison." In Muraskin, R. (Ed.), It's a Crime: Women and Justice. New Jersey: Prentice Hall. 205-213.

McMahon, M. (Ed.) (2000). Assessment to Assistance: Programs for Women in Community Corrections. American Correctional Association. Lanham, MD.

McMahon, M. (1992). The Persistent Prison? Rethinking Decarceration and Penal Reform. Toronto: University of Toronto Press.

Merton, R. (1938). "Social Structure and Anomie." American Sociological Review. 3: 672-82.

Messerschmidt, J. (2000). Nine Lives: Adolescent masculinities, the body, and violence. Boulder: Westview.

Messerschmidt, J. (1997). Crime as Structured Action: Gender, Race, Class and Crime in the Making. Thousand Oaks, CA.: Sage.

Messerschmidt, J. (1993). Masculinities and Crime: Critique and Reconceptualization of Theory. Lanham, MD: Rowman.

Messerschmidt, J. (1986). Capitalism, Patriarchy, and Crime: Toward a Socialist Feminist Criminology. Totowa, N.J.: Rowman \& Littlefield. 
Micucci, A., Maidment, D., Gomme, I. (1997). "Cleaner Than I Ever Was: The Experiences of Female Offenders in a Monitored Conditional Release Program in Eastern Canada." Journal of Offender Monitoring. 10 (1): 1-11.

Miles, M., and Huberman, A. (1984). Qualitative Data Analysis: A Sourcebook of New Methods. Beverly Hills, CA: Sage.

Miller, S. (Ed.) (1998). Crime Control and Women: Feminist Implications of Criminal Justice Policy. Thousand Oaks, CA.: Sage.

Mills, C. (1959). The Sociological Imagination. New York: Oxford University Press.

Monster, M. (2000). "There's Nothing Offered Here": The Rhetoric and Reality of a Rehabilitative Approach at the Newfoundland and Labrador Correctional Centre for Women. Unpublished Master of Arts' Thesis. Department of Sociology, Memorial University of Newfoundland.

Monture-Angus, P. (2002). The Lived Experience of Discrimination: Aboriginal Women Who Are Federally Sentenced. Human Rights Complaint on Behalf of Federally Sentenced Women. Ottawa.

Morash, M., and Schram, P. (2002). The Prison Experience: Special Issues of Women in Prison. Prospect Hills, Illinois: Waveland Press.

Morris, A., and Gelsthorpe, L. (1991). "Feminist Perspectives in Criminology: Transforming and Transgressing." Women \& Criminal Justice. 2 (2): 3-26.

Mosher, J. (2002). "The Shrinking of the Public and Private Spaces of the Poor." In Hermer, J., and Mosher, J. (Eds.). Disorderly People: Law and the Politics of Exclusion in Ontario. Halifax: Fernwood Publishing. 41-53.

Mosher, J., Evans, P., Little, M., Ontario Association of Interval Houses, and Ontario Social Safety Network. (2004). Walking on Eggshells: Abused Women's Experiences of Ontario's Welfare System. Final Report of Research Findings from the Woman and Abuse Research Project. Ontario. 
Motiuk, L., and Blanchette, K. (1998). Assessing Female Offenders: What Works? Paper presented to the International Community Corrections Association, Annual Conference. Arlington, Virginia.

Naffine, N. (1996). Feminism \& Criminology. Temple University Press: Philadelphia.

Newburn, T., and Stanko, E. (Eds.) (1994). Just boys doing business?: Men, masculinities and crime. London: Routledge.

Newfoundland and Labrador. Statistics Agency. (2004). Government of Newfoundland and Labrador. Accessed at: http://www.stats.gov.nl.ca/

Newfoundland and Labrador. Department of Health. (May 2004). Oxycontin Task Force: Final Report. St. John's, NL.: Queen's Printer.

Newfoundland and Labrador Department of Justice. (2001). Bi-Annual Report: Division of Corrections \& Community Services. St. John's, NL.: Queen's Printer.

Newfoundland and Labrador. Department of Justice. (1999). Bi-Annual Report: Division of Corrections \& Community Services. St. John's, NL.: Queen's Printer.

Nielsen, M., and Silverman, R. (1996). Native Americans, Crime, and Justice. Boulder, Colorado: Westview Press.

Nova Scotia Correctional Services. (1992). Blueprint for Change. Solicitor General's Special Committee on Provincially Incarcerated Women. Halifax, NS.

O'Brien, D. (1991). Suffer Little Children: An Autobiography of a Foster Child. St. John's, Newfoundland: Breakwater Books.

O'Brien, P. (2001). Making It in the "Free World": Women in Transition from Prison. Albany: State University of New York Press.

O'Grady, B., and Blight, R. (2002). "Squeezed to the Point of Exclusion: The Case of Toronto Squeegee Cleaners." In Hermer, J., and Mosher, J. (Eds.). Disorderly People: Law and the Politics of Exclusion in Ontario. Halifax: Fernwood Publishing. 23-39.

O'Malley, P. (2000). "Risk Societies and the Government of Crime”. In Brown, M., and Pratt, J. (Eds.). Dangerousness, Risk and Modern Society. London: Routledge. 
Parent, C. (1998). Féminismes \& criminologie. Paris, Bruxelles: De Boeck Université.

Pate, K. (2003). "A Tribute to Gayle Horii." Journal of Prisoners on Prisons. 12: 163-169.

Peters, Y. (2003). Federally Sentenced Women with Mental Disabilities: A Dark Corner in Canadian Human Rights. DisAbled Women's Action Network Canada. Ottawa.

Petersilia, J. (2003). When Prisoners Come Home: Parole and Prisoner Reentry. New York: Oxford University Press.

Pimlott, S., and Sarri, R. (2002). "The Forgotten Group: Women in Prisons and Jails.” In Figueira-McDonough, J., and Sarri, R. (Eds.). Women at the Margins: Neglect, Punishment, and Resistance. The Haworth Press. 55-85.

Pollack, S. (2003), Results of CAEFS Survey, Mental Health Services, Elizabeth Fry Societies. Ottawa: CAEFS.

Pollack, S. (2000). “Reconceptualizing Women's Agency and Empowerment: Challenges to SelfEsteem Discourse and Women's Lawbreaking." Women \& Criminal Justice. 12 (1): 75-89.

Pollak, O. (1950). The Criminality of Women. New York: Barnes.

Quinney, R. (1970). The Social Reality of Crime. Boston: Little, Brown.

Raphael, J. (2000). Saving Bernice: Battered Women, Welfare, and Poverty. Boston: Northeastern University Press.

Reiman, J. (2004). The Rich Get Richer and the Poor Get Prison: Ideology, Class and Criminal Justice. Needham Heights, MA.:Allyn and Bacon.

Renzetti, C., Edleson, J., and Bergen, R. (Eds.). (2001). Sourcebook on Violence Against Women. Thousand Oaks, CA.: Sage.

Renzetti, C. (1998). "Connecting the Dots: Women, Public Policy, and Social Control.” In Miller, S. (Ed.). Crime Control and Women: Feminist Implications of Criminal Justice Policy. Thousand Oaks, CA.: Sage. 181-189.

Richie, B. (2001). "Challenges Incarcerated Women Face as They Return to Their Communities: Findings From Life History Interviews." Crime \& Delinquency. 47 (3): 368-389. 
Ristock, J., and Pennell, J. (1996). Community Research as Empowerment: Feminist Links, Postmodern Interruptions. Oxford University Press.

Rivera, M. (1996). Giving Us a Chance: Needs Assessment: Mental Health Resources for Federally Sentenced Women in the Regional Facilities. Ottawa: Correctional Service Canada.

Ross, R., and Gendreau, P. (1980). Effective Correctional Treatment. Toronto: Butterworths.

Rossiter, H. (2001). Female Offenders in the Newfoundland Penitentiary System: 1990-2000: A Cross-Sectional Profile and Emergent Trends. Unpublished Honours' Dissertation. Department of Sociology. Memorial University of Newfoundland

Rothman, D. (1980). Conscience and Convenience: The Asylum and Its Alternatives in Progressive America. Boston: Little, Brown.

Schur, E. (1984). Labeling Women Deviant: Gender, Stigma, and Social Control. New York: Random House.

Schwandt, T. (2001). Dictionary of Qualitative Inquiry. Thousand Oaks, CA: Sage.

Schwartz, M., and Hatty, S. (2003). Controversies in Critical Criminology. Cincinnatti, OH: Anderson Publishing.

Scraton, P. (1990). "Scientific knowledge or masculine discourses? Challenging patriarchy in criminology." In Gelsthorpe, L., and Morris, A. (Eds.) Feminist Perspectives in Criminology. Open University Press. Milton Keynes. 10-25.

Scull, A. (1977). Decarceration: Community Treatment and the Deviant: A Radical View. New Jersey: Prentice Hall.

Seymour, P., and Greene, J. (2000). A Community Strategy for Federally Sentenced Women on Conditional Release: Phase II Project Report. St. John's, NL.

Shaw, M. (1994). "Women in Prison: A Literature Review." Forum on Corrections Research. $6(1): 13-18$.

Shaw, M. (1990). The Federal Female Offender-- Report on a Preliminary Study. Ottawa: Solicitor General Canada. 
Shaw, M., and Hannah-Moffat, K. (2004). "How cognitive skills forgot about gender and diversity." In Mair, G. (Ed.). What Matters in Probation. Devon, UK: Willian Publishing. 90-121.

Simon, R. (1975). Women and Crime. Lexington, MA: Lexington Books.

Singleton, R., Straits, B., Straits, M., McAllister, R. (1988). Approaches to Social Research. New York: Oxford University Press.

Smart, C. (1990).'Feminist approaches to criminology or postmodern woman meets atavistic man.” In Gelsthorpe, L., and Morris, A. (Eds.). Feminist Perspectives in Criminology. Open University Press. 70-84.

Smith, D. (1987). "The Everyday World as Problematic: A Feminist Methodology." The Everyday World as Problematic: A Feminist Sociology. Milton Keynes: Open University Press.

Solicitor General Canada. (2002). Corrections and Conditional Release Statistical Overview. Ottawa: Solicitor General Canada.

Solicitor General Canada. (1997). Female Offender Recidivism. Research Summary: Corrections Research and Development. Ottawa: Solicitor General Canada.

Solomon, H. (1976). Community Corrections. Boston: Holbrook Press.

St. John's Status of Women Council. (2003). Something's Got to Change - Research Report: Gender Inclusive Analysis and Housing Policy Development in Newfoundland and Labrador. St. John's: SJSWC.

Stanley, L., and Wise, S. (2000). "But the empress has no clothes: Some awkward questions about the 'missing revolution' in feminist theory." Feminist Theory. 1 (3): 261-288.

Stanley, L., and Wise, S. (1983). Breaking Out: Feminist Consciousness and Feminist Research. London: Routledge \& Kegan Paul.

Strategic Social Plan. (2004). Community Accounts Profile. Government of Newfoundland and Labrador. Available at: www.communityaccounts.ca

Strauss, A. (1987). Qualitative Analysis for Social Scientists. Cambridge University Press. 
Strauss, A., and Corbin, J. (1990). Basics of Qualitative Research. Thousands Oaks, CA.: Sage.

Sudbury, J. (2004). Global Lockdown: Race, Gender and the Prison Industrial Complex. (Ed.). Routledge.

Sweet, B. (June 24, 2003). “Cry for Help: Judge Denies Abuse Victims' Request for Federal Time." The Telegram. St. John's, NL.:A1.

Sykes, G. (1958). The Society of Captives: A Study of Maximum Security Prison. Princeton, N.J.: Princeton University Press.

Task Force on Federally Sentenced Women. (1990). Creating Choices: Report of the Task Force on Federally Sentenced Women. Ottawa: Ministry of the Solicitor General.

Tong, R. (1998). Feminist Thought: A More Comprehensive Introduction. Boulder: Westview Press.

The Evening Telegram. "Back in the World: A Special Report." May 6, 1995: 17.

The Express. "Women's Lock-up Called Inhumane." November 16, 1994: 1.

Van Wormer, K. (2003). "Prison Privatization and Women." In Coyle, A., Campbell, A., and Neufeld, R. (Eds.). Capitalist Punishment: Prison Privatization and Human Rights. Atlanta: Clarity Press. 102-113.

Waquant, L. (2003). “America's New "Peculiar Institution": On the Prison as Surrogate Ghetto." In Blomberg, T., and Cohen, S. (Eds.). Punishment and Social Control. New York: Aline de Gruyter. 471-482.

Warr, M. (2002). Companions in Crime: The Social Aspects of Criminal Conduct. Cambridge University Press.

Warren, C. (1981). "New Forms of Social Control: The Myth of Deinstitutionalization." American Behavioural Scientist. 24 (6):724-40.

Watson, L. (1995). "In the best interest of the child - The mother-child program." Forum on Corrections Research. 7 (2): 25-27.

Websdale, N. (1998). Rural Woman Battering and the Justice System: An Ethnography. Thousand Oaks, CA.: Sage. 
Websdale, N., and Chesney-Lind, M. (1998). Doing violence to women: Research synthesis on the victimization of women. In Bowker, L. (Ed.), Masculinities and violence. Thousand Oaks, CA.: Sage. 55-81.

Welch, M. (1997). "Regulating the Reproduction and Morality of Women: The Social Control of Body and Soul." Women and Criminal Justice. 9 (1): 17-38.

Western Star. "Money made available to establish Elizabeth Fry Society in province.” May 10, 1997: 1 .

Wilson, W.J. (1996). When Work Disappears: The World of the New Urban Poor. New York: Knopf.

Wolf, D. (1996). “Situating Feminist Dilemmas in Fieldwork." In Wolf, D.L. (Ed.). Feminist Dilemmas in Fieldwork. Boulder, Colorado: Westview.

Women's Issues Task Force (WITF). (1995). Women's Voices: Women's Choices: Report of the Women's Issues Task Force. Toronto: Ontario Ministry of Correctional Services.

Woodrow, R. (1998). Women on the Inside Need Friends on the Outside: A Report on the Needs of Incarcerated Females in Newfoundland and Labrador. Emerging Elizabeth Fry Society of Newfoundland and Labrador, St. John's, Newfoundland.

Worrall, A. (1997). Punishment in the Community: The Future of Criminal Justice. Longman: London.

Young, J. (1999). The Exclusive Society. London: Sage. 
APPENDIX A:

LETTER OF INFORMATION 


\section{LETTER OF INFORMATION}

My name is Donna Maidment. I am a PhD student at Carleton University and I am conducting research on the experiences of provincially sentenced women in Newfoundland and Labrador who return to prison following a period of release (less than two years) with a comparative group of women who have 'successfully' avoided a return to prison following a two-year stint in the community.

The proposed exploratory research will employ in-depth interviews with provincially sentenced women who have successfully completed their sentences in the province of Newfoundland and Labrador with women who have been consistently returned to prison (minimum of four admissions) in the province for commission of new offences or violation of the terms of their community restrictions. Interviews will last approximately 90 minutes and will be conducted and tape-recorded by myself. This study is independent of any government departments, including Department of Justice, and is being supervised by the Department of Sociology and Anthropology at Carleton University, Ottawa.

Interviews will be focus in three major areas: life before, during and after prison. However, the central focus of the research will be women's lives after prison. To understand what keeps women out of prison it is important to look at their time spent in prison including factors which might contribute to their 'success' such as length of sentence, place of incarceration, involvement in rehabilitative programming at the prison, counselling for substance abuse, peer associates, etc.

Participation in this study is voluntary and either myself or you may end the interview at any time. You may refuse to answer any question. There will not be any negative consequences should you decide not to complete the interview. If you do end the interview I will ask your permission to use the information I have collected to that time.

Every effort will be taken by myself to minimize any risk factors for you. First, issues around social status and anonymity in the community will be addressed by allowing you to choose a time and location that is suitable to you for conducting the interview and that does not jeopardize in any way the chances of others knowing about your criminal background (i.e., employer, family) or your participation in this study, should you wish that information to remain confidential. Second, I will provide you with the name and telephone number of a counselor in your area should you wish to speak to someone any time after this interview. Also, I am available via telephone and/or in person following this interview should you wish to talk about any other matters of concern. Finally, no information will be shared with corrections' officials or anyone else involved in the legal system. The information you provide will be held in strict confidence and will not be released to any organization or appear in the written thesis report. The information provided will be tape-recorded and will not be accessible to third parties. These assurances of privacy are intended to allow you to provide honest answers that are as complete as possible. 
Tape-recordings will be transcribed immediately following the interviews. Each tape will then be erased and both the transcripts and consent forms will be kept in a safety deposit box accessible only by me. You will be identified on the transcripts by number only-no names will appear. Also, when writing about individual cases and transcribing the data, pseudonyms will be used and any information that could enable others to identify you will be excluded. You will be remunerated by myself (at a rate of $\$ 10$ per hour) for your time.

This project has been reviewed and received ethics clearance through the Carleton University Research Ethics Committee. Any questions or concerns about study involvement may be directed to the ethics committee chair at the following address:

Prof. Klaus Pohle

Ethics Committee Chair

Carleton University Ethics Committee

(613) 520-7434 (Ottawa)

Questions about the research or requests to receive a copy of the findings of this research should be directed to the me at the following number:

MaDonna R. Maidment (Principal Investigator)

Ph.D. Candidate

Sociology and Anthropology Department, Carleton University

709-579-5798 (St. John's)

Other concerns or complaints about this research and/or participation in the research should be directed to:

Dr. Dennis Forcese

Graduate Co-ordinator

Sociology and Anthropology Department, Carleton University

613-520-0262 (Ottawa) 
APPENDIX B:

INFORMED CONSENT FORM 


\section{INFORMED CONSENT FORM}

I, , have been approached by Donna Maidment, a PhD student in Sociology at Carleton University to participate in a research project that is a comparative study of women who have stayed out of prison for a two-year period with women who have been returned to custody prior to this time. This research project is independent of any government departments, including Department of Justice.

This study attempts to find out about the process of community release for women in the provincial correctional system in Newfoundland and Labrador. In this regard, I am being asked to relate my prison experiences, the programs and services that were made available to me within the prison, negotiated release plans, how I coped with release back into the community, what services were available to me upon release, my involvement with other social services agencies, and the coping mechanisms I used to successfully complete my parole/probation term.

My participation in this study involves a 90-minute interview at a time and place that is convenient to myself and the researcher. My participation is voluntary and I may end the interview at any time. I may refuse to answer any question. If I am uncomfortable with the interview, I may end it at any time. If I do end the interview I will/will not (circle one) give the researcher permission to use the data I have provided to that time.

Every effort has been taken by the researcher to minimize any risk factors for myself. First, issues around social status and anonymity in the community will be addressed by allowing me to choose a time and location that is suitable to conducting an interview and that does not jeopardize in any way the chances of others knowing about my criminal background (i.e., employer, family) or participation in this study, should I wish that information to remain confidential. Second, the researcher will provide me with the name and telephone number of a counselor in my area should I wish to speak to someone any time after this interview. Also, the researcher is available via telephone and/or in person following this interview should I wish to talk about any other matters of concern. Finally, no information will be shared with corrections' officials or anyone else involved in the legal system. All information will be held in strict confidence and my name will not be released to any organization or appear in the written thesis report.

The information I provide will be tape recorded immediately following the interviews. Each tape will then be erased. None of these tapes will be accessible to third parties. Transcripts and consent forms will be kept in separate envelopes so that my consent form cannot be associated with my interview. I will be identified on the transcripts by number only-no names will appear. Also, when writing about individual cases and transcribing the data, pseudonyms will be used and any information that could enable others to identify me will be excluded. The Informed Consent Form and transcripts will be kept in a safety deposit box accessible only by the researcher. These assurances of privacy are intended to allow me to provide honest answers that are as complete as possible. 
I will be remunerated by the researcher (at a rate of $\$ 10.00$ per hour) for my time. I will be paid at the end of the interview. If I end the interview early I will still be paid for my time.

Participant Signature

Date

If you have any questions about the research or would like to receive a copy of the findings of this research, please call me at the following number:

MaDonna R. Maidment (Principal Investigator)

Ph.D. Candidate

Sociology and Anthropology Department, Carleton University

709-579-5798 (St. John's)

Should you have any concerns or complaints about this research and/or your participation in the research, please feel free to contact:

Dr. Dennis Forcese

Graduate Co-ordinator

Sociology and Anthropology Department, Carleton University

613-520-0262 (Ottawa)

Prof. Klaus Pohle

Ethics Committee Chair

Carleton University Ethics Committee

(613) 520-7434 (Ottawa) 
APPENDIX C:

RESEARCH INSTRUMENT 
RESEARCH INSTRUMENT

\section{GETTING OUT AND STAYING OUT: THE PLIGHT OF FEMALE OFFENDERS AND THEIR EXPERIENCES OF COMMUNITY REINTEGRATION}

Interview Number:

Date: 2003

Start Time:

Finish Time:

Introduce myself, telling them I am a researcher from Carleton University completing my Ph.D. research in the area of women's experiences of community sentences and reintegration. Read the following:

Thank-you for agreeing to do this interview. The interview will take about an hour and a half. It is important that you understand that you don't have to answer any question(s) you do not want to and that if either you or I want to end the interview at anytime, we can.

Let's begin with a few background questions.

1. How old are you?

2. What is your present marital status?

3. How much schooling have you completed?

4. Are you currently employed?

If yes, what type of work do you do?

What type of work have you done in the past?

PROBE: Employment history, level of training, nature of employment (full-time, part-time, seasonal), job satisfaction, future employment plans, future education/training plans.

5. What is your major source of income? (Social Assistance; Employment Insurance, Disability Insurance, Employment, Other.)

Let's talk a little now about your criminal history and prison experiences.

6. Can you give me a sketch of your past criminal convictions. 
PROBE: Juvenile record, types and length of convictions, federal/provincial incarceration.

7. Can you describe your prison experiences?

8. Were you involved in programming at the prison? If so, what type, length, nature, etc.

9. Would you say that your prison experience equipped you to cope more effectively with life on the outside?

PROBE: Release plans

10. What sorts of problems/difficulties did prison present for you? For your family? For your children?

PROBE: Pains of Imprisonment

Now let's turn to your community release experiences.

11. What type of community release were you granted?

PROBE: Statutory release, probation order, mandatory supervision.

12. What portion of your sentence was served in the community?

13. What conditions were placed upon your release?

PROBE: Halfway house, counselling, employment training, reporting to a probation/parole officer

14. Can you describe your experiences in going from prison into the community?

PROBE: Transitional period from prison back into the community.

Another important area in discussing your prison and community experiences might be child care responsibilities.

15. Do you have children? If so, what are their ages?

16. Do they live with you? (Living arrangements before incarceration and during community sentence)

17. With whom did they live during your incarceration? 
18. How would you say being on community sentence affected your day to day interactions with your kids, if at all?

PROBE: What impact did incarceration and community supervision have on your children? Attendance at programming? Visits to parole office?

Let's talk a bit about your experiences after prison.

19. Can you describe the different agencies you were involved with during probation (e.g., mental health, child protection, welfare, etc.)

20. Did you participate in programming upon your release? If so, describe the nature and frequency of these sessions? Did you find these programs useful?

PROBE: Who/what constituted the 'community' for these women?

21. Where were these programs offered? By whom?

22. Can you describe any barriers/challenges you faced in community reintegration and how you managed to deal with these obstacles?

PROBE: Gender-specific programming?

23. What supports were made available to you during your community term?

PROBE: Employment counselling; child care; mandatory programming; etc.

24. What role(s) did community organizations play in your staying out/returning?

PROBE: Community mental health services, programs/treatment services, familial/peer supports, community education resources, Social Services; CSC; Emmanuel House; Department of Justice; Child Protection Services; Elizabeth Fry Society; John Howard Society.

25. What do you see as the major needs of women being released to the community?

PROBE: e.g., housing, child care, employment, peer support, counselling services, mental health services.

26. Are these needs being met? If so, how? Explain.

If not, how could they be met?

27. What would you describe as the major factors which contributed to the successful (or 
unsuccessful) completion of your community sentence?

28. What would it take to keep you from coming back to prison?

Alternatively, what would bring you back into prison?

\section{PROBE:}

Thank you so much for your time and patience in completing this interview. 
APPENDIX D:

CARLETON UNIVERSITY ETHICS APPLICATION 


\section{APPLICATION TO THE CARLETON UNIVERSITY ETHICS COMMITTEE}

Submitted to:

Submitted by:
The Office of Research Services

Room 1501 Dunton Tower

MaDonna Maidment

Ph.D. Candidate

Sociology and Anthropology Department, Carleton University

Submission Date:

December 20, 2002

The attached Ph.D. Dissertation proposal is submitted for review by the Carleton University Ethics Committee and is governed by the Tri-Council Policy Statement: Ethical Conduct for Research Involving Humans.

\section{GETTING OUT AND STAYING OUT: \\ THE PLIGHT OF FEMALE OFFENDERS AND THEIR EXPERIENCES OF COMMUNITY REINTEGRATION}

MaDonna R. Maidment (Ph.D. Candidate - Carleton University, Sociology and Anthropology Department)

Dr. Walter DeKeseredy (Supervisor - Ohio University, Sociology and Anthropology Department)

Dr. Dennis Forcese (Committee Member - Carleton University, Sociology and Anthropology Department)

Dr. Colette Parent (Committee Member - University of Ottawa, Department of Criminology)

MaDonna R. Maidment

Ph.D. Candidate

Sociology and Anthropology Department

Carleton University

709-576-7522

donnamaidment@yahoo.com
Dr. Walter DeKeseredy

$\mathrm{Ph}$.D. Supervisor

Sociology and Anthropology Department

Ohio University

740-594-8765

dekesere@ohio.edu 
Requirement 1: $\quad$ Please see attached research proposal.

Requirement 2: $\quad$ Purpose of the Research

Much of the growing body of empirical research on women's corrections in Canada has focussed on the prison. Considerably less attention has been placed on women serving sentences in the community. Furthermore, when women's experiences of community sanctions are examined, researchers typically focus on factors that propel women back to prison (e.g., negative peer associations, lack of employment, substance abuse issues, histories of physical and/or sexual abuse). The proposed research seeks to fill this gap by examining the factors which contribute to women 'successfully' avoiding a return to prison.

It is well-documented in the literature on women in conflict with the law that the vast majority are single mothers, live in poverty, have histories of physical and/or sexual abuse, low levels of education, and mental health issues. The empirical question guiding this research, then, is: how do these women, following further marginalization and institutionalization brought about by their prison experiences, manage to overcome the obstacles to community re-entry while others do not?

The purpose of the proposed research is to compare the experiences of provincially sentenced women offenders who return to prison following a period of release (less than two years) with a comparative group of women who have 'successfully' avoided a return to prison following a twoyear stint in the community. Closely related to this objective, the proposed research will focus on the formal and informal social control mechanisms both within and outside the criminal justice system (i.e., child protection services, mental health system, social services, etc.) which govern the lives of women in the community.

The proposed exploratory research will employ semi-structured, in-depth interviews with provincially sentenced women who have successfully completed their sentences in the province of Newfoundland and Labrador $(n=15)$ with offenders who have been consistently returned to prison (minimum of four admissions) in the province for commission of new offences or violation of the terms of their community restrictions $(n=15)$.

Interviews will be constructed around two major themes: life during and after prison. Consistent with the major focus of the proposed research, however, the central thrust of the analysis will centre around women's lives after prison. In looking at what keeps women out of prison it is necessary to explore their prison experiences including factors which might contribute to their 'success' such as length of sentence, place of incarceration, involvement in rehabilitative programming at the prison, counselling for substance abuse, peer associates, etc. Conversely, one's prison experiences might negatively impact their chances for successful community reintegration. 
Theoretically, the proposed research will emerge from a grounded perspective which emphasizes an inductive approach to data analysis and theory development. Given the dearth of literature which looks at the life trajectories of women offenders and the neglect of research which looks at marginalized women and their post-prison experiences, a grounded theoretical approach is in order. QSR-NUD*IST4 software will assist the development of theory by interpreting the results generated by the data and identifying and inputting major themes and concepts which emerge throughout the research.

\section{B) Recruitment Process}

Socio-economic and criminal history data on all provincially sentenced women offenders in the province of Newfoundland and Labrador during the period between 1990-2000 $(n=359)$ has been made available to the principal investigator. This data is based on the previous work of Memorial University sociologist, Dr. Larry Felt (2001), wherein a database using SPSS (Version 11.0) has been compiled and contains a statistical overview of the total provincially sentenced female offender population for this 11-year period. The constructed variables include: AGE, EDUCATION LEVEL, OCCUPATION, OFFENCE, SENTENCE LENGTH, REPORTED PSYCHIATRIC PROBLEMS, PREVIOUS INCARCERATION, MARITAL STATUS, TYPE OF ADMISSION, ETHNICITY, and REPORTED ALCOHOL/DRUG PROBLEMS. The women in this database are identifiable only by ID number.

This database has been used to locate two sample populations: (1) women who have been consistently returned to custody following a period of community release. It has been determined that the total number of women deemed to be 'chronic recidivists' (more than four prison admissions) stands at 24 . From this number, a total of 15 women were tracked for study participation; (2) women who have not returned to custody following a two-year period of community release. Based on the number of 'chronic recidivists' contacted for this study, a matched sample of women who have been imprisoned but who have successfully avoided a return to custody following a two-year community stint will be interviewed. These comparative populations have been matched based on the above-noted variables contained within the SPSS database.

Following the production of a comparative sample of women who have stayed out against those who have consistently been returned to prison, I have matched the offender's identification numbers from the SPSS database to the offender's name obtained through the assistance of the Director of Adult Corrections. A Letter of Support (see attached) from the Director indicates the full cooperation of provincial justice officials in carrying out this study and locating potential respondents from their prison records. Initial contact eliciting respondent participation will be carried out by the classification officer at the Newfoundland and Labrador Correctional Centre for Women (NLCCW) based on a total eligible population of 24 . The classification officer will contact and inform the entire eligible population about the nature of the research and provide potential respondents with the name and telephone number of the principal investigator, should they wish to participate in the study. This allows the principal investigator access to only those women who have agreed to participate in the study and ensures corrections' officials are not privy 
to the names of those women who do wish to participate. This approach ensures respondent anonymity as correctional staff are not made aware of the names of women who have agreed to participate. Further assurances of anonymity are guaranteed by the researcher through the use of pseudoynms. Also, situations will be altered to avoid identification of women's own unique experiences (i.e., key distinguishable socio-ecomomic factors which might reveal a respondent's identity including location, previous and/or current work experiences, etc.).

\section{C) Process for Obtaining Informed Consent}

Participants will be advised prior to the interview that their participation is entirely voluntary and is in no way linked to the provincial Department of Justice. Information obtained during the interviews will not be shared with any third parties.

Please see attached Letter of Information and Informed Consent Form.

\section{D) Research Instrument}

In-depth, face-to-face, semi-structured interviews will be conducted by myself, MaDonna R. Maidment, with thirty (30) female offenders in the province of Newfoundland and Labrador.

Please see attached Research Instrument for questions (This instrument will be pre-tested prior to commencement of data collection).

\section{E) Means of Ensuring Anonymity/Confidentiality; Access to Data; Storage of Data}

The names of participants will be coded with a number and a list of codes matched with names will be secured in a locked box by the principal researcher separated from the interview data. Pseudonyms will be assigned to the participants in the dissertation and situations will be altered to avoid identification of their own experiences.

The interview data will be stored in a locked safety deposit box, devoid of names, in the possession of MaDonna Maidment. Tape-recorded interviews will be erased following transcription while written transcripts will be retained for an indefinite period for purposes of future research and analysis.

\section{F) Means of Discussing Risks/Benefits with Participants}

At the beginning of each interview, it will be clearly stated that participation in this study is being conducted independent of any government departments and information will not be shared with 
any third parties. Therefore, participants will be made aware that they will not benefit from participation in terms of special privileges afforded through any government agencies (i.e., Justice, Child Protection, Social Services, etc.). Likewise, there will not be any negative consequences should they decide not to complete the interview. It will be made clear that participants will be remunerated by myself (at a rate of $\$ 10$ per hour) for their time.

As stated in the Informed Consent Form, both the participant and myself (the interviewer) are permitted to end the interview at any point and the participant does not have to answer any question(s) she does not want to.

\section{G) Process of Dissemination of Research Results to Participants}

Every effort to disseminate the research results to participants in this study will be made. My name and the Sociology and Anthropology department telephone number will be provided on the informed consent form (which participants will receive a copy of) and it will be explained to each participant that should they be interested in reviewing the results of the research (or are interested in the progress of the research) they can contact me directly via telephone. Although the emphasis is placed on the participant to contact me for research results, every effort will be made to provide interested participants with the requested information.

As an active volunteer with women in conflict with the law for the past 6 years (i.e., founding member of local E-Fry Society; Canadian Association of Elizabeth Fry Societies), I have developed a professional network of individuals who work with female offenders and many have expressed interest in this research. My research findings will be shared and disseminated with key stakeholders involved with women in conflict with the law.

\section{H) Tri-Council Policy Statement "Ethical Conduct for Research Involving Humans"}

I, MaDonna R. Maidment, agree to comply with the Tri-Council Policy Statement "Ethical Conduct for Research Involving Humans."

Signature

Date 


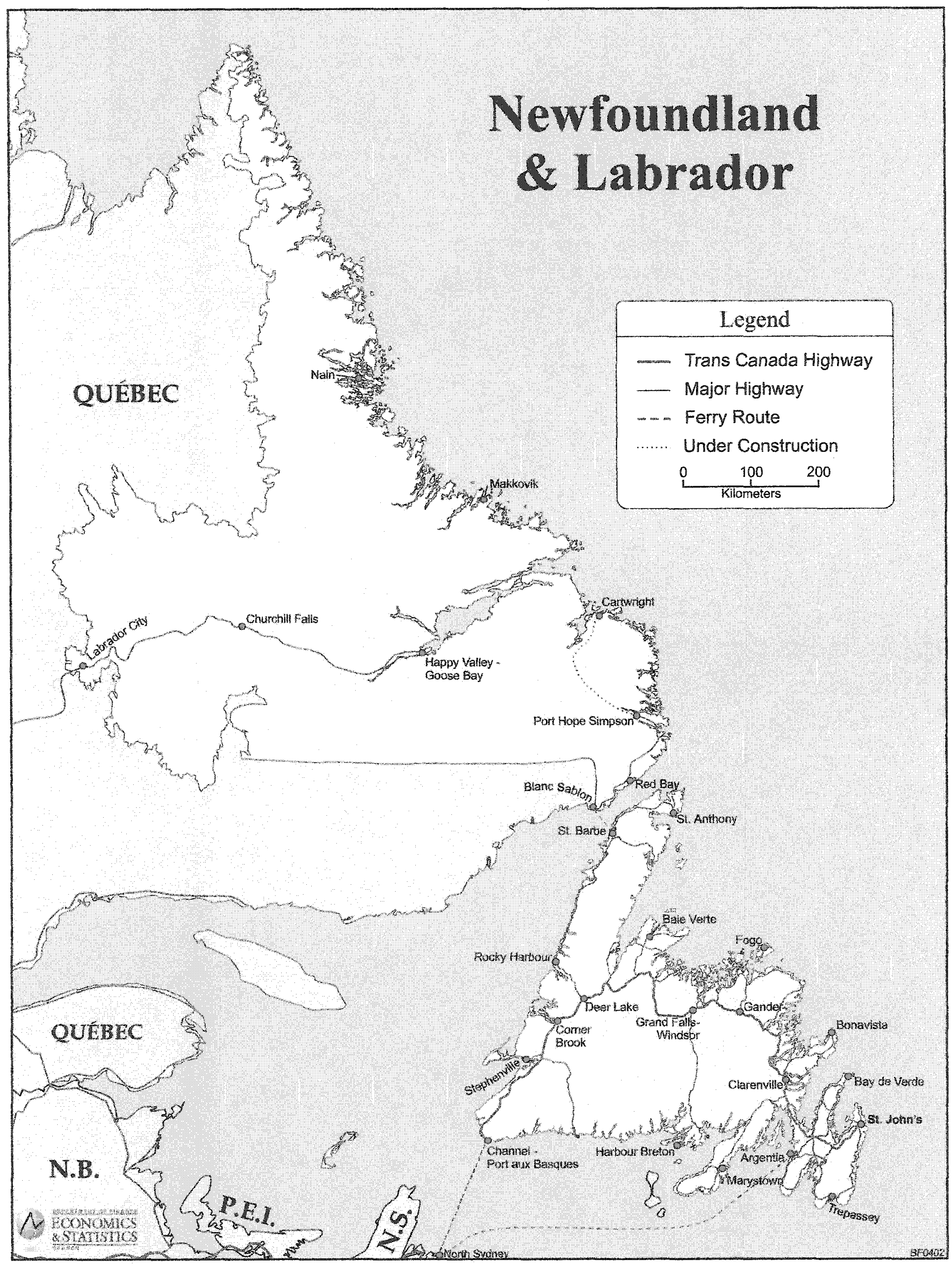

